UNIVERSIDADE DE BRASÍLIA

FACULDADE DE TECNOLOGIA

DEPARTAMENTO DE ENGENHARIA CIVIL E AMBIENTAL

\title{
TRATAMENTO DE ESGOTOS SANITÁRIOS USANDO REATOR UASB SEGUIDO DE MICROFILTRAÇÃO POR MEMBRANA SUBMERSA.
}

MAURO ROBERTO FELIZATTO

ORIENTADOR: MARCO ANTONIO ALMEIDA DE SOUZA

TESE DE DOUTORADO EM TECNOLOGIA AMBIENTAL E RECURSOS HÍDRICOS

PUBLICAÇÃO: PTARH-TD- 017/2017

BRASÍLIA/DF: MARÇO - 2017 
UNIVERSIDADE DE BRASÍLIA

FACULDADE DE TECNOLOGIA

DEPARTAMENTO DE ENGENHARIA CIVIL E AMBIENTAL

TRATAMENTO DE ESGOTOS SANITÁRIOS USANDO REATOR UASB SEGUIDO DE MICROFILTRAÇÃO POR MEMBRANA

SUBMERSA.

\section{MAURO ROBERTO FELIZATTO}

TESE SUBMETIDA AO DEPARTAMENTO DE ENGENHARIA CIVIL E AMBIENTAL DA FACULDADE DE TECNOLOGIA DA UNIVERSIDADE DE BRASÍLIA COMO PARTE DOS REQUISITOS NECESSÁRIOS PARA A OBTENÇÃO DO GRAU DE DOUTOR EM TECNOLOGIA AMBIENTAL E RECURSOS HÍDRICOS.

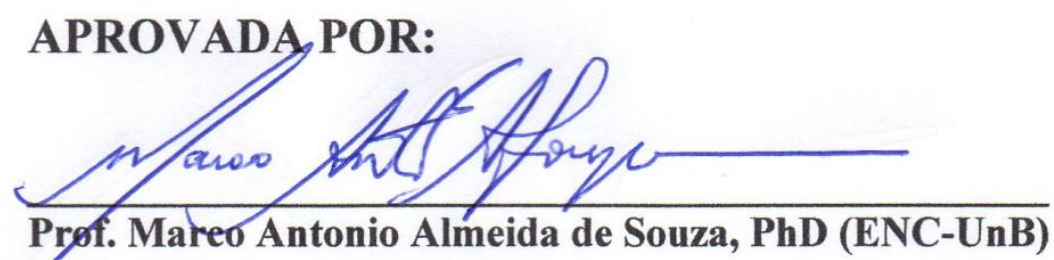

(Orientador)

AKBCuncerim

Prof ${ }^{a}$ Ariuska Karla Barbosa Amorim, Doutora (ENC/FT/UnB)

(Examinadora Interna)

Prof ${ }^{\text {a }}$ Yovanka Péres Ginoris, Doutora (ENC/FT/UnB)

(Examinadora Interna) $\longrightarrow$

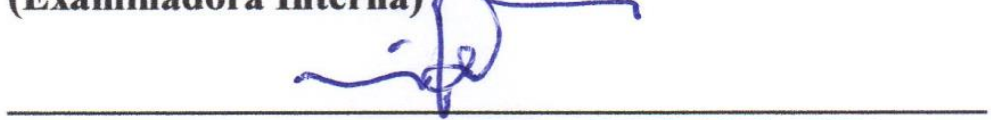

Prof. Ivanildo Hespanhol, PhD (CIRRA/EP-USP)

(Examinador Extermo)

flnorfe

Prof ${ }^{\mathrm{a}}$ Liliana Pena Nava,, Đoutora (UFT)

(Examinadora Externa)

BRASÍLIA/DF, 7 DE MARÇO DE 2017 


\section{FICHA CATALOGRÁFICA}

\section{FELIZATTO, MAURO ROBERTO}

Tratamento de esgotos sanitários usando reator $U A S B$ seguido de microfiltração por membrana submersa [Distrito Federal] 2017.

xxix, 186p., 210 x 297 mm (ENC/FT/UnB, Doutor, Tecnologia Ambiental e Recursos Hídricos, 2017).

Tese de Doutorado - Universidade de Brasília. Faculdade de Tecnologia.

Departamento de Engenharia Civil e Ambiental.
1. Reúso de água
2. Membranas submersas
3. $U A S B$
4. Microfiltração
I. ENC/FT/UnB
II. Título (série)

\section{REFERÊNCIA BIBLIOGRÁFICA}

FELIZATTO, M. R. (2017). Tratamento de esgotos sanitários usando reator UASB seguido de microfiltração por membrana submersa. Tese de Doutorado em Tecnologia Ambiental e Recursos Hídricos, Publicação PTARH.TD - 017/2017, Departamento de Engenharia Civil e Ambiental, Universidade de Brasília, Brasília, DF, 186p.

\section{CESSÃO DE DIREITOS}

AUTOR: Mauro Roberto Felizatto.

TÍTULO: Tratamento de esgotos sanitários usando reator $U A S B$ seguido de microfiltração por membrana submersa.

GRAU: Doutor

ANO: 2017

É concedida à Universidade de Brasília permissão para reproduzir cópias desta tese de doutorado e para emprestar ou vender tais cópias somente para propósitos acadêmicos e científicos. $\mathrm{O}$ autor reserva outros direitos de publicação e nenhuma parte dessa tese de doutorado pode ser reproduzida sem autorização por escrito do autor.

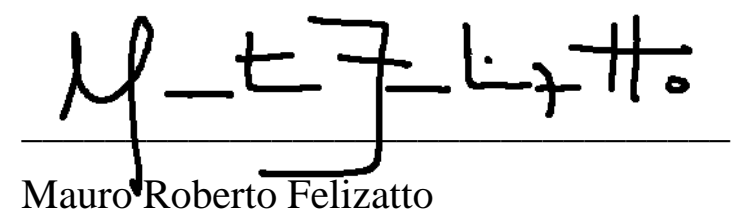

QE 32 Conjunto H Casa 41, Guará 2

71.065-081 Brasília/DF - Brasil

Endereço Eletrônico: ptarh@felizatto.com 


\section{DEDICATÓRIA}

As mulheres da minha vida: Mãe, Irmãs, Esposa e Filhas.

Em especial, a Miguel, meu neto. 


\section{EPÍGRAFE}

Na tua comprida viajem te cansaste; contudo não disseste: Não há esperança; achastes com que renovar as tuas forças; por isso não enfraquecestes

(Isaías 57, 10) 


\section{AGRADECIMENTOS}

A Deus por tudo, sempre, toda gratidão pelo maior presente que é a vida. Agradeço também pelas pessoas que o Senhor colocou em meu caminho. Algumas delas me inspiram, me ajudam, me desafiam e me encorajam a ser uma pessoa humana cada dia melhor.

Ao professor Marco Antonio Almeida de Souza pela participação efetiva e orientação na pesquisa, apontando caminhos e proporcionando condições adequadas ao desenvolvimento dos trabalhos. Também agradeço pelo tratamento amigo que sempre me ofereceu, em especial e recordando, a quase dez anos atrás me presenteou com o livro "Reúso das Águas de Esgoto Sanitário, inclusive desenvolvimento de tecnologias de tratamento para este fim”, trabalho em que é coautor e na dedicatória escreveu: ...“Ao Mauro, umas das “maiores" promessas do PTARH”, tardiamente agradeço imensamente, e assim espero no seu conceito, continuar sendo.

A Companhia de Saneamento Ambiental do Distrito Federal, CAESB, como instituição, por sempre incentivar-me aos estudos relacionados com os processos de tratamento de esgotos sanitários.

Aos colaboradores e funcionários da CAESB lotados na ETE Gama, pela vibração e pela ajuda em todos os momentos necessários, em especial a: Ênio (filho do seu Enoque), Lopes (grande mestre da manipulação com metais, plásticos, etc.), Osvaldo (colaborador sempre e mestre), Divinão (sempre emitindo boas energia), Ronaldo (o nosso artista artesão - o fabricante de charretes), Ermelinda (cuidadora do nosso asseio e organização da casa de química), Leila (pelo café "preto" da tarde, por cuidar de nosso asseio e organização no escritório do laboratório), José Antônio e Xavier (mestres conhecedores dos circuitos elétricos e eletrônicos), Carlos Alexandre, Edson e Cristiano (pelo apoio irrestrito em todos os momentos), Juan e Débora (pelo apoio moral nas conversas na casa de química) e a Letícia e Rogério Botelho.

Ainda na CAESB, em especial aos amigos apoiadores e conselheiros, de sempre, Antônio Carlos Teixeira Pinto Filho e Klaus Dieter Neder. Uma grande homenagem a Walter Lúcio, que ofereceu todas as condições para o término deste trabalho acadêmico. 
A equipe da pesquisa na ETE Gama: Alan Saliba (in memoriam), Felipe Nery e Henrique Bezerra. Sentimentos especiais, pela sofrimento da falta da presença do maior entusiasta da pesquisa e da vida, que era o Alan, que infelizmente nos deixou durante a realização do trabalho experimental. Ao Felipe: o agradecimento eterno. Ao Henrique: um conselheiro, um amigo para todos os momentos e para sempre.

Aos meus amigos, sempre vibradores, Anísio Neto (meu comprade), Fenando Diniz, Jörgen Michel e Paulo Maurício (meu comprade).

A professora Yovanka Pérez Ginoris pelo amor, pelo carinho e pela contribuição crítica na etapa de consolidação da ideia e direcionamento da pesquisa, como participante de todas etapas deste trabalho, do Seminário 1 até a Defesa Final (excetuando a qualificação).

A professora Ariuska Karla Barbosa Amorim pelo acompanhamento carinhoso, colaborador e pelas discussões "calorosas" durante todas etapas deste trabalho, do Seminário 1 até a Defesa Final.

A Jorge, a Norma, pela torcida e pelo carinho nas análises das amostras de todo o trabalho. A Roseli, pela colaboração nas análises de Óleos e Graxas e Agentes Surfactantes do experimento. Meu eterno agradecimento a vocês.

Aos professores Cristina Célia Brandão, Oscar de Moraes Cordeiro Netto e Sergio Koide, pelo carinho, ajuda e a amizade.

A todos os professores do PTARH por contribuir com meu crescimento ao longo do curso.

Aos amigos e companheiros do PTARH que se fizeram presentes durante o curso.

Ao examinador externo, professor Ivanildo Hespanhol, pela pronta aceitação de participar da banca e pela especial colaboração na melhoria final do trabalho.

A professora Liliana, examinadora externa, pela especial colaboração na melhoria final do trabalho. 


\title{
RESUMO
}

\section{TRATAMENTO DE ESGOTOS SANITÁRIOS USANDO REATOR UASB SEGUIDO POR MICROFILTRAÇÃO POR MEMBRANA SUBMERSA}

\author{
Autor: Mauro Roberto Felizatto \\ Orientador: Marco Antonio Almeida de Souza \\ Programa de Pós-graduação em Tecnologia Ambiental e Recursos Hídricos \\ Brasília, Março de 2017
}

A incorporação da tecnologia de separação por membranas em processos anaeróbios representa uma inovação importante no desenvolvimento da engenharia de tratamento biológico de efluentes de reatores $U A S B$. Esta pesquisa consistiu na avaliação da filtração através de membranas submersas, de microfiltração $(0,40 \mu \mathrm{m})$, provido de sistema de retrolavagem, durante contínuo tratamento do efluente do reator $U A S B$ operando com esgotos sanitários. As membranas utilizadas foram do tipo fibras-ocas e fabricadas com o polímero poli(éter-imida). Durante a operação em modo contínuo por longo período, foi observado o declínio contínuo e acentuado do fluxo do permeado com o decorrer do tempo, com valor final de 5,50 LMH, e que a unidade de microfiltração não respondeu ao método contínuo de controle da incrustação (retrolavagem). O restabelecimento da resistência da membrana limpa $\left(1,8 \times 10^{12} \mathrm{~m}^{-1}\right)$ só ocorreu com limpeza química efetuada com solução de hipoclorito de sódio. A perda de permeado relativa ao consumo diário no uso na retrolavagem levantado foi de $24 \%$ e o consumo específico de energia elétrica do sistema apurado foi de $2,80 \mathrm{kWh} / \mathrm{m}^{3}$. A remoção de matéria orgânica alcançada pela microfiltração de efluente do reator $U A S B$ foi de $87 \%$ para DBO e $84 \%$ para DQO, a remoção global de SST foi de 99\% e de 2,02 unidades logarítmicas para Coliformes fecais (CF). Os resultados médios de densidade de CF ( 10 NMP/100 m $\ell)$ e sua remoção $(2,02$ unid. log.) e ausência de ovos de helmintos viáveis no permeado atingiram um nível, nesta pesquisa, que possibilita o reúso de água para irrigação restrita na agricultura altamente mecanizada e para irrigação irrestrita por gotejamento de culturas elevadas, segundo as diretrizes da OMS.

Palavras-chave: Tratamento de esgotos sanitários, Reúso de água, UASB, Microfiltração, Membranas submersas 


\title{
ABSTRACT \\ MUNICIPAL WASTEWATER TREATMENT USING UASB FOLLOWED BY SUBMERGED MEMBRANE MICROFILTRATION.
}

\author{
Author: Mauro Roberto Felizatto \\ Supervisor: Marco Antonio Almeida de Souza \\ Graduate Program in Environmental Technology and Water Resources \\ Brasilia, March 2017
}

The incorporation of membrane separation technology into anaerobic processes represents an important innovation in the development of biological treatment engineering for UASB reactor effluent. This research evaluated the performance of a submerged membranes filtration, microfiltration membranes $(0,4 \mu \mathrm{m})$ provided with a backwash system, during continuous treatment of the UASB reactors effluents operating with municipal wastewater. The hollow fiber membranes were manufactured by polyetherimide material. In the longterm operation, the continued and accented decrease of permeate flux over the time was observed, with a final permeate flux approached of 5.50 LMH. The microfiltration unit seems not to answer satisfactorily to strategy in limiting the fouling control (backwash). The restoration of the clean membrane resistance $\left(1.8 \times 10^{12} \mathrm{~m}^{-1}\right)$ only occurred with chemical cleaning carried out with sodium hypochlorite solution. The permeate loss relative to the daily consumption in the backwash was $24 \%$ and the specific energy consumption of the system was $2.80 \mathrm{kWh} / \mathrm{m}^{3}$. The removal of organic matter by the microfiltration of the UASB reactor effluent reached was $87 \%$ for BOD and $84 \%$ for COD, 99\% for TSS removal and $2.02 \mathrm{log}$. units for fecal coliforms (FC). In this study, the results of the geometric means of FC density ( 10 $\left.0^{5} \mathrm{MPN} / 100 \mathrm{~m} \ell\right)$ and its removal (2.02 log. units) and absence of viable helminthes eggs in the permeate reached a level of water reuse for restricted irrigation in agriculture highly mechanized and for unrestricted drip irrigation of high crops, according to WHO guidelines.

Key-words: Municipal wastewater treatment, Water reuse, UASB, Microfiltration, Submerged membranes. 


\section{SUMÁRIO}

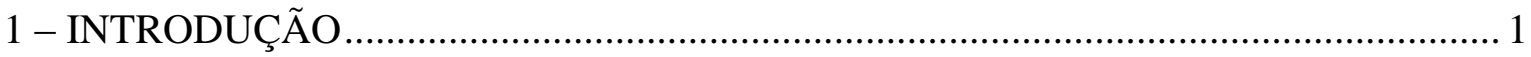

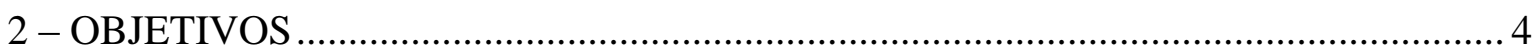

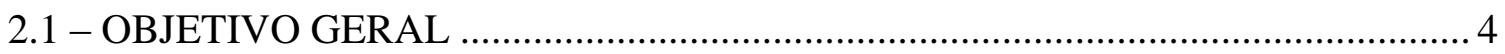

2.2 - OBJETIVOS ESPECÍFICOS .......................................................................... 4

3 - FUNDAMENTAÇÃO TEÓRICA E REVISÃO BIBLIOGRÁFICA................................5

3.1 - FUNDAMENTAÇÃO TEÓRICA ……………………………………….....

3.1.1 - Filtração por Membranas ………………………………………………….

3.1.1.1 - Características das Membranas ………………………………………….... 10

3.1.1.2 - Classificação das Membranas........................................................................ 11

3.1.2 - Membranas de Microfiltração ........................................................................... 25

3.1.2.1 - Aspectos Operacionais nos Sistemas de Separação por Membranas ......... 26

3.1.2.2 - Mecanismos de Rejeição de Solutos por Membranas .................................... 30

3.1.2.3 - Modelos Matemáticos para Predizer o Fluxo em Microfiltração ................. 32

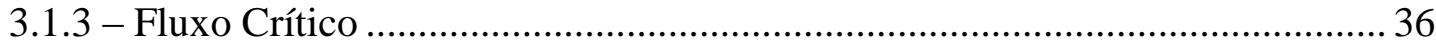

3.1.4 - Incrustações em Membranas (Fouling) .............................................................. 38

3.1.4.1 - Quantificação do Fluxo na Incrustação ....................................................... 41

3.1.4.2 - Métodos de Redução da Incrustação .............................................................. 44

3.1.5 - Uso de Membranas em Tratamento de Águas Residuárias.............................. 49

3.1.5.1 - Biorreatores Aeróbios com Membranas......................................................... 51

3.1.5.2 - Biorreatores Anaeróbios com Membranas ....................................................... 53

3.1.5.3 - Filtração por Membranas........................................................................... 59

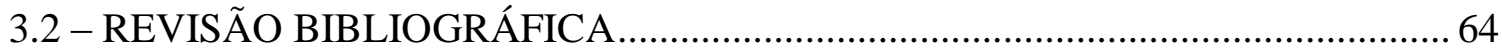

3.2.1 - Pré-tratamento (Peneiramento Fino encontrado na literatura) ……………...... 69

3.2.2 - Configurações Experimentais encontradas na literatura ................................. 71

3.2.3 - Condições Operacionais encontradas na literatura …………………………... 76

3.2.4 - Desempenhos Obtidos na literatura ……………………………………….... 79

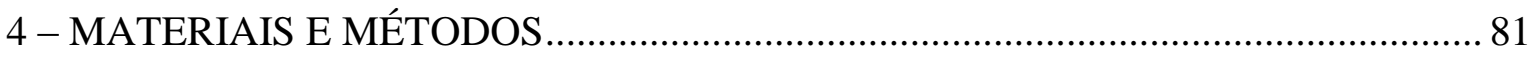

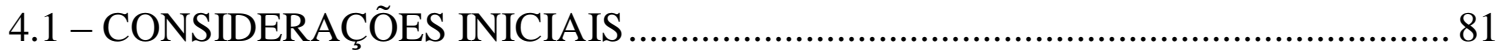

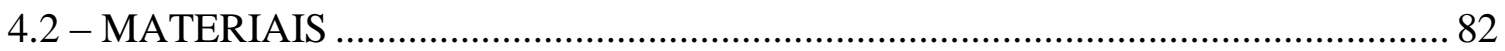

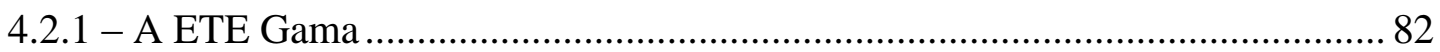

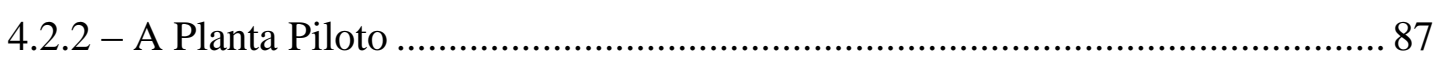

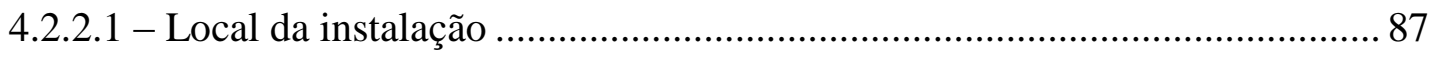




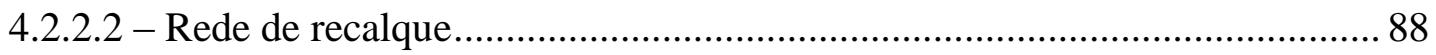

4.2.2.3 - Medidor de Energia Elétrica.................................................................. 91

4.2.2.4 - Unidade de Filtração por Membranas Submersas ...................................... 92

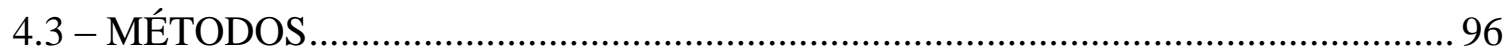

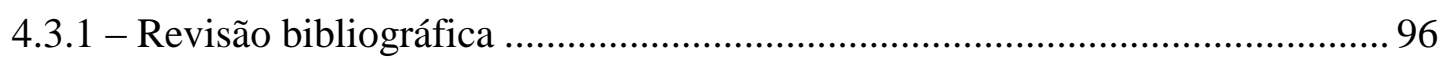

4.3.2 - Aquisição e instalação da planta-piloto ........................................................ 96

4.3.3 - Partida da planta-piloto e treinamento .......................................................... 98

4.3.4 - Ensaios preliminares (Operação de curta-duração)......................................... 99

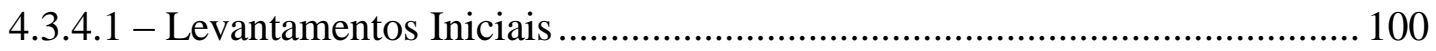

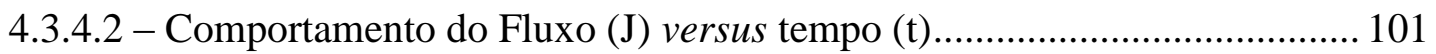

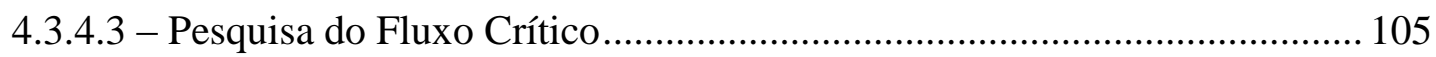

4.3.4.4 - Investigação do Tempo de Retrolavagem com máxima eficiência ........... 107

4.3.5 - Monitoramento do processo UASB/FSM (Operação de longa duração)...... 109

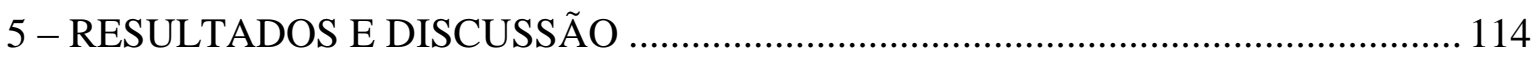

5.1 - ENSAIOS PRELIMINARES (OPERAÇÃO DE CURTA DURAÇÃO) ............... 114

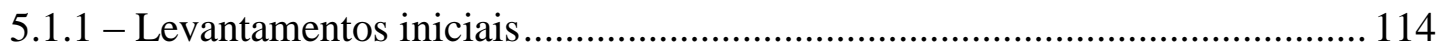

5.1.2 - Comportamento do Fluxo versus tempo .................................................... 115

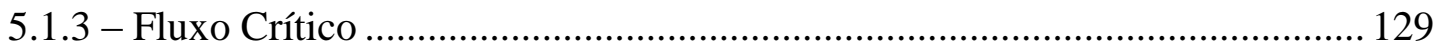

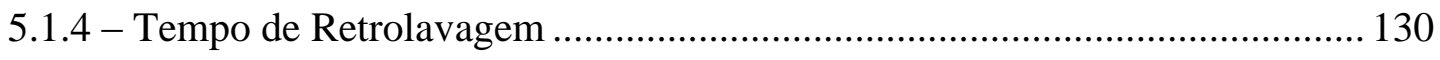

5.2 - MONITORAMENTO DO PROCESSO UASB/FSM (OPERAÇÃO DE LONGA

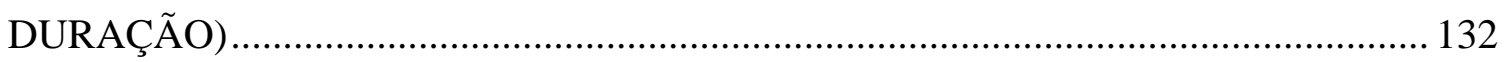

5.2.1 - Condições Operacionais .............................................................................. 133

5.2.2 - Monitoramento e Controle de Qualidade .................................................... 149

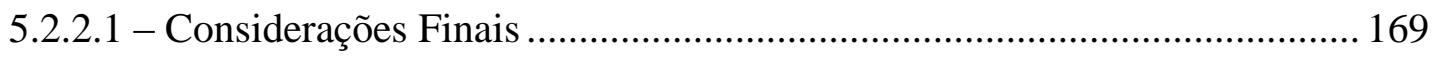

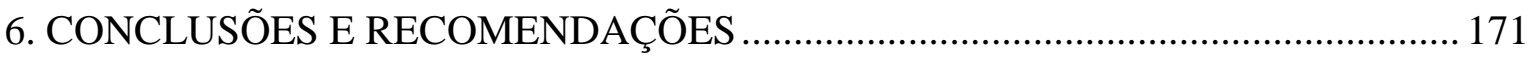

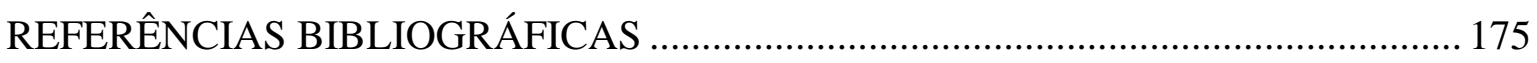

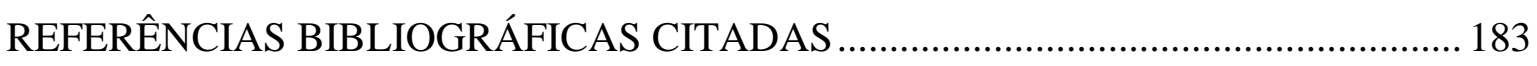

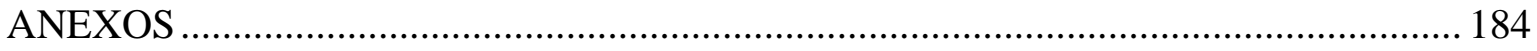

ANEXO 1 - CERTIFICADO DE QUALIDADE DE MÓDULOS Nº 1451 ................. 185

ANEXO 2 - FIGURA REPRESENTANDO AS ESTATISTICAS DESCRITIVAS DO

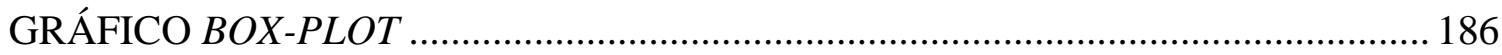




\section{LISTA DE TABELAS}

Tabela 3.1 - Classificação das membranas pela porosidade média utilizada no tratamento de água e esgotos e características do material rejeitado (adaptado de: Constanzi, 2007 e Radjenović et al., 2008).

Tabela 3.2 - Soluções de produtos químicos para limpeza de acordo com o tipo de incrustante (adaptado de: Arnal et al., 2011).

Tabela 3.3- Abertura da tela do peneiramento fino recomendado/instalado para instalação a montante dos Tanques com Membranas (BRMs aeróbios e anaeróbios e Filtração direta)

Tabela 3.4 - Condições operacionais avaliadas das duas corridas efetuadas no experimento de Wen et al. (1999).

Tabela 3.5 - Dados obtidos de pesquisas em escala de bancada para sistemas anaeróbios/filtração por membranas para o controle de incrustação de acordo com o reator, com a membrana e a condição operacional reportado por Smith et al. (2012). 78

Tabela 3.6 - Dados da qualidade do afluente das duas Corridas efetuadas no experimento de Wen et al. (1999)

Tabela 3.7 - Características do Esgoto Bruto utilizado na pesquisa de An et al. (2009).... 79

Tabela 4.1 - Principais Parâmetros de Projeto da ETE Gama (fonte: CAESB, 2003) ....... 83

Tabela 4.2 - Características da Qualidade da Água preconizadas no projeto da ETE Gama (fonte CAESB, 2003).

Tabela 4.3 - Variáveis de controle operacional e métodos empregados na avaliação da ETE Gama (fonte: Felizatto et al., 2014).

Tabela 4.4 - Histórico do desempenho dos reatores tipo UASB da ETE Gama do período de janeiro/2007 a julho/2014 86

Tabela 4.5 - Datas dos levantamentos do fluxo contra o tempo para diferentes pressões testadas 101

Tabela 4.6 - Condições operacionais iniciais sugeridas pela fornecedora da unidade de microfiltração (PAM Membrana Seletivas, 2014).

Tabela 4.7 - Condições Operacionais a serem monitoradas e frequências de medições para a Planta-piloto FMS - Filtrando

Tabela 4.8 -Variáveis monitoradas na verificação do desempenho global através das amostras compostas do: efluente do $U A S B$ (alimentação), descarte do TQ01 e permeado da Planta-piloto FMS e suas frequências 
Tabela 4.9 - Padrões para Efluentes de Sistemas de Tratamento de Esgotos Sanitários resolução CONAMA 430/11 (Brasil, 2011).

Tabela 4.10 - Diretrizes para remoção e concentração (E. Coli - NMP/100 m $\ell$ ) para o reúso de água em irrigação irrestrita e restrita de culturas na agricultura, segundo a OMS (WHO, 2006).

Tabela 4.11 - Diretrizes primárias e metas de qualidade da água de reúso para irrigação para garantia da saúde da população (WHO, 2006)

Tabela 4.12 - Valores de referência para classificação dos Sistemas de Tratamento de Esgotos Sanitários para o Programa de Despoluição de Bacias Hidrográficas (PRODES) da Agência Nacional de Água (ANA) segundo os níveis mínimos de remoção para variáveis específicas, incluindo os custos de implantação para cada tipo de sistema (Libânio et al., 2007)

Tabela 5.1 - Resultados dos testes de levantamento das permeabilidades hidráulicas iniciais executados nos dias 23 e 24/11/2015 e o valor de referência certificado pela fornecedora. 114

Tabela 5.2 - Resultados do levantamento da integridade pelo monitoramento da Turbidez durante microfiltração de solução de amido de milho $(1 \mathrm{~g} / \ell)$ executado no dia 24/11/2015 e o valor de integridade certificado pela fornecedora.

Tabela 5.3 - Valores dos parâmetros dos modelos que representam o fluxo $\mathrm{J}_{20}$ em função do tempo para microfiltração de efluente de reator $U A S B$ com PTM de -0,10, - 0,15 e 0,20 bar determinados na pesquisa.

Tabela 5.4 - Valores dos parâmetros dos modelos que representam a resistência desenvolvida $(\mathrm{R})$ em função do tempo para microfiltração de efluente de reator $U A S B$ com PTM de -0,10, -0,15 e -0,20 bar determinados na pesquisa.

Tabela 5.5 - Balanço hídrico do levantamento do tempo de retrolavagem de máxima eficiência para tempos testados de 30", 60" e 75" microfiltrando efluente do reator $U A S B$ 131

Tabela 5.6 - Fluxos médios diários (LHM) por dia da semana de operação contínua da microfiltração do efluente do reator UASB (28/03 a 28/10/2016) (*).

Tabela 5.7 - Produtividade dos 61 dias de operação contínua da microfiltração de efluente do reator $U A S B$, correspondente aos volumes produzidos de permeado e os volumes de permeados consumidos na retrolavagem diários (28/03 a 20/10/2016). 
Tabela 5.8 - Consumos específicos de energia elétrica $\left(\mathrm{kWh} / \mathrm{m}^{3}\right)$ por dia da semana de operação contínua da microfiltração do efluente do reator $U A S B(28 / 03$ a 28/10/2016).

Tabela 5.9 - Volumes diários medidos da alimentação, do descarte e do permeado durante a operação de longo termo da pesquisa de microfiltração de efluente de reator UASB.

Tabela 5.10 - Medidas estatísticas das séries temporais de $\mathrm{pH}$ monitorados na pesquisa de microfiltração de efluente do reator $U A S B$ para as amostras: afluente a ETE Gama, da alimentação ao TQ 01, do descarte do TQ01 e do permeado das 61 corridas executadas (28/03 a 20/10/2016).

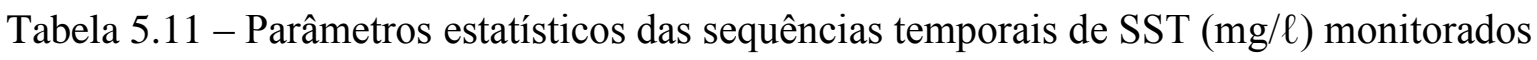
na pesquisa de microfiltração de efluente do reator $U A S B$ para as amostras: afluente a ETE Gama, da alimentação ao TQ 01, do descarte do TQ01 e do permeado das 61 corridas executadas (28/03 a 20/10/2016).

Tabela 5.12 - Parâmetros estatísticos das séries temporais de Turbidez (uT) ensaiados na pesquisa de microfiltração de efluente do reator $U A S B$ para as amostras: da alimentação ao TQ 01, do descarte do TQ01 e do permeado das 61 corridas executadas

Tabela 5.13 - Medidas estatísticas das estimativas dos diâmetros médios geométricos em massa $(\mu \mathrm{m})$ verificados na pesquisa de microfiltração de efluente do reator $U A S B$ para as amostras: da alimentação ao TQ 01, do descarte do TQ01 e do permeado das 61 corridas ensaiadas (28/03 a 20/10/2016).

Tabela 5.14 - Medidas estatísticas das séries temporais de Sólidos Dissolvidos Totais (SDT), SDT voláteis (SDTv) e SDT fixos (SDTf) monitorados $(\mathrm{mg} / \ell)$ na pesquisa de microfiltração de efluente do reator $U A S B$ para as amostras: alimentação do TQ 01, descarte do TQ01 e do permeado das 61 corridas executadas

Tabela 5.15 - Medidas estatísticas das sequencias temporais de Demanda Bioquímica de Oxigênio (DBO em $\mathrm{mg} / \ell$ ) monitorados na pesquisa de microfiltração de efluente do reator $U A S B$ para as amostras: afluente a ETE Gama, da alimentação ao TQ 01 e do permeado das 61 corridas executadas (28/03 a 20/10/2016). 161

Tabela 5.16 - Parâmetros estatísticos das séries temporais das concentrações das Demandas Químicas de Oxigênio (DQO em $\mathrm{mg} / \ell$ ) levantadas nesta pesquisa de microfiltração de efluente do reator $U A S B$ para as amostras: afluente a ETE Gama, 
alimentação do TQ 01, descarte do TQ01 e do permeado das 61 corridas ensaiadas (28/03 a 20/10/2016). 163

Tabela 5.17 - Medidas estatísticas das séries temporais das concentrações de Óleos e

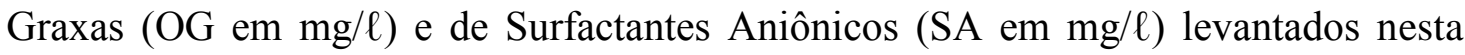
pesquisa de microfiltração de efluente do reator $U A S B$ para as amostras: alimentação do TQ 01 e do permeado das 61 corridas ensaiadas (28/03 a 20/10/2016). 165

Tabela 5.18 - Medidas estatísticas das sequências temporais dos logaritmos dos Coliformes Fecais (CF em NMP/100 m $)$ ) monitorados na pesquisa de microfiltração de efluente do reator $U A S B$ para as amostras: afluente a ETE Gama, da alimentação ao TQ 01 e do permeado das 61 corridas executadas (28/03 a 20/10/2016) 168 


\section{LISTA DE FIGURAS}

Figura 3.1 - Diagramas esquemáticos dos Processos de Separação por Membranas (adaptado de: Singh, 2006)

Figura 3.2 - Definição esquemática para a Filtração por Membrana (adaptado de: Metcalf e

Eddy, 2016)

Figura 3.3 - Fotomicrografia Eletrônica de uma membrana de ultrafiltração, mostrando a

espessura da camada filtrante no topo e os macroporos no seu interior 10

Figura 3.4 - Classificação das membranas em relação à morfologia

Figura 3.5 - Estruturas moleculares dos monômeros dos principais materiais poliméricos utilizados para fabricação das membranas (adaptado de: Aptel e Buckley, 1996)....... 15

Figura 3.6 - Espectro dos tipos de processos de separação com membranas, finalidade da separação, possíveis massa molecular do concentrado ou rejeitado no tratamento de água e águas residuárias (adaptado de: Hai e Yamamoto, 2011). 17

Figura 3.7 - Esquema do módulo de membrana tubular 19

Figura 3.8 - Esquema do módulo de membrana de fibra oca 20

Figura 3.9 - Esquema do módulo de membrana em espiral 21

Figura 3.10 - Esquema do módulo de placas planas.... 22

Figura 3.11 - Representação do ângulo de contato para membranas com material da superfície hidrofílica e hidrofóbica (adaptado de: Cheryan, 1998). 23

Figura 3.12 - Ilustração da sensibilidade dos métodos usados para monitoramento da Integridade de membranas através de testes em tratamento de água com vista a rejeitar protozoários parasitas (adaptado de: Yoon, 2016). .25

Figura 3.13 - Desenho esquemático dos dois modos básicos de operação em microfiltração: (a) Frontal e (b) Tangencial (adaptado de: Cheryan, 1998).

Figura 3.14 - Desenhos esquemáticos da representação da classificação da microfiltração tangencial em relação à alimentação e o permeado: (a) Defasagem em $90^{\circ}$ ou Fluxo cruzado, (b) Paralelas ou Co-corrente, (c) Contrárias ou Contra-corrente e (d) Mistura perfeita (adaptado de: Mulder, 1992) 28

Figura 3.15 - Representação gráfica cronológica para três modos de operação: (a) Fluxo constante, (b) Pressão transmembrana constante e (c) Pressão transmembrana e fluxos variáveis (adaptado de: Metcalf e Eddy, 2007). .28

Figura 3.16 - Desenho esquemático de um sistema de microfiltração (adaptado de: Metcalf e Eddy, 2007). .29 
Figura 3.17 - Desenho esquemático das duas categorias de filtração: (a) filtração de superfície e (b) filtração de profundidade (adaptado de: Baker, 2004)

Figura 3.18 - Esquema dos mecanismos envolvidos na retenção de partículas em filtração de profundidade na microfiltração por membranas (adaptado de: Baker, 2004).

Figura 3.19 - Representação Esquemática de um corte na seção de uma membrana assimétrica de microfiltração e suas características morfológicas.

Figura 3.20 - Representação da polarização de concentração do soluto no processo de separação por microfiltração (adaptado de: Cheryan, 1998)

Figura 3.21 - Representação esquemática da polarização da concentração durante a filtração por membranas em microfiltração de solutos coloidais e macromoléculas, mostrando a formação da camada gel ou torta (adaptado de: Cheryan, 1998)

Figura 3.22 - Gráfico representativo da correlação generalizada entre parâmetros operacionais e o fluxo, indicando as áreas de controle da pressão transmembrana e de controle da transferência de massa (adaptado de: Cheryan, 1998). 37

Figura 3.23 - Gráfico ilustrando o fluxo $(\mathrm{J})$ em função do tempo $(\mathrm{t})$, distinguindo a polarização da concentração da incrustação (adaptado de: Mulder, 1992) 39

Figura 3.24 - Ilustração do gradual bloqueio dos poros pela ação de macromoléculas (círculos vazados) e flocos microbianos (elipses escuras).

Figura 3.25 - Ilustração esquemática resumida das resistências atuantes, na superfície e dentro dos poros da membrana, durante a filtração (adaptado de: Pinnekamp, 2003) . 44 Figura 3.26 - Gráfico do Fluxo em função do tempo de uma microfiltração, linha superior com retrolavagem e inferior sem (adaptado de: Mulder, 1992).

Figura 3.27 - Desenho esquemático para microfiltração em fibras ocas nas condições (a) fluxo de permeado em operação normal e (b) em retrolavagem (adaptado de: Mulder, 1992).

Figura 3.28 - Esquema do processo de Lodos Ativados nas configurações convencional (a) e BRM (b) - a linha tracejada delimita o nível de tratamento denominado de secundário

Figura 3.29 - Configurações de Reatores Biológicos Anaeróbios com separação por membranas - BRM-An (adaptado de: Visvanathan e Abeynayaka, 2012).

Figura 3.30 - Esboço esquemático da definição das configurações e modos operacionais da filtração por membranas: (a) fluxo tangencial pressurizado, (b) retrolavagem do fluxo tangencial pressurizado, (c) fluxo frontal pressurizado, (d) retrolavagem do fluxo frontal pressurizado, (e) membranas submersas com extração a vácuo e (f) 
retrolavagem de membranas submersas com extração a vácuo (Adaptado de: Metcalf e Eddy, 2007)

Figura 3.31 - Fotografias de instalações típicas de configurações de membranas pressurizadas e submersas para filtração de efluentes secundários sedimentados: (a) e (b) microfiltração submersa, (c) módulo de ultrafiltração (fibras ocas) usado em tanque aberto estruturado no solo e (d) módulo de microfiltração (placa plana) instalados em tanque aberto apoiado (adaptado de: Metcalf e Eddy, 2007) 64

Figura 3.32 - Evolução do mercado por meio do número de instalações de estações de tratamento para tratamento de esgotos industrial e sanitários por BRMs aeróbios na Europa (adaptado de: Lesjean e Huisjes, 2008)

Figura 3.33 - Evolução do número publicações em revistas científicas sobre BRM-An e UASB (adaptado de: Ranade e Bhandari, 2014).

Figura 3.34 - Evolução do número de artigos científicos publicados em revistas sobre o uso de tratamento de águas residuárias industriais e municipais com BRM-An (adaptado de: Ranade e Bhandari, 2014). 68

Figura 3.35 - Diagrama esquemático de Biorreator anaeróbio (reator UASB) acoplado ao módulo de membranas de fibra oca submersas (adaptado de: Wen et al., 1999) .72

Figura 3.36 - Configuração esquemática da planta-piloto de reator $U A S B$ acoplado a módulo de membrana tubular externo (adaptado de: An et al., 2009). .74

Figura 3.37 - Diagrama esquemático de reator $U A S B$ acoplado a módulo tubular de membranas submerso (adaptado de: Cerón-Vivas et al., 2012). 76

Figura 4.1 - Etapas envolvidas nos Materiais e Métodos desta Pesquisa. 81

Figura 4.2 -Desenho esquemático visto em planta e sem escala do reator aerado da ETE Gama (fonte: Felizatto et al., 2014).

Figura 4.3 - Fluxograma da Estação de Tratamento de Esgotos do Gama (fonte: Felizatto et al., 2014). .85

Figura 4.4 - Edifício de instalação da Planta-piloto FMS-PTARH/UnB/RENTED/CAESB Casa de Química da ETE Gama. 87

Figura 4.5 - Planta-piloto FMS PTARH-UnB-RENTED/CAESB instalada no interior da Casa de Química da ETE Gama. Detalhe do Medidor de energia elétrico instalado na lateral do console do quadro elétrico já existente. 88

Figura 4.6 - Bomba submersível modelo XKS-401PW do fabricante Ferrari .89

Figura 4.7 - Croqui (sem escala) em corte do Filtro em "Y", fabricante DECA, em destaque a tela metálica cilíndrica perfurada com diâmetros dos furos de $0,5 \mathrm{~mm}$.... 89 
Figura 4.8 - Fotografia do local do poço de bombeamento da rede de recalque da Plantapiloto FMS - PTARH/UnB/RENTED/CAESB e da instalação do pré-tratamento (peneiramento fino). Caixa de passagem do efluente do reator anaeróbio A e B da ETE Gama.

Figura 4.9 - Redes de alimentação e saída (permeado e descarte de fundo do Tanque 01-

Tanque com membranas) da FMS - PTARH/UnB/RENTED/CAESB. 91

Figura 4.10 -Fluxograma da Planta-piloto FMS - PTARH-UnB/CAESB. 94

Figura 4.11 - Fluxograma do levantamento do fluxo $(\mathrm{J})$ contra o tempo (t) na filtração direta por membranas de efluente de reator $U A S B$ para PTM de -0,1, -0,15 e -0,20 bar.

Figura 4.12 - Diagrama esquemático do procedimento para determinação da distribuição do tamanho das partículas (pela massa) usando filtração em série através de membranas filtrantes de diferentes dimensões de poros - 0,22 $\mu \mathrm{m}, 0,45 \mu \mathrm{m}, 0,70 \mu \mathrm{m} \mathrm{e}$ 1,2 $\mu \mathrm{m}$ (adaptado de Metcalf e Eddy, 2007). 104

Figura 4.13 - Fluxograma do levantamento do fluxo crítico $\left(\mathrm{J}_{\mathrm{c}}\right)$ na filtração direta por membranas de efluente de reator $U A S B$ para PTM aplicadas de $-0,02 ;-0,05 ;-0,08$; 0,$10 ;-0,15$ e 0,20 bar. 106

Figura 4.14 - Fluxograma do levantamento do tempo de retrolavagem na filtração direta por membranas de efluente de reator $U A S B$ para tempos de retrolavagem variando de 30 a 75 segundos. 108

Figura 5.1 - Gráfico do fluxo padronizado, $\mathbf{J}_{20}$, e da resistência desenvolvida ao longo da filtração do efluente do reator $U A S B$ realizada com PTM de $-0,1$ bar no dia $04 / 12 / 2015$. 116

Figura 5.2 - Gráfico do fluxo padronizado, $\mathbf{J}_{20}$, e da resistência desenvolvida ao longo da filtração do efluente do reator $U A S B$ realizada com PTM de $-0,1$ bar no dia $07 / 12 / 2015$.

Figura 5.3 - Gráfico do fluxo padronizado, $\mathbf{J}_{20}$, e da resistência desenvolvida ao longo da filtração do efluente do reator $U A S B$ realizada com PTM de $-0,1$ bar no dia 06/01/2016. 117

Figura 5.4 - Gráfico do fluxo padronizado, $\mathbf{J}_{20}$, e da resistência desenvolvida ao longo da filtração do efluente do reator $U A S B$ realizada com PTM de $-0,15$ bar no dia $11 / 12 / 2016$. 
Figura 5.5 - Gráfico do fluxo padronizado, $\mathrm{J}_{20}$, e da resistência desenvolvida ao longo da filtração do efluente do reator $U A S B$ realizada com PTM de $-0,15$ bar no dia $14 / 12 / 2016$. 118

Figura 5.6 - Gráfico do fluxo padronizado, $\mathbf{J}_{20}$, e da resistência desenvolvida ao longo da filtração do efluente do reator $U A S B$ realizada com PTM de $-0,15$ bar no dia $15 / 12 / 2016$.

Figura 5.7 - Gráfico do fluxo padronizado, $\mathbf{J}_{20}$, e da resistência desenvolvida ao longo da filtração do efluente do reator $U A S B$ realizada com PTM de $-0,20$ bar no dia 08/12/2016. 119

Figura 5.8 - Gráfico do fluxo padronizado, $\mathbf{J}_{20}$, e da resistência desenvolvida ao longo da filtração do efluente do reator $U A S B$ realizada com PTM de $-0,20$ bar no dia 09/12/2016. 120

Figura 5.9 - Gráfico do fluxo padronizado, $\mathbf{J}_{20}$, e da resistência desenvolvida ao longo da filtração do efluente do reator $U A S B$ realizada com PTM de $-0,20$ bar no dia $10 / 12 / 2016$. 120

Figura 5.10 - Gráfico do fluxo padronizado, $\mathrm{J}_{20}$, em função do tempo ao longo da filtração do efluente do reator $U A S B$ realizada com PTMs de -0,10, -0,15 e -0,20 bar

Figura 5.11 - Decaimento do fluxo padronizado $\left(\mathrm{J}_{20}\right)$ em função do tempo ao longo da filtração do efluente do reator $U A S B$ realizada com PTMs de -0,10, -0,15 e -0,20 bar. 124

Figura 5.12 - Gráfico da resistência desenvolvida (R) em função do tempo ao longo da filtração do efluente do reator $U A S B$ realizada com PTMs de $-0,10,-0,15$ e $-0,20$ bar. 125

Figura 5.13 - Gráfico das resistências desenvolvidas $\mathrm{R}_{\mathrm{T}}$ (total), $\mathrm{R}_{1}$ (primeira limpeza), $\mathrm{R}_{2}$ (segunda limpeza) e $\mathrm{R}_{0}$ (última limpeza) para todas as PTMs testadas no Levantamento iniciais $(-0,10,-0,15$ e $-0,20$ bar $)$. 126

Figura 5.14 - Gráfico das resistências médias desenvolvidas $\mathrm{R}_{\mathrm{T}}$ (total), $\mathrm{R}_{1}$ (primeira limpeza), $\mathrm{R}_{2}$ (segunda limpeza) e $\mathrm{R}_{0}$ (última limpeza) para todas as PTMs testadas no Levantamento iniciais $(-0,10,-0,15$ e $-0,20$ bar $)$.

Figura 5.15 - Gráfico do fluxo médio (J em LMH) gerado a partir dos volumes produzidos de permeado nas três corridas sucessivas de cada PTM testada $(-0,10,-0,15$ e $-0,20$ bar) 
Figura 5.16 - Gráfico do fluxo (J) em função das PTMs aplicadas (-0,02, -0,05, -0,08, 0,10, - 0,15 e -0,20 bar) e o fluxo médio $\left(\mathrm{J}_{\mathrm{m}}\right)$ para investigação do Fluxo Crítico para a microfiltração de efluente de reator UASB.

Figura 5.17 - Gráfico do Volume produzido líquido médio de permeado em função dos tempos de retrolavagem testados (30", 45" e 75") para operação de microfiltração de efluente do reator $U A S B$.

Figura 5.18 - Gráfico do comportamento do fluxo normalizado da operação de microfiltração de efluente de reator $U A S B$ de 28/03 a 20/04/2016 (PTM de -0,1 bar).

Figura 5.19 - Gráfico da evolução da incrustação medida através da resistência desenvolvida na operação de microfiltração de efluente de reator $U A S B$ de 28/03 a 20/04/2016 (PTM de -0,1 bar). 134

Figura 5.20 - Gráfico do comportamento do fluxo normalizado da operação de microfiltração de efluente de reator $U A S B$ de 25/04 a 12/05/2016 (PTM de -0,1 bar). 134

Figura 5.21 - Gráfico da evolução da incrustação medida através da resistência desenvolvida na operação de microfiltração de efluente de reator $U A S B$ de 25/04 a 12/05/2016 (PTM de -0,1 bar)

Figura 5.22 - Gráfico do comportamento do fluxo normalizado da operação de microfiltração de efluente de reator $U A S B$ de 22/08 a 15/09/2016 (PTM de -0,1 bar).

Figura 5.23 - Gráfico da evolução da incrustação medida através da resistência desenvolvida na operação de microfiltração de efluente de reator $U A S B$ de 22/08 a 15/09/2016 (PTM de -0,1 bar) 136

Figura 5.24 - Gráfico do comportamento do fluxo normalizado da operação de microfiltração de efluente de reator $U A S B$ de 19/09 a 20/10/2016 (PTM de -0,1 bar). 136

Figura 5.25 - Gráfico da evolução da incrustação medida através da resistência desenvolvida na operação de microfiltração de efluente de reator $U A S B$ de 19/09 a 20/10/2016 (PTM de -0,1 bar)

Figura 5.26 - Gráficos box-plot dos fluxos médios desmembrados por dias da semana: J2 (Segunda-feira), J3 (Terça-feira), J4 (Quarta-feira) e J5 (Quinta-feira) da operação contínua de microfiltração do efluente do reator $U A S B$ (28/03 a 28/10/2016). 139 
Figura 5.27 - Produtividade das sete (7) semanas iniciais da operação contínua da microfiltração de efluente do reator $U A S B$, correspondente aos volumes produzidos de permeado (VPP) e os volumes de permeados consumidos na retrolavagem (VCR) diários (28/03 a 13/05/2016).

Figura 5.28 - Produtividade das nove (9) semanas finais da operação contínua da microfiltração de efluente do reator $U A S B$, correspondente aos volumes produzidos de permeado (VPP) e os volumes de permeados consumidos na retrolavagem (VCR) diários (22/08 a 20/10/2016). 141

Figura 5.29 - Perdas na retrolavagem das sete (7) semanas iniciais da operação contínua da microfiltração de efluente do reator UASB (28/03 a 13/05/2016).

Figura 5.30 - Perdas na retrolavagem das nove (7) semanas finais da operação contínua da microfiltração de efluente do reator $U A S B$ (22/08 a 20/10/2016).

Figura 5.31 - Gráficos box-plot dos consumos específicos de energia elétrica $\left(\mathrm{kWh} / \mathrm{m}^{3}\right)$ por dia da semana: P2 (Segunda-feira), P3 (Terça-feira), P4 (Quarta-feira) e P5 (Quinta-feira) da operação contínua da microfiltração do efluente do reator UASB (28/03 a $28 / 10 / 2016)$. 144

Figura 5.32 - Gráfico do tempo de detenção hidráulico calculado diariamente para todas as corridas da operação contínua da microfiltração do efluente do reator UASB .

Figura 5.33 - Gráfico da recuperação - S (\%) calculada diariamente para todas as corridas da operação contínua da microfiltração do efluente do reator UASB (28/03 a 28/10/2016). 146

Figura 5.34 - Gráfico da sequência das permeabilidades hidráulicas (K) filtrando água potável da CAESB após o protocolo de limpeza executado na pesquisa: retrolavagem e limpeza hidráulica/química no período de 23/11/2015 a 20/10/2016. 148

Figura 5.35 - Gráfico da sequência das resistências para membranas limpas (R), filtrando água potável da CAESB após o protocolo de limpeza executado na pesquisa: retrolavagem e limpeza hidráulica/química no período de 23/11/2015 a 20/10/2016.148

Figura 5.36 - Gráficos box-plot das séries temporais de $\mathrm{pH}$ monitorados na pesquisa de microfiltração de efluente do reator $U A S B$ para as amostras: afluente a ETE Gama, da alimentação ao TQ 01, do descarte do TQ01 e do permeado das 61 corridas executadas (28/03 a 20/10/2016).

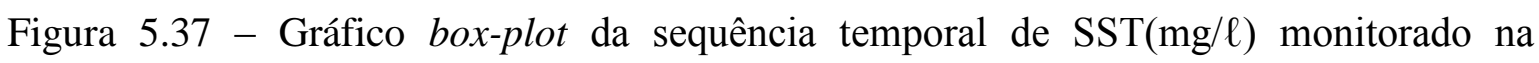
pesquisa de microfiltração de efluente do reator $U A S B$ para a amostra afluente a ETE Gama (28/03 a 20/10/2016). 152 


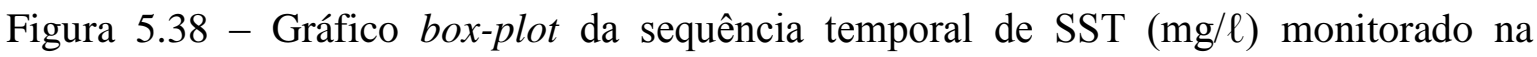
pesquisa de microfiltração de efluente do reator $U A S B$ para a amostra de permeado das 61 corridas executadas (28/03 a 20/10/2016).

Figura 5.39 - Gráficos box-plot das remoções parciais no reator UASB (ReSSTu) e nas membranas submersas (ReSSTm) e remoção global do tratamento (ReSSTt) da pesquisa de microfiltração do efluente do reator $U A S B(28 / 03$ a 20/10/2016).

Figura 5.40 - Gráficos box-plot das séries temporais de Turbidez (uT) levantadas na pesquisa de microfiltração de efluente do reator $U A S B$ para as amostras: da alimentação ao TQ 01 e do descarte do TQ01 das 61 corridas executadas (28/03 a 20/10/2016)

Figura 5.41 - Gráfico box-plot da remoção de Turbidez pela unidade de filtração por membranas submersas (ReTurm) da pesquisa de microfiltração do efluente do reator UASB (28/03 a 20/10/2016). 155

Figura 5.42 - Gráficos box-plot das estimativas dos diâmetros médios geométricos em massa $(\mu \mathrm{m})$ computados na pesquisa de microfiltração de efluente do reator $U A S B$ para as amostras: da alimentação ao TQ 01 e do descarte do TQ01 das 61 corridas executadas (28/03 a 20/10/2016). 158

Figura 5.43 - Gráficos box-plot das séries temporais de Turbidez (uT) levantadas na pesquisa de microfiltração de efluente do reator $U A S B$ para as amostras: da alimentação ao TQ 01 e do descarte do TQ01 das 61 corridas executadas (28/03 a 20/10/2016) 160

Figura 5.44 - Gráficos box-plot das séries de $\mathrm{DBO}(\mathrm{mg} / \ell)$ monitorados na pesquisa de microfiltração de efluente do reator $U A S B$ para as amostras: afluente a ETE Gama, alimentação do TQ 01 e do permeado das 61 corridas ensaiadas (28/03 a 20/10/2016).

Figura 5.45 - Gráficos box-plot das remoções parciais de DBO no reator UASB (ReDBOu) e nas membranas submersas (ReDBOm) e remoção global do tratamento (ReDBOt) da pesquisa de microfiltração do efluente do reator UASB (28/03 a 20/10/2016). 162

Figura 5.46 - Gráficos box-plot das sequências temporais das concentrações das Demandas

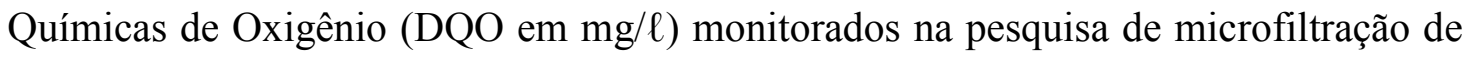
efluente do reator $U A S B$ para as amostras: afluente a ETE Gama, alimentação do TQ 01 e do permeado das 61 corridas ensaiadas (28/03 a 20/10/2016). 164 
Figura 5.47 - Gráficos box-plot das remoções parciais de DQO no reator UASB (ReDQOu) e nas membranas submersas (ReDQOm) e remoção global do tratamento (ReDQOt) da pesquisa de microfiltração do efluente do reator UASB (28/03 a 20/10/2016). 165

Figura 5.48 - Gráficos box-plot das sequências temporais das concentrações de Óleos e

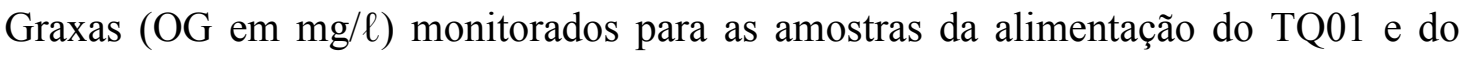
permeado das 61 corridas ensaiadas (28/03 a 20/10/2016). 166

Figura 5.49 - Gráficos box-plot das sequências temporais das concentrações de Surfactante Aniônicos (SA em $\mathrm{mg} / \ell$ ) monitorados nesta pesquisa para as amostras da alimentação do TQ01 e do permeado das 61 corridas ensaiadas (28/03 a 20/10/2016). 166

Figura 5.50 - Gráficos box-plot das séries temporais transformadas pela função logaritmo na base 10 das concentrações de Coliformes Fecais (CF em NMP/100 m $\ell$ ) monitorados na pesquisa de microfiltração de efluente do reator UASB para as amostras: afluente a ETE Gama, alimentação do TQ 01 e do permeado das 61 corridas ensaiadas (28/03 a 20/10/2016). 168

Figura 5.51 - Gráficos box-plot das remoções parciais de Coliforme Fecais (em unidades logarítmicas) no reator $U A S B(\mathrm{ReCFu})$ e nas membranas submersas ( $\mathrm{ReCFm}$ ) e a remoção global do tratamento $(\mathrm{ReCFt})$ da pesquisa de microfiltração do efluente do reator $U A S B(28 / 03$ a 20/10/2016). 169 


\section{LISTA DE SÍMBOLOS, NOMENCLATURAS E ABREVIAÇÕES}

$\frac{d V}{d t}$ Derivada de primeiro grau do volume em relação ao tempo (vazão ou fluxo)

A

a.

AC.

$\mathrm{A}_{\mathrm{e} 1}$

$\mathrm{A}_{\mathrm{e} 2 \text {. }}$

$\mathrm{A}_{\mathrm{n}}$.

ANA

An-MBR

APHA

AWWA

$\mathrm{A}_{\mathrm{x} 1}$

$\mathrm{A}_{\mathrm{x} 2}$.

B.

bar

BARDENPHO $^{\circledR}$
Área da superfície da membrana

Afluente Acetado de Celulose Primeira Zona Aeróbia Segunda Zona Aeróbia Zona Anaeróbia Agência Nacional das Águas Anaerobic Membrane Bioreactor American Public Healthy Association American Water Works Association Primeira Zona Anóxica Segunda Zona Anóxica Bancada

BRM Biorreatores com Membranas ou Reatores Biológicos com Membranas BRM-An Biorreatores Anaeróbios com Membranas BRM-EAn Biorreatores Anaeróbios com Membranas Externas BRM-SAn Biorreatores Anaeróbios com Membranas Submersas BS01 Bomba submersa de alimentação BS02 Bomba de sucção das Membranas c. Corrente do Concentrado c. $v$ Cavalo vapor (unidade de potência) $\mathrm{c}_{\mathrm{a}}$ .Concentração do soluto na alimentação

CAESB Companhia de Saneamento Ambiental do Distrito Federal $\mathrm{c}_{\mathrm{c}}$ Concentração do soluto no concentrado $\mathrm{c}$ .Concentração do soluto na camada limite

CEDAE Companhia Estadual de Águas e Esgotos -Rio de Janeiro CETESB Companhia Ambiental do estado de São Paulo

$\mathrm{CF}$ Coliformes Fecais $\mathrm{c}_{\mathrm{g}}$ .Concentração do soluto na camada gel 
CLP.

.Controlador Lógico Programável

COT. Carbono Orgânico Total

$\mathrm{COV}$

.Carga Orgânica por Unidade de Volume de Reator

$\mathrm{c}_{\mathrm{p}}$ .Concentração do soluto no permeado

$\mathrm{c}_{\mathrm{sa}}$ Concentração de determinado soluto na alimentação

$\mathrm{c}_{\mathrm{sp}}$ .Concentração de determinado soluto no permeado

CT. Coliformes Totais

Da. Dalton

DAD

Decantador e adensador de lodo não capturado

DBO Demanda Biológica ou Bioquímica de Oxigênio

$\mathrm{D}$ Coeficiente de difusão do soluto i

$\mathrm{D}_{\mathrm{mg}}$ Diâmetro médio geométrico em massa $\mathrm{d}_{\mathrm{p}}$. Diamêtro médio dos poros da membrana

DQO Demanda Química de Oxigênio EDTA Ácido Etilenodiamino Tetra-Acético

Ef Efluente

EGSB Expanded Granular Sludge Bed

EPAI Estação Produtora de Água Industrial

EPAR Estação de Produção de Água de Reúso EPM Esteira de peneiramento mecanizado abertura 3 milímetros EPS Extracellular polymeric substances

ETE Estação de tratamento de esgotos

ETEs Estações de tratamento de esgotos

FAD Flotação por Ar dissolvido

FINEP Fundo de Financiamento de Estudos de Projetos e Programas

FMS. Filtração por membranas submersas

FY01 Filtro em "Y" número 1, com peneira de 0,5 mm

FY02 Filtro em "Y" número 2, com peneira de $0,5 \mathrm{~mm}$

GG. Grade grosseira abertura 3 polegadas GIS Sistema de informação geográfica

$\mathrm{H}_{2} \mathrm{~S}$ Ácido Sulfídrico

$\mathrm{H}_{2} \mathrm{SO}_{4}$ Ácido Sulfúrico

IHM. Interface Homem Máquina

IP-68........Grau de Proteção de Motor Elétrico (total contra a poeira e imersão permanente) 
IPCC sigla em inglês para Painel Intergovernamental sobre Mudanças Climáticas .Internacional Union of Pure and Applied Chemists .Fluxo mássico ou volumétrico do permeado

$\mathrm{Kg} \mathrm{DBO} / \mathrm{d}$ Quilos de Demanda Biológica de Oxigênio por dia $\mathrm{kPa}$ Quilo Pascal (unidade de pressão) $\mathrm{kW}-\mathrm{h}$ Quilo Watts hora (unidade de consumo de energia elétrica da potência útil) $\ell$ litro(s)

$\ell /$ hab.d. .litros por habitantes por dia $\ell / \mathrm{s}$ litros por segundos

$\mathrm{LMH}$ litros por metros quadrados por hora $\mathrm{m}$. .metro ou metros (unidade de comprimento) M. Concentração molar (número de moles/litro) MBR Membrane Bioreactors ou Membrane Biological Reactors $\mathrm{mm}$ milímetro ou milímetros (unidade de comprimento) MMC. Massa Molecular de Corte $\mathrm{mS}$ mili-Siemens (unidade de medida da condutividade elétrica da água) $\mathrm{mV}$ mili-Volts (unidade de medida do pOR)

$\mathrm{NH}_{4}{ }^{+}$ Nitrogênio na forma amoniacal, expressos em mg $\mathrm{N}$ por litro

$\mathrm{NO}_{2}$ Nitrogênio na forma nitrificada (Nitrito), expressos em mg $\mathrm{N}$ por litro

$\mathrm{NO}_{3}{ }^{-}$ Nitrogênio na forma nitrificada (Nitrato), expressos em mg $\mathrm{N}$ por litro $\mathrm{NO}_{\mathrm{x}}{ }^{-}$.............Nitrogênio na forma nitrificada (Nitrito + Nitrato), expressos em $\mathrm{mg} \mathrm{N}$ por litro $\mathrm{N}_{\mathrm{T}}$ Nitrogênio total, expressos em $\mathrm{mg} \mathrm{N}$ por litro

NTK Nitrogênio Total de Kjehdäl, expressos em mg N por litro p. Corrente do Permeado PAN. Poliacrilonitrila PC Policarbonato

PE .Polietileno

PEI Polieterimida PES .Polieterssulfona $\mathrm{pH}$ Potencial Hidrogeniônico Phosphorus Reduction Oxidation 
$\mathrm{PPi}$ Planta Piloto

PS Polisulfona $\mathrm{P}_{\mathrm{T}}$ Fósforo Total, expressos em mg P por litro PTARH............Programa de pós-graduação em Recursos Hídricos e Tecnologia Ambiental PTFE Politetrafluoretileno

PTM Pressão Transmembrana ou Pressão aplicada PVC. Policloreto de Vinila

PVDF Fluoreto de polivinilideno Vazão

$\mathrm{Q}_{\mathrm{a}}$ .Vazão de alimentação

$\mathrm{Q}_{\mathrm{c}}$ Vazão do concentrado Vazão máxima Qmed Vazão média $\mathrm{Q}_{\mathrm{p}}$ Vazão do permeado $\mathrm{R}$ Coeficiente de rejeição ou de retenção $\mathrm{R}_{\mathrm{a}}$ Resistência devido à adsorção

RENTED Rede Nacional de Tratamento de Esgotos Descentralizados $\mathrm{R}_{\mathrm{m}}$ Resistência da membrana RMSP Região Metropolitana de São Paulo $\mathrm{R}_{\mathrm{p}}$ Resistência devido ao bloqueio dos poros $\mathrm{R}_{\mathrm{pc}}$ .Resistência devido à polarização da concentração

$\mathrm{R}_{\mathrm{t} .}$ Resistência da torta $\mathrm{R}_{\mathrm{T}}$. Resistência total S. Coeficiente de rendimento ou recuperação

SABESP .Companhia de Saneamento Básico do Estado de São Paulo SANASA Sociedade de Abastecimento de Água e Saneamento S.A SES Sistema de Esgotamento Sanitário

$\mathrm{SH}$ Sistema híbrido SMP. Soluble microbial products SP01 Soprador de Ar para limpeza 1 
Tanque de Limpeza com permeado

Volts (unidade de tensão elétrica)

VA01 Válvula de Agulha Controladora de Fluxo

VE01 Válvula de Esfera Manual número 1

VE02 Válvula de Esfera Manual número 2

VE03 Válvula de Esfera Manual número 3

VE04 Válvula de Esfera Manual número 4

VE05 .Válvula de Esfera Manual número 5

VE06 Válvula de Esfera Manual número 6

VE07 .Válvula de Esfera Manual número 7

VE08 Válvula de Esfera Manual número 8 VE09 .Válvula de Esfera Manual número 9

VG01 Válvula Globo Manual número 1 Válvula Solenóide Controladora de Fluxo VT01 Válvula Solenóide de Três vias número 1 VT02 Válvula Solenóide de Três vias número 2 $\mathrm{W}$ Watts (unidade de potência) WEF Water Environment Federation WPCF Water Protection Control Federation $\boldsymbol{\theta}$ Ângulo de contato $\boldsymbol{\delta}$ Espessura da camada limite $\varepsilon$ Porosidade da membrana $\mu$. Viscosidade absoluta ou dinâmica do líquido $\Delta \mathrm{P}$ Variação da pressão aplicada $\Delta \mathrm{x}$ Espessura da camada filtrante da membrana 


\section{1 - INTRODUÇÃO}

No Brasil e na América do Sul, as mudanças climáticas já verificadas e as previstas colocarão em risco a segurança hídrica dessas regiões e terão impactos diretos no abastecimento de água doméstico e industrial e em setores fortemente dependentes deste recurso, como o de geração de energia hidrelétrica e a agricultura. $\mathrm{O}$ alerta vem do Intergovernmental Panel on Climate Change - IPCC (2014) e destaca que as projeções de mudanças climáticas de maior repercussão para as Américas do Sul e Central ocorrerão nas zonas áridas e semiáridas, hoje já vulneráveis.

A intensificação de secas e cheias na América do Sul, previsões que já estão sendo confirmadas, também afetam e afetarão cada vez mais o abastecimento de água das grandes cidades, a geração de energia hidrelétrica e a produção de alimentos. Como exemplo, podem ser citadas as recentes ocorrências de eventos climáticos extremos, com períodos de secas combinados com os de altas temperaturas, fatos presenciados nos últimos quatro anos na região Sudeste do Brasil. Esses eventos acabaram impondo à maior região metropolitana do Brasil, São Paulo, abastecida pelas represas Cantareira, Alto do Tietê e Guarapiranga, uma crise de insegurança hídrica nunca dantes enfrentada na história do saneamento brasileiro, mesmo sendo localizada numa região de abundância hídrica (Mendonça e Mendonça, 2016).

Com esse cenário de esgotamento dos recursos hídricos, tanto em qualidade e quantidade, adicionado às tendências cada vez mais restritivas de políticas ambientais de descargas de efluentes, consideravelmente tem aumentado o número de projetos de reúso de água no mundo e, de forma mais acanhada, no Brasil (Bixio e Wintgens, 2006; Bixio et al., 2008).

No reúso de água, os microrganismos, principalmente os patogênicos, representam a ameaça mais comum, devido à elevada concentração de espécies potencialmente infecciosas que rotineiramente estão presentes no efluente de processos de tratamento secundário de esgotos sanitários. O papel principal das membranas em sistemas de recuperação de água, portanto, é o auxílio na retenção de microrganismos, pois a maioria dos processos de membranas age como uma barreira relativamente eficaz a todos os microrganismos, incluindo vírus. Isso é verdade até para a microfiltração, que pelo 
tamanho dos poros por si só não seria capaz de reter a maioria dos vírus na faixa de tamanhos maiores (Wintgens et al., 2005).

Um diagnóstico realizado por uma pesquisa na região da América Latina, Noyola et al. (2013) identificaram três principais tecnologias utilizadas para o tratamento de esgotos sanitários: lagoas de estabilização, lodos ativados (aeração prolongada e convencional) e reatores UASB (Upflow Anaerobic Sludge Blanket). Nessa pesquisa, 2.734 estações de tratamento foram consultadas em seis países da região (Brasil, Colômbia, Chile, República Dominicana, Guatemala e México). A distribuição por número para essas três tecnologias foi 38, 26 e 17\%, respectivamente, correspondendo a $81 \%$ das ETEs (Estações de Tratamento de Esgotos Sanitários) consultadas. Vale notar que o sistema UASB, embora um recente no campo de tratamento de esgotos sanitários, com menos de 25 anos de aplicação em escala real no mercado específico, ocupou o terceiro lugar deste ranqueamento, ficando atrás de processos antigos, como é o caso de lodos ativados, com mais de um século de aplicação na área.

No caso do Brasil, a aceitação e a disseminação dos reatores $U A S B$ para o tratamento de esgotos sanitários colocou o país numa posição de vanguarda em nível mundial (Chernicharo, 2007; Chernicharo et al., 2015; Jordão et al., 2007). Chernicharo (2007) estimou que existiam no Brasil, na época, em torno de 400 reatores UASB tratando esgotos sanitários, a maioria deles localizado nos estados do Paraná, da Bahia, de Minas Gerais e no Distrito Federal.

Com essa posição destacada do reator $U A S B$ no tratamento de esgotos sanitários, integrá-lo sequencialmente à filtração direta por membranas submersas tem despertado o interesse, e tem-se mostrado recentemente em algumas pesquisas com um potencial promissor na melhoria da qualidade da água - física, química e, principalmente, microbiológica (Chernicharo et al., 2015). Portanto, faz-se necessário e relevante para o tratamento de esgotos sanitários e o reúso de água explorar o conhecimento dessa configuração, e com isso, aprofundar o entendimento nos pormenores da operação e o desempenho de tal combinação.

Este projeto integra a cooperação técnica CAESB-PTARH/FT/UnB e faz parte do Projeto de pesquisa em Rede denominado RENTED e que tem entre seus objetivos pesquisar o 
potencial do processo de separação utilizando membranas como filtração direta do efluente de reator $U A S B$, no quesito da melhoria da qualidade do efluente final com vista a ser usado em irrigação restrita e/ou irrestrita. O projeto de pesquisa foi desenvolvido por meio da instalação e operação de uma planta piloto de vazão de projeto de permeado de 60 litros/hora, que foi alocada na área da ETE Gama de propriedade da CAESB (Companhia de Saneamento Ambiental do Distrito Federal). 


\section{2 - OBJETIVOS}

\section{1 - OBJETIVO GERAL}

O objetivo da pesquisa foi o de avaliar o potencial do processo composto por reator "UASB" seguido de Filtração por Membranas Submersas de microfiltração operando no tratamento de esgotos sanitários não segregados, com especial atenção ao reúso de água.

\section{2 - OBJETIVOS ESPECÍFICOS}

Para o desenvolvimento desta pesquisa, os seguintes objetivos específicos foram propostos:

1. Estabelecer as condições operacionais específicas da Filtração por Membranas Submersas (FMS) para efluente do reator $U A S B$;

2. Avaliar se o efluente tratado (permeado) do sistema acoplado $U A S B / F M S$ atende aos padrões mais restritivos de lançamentos de efluentes em corpos receptores, comparando a qualidade do efluente (permeado) com os padrões de lançamento de efluentes preconizados pelo CONAMA - Conselho Nacional de Meio Ambiental;

3. Avaliar o desempenho global do sistema $U A S B / F M S$ com os valores preconizados pelo Programa de Despoluição de Bacias Hidrográficas da Agência Nacional de Água (PRODES/ANA);

4. Avaliar se o efluente tratado (permeado) do sistema acoplado UASB/FMS atende aos padrões mais exigentes de reúso de água para irrigação, restrita e/ou irrestrita, comparado com as diretrizes estabelecidas pela Organização Mundial de Saúde; e

5. Avaliar o consumo de energia elétrica no sistema acoplado UASB/FMS e comparar com o consumo atual em ETEs da CAESB e com os valores encontrados na literatura. 


\section{3 - FUNDAMENTAÇÃO TEÓRICA E REVISÃO BIBLIOGRÁFICA}

\section{1 - FUNDAMENTAÇÃO TEÓRICA}

Antes de dar início à revisão bibliográfica, é indispensável a explanação da terminologia básica encontrada no tema da pesquisa. Metcalf e Eddy (2003), WEF (2006) e Howe et al. (2012) apresentam alguns dos termos comumente encontrados em pesquisas correlatas à aplicação do processo de separação por membranas e são apresentados e descritos, de forma sucinta, a seguir:

Coeficiente de transferência de massa: unidade de massa ou volume transferido através da membrana baseada em uma determinada força motriz.

Concentrado, retido, fase retida, rejeito ou corrente residual: solução contendo água e materiais impermeáveis retidos no lado da alimentação de uma membrana semipermeável. Solução com concentração de STD maior que a da alimentação.

Dalton: unidade de massa molecular, igual a $\frac{1}{12}$ da massa atômica do isótopo 12 do Carbono (isolado e neutro). Equivalente à unidade de massa atômica (uma).

Densidade de empacotamento: área da membrana por unidade de volume, ocupado pelo módulo de filtragem.

Elemento da membrana: unidade contendo um agrupamento de membranas provendo uma determinada área nominal.

Faixa de retenção: designação do tamanho das partículas retidas pela membrana. A retenção é dada em tamanho do poro para a microfiltração e em massa molecular de corte para a ultrafiltração.

Filtração frontal (Dead-end): técnica de filtração na qual a alimentação é direcionada de forma perpendicular à superfície da membrana.

Filtração tangencial (Cross-flow): técnica de filtração na qual a corrente alimentada é bombeada em alta velocidade de forma paralela à superfície da membrana para minimizar os efeitos da incrustação. 
Fluxo específico: fluxo dividido pela pressão transmembrana (J/PTM).

Fluxo: taxa volumétrica ou mássica transferida através da superfície da membrana, usualmente é a vazão de permeado dividido pela área da superfície da membrana (Q/A).

Incrustação (Fouling): processo que resulta na perda de desempenho da membrana devido à deposição de substâncias em suspensão e dissolvidas na superfície externa, na abertura e no interior dos poros. Pode ser reversível ou irreversível.

Massa molecular de corte: massa da molécula retida na membrana ou o mesmo que a faixa de retenção, muito usado na ultrafiltração, quase sempre expresso em kDa.

Matriz ou trem: estágios múltiplos conectados em série.

Membrana assimétrica: membrana que tem sua morfologia variável ao longo de sua espessura.

Membrana homogênea: membrana que tem sua morfologia constante ao longo de sua espessura.

Membrana semipermeável: membrana que é permeável para alguns componentes da solução ou suspensão alimentada e impermeável para outros.

Módulo: unidade completa consistindo de membranas, estrutura de suporte da pressão, vácuo, ou da corrente elétrica e canais ou dispositivos de entrada (alimentação) e saídas (permeado e concentrado).

Peneiramento: processo no qual as partículas retidas são superiores ao diâmetro dos espaços vazios (poros).

Permeabilidade: fluxo específico, geralmente de água limpa e deionizada, através da membrana nova ou limpa.

Permeado, produto ou corrente permeada: água e componentes permeáveis que passam pela membrana. Solução com concentração de STD menor que a da alimentação.

Pressão transmembrana: pressão diferencial entre o lado da alimentação e o do permeado. 


\subsection{1 - Filtração por Membranas}

Segundo Judd (2011), a indústria de membranas começou sua existência a partir do início do século XX, sendo que, no princípio, as pesquisas acadêmicas objetivaram a elucidação dos fenômenos físico-químicos e dos mecanismos de difusão envolvidos no processo de separação por membranas. Entretanto, as descobertas de alguns desses conhecimentos ainda impactam as pesquisas básicas e até as aplicações industriais nos dias atuais, tais como lei de difusão de Fick, enunciada em 1855, e a equação da pressão osmótica de van`t Hoff, em 1887, sendo esse último laureado como o primeiro ganhador do Nobel em Química, em 1901, pelo desenvolvimento desta importante equação e também por sua dedicação aos estudos e elucidação das leis da dinâmica da química.

Thomas Graham, em 1861, foi o pioneiro nos trabalhos de separação de gases utilizando membranas de borracha, ele inspirou suas pesquisas em Schmidt (1856 apud Judd, 2011) que usou membrana de coração bovino (poros de 1-50 nm) para separação de Acácia solúvel, trabalho considerado o primeiro documento relatando experimentos com membranas e datado de 1856 (Judd, 2011).

A primeira membrana foi desenvolvida a partir de colódio (nitrocelulose) sintetizada por Bechhold, em 1907. Este trabalho serviu de exemplo para o início da fabricação de membranas produzidas por colódio em escala comercial pela empresa Sartorius Werke Ltda., estabelecida na Alemanha em 1925 e tendo iniciado sua consolidação no laboratório do pesquisador Zsigmondy, da Universidade de Goettingen (Judd, 2011).

Judd (2011) reporta que os alemães durante a Segunda Grande Guerra Mundial tiveram seus sistemas de abastecimento de água danificados e por isto desenvolveram a técnica de membranas filtrantes para detecção rápida de bactérias em águas para consumo humano, utilizando as membranas fabricadas pela Sartorius.

Do início até a atualidade, outros métodos de preparação de membranas foram desenvolvidos e com isso os processos de separação com membranas tiveram difundida sua utilização em diversos setores do ramo industrial, como nas indústrias química, alimentícia, farmacêutica, médica e biotecnologia. São exemplos de aplicação a serem considerados: a dessalinização de águas salobras e salinas, o tratamento de águas 
residuárias industriais e a purificação e/ou concentração de produtos farmacêuticos (Judd, 2011; Pabby et al., 2015).

Na Figura 3.1 esboçam-se os diversos processos de separação por membrana, excetuando a nanofiltração, ilustrando os fluxogramas, descrevendo os tipos de materiais que são seletivamente permeados e as forças motrizes responsáveis pelo transporte de massa através da membrana.

\begin{tabular}{|c|c|c|c|}
\hline PROCESSO & MECANISMOS & PERMEADO & $\begin{array}{c}\text { FORÇA } \\
\text { MOTRIZ }\end{array}$ \\
\hline $\begin{array}{l}\text { Micro- } \\
\text { Filtração }\end{array}$ & $\stackrel{\text { Alimentacão }}{\rightarrow} \underset{\text { Membrana Microporosa }}{\rightarrow} \rightarrow \underset{\text { Permeado }}{\rightarrow}$ & $\begin{array}{l}\text { Água } \\
\mathrm{e} \\
\text { Substâncias } \\
\text { Dissolvidas }\end{array}$ & $\begin{array}{l}\text { Diferença de } \\
\text { Pressão } \\
\text { Valor tipico de } \\
0,07 \mathrm{kPa}\end{array}$ \\
\hline Diálise & 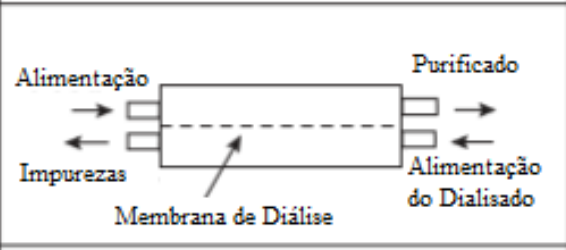 & $\begin{array}{l}\text { Íons e } \\
\text { compostos } \\
\text { orgânicos de } \\
\text { baixo peso } \\
\text { molecular } \\
\text { (Ureia, etc.) }\end{array}$ & $\begin{array}{l}\text { Diferença de } \\
\text { Concentração } \\
\text { e } \\
\text { Alimentação } \\
\text { do Dialisado }\end{array}$ \\
\hline $\begin{array}{l}\text { Eletro- } \\
\text { Diálise }\end{array}$ & Concentrado & Íons & $\begin{array}{l}\text { Voltagem } \\
\text { Tipica de } \\
1 \text { a } 2 \text { V/par de } \\
\text { células }\end{array}$ \\
\hline $\begin{array}{l}\text { Osmose } \\
\text { Inversa }\end{array}$ & 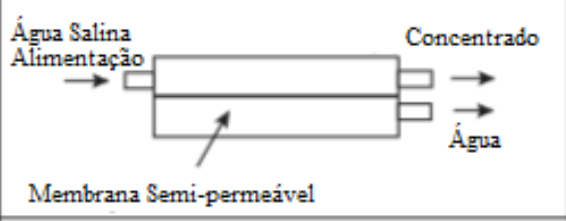 & Água & $\begin{array}{l}\text { Diferença de } \\
\text { Pressão } \\
\text { de } 0,7 \text { a } 5,5 \\
\mathrm{kPa}\end{array}$ \\
\hline $\begin{array}{l}\text { Ultra- } \\
\text { Filtração }\end{array}$ & Alimentacão & $\begin{array}{l}\text { Águas } \\
\mathrm{e} \\
\text { Sais }\end{array}$ & $\begin{array}{l}\text { Diferença de } \\
\text { Pressão } \\
\text { de } 0,07 \text { a } 0,7 \\
\mathrm{kPa}\end{array}$ \\
\hline $\begin{array}{l}\text { Separação } \\
\text { de Gases }\end{array}$ & $\stackrel{\text { Alimentacão }}{\rightarrow}$ & $\begin{array}{l}\text { Gases } \\
\mathrm{e} \\
\text { Vapores }\end{array}$ & $\begin{array}{l}\text { Diferença de } \\
\text { Pressão } \\
\text { de } 1 \text { a } 100 \text { atm }\end{array}$ \\
\hline
\end{tabular}

Figura 3.1 - Diagramas esquemáticos dos Processos de Separação por Membranas (adaptado de: Singh, 2006)

As membranas de nanofiltração tem diâmetro de poros em torno de $0,001 \mu \mathrm{m}$ e removem a maior parte das moléculas de matéria da orgânica, quase todos os vírus e uma grande 
variedade de sais. A nanofiltração remove os íons bivalentes, que tornam a água dura, por isso a nanofiltração é frequentemente usada para abrandamento de água dura, operando com pressões intermediárias entre a ultrafiltração e a osmose inversa (Howe et al., 2012).

A membrana filtrante, também, pode ser conceituada como uma barreira seletiva, fisicamente constituída por um filme fino sólido, que separa duas soluções e transporta seus componentes através dos poros desse filme (Schneider e Tsutiya, 2001).

Na Figura 3.2 apresenta-se o esquema para a definição do processo de separação por membranas, onde se observam as três principais correntes: a de entrada ou alimentação e as duas de saídas. A fase líquida que atravessa a membrana semipermeável é denominada de permeado ou produto, isto quando se deseja usar o processo para melhorar a qualidade de uma água residuária, por exemplo. A corrente com os constituintes retidos é conhecida como concentrado, retido, rejeito ou resíduo (Green e Perry, 2008).

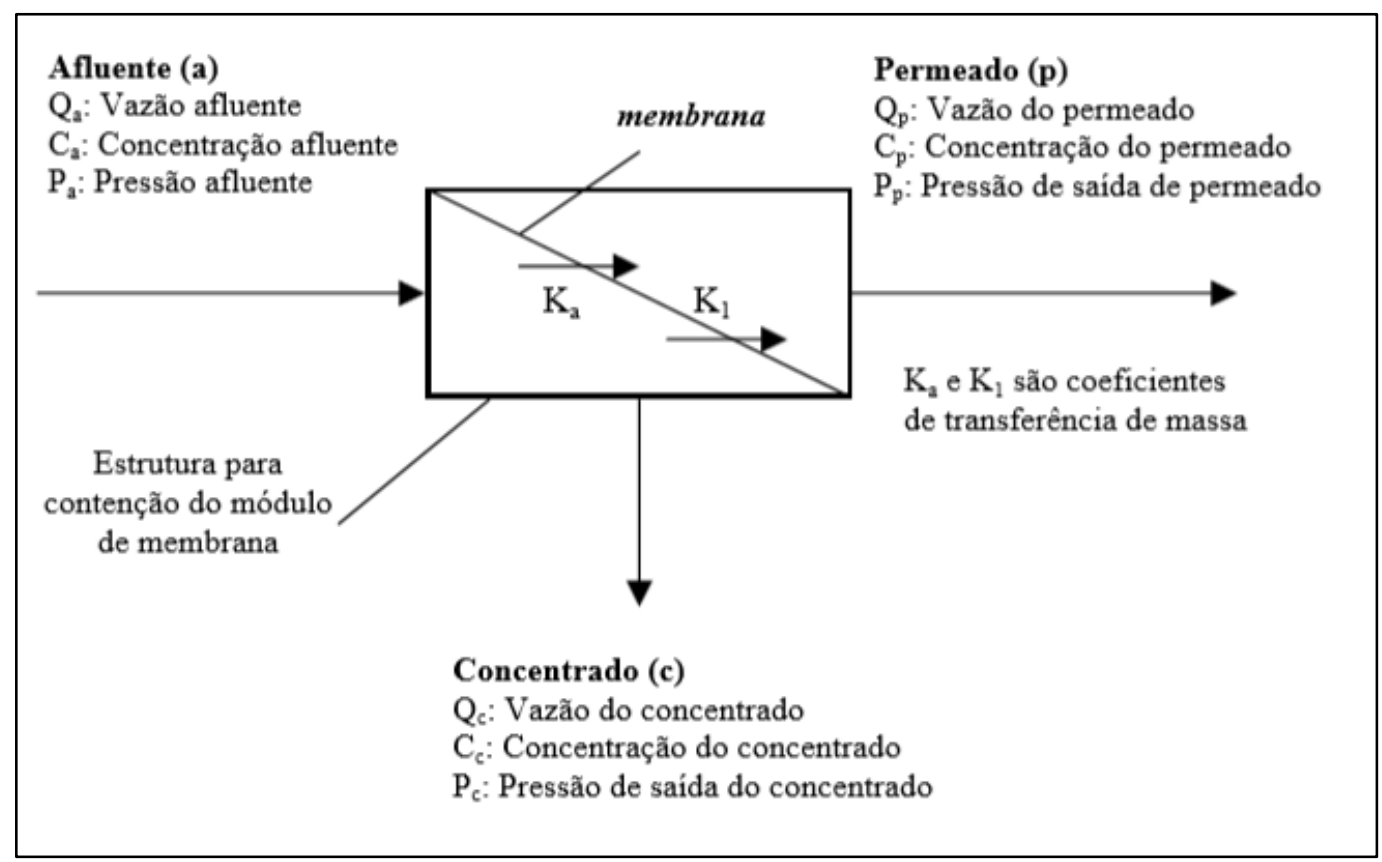

Figura 3.2 - Definição esquemática para a Filtração por Membrana (adaptado de: Metcalf e Eddy, 2016)

A operação é de separação de componentes de uma solução ou suspensão na qual a faixa de diâmetros estende-se até aos constituintes dissolvidos, tipicamente de $10^{-4}$ a $0,1 \mu \mathrm{m}$ e é promovido por ação de uma força motriz, pressão, potencial elétrico ou gradiente de concentração (Metcalf e Eddy, 2003). 
A separação por Membrana é referida como um processo e não denominada de operação unitária devido ao fato de que nesse ambiente ocorrem transformações ligadas a mecanismos das propriedades químicas da matéria, do tipo adsorção de materiais na superfície e no interior dos poros que posteriormente ocorrem na camada retida ou também denominada de torta, principalmente quando aplicada ao chamados biorreatores com membranas - BRMs (Judd, 2011).

\subsubsection{1 - Características das Membranas}

As características físicas fundamentais relacionadas à membrana são: (i) espessura, (ii) porosidade, (iii) seletividade e (iv) permeabilidade.

\section{- Espessura}

É a profundidade do filme sólido onde ocorre o processo de separação. E em membranas homogêneas, quanto maior é essa subcamada, maior será a resistência à filtração ou ao fluxo, e com isso menor é a taxa de permeação. Já em membranas sintetizadas em suporte macroporoso (diâmetros de poros maiores), a resistência ao fluxo decresce. Esta camada também é, na maioria das vezes, denominada de pele. Na Figura 3.3, ilustra-se uma membrana de ultrafiltração mediante a fotografia por microscópio de varredura eletrônica com aumento de 1.500 vezes, em que se verifica a espessura da mesma e a estrutura dos poros da membrana de ultrafiltração.

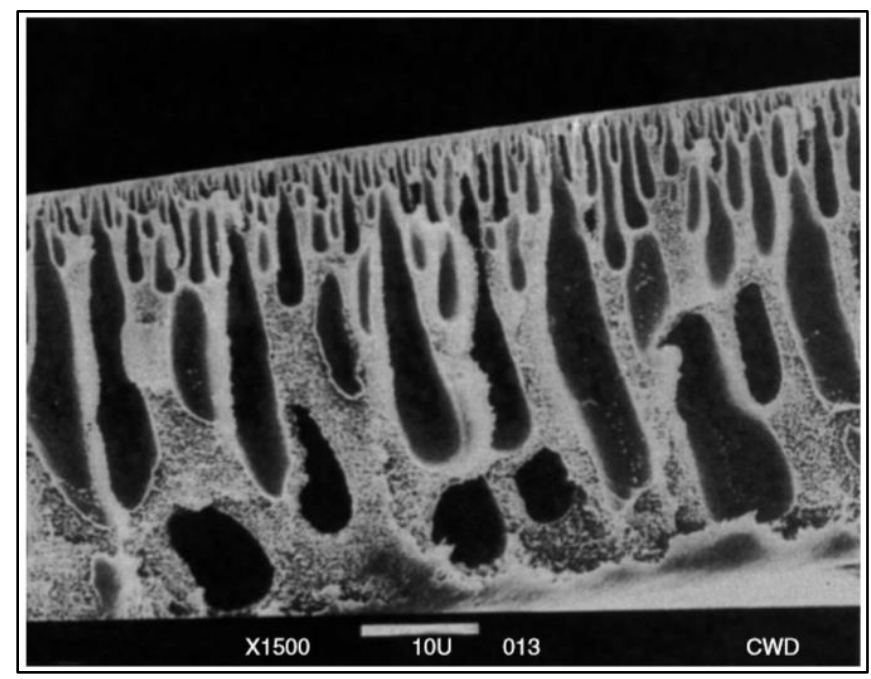

Figura 3.3 - Fotomicrografia Eletrônica de uma membrana de ultrafiltração, mostrando a espessura da camada filtrante no topo e os macroporos no seu interior (adaptado de: Singh, 2015). 
Na imagem da Figura 3.3 mostra-se a membrana denominada assimétrica, com detalhe da camada no topo ou pele, responsável pela filtração, e os macroporos no seu interior, que têm como função facilitar o escoamento hidráulico e dar suporte à pele, pelo fato de ser uma fina camada permeante.

- Porosidade

Volume ocupado pelos vazios (poros) dividido pela superfície da membrana, expressa em volume de poros por metro quadrado.

- Seletividade

Definida como a capacidade da membrana em reter ou não determinadas substâncias, ou seja, qual o diâmetro de corte do processo de separação. Esta propriedade depende da distribuição dos diâmetros dos poros da membrana, sendo que o diâmetro de corte é um valor médio de uma distribuição de tamanhos de poros. Em microfiltração é expressa em diâmetro médio dos poros (em $\mathrm{nm}$ ou $\mu \mathrm{m}$ ), enquanto em ultrafiltração é sempre referenciada com a massa molecular de corte (MMC, em $\mathrm{kDa})$.

- Permeabilidade

É considerada como a relação entre a vazão do permeado pela área da membrana e a força motriz aplicada, sendo que a vazão é a somatória das taxas volumétricas ou mássicas de cada poro que se comporta como vários capilares de escoamento. $\mathrm{O}$ transporte efetuado através da membrana depende da força motriz, que pode ser: mecânica, química, elétrica e térmica.

A membrana ideal deve ter elevadas seletividade e permeabilidade, entretanto quando se maximiza a seletividade, geralmente diminui-se a permeabilidade e vice-versa. A eficiência do processo de separação por membrana depende do fluxo e da seletividade.

\subsubsection{2 - Classificação das Membranas}

As membranas podem ser categorizadas por diferentes critérios, como: (a) Textura Física, (b) Morfologia, (c) Material, (d) Diâmetro dos Poros, (e) Geometria, (f) Hidrofilicidade e (h) Integridade. 


\section{- Textura Física}

As membranas podem ter texturas densas ou porosas. Nas densas, a transferência molecular é feita pelo mecanismo de solução-difusão, e elas são sintetizadas a partir de polímeros de alta densidade, tendo a osmose inversa como exemplo típico deste grupo.

A membrana porosa deve apresentar poros fixos, boa resistência mecânica, porém não devem ser muito espessas, pois a espessura influencia o fluxo do permeado de modo a diminuí-lo com o seu aumento. As membranas de microfiltração e ultrafiltração são características deste grupo.

\section{- Morfologia}

Em essência, a membrana é nada mais do que uma interface discreta, película fina que regula a permeação de espécies químicas ao entrarem em contato com esta interface. A interface pode ser, do ponto de vista da composição molecular, homogênea, isto é, possuir composição e estrutura completamente uniforme - Simétrica ou Isotrópica. Também pode ser química e fisicamente heterogênea, por exemplo, contendo orifícios ou poros de dimensões finitas, ou consistindo de algum tipo de estrutura em camadas - Assimétrica ou Anisotrópica (Baker, 2004). Na Figura 3.4 ilustra-se a classificação das membranas com relação à morfologia e também se apresentam as subclassificações dos dois principais tipos.

As membranas isotrópicas porosas possuem uma estrutura rígida com poros aletoriamente distribuídos. A membrana porosa é semelhante a um filtro convencional, tem estrutura rígida, cheia de vazios interconectados. A grande diferença do filtro convencional é que, no caso da membrana, os diâmetros dos poros são extremamente pequenos, da ordem de 0,01 a $10 \mu \mathrm{m}$ (Baker, 2004). 


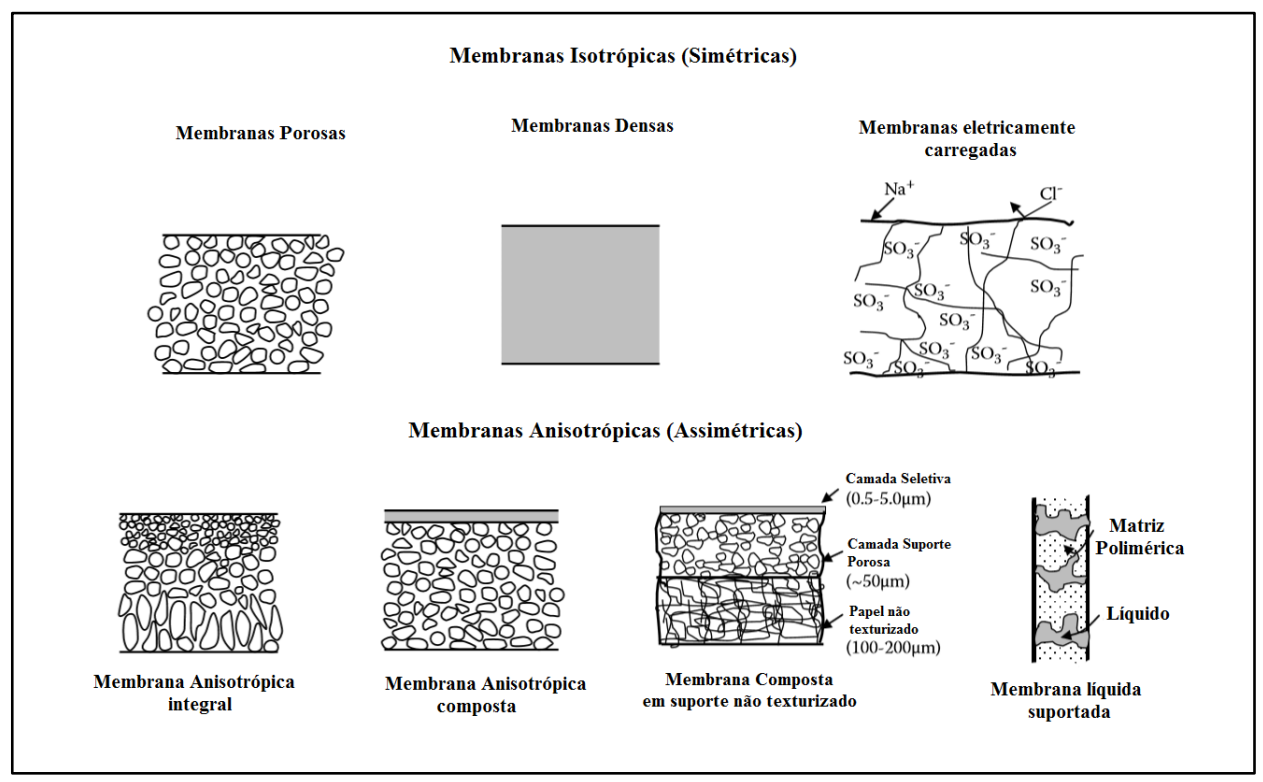

Figura 3.4 - Classificação das membranas em relação à morfologia (adaptado de: Mohanty e Purkait, 2012).

A separação dos solutos é feita da seguinte forma: (i) todas as partículas maiores do que os poros maiores são completamente rejeitadas; (ii) as partículas com diâmetros intermediários (menores do que os poros maiores e maiores do que os menores) são rejeitadas de forma parcial, de acordo com a distribuição do tamanho dos poros da membrana e (iii) as partículas menores do que os menores poros irão passar através da membrana. Assim, o processo de separação de solutos através das membranas porosas é principalmente função do tamanho molecular e da distribuição de tamanho dos poros. Em geral, apenas as moléculas que diferem consideravelmente de tamanho podem ser separadas eficazmente por membrana porosa, por exemplo, na ultrafiltração e na microfiltração. As membranas isotrópicas densas são formadas por um filme denso onde o permeado é transferido por difusão. Já as membranas isotrópicas eletricamente carregadas podem ser densas ou porosas e impregnadas de íons positivos e negativos (Baker, 2004).

As membranas anisotrópicas apresentam uma camada superior, de permeabilidade seletiva, porosa ou densa, apoiada sobre outra estrutura porosa muito mais espessa. A camada superficial, também chamada de pele, e a sua estrutura pode ser feita com o mesmo material (integrais) ou não (compostas). Em membranas compostas, as camadas são normalmente feitas a partir de diferentes materiais, mas as propriedades de separação e as taxas de permeação da membrana são determinadas exclusivamente pela pele e a função da subestrutura é de suporte mecânico. A espessura ótima do filme é, geralmente, muito fina 
(0,1 a $1,0 \mathrm{~mm})$ para ser mecanicamente estável e de modo que estes filmes possam ser fixados e suportados. As espessuras de cada uma das partes da membrana composta (o suporte e a pele) podem ser otimizadas de forma independente, objetivando melhorar o desempenho em relação à seletividade, ao fluxo e a estabilidade química e térmica (Mohanty e Purkait, 2012).

\section{- Material}

As membranas podem ser naturais (biológicas) ou artificiais (sintéticas). As que são sinteticas são produzidas a partir de uma variedade de materiais, tais como metais e materiais cerâmicos (membranas inorgânicas) e polímeros (membranas orgânicas). As membranas inorgânicas têm melhor estabilidade química, mecânica e térmica, no entanto, elas são utilizadas apenas em determinadas aplicações, onde a membrana necessita ser resistente à agressividade de um determinado solvente e, por conta disto, apresentam custos mais altos quando comparadas com as orgânicas (Baker, 2004). As membranas também podem ser sólidas e líquidas, sendo que estas últimas têm seu uso restrito a casos muito particulares e não são aplicadas no tratamento de efluentes.

As membranas mais utilizadas no tratamento de água e de águas residuárias são as orgânicas, porque elas são mais flexíveis e podem ser colocadas em módulos compactos, com área superficial muito elevada. Elas podem ser feitas a partir de celulose e de alguns polímeros sintetizados, uma vez que a estabilidade química, mecânica e térmica desses polímeros atende ao uso na área de saneamento (Cheryan, 1998).

Os principais materiais sintetizados utilizados na fabricação das membranas estão demonstrados na Figura 3.5, na qual do lado esquerdo, ilustram-se as fórmulas moleculares dos monômeros e do direito os nomes dos polímeros, e destacados entre os parênteses estão as abreviaturas dos mesmos. 


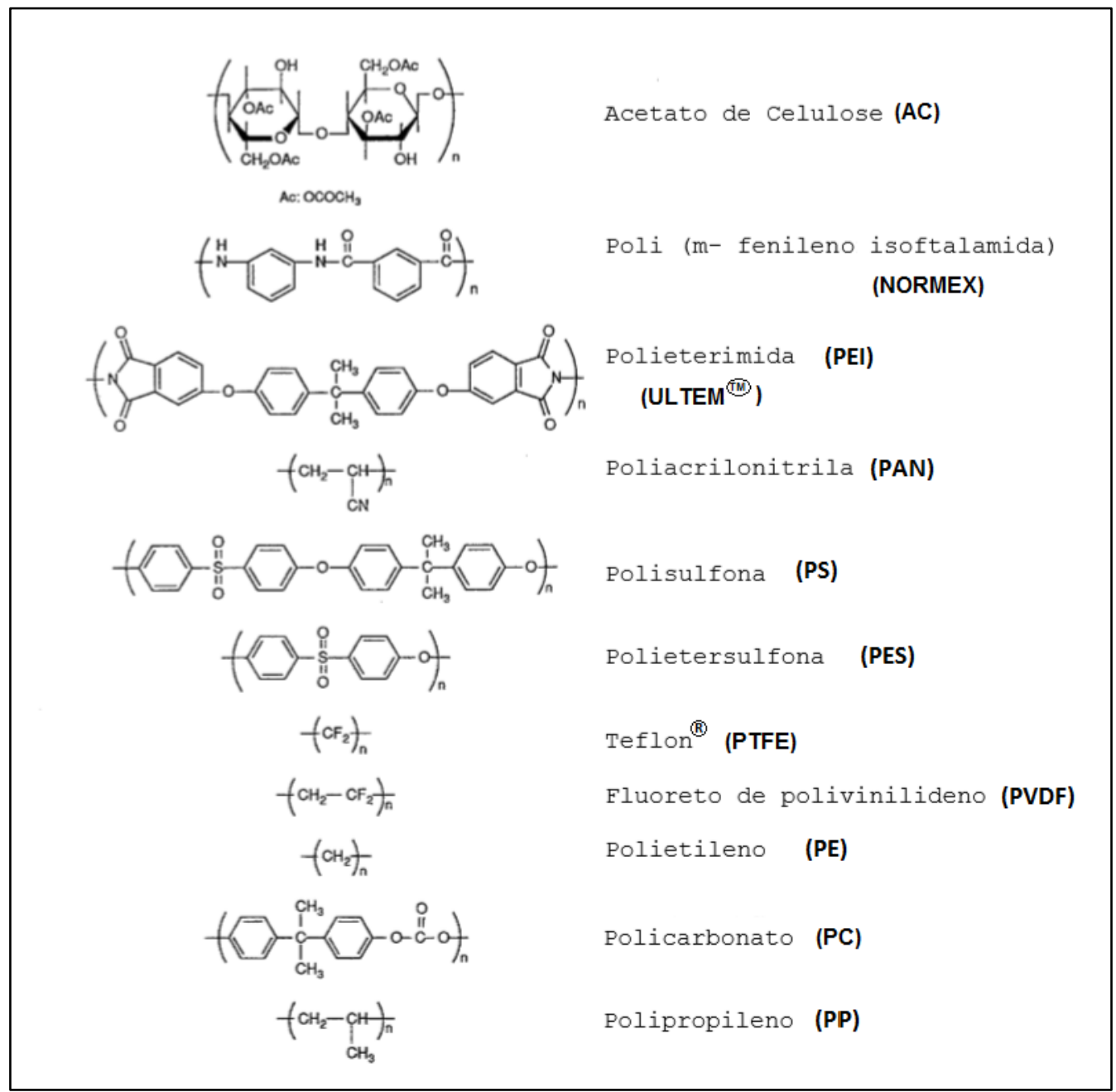

Figura 3.5 - Estruturas moleculares dos monômeros dos principais materiais poliméricos utilizados para fabricação das membranas (adaptado de: Aptel e Buckley, 1996).

As membranas de cerâmica apresentam boas resistências química e física, suportam altas temperaturas e operam em faixas mais abrangentes de $\mathrm{pH}$, porém devido ao seu alto custo de produção e às necessidades operacionais de altas pressões, bem como a exigência de grande consumo de energia elétrica, somente são usadas em casos muito específicos de tratamento de efluentes industriais e também em digestão anaeróbia.

Ultimamente, módulos fabricados com metais têm mostrado desempenho operacional bom (hidráulico e com relação às incrustações), quando utilizados para tratamento de efluente em BRMs Anaeróbios (Silva, 2009). 
Aptel e Buckley (1996) exemplificam que alguns polímeros têm seus usos em filtração por membranas em situações específicas, tais como:

1. Tratamento de água - membranas compostas por acetato de celulose (di e triacetato), pois apresentam a vantagem de serem resistentes à agressividade provocada pelo Cloro;

2. Dessalinização - as membranas compostas por poliimidas são superiores na seletividade e estabilidade quando comparadas às sintetizadas por ésteres;

3. Ultrafiltração - membranas com polissulfona e polieterssulfona tem tendência à adsorção na filtração, portanto estes polímeros são mais utilizados como suporte na confecção das membranas compostas e para esta aplicação utilizando outro polímero para a pele. A poliacrilonitrila é um dos polímeros mais utilizados em membranas de ultrafiltração;

4. Microfiltração - membranas porosas com politetrafluoretileno, polivinilidina, polietileno, policarbonato e polipropileno são as preferidas pela qualidade de excelência na estabilidade química e térmica.

\section{- Diâmetro dos Poros}

O poros das membranas podem ser classificados segundo o seu tamanho em: macroporos - diâmetros médios maiores que $50 \mathrm{~nm}$, mesoporos de 2 a $50 \mathrm{~nm}$, e microporos, que são os diâmetros menores que $2 \mathrm{~nm}$, classificação preconizada pela IUPAC em 1985, segundo Mulder (1992).

Os processos de separação por membranas mais aplicados em tratamento de água e águas residuárias são denominadas de: microfiltração, ultrafiltração, nanofiltração e osmose inversa (Mulder, 1992).

A Tabela 3.1 classifica os processos de separação pelos diâmetros médios dos poros e em relação aos componentes rejeitados (corrente concentrada). Portanto, as membranas mais usadas no tratamento de água e águas residuárias são as denominadas de porosidade média, como pode ser observado na Tabela 3.1, que são as de microfiltração e ultrafiltração. Isto implica em que as membranas de microfiltração possuem a maioria dos diâmetros dos poros classificados como macroporos, e as membranas de ultrafiltração possuem a maior parte como mesoporos (Mulder, 1992). 
Tabela 3.1 - Classificação das membranas pela porosidade média utilizada no tratamento de água e esgotos e características do material rejeitado (adaptado de: Constanzi, 2007 e

Radjenović et al., 2008).

\begin{tabular}{lll}
\hline Processo & Faixa de Separação & Rejeito \\
\hline Microfiltração & 100 a $1.000 \mathrm{~nm}$ & $\begin{array}{l}\text { Protozoários, bactérias, } \\
\text { (parcialmente) e partículas. }\end{array}$ \\
$\begin{array}{l}\text { Ultrafiltração } \\
\text { Nanofiltração }\end{array}$ & $\begin{array}{l}5 \text { a } 100 \mathrm{~nm} \\
1 \text { a } 5 \mathrm{~nm}\end{array}$ & $\begin{array}{l}\text { Colóides, vírus (todos) e endotoxinas. } \\
\text { Íons di e trivalentes, pesticidas, herbicidas } \\
\text { e sais bivalentes. }\end{array}$ \\
Osmose Inversa & $0,1 \mathrm{a} 1 \mathrm{~nm}$ & $\begin{array}{l}\text { Íns, sais, pesticidas, herbicidas, íons } \\
\text { metálicos, disruptores endócrinos e } \\
\text { subprodutos da desinfecção. }\end{array}$ \\
\hline
\end{tabular}

Na Figura 3.6 esboça-se a finalidade da separação, demonstrando o tipo de material ou substância rejeitada e sua massa molecular aproximada em função do tipo de processo utilizado no tratamento, seja de água ou de água residuária.

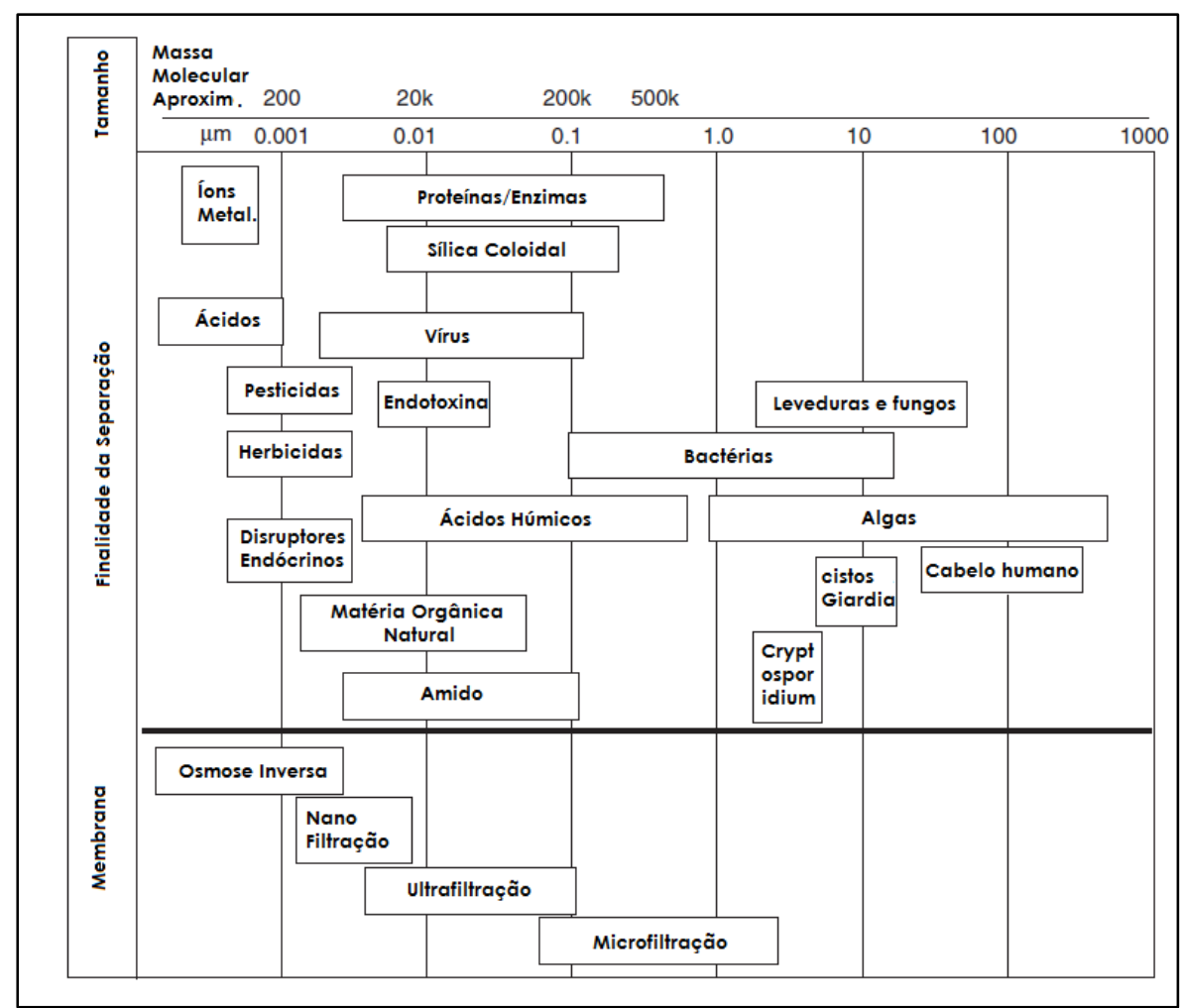

Figura 3.6 - Espectro dos tipos de processos de separação com membranas, finalidade da separação, possíveis massa molecular do concentrado ou rejeitado no tratamento de água e águas residuárias (adaptado de: Hai e Yamamoto, 2011).

\section{- Geometria}

A configuração geométrica das membranas pode ser plana ou cilíndrica, sendo que a cilíndrica pode ser tubular ou fibra oca. A diferença entre a tubular e a fibra oca se 
manifesta pelo diâmetro interno da membrana, a tubular com diâmetro interno maior que 3 $\mathrm{mm}$, enquanto as fibras ocas, mais finas, com valores menores que $3 \mathrm{~mm}$.

Uma das grandes prerrogativas dos BRMs é de serem modulares, sendo que o módulo é a menor unidade que contém as membranas, as estruturas de suporte, os canais de alimentação e permeado (Mohanty e Purkait, 2012).

Segundo Amaral (2008) e Constanzi (2007), os módulos são idealizados com os seguintes propósitos:

1. Produzir uma unidade compacta, de forma que maximize a área superficial pelo volume ocupado pelo módulo, ou seja, maior densidade de empacotamento;

2. Criar canais independentes, do concentrado e do permeado, de modo que se evite a mistura ou contaminação;

3. Minimizar o requisito energético por volume de permeado;

4. Circular o líquido internamente com elevado grau de turbulência, de modo a promover a maior transferência de massa no lado da alimentação;

5. Produzir unidade que facilite a modularização e

6. Produzir unidade que facilite a limpeza.

As membranas são apresentadas em módulos, sendo a geometria dos módulos comerciais mais usuais: (i) tubular, (ii) fibra oca, (iii) espiral e (iv) placa plana.

\section{a. Módulo Tubular}

Na configuração tubular, a membrana tubular é moldada no interior de um tubo de suporte. Os tubos, individualmente ou em feixes, são colocados num vaso de pressão. A alimentação é bombeada através do tubo e o produto é recolhido no exterior dos tubos. $\mathrm{O}$ retido continua a fluir através do tubo de alimentação. Essas unidades são usadas geralmente para tratamento de água com alto teor em sólidos em suspensão ou potencial de incrustação. Unidades tubulares são os mais fáceis de limpar, procedimento realizado através da circulação de produtos químicos e de bombeamento de água limpa.

Na Figura 3.7 ilustra-se o esquema de um módulo de membrana tubular, mostrando que as membranas estão localizadas dentro de um tubo, uma vez que não são auto suportadas. $\mathrm{O}$ 
tubo é constituído por um tipo especial de material, tal como cerâmica para suportar a membrana. A alimentação neste tipo de módulo ocorre habitualmente no interior dos tubos, uma vez que as membranas envolvem a circunferência do interior do tubo. As membranas tubulares têm diâmetros de 5 a $15 \mathrm{~mm}$. Esse tipo tem o inconveniente de baixa densidade de empacotamento, 20 a $30 \mathrm{~m}^{2} / \mathrm{m}^{3}$, o que resulta em alto custo de capital (Mohanty e Purkait, 2012).

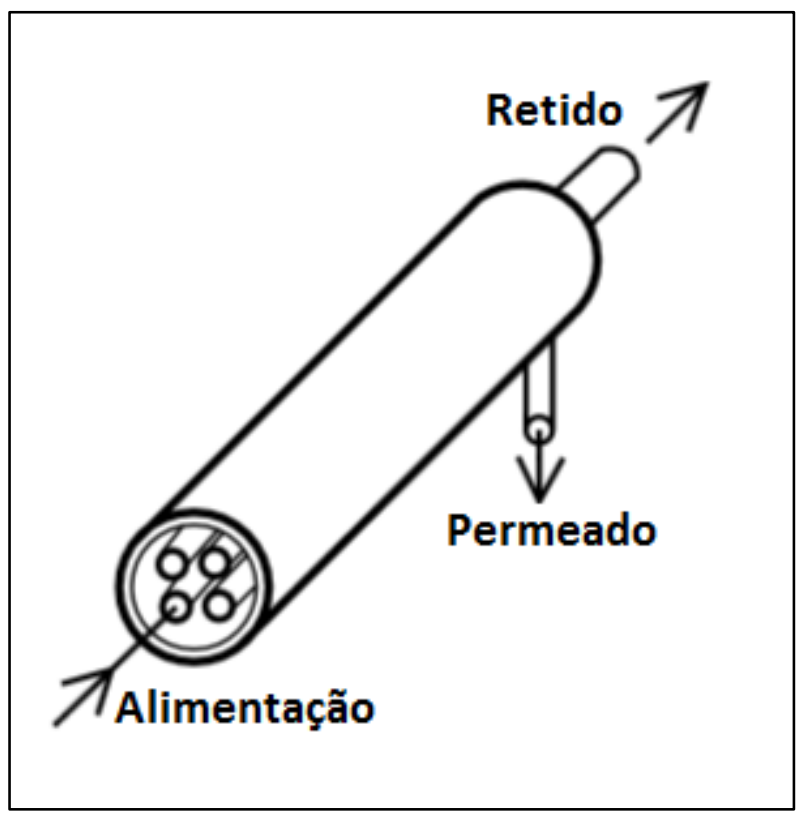

Figura 3.7 - Esquema do módulo de membrana tubular (adaptado de: Mohanty e Purkait, 2012).

b. Módulo de Fibra Oca

O módulo de membrana de fibra oca é constituído por um feixe de centenas a milhares de fibras ocas. Todo o conjunto é inserido dentro de um vaso de pressão. A alimentação pode ser aplicada no interior (fluxo dentro para fora) da fibra ou do lado de fora (fluxo de fora para dentro). Módulos de membranas de fibras ocas são os mais comumente utilizados em biorreatores de membrana tratando águas residuárias (Mohanty e Purkait, 2012).

Esse tipo de módulo, ilustrado na Figura 3.8, contém milhares de fibras ocas num volume compactado e seladas na extremidade e alojadas dentro de um invólucro. A solução de alimentação flui tanto no modo paralelo ou radial com respeito às fibras, dependendo da direção do permeado. Assim, a configuração em membranas de fibras ocas permite o acondicionamento de grandes áreas de membrana em volumes muito compactos, ou seja, é 
a geometria modular que apresenta maior densidade de empacotamento de membrana dentre todos os módulos, com valores de 5.000 a $40.000 \mathrm{~m}^{2} / \mathrm{m}^{3}$, o que leva a diminuir os custos de produção das membranas (Mohanty e Purkait, 2012).

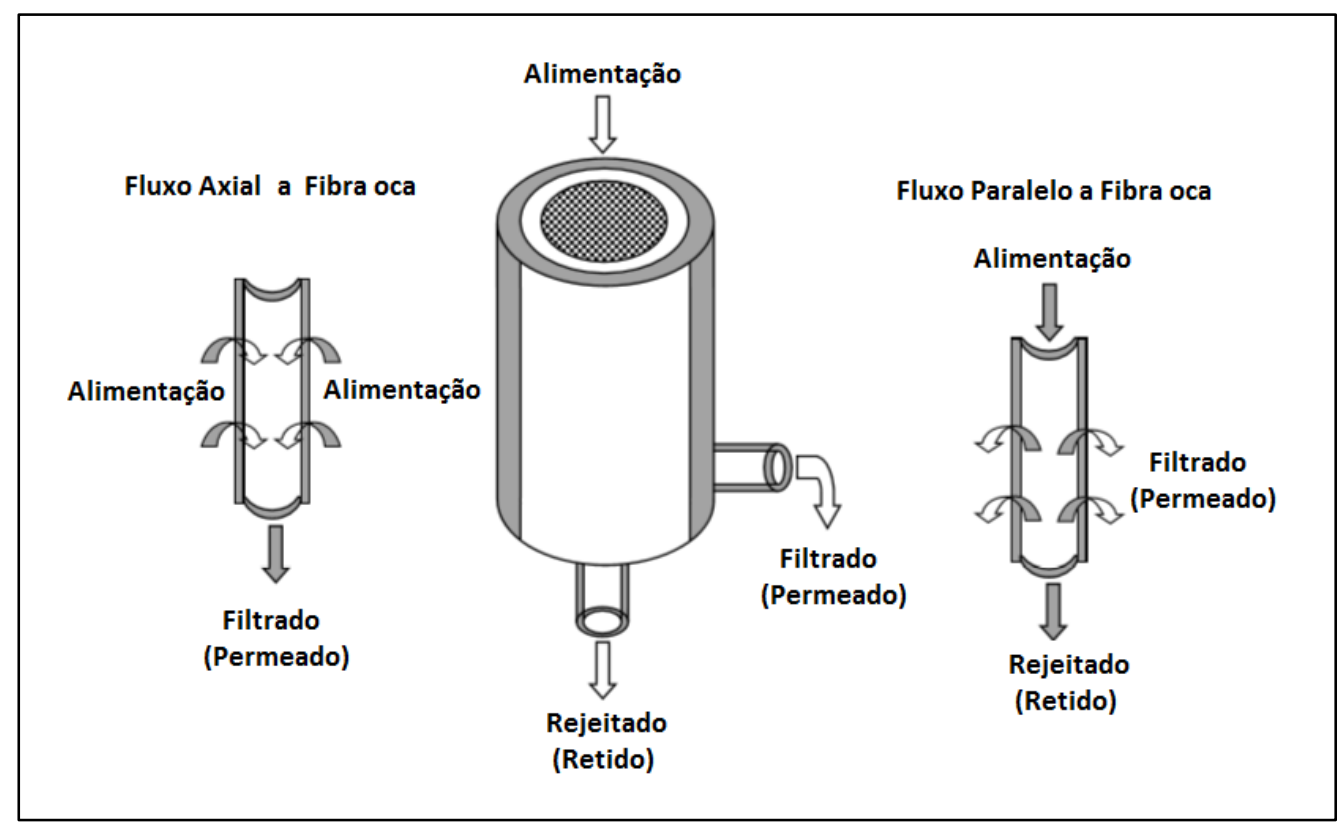

Figura 3.8 - Esquema do módulo de membrana de fibra oca (adaptado de: Mohanty e Purkait, 2012).

\section{c. Módulo Espiral}

No módulo de membrana em espiral, como se pode observar na Figura 3.9, espaçadores flexíveis são colocados entre os planos das membranas e do permeado. As membranas são seladas em três lados. O lado aberto está ligado a um tubo perfurado. Um espaçador da alimentação flexível é adicionado e as placas planas são laminadas para uma configuração circular apertada. Compostos de película fina são usados mais comumente em módulos de membranas em espiral. O termo espiral deriva do fato de que o fluxo na disposição enrolada das membranas e das folhas de suporte segue um padrão de fluxo em espiral (Mohanty e Purkait, 2012).

O módulo em espiral é constituído por membranas de folhas planas montadas em forma de camadas, todas são enroladas em torno de um tubo perfurado central que atua como o canal para o permeado, como pode ser observado na Figura 3.9. As membranas e os envelopes são fabricados com formas planas, incluindo os distribuidores da alimentação e do permeado como demonstrado na Figura 3.9. Todos são selados e enrolados em torno do 
tubo central para acondicionar grande área em pequeno volume. Módulos em espiral são mais compactos e mais baratos do que os módulos de placa, a substituição do módulo é fácil, e a modularidade permite o escalonamento apenas pela adição de mais unidades em paralelo. Eles possuem área superficial moderadamente elevada por unidade de volume (800 a $1.000 \mathrm{~m}^{2} / \mathrm{m}^{3}$ ). Os distribuidores entre camadas de membranas promovem fluxo turbulento para garantir baixa incrustação e vida mais longa (Mohanty e Purkait, 2012).

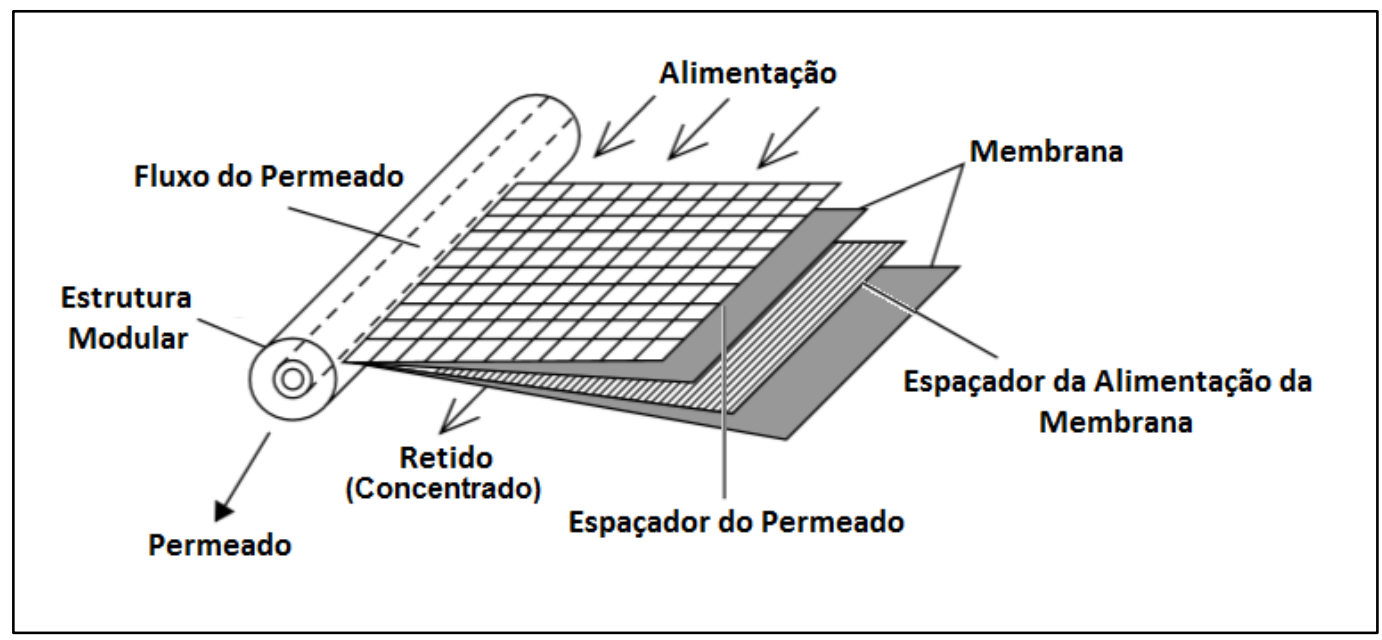

Figura 3.9 - Esquema do módulo de membrana em espiral (adaptado de: Mohanty e Purkait, 2012).

d. Módulo de Placa Plana

O módulo de placa plana é composto de uma série de membranas planas e placas de apoio. A água a ser tratada passa entre as membranas de dois conjuntos de membranas adjacentes. A placa suporta as membranas e proporciona um canal para que o permeado possa escoar para fora da unidade.

Um módulo de placa é semelhante à de um filtro prensa, como se pode observar na Figura 3.10. As membranas planas são colocadas de uma maneira tipo "sanduíche" com as suas faces voltadas uma para a outra para a alimentação. Um distribuidor específico é colocado entre cada alimentação e o canal do permeado. O número de conjuntos de membranas necessários para uma dada superfície, equipada com os distribuidores de alimentação, de câmara de vácuo, juntas de vedação e duas placas de extremidade, constituem um módulo de placa e armação, vários desses módulos podem ser dispostos em série ou paralelo. A principal vantagem deste módulo é a sua flexibilidade para diferentes tarefas de separação; 
por exemplo, os distribuidores de alimentação substituíveis para meios viscosos ou em caso em que é necessária alta turbulência. No entanto, estes módulos oferecem baixa área de superfície por unidade de volume, variando de 400 a $600 \mathrm{~m}^{2} / \mathrm{m}^{3}$ (Mohanty e Purkait, 2012).

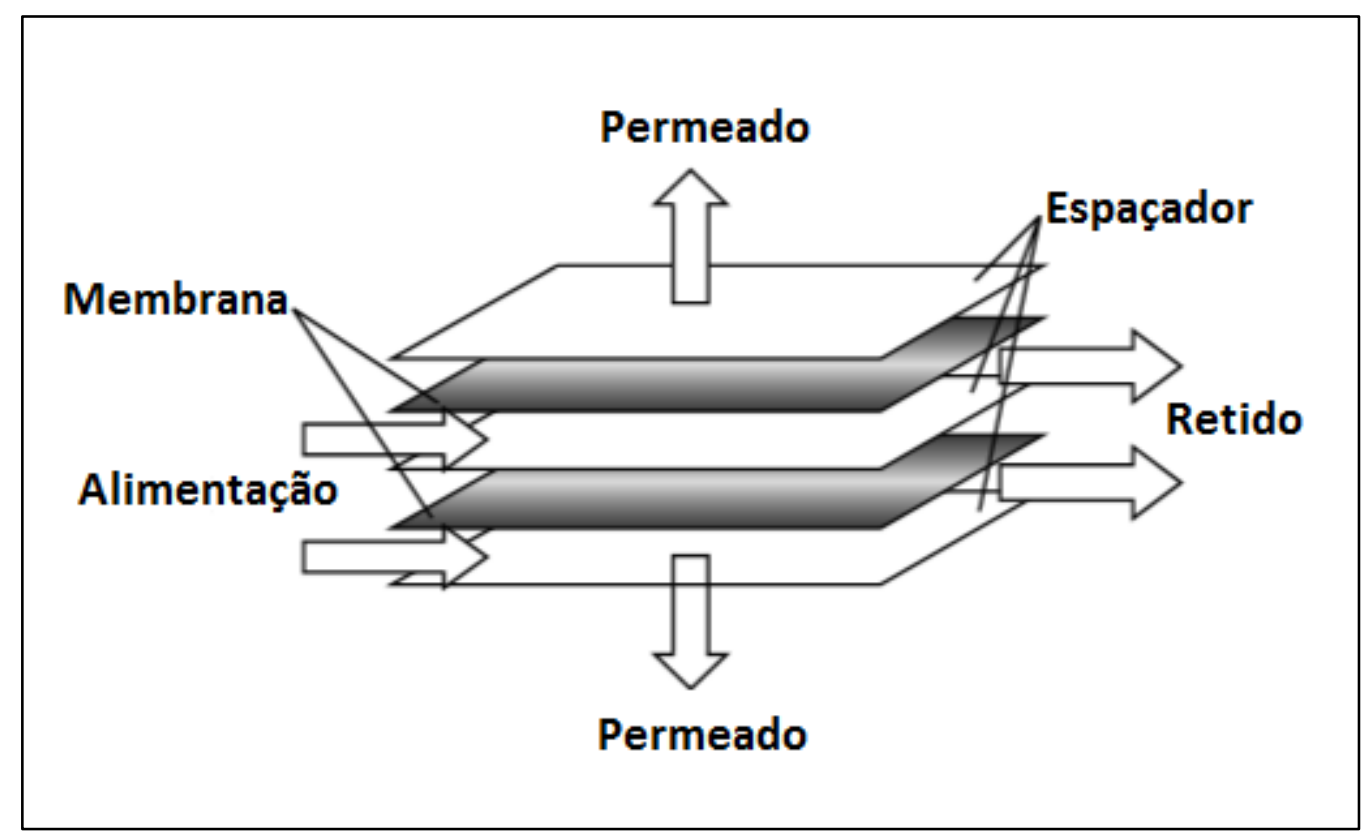

Figura 3.10 - Esquema do módulo de placas planas (adaptado de: Mohanty e Purkait, 2012).

\section{- Hidrofilicidade}

Em soluções aquosas alimentadas aos processos de separação com membranas, o ideal é que a membrana seja hidrofílica, ou seja, tenha atração pela água. Se o material da membrana for hidrofóbico, terá a capacidade de adsorver componentes que são hidrofóbicos ou anfotéricos, resultando em incrustação. Por exemplo, muitas proteínas têm regiões hidrofóbicas nas suas estruturas que podem interagir fortemente com materiais hidrofóbicos. Por infortúnio, muitas membranas poliméricas de grande robustez são relativamente hidrofóbicas, repelem a água, mas atraem as substâncias orgânicas e óleos (Cheryan, 1998).

Uma medida da hidrofilicidade relativa de uma membrana é por meio da observação do ângulo de contato com uma gota d'água. $\mathrm{O}$ instrumento que tem a finalidade de medir a capacidade de umedecimento de uma superfície é chamado de Goniômetro, e na Figura 3.11 ilustra-se essa medição. 
Observa-se na Figura 3.11 que a gota de água colocada sobre um material completamente hidrófilo se espalha sobre a superfície, o que resulta em um ângulo (ө) de contato baixo ou praticamente nulo. Um material hidrofóbico, por outro lado, faz com que a gota d'água tenha o mínimo de contato com a superfície possível, resultando num elevado ângulo (ө).

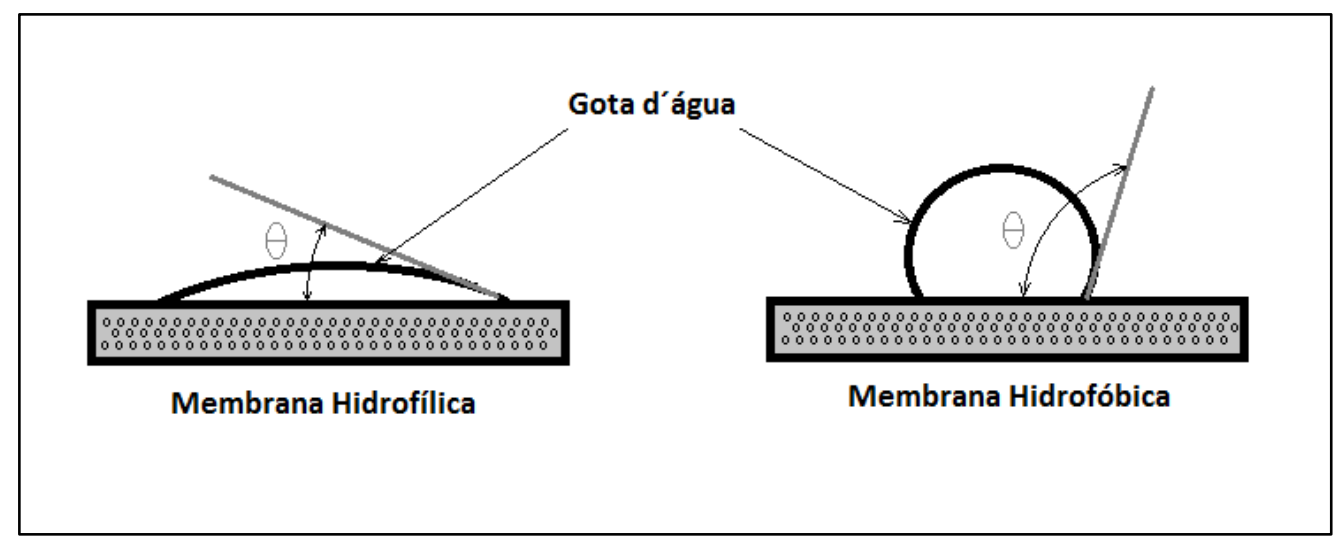

Figura 3.11 - Representação do ângulo de contato para membranas com material da superfície hidrofílica e hidrofóbica (adaptado de: Cheryan, 1998).

O tratamento para a modificação da superfície das membranas, modificando a sua característica para mais hidrofílicas, tem demostrado frequentemente apenas um modesto aumento no fluxo, em torno de $10 \%$, isto se deve provavelmente ao fato de que as substâncias excretadas (soluble microbial products - SMP) pelos microrganismos quimicamente "enxergam" diretamente a camada gel, que, uma vez rapidamente formada, reveste o material da membrana, que fica por baixo. Portanto a garantia do fluxo passa pelas limpezas eficazes e menos custosas e pelas práticas operacionais, e não pela hidrofilicidade do material das membranas (Stuckey, 2012).

\section{- Integridade}

A Integridade da membrana diz respeito à qualidade na confecção da membrana e na montagem desta no módulo, inicialmente, e mais ao desgaste ao longo do tempo de operação. A perda da integridade se deve aos defeitos iniciais ou os que ocorrem com o uso do módulo de membrana, dos tipos: furos, quebras, vedações inadequadas ou poros de grandes dimensões (fora da curva de distribuição dos diâmetros dos poros da membrana). A Integridade (ou o seu monitoramento) tem sido considerada um ponto crítico no uso da filtração por membranas, principalmente, quando os objetivos são a remoção de patógenos 
como protozoários parasitas, como por exemplo Giardia (6 a $18 \mu \mathrm{m})$ ou Cryptosporidium (3 a $7 \mu \mathrm{m}$ ), que são resistentes à desinfecção por cloro no tratamento de água. No tratamento e reúso de água, o rigor em relação à Integridade não é uma prioridade, tanto nos BRMs ou nos pós-tratamentos, por que o efluente final quase sempre não é para uso de contato primário ou mesmo para o consumo humano e também por que o permeado pode ser facilmente desinfetado por Ultravioleta e Cloração e com isto atingir as metas das diretrizes de qualidade para o reúso em questão (Yoon, 2016).

Yoon (2016) relata que os métodos para medição da integridade podem ser divididos em diretos e indiretos. Os diretos são testes executados na membrana, enquanto os indiretos utilizam de outras substâncias para a verificação da integridade da membrana. Os diretos são: decaimento da pressão, fluxo de ar difuso, sônico e ponto de bolha. O método mais utilizado é o ponto de bolha, que, como o sônico, detecta vazamentos, não sendo possível a detecção de vazamentos com o método do decaimento da pressão. A medição da integridade da membrana, de forma indireta, pode ser monitorada pela turbidez, contagem de partículas e contagem microbiana.

O espectro de detecção dos métodos de determinação e monitoramento da Integridade de membranas para filtração no tratamento de água potável está ilustrado na Figura 3.12, onde se lê no eixo das abcissas os valores de rejeição de protozoários, tais como Giardia e Cryptosporidium, em unidades logarítmicas. Por exemplo, se um método pode detectar a violação da integridade quando a remoção do Cryptosporidium foi $99 \%$ ou menos, a sensibilidade do método é 2 unidades $\operatorname{logs}$ para o Cryptosporidium, pois $2=-\log (1-$ 0,99). Observa-se ainda na Figura 3.12 que os métodos diretos (Decaimento da Pressão e Fluxo de Ar Difusivo) são mais sensíveis do que os indiretos (Turbidez e Contagem de Partículas).

A extensão dos vazamentos (fugas) não é só afetada pelo número de fibras comprometidas, em membrana de fibra oca como exemplo, mas também pela localização dos furos e danos. Se ocorrer longe da saída do permeado menos fluxo inadequado ocorre devido à perda de pressão interna na fibra em comparação com o caso do dano ser próximo a saída do permeado (Yoon, 2016). 


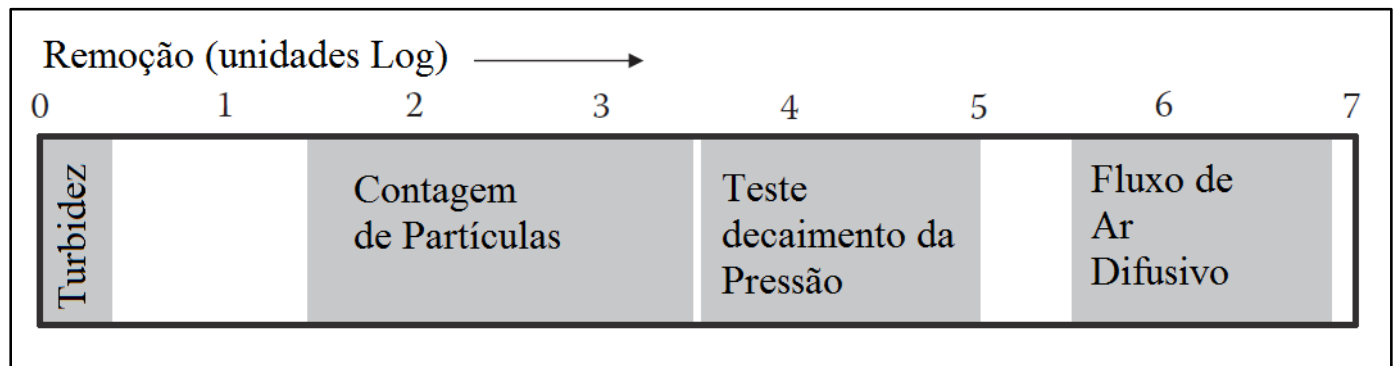

Figura 3.12 - Ilustração da sensibilidade dos métodos usados para monitoramento da Integridade de membranas através de testes em tratamento de água com vista a rejeitar protozoários parasitas (adaptado de: Yoon, 2016).

Metcalf e Eddy (2007) exemplificaram e compararam a Integridade inicial de membranas de fibra oca utilizadas para tratar efluente secundário num projeto de reúso de água, e após o impacto da quebra de 6 fibras num total de $6000(0,10 \%)$. O impacto promove uma redução na rejeição de 2 unidades logs, com a concentração organismos heterotróficos no permeado aumentando de 10 para 1010 organismos/ $\ell$ após a quebra, partindo da concentração de alimentação de um afluente de $10^{6}$ organismos/ $\ell$.

Como uma informação relevante e adicional, Baker (2004) reporta que em tratamento de água para consumo humano o objetivo da medição da integridade de membranas é de 4 e pode ser até 5 unidades logs.

\subsection{2 - Membranas de Microfiltração}

A microfiltração por membranas é o processo que mais se assemelha à filtração convencional de partículas, sendo intermediária entre esta e a ultrafiltração.

Os tamanhos dos poros das membranas da microfiltração variam de 0,1 a $1 \mu \mathrm{m}$, tornando o processo adequado e já há algum tempo consolidado para produzir concentrados em sólidos em suspensão, bactérias e moléculas com massas molares médias de 200.000 a 500.000 Da, o mecanismo de transferência é efetuado pela pressão aplicada, quase sempre menor do que 2,0 bar (Baker, 2004 e Mulder, 1992).

As membranas de microfiltração podem ser preparadas a partir de materiais de diversas composições química, tanto orgânicos (polímeros) quanto inorgânicos (cerâmica, metais, vidros). 
Várias técnicas podem ser utilizadas para a preparação das membranas poliméricas isotrópicas: (i) sinterização, (ii) estiramento, (iii) gravação (track-etching) e (iv) inversão de fases. Para a produção das membranas de microfiltração anisotrópicas as técnicas usadas são: (i) precipitação térmica, (ii) precipatação por evaporação de solvente, (iii) precipitação por presença de não solvente e (iv) precipitação por imersão (Mulder, 1992).

Para a caracterização dos diâmetros dos poros, da distribuição desses tamanhos e resistência ao transporte, são utilizadas as técnicas de microscopia eletrônica de varredura (MEV), medições de ponto de bolha, porosimetria pelo método de intrusão de mércurio e medições de permeação de gás-líquido (Mulder, 1992; Cheryan, 1998).

\subsubsection{1 - Aspectos Operacionais nos Sistemas de Separação por Membranas}

O fluxo do permeado através das membranas de microfiltração pode ser descrito pela Lei de Darcy, sendo este fluxo diretamente proporcional ao gradiente de presão aplicado, como demonstrado pela Equação 3.1 (Mulder, 1992).

$$
\mathrm{J}=\mathrm{K} \cdot \Delta \mathrm{P}
$$

Onde: J é o fluxo mássico ou volumétrico de permeado; K é a constante de permeabilidade ou permeabilidade hidráulica da membrana e o $\Delta \mathrm{P}$ pode receber três denominações: gradiente de pressão, pressão transmembrana (PTM) ou pressão aplicada.

A constante de permeabilidade ou permeabilidade, $\mathrm{K}$, depende de fatores estruturais da membrana, como porosidade, ângulo de contato e distribuição dos diâmetros dos poros, e das características reológicas do liquido que permeia a membrana, como a viscosidade (Mulder, 1992).

Duas formas distintas podem ser utilizadas na operação da microfiltração por membranas: (i) Filtração frontal (dead-end ou in-line) e (ii) Filtração tangencial (cross-flow). A Figura 3.13 apresenta os dois modos de operação. Na microfiltração frontal o sentido do fluxo de alimentação e permeado é o mesmo, nesta operação toda a alimentação é comprimida através da superfície da membrana, formando a torta e com isto aumentando a resistência 
$\left(\mathrm{R}_{\mathrm{T}}\right)$ ao longo do tempo, diminuindo o fluxo do permeado podendo cessar completamente, como pode se verificar no gráfico correspondente (a) a esse modo de operação na Figura 3.13 .

Na microfiltração tangencial a alimentação flui paralela à superfície da membrana de maneira a ser dividida em duas correntes, a do retido e a do permeado. Este tipo de operação reduz a formação contínua da torta, com tendência do fluxo e da resistência da torta a determinados valores, em função do tempo, como ilustrado pelo gráfico relativo (b) a esse tipo de operação na Figura 3.14.

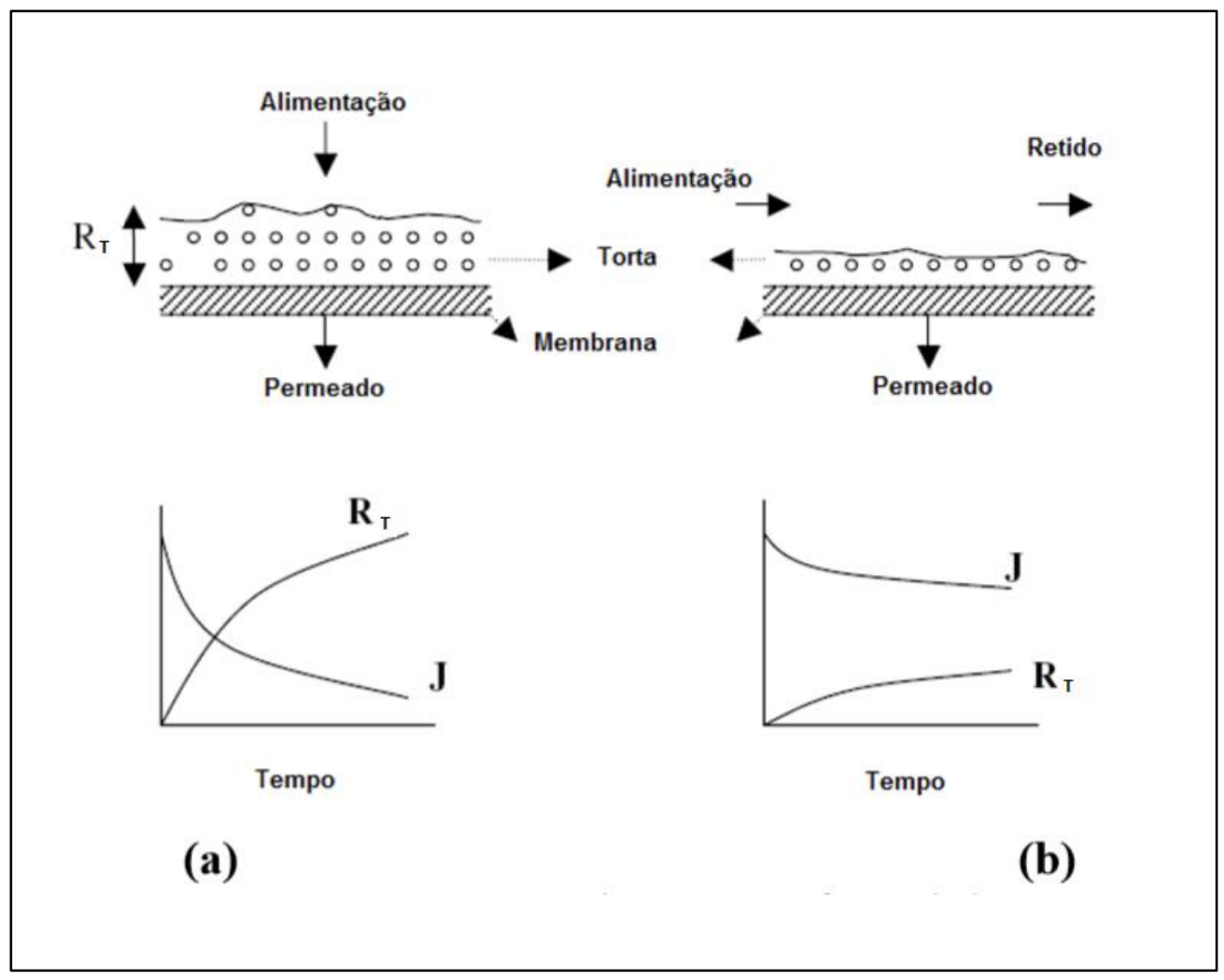

Figura 3.13 - Desenho esquemático dos dois modos básicos de operação em microfiltração: (a) Frontal e (b) Tangencial (adaptado de: Cheryan, 1998).

$\mathrm{Na}$ microfiltração tangencial existem distintas opções de operações cruzadas entre as correntes de alimentação e a do permeado, são elas: (i) Defasagem em $90^{\circ}$ ou Fluxo cruzado, (ii) Paralelas ou Co-corrente, (iii) Contrárias ou Contra-corrente e (iv) Mistura perfeita (Mulder, 1992). A Figura 3.14 apresenta esquematicamente estas diferentes alternativas. 
Metcalf e Eddy (2003) ressalta que a microfiltração por membranas de acordo com o fluxo de permeado e o gradiente de pressão ou pressão transmembrana aplicada pode ser operada de três maneiras distintas. A Figura 3.15 apresenta as duas variáveis como séries temporais, demonstrando essas três formas de operação.

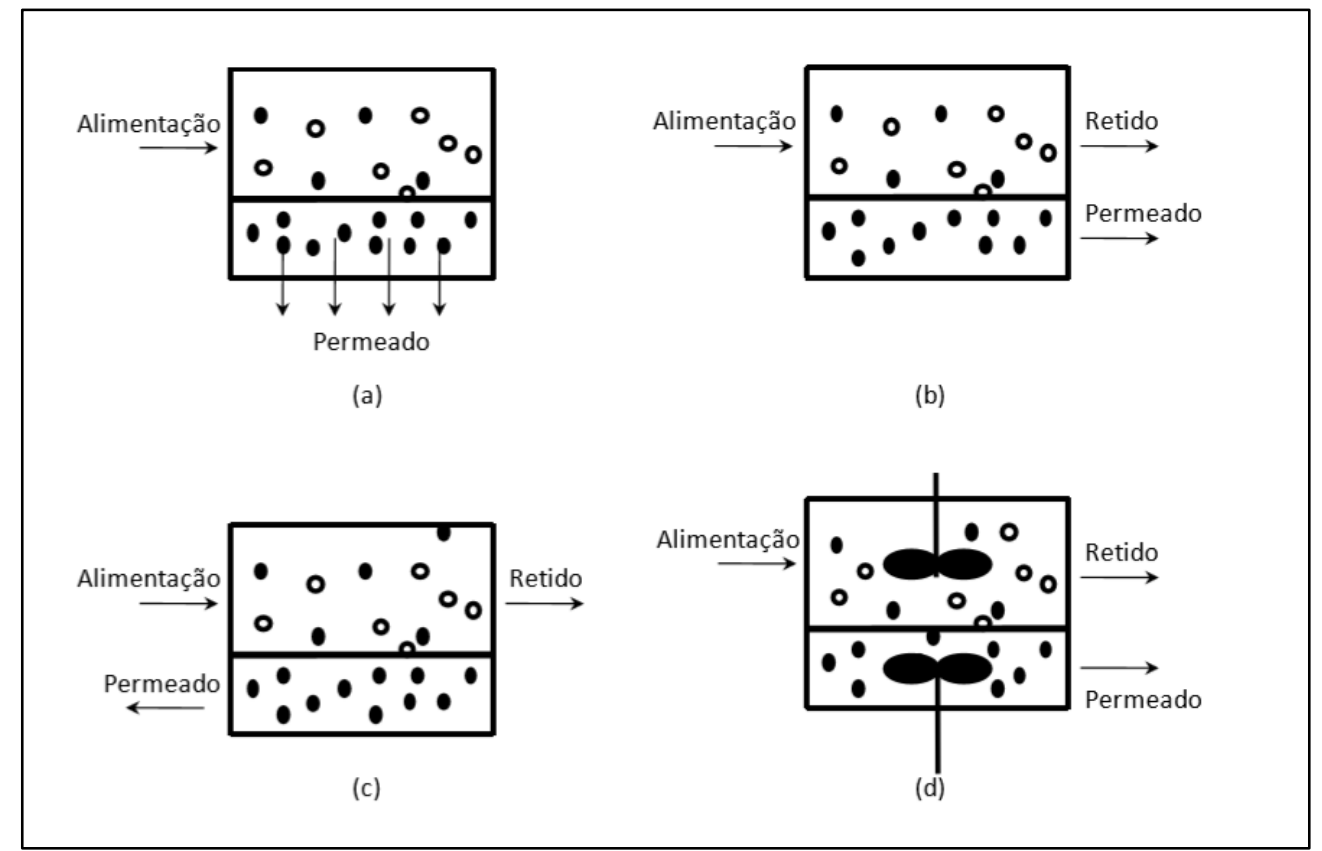

Figura 3.14 - Desenhos esquemáticos da representação da classificação da microfiltração tangencial em relação à alimentação e o permeado: (a) Defasagem em $90^{\circ}$ ou Fluxo cruzado, (b) Paralelas ou Co-corrente, (c) Contrárias ou Contra-corrente e (d) Mistura perfeita (adaptado de: Mulder, 1992)

Observa-se na Figura 3.15 que a operação (a) mantendo-se o fluxo constante, proporciona a variação da pressão transmembrana e aumentando-a em relação ao período de carreira.

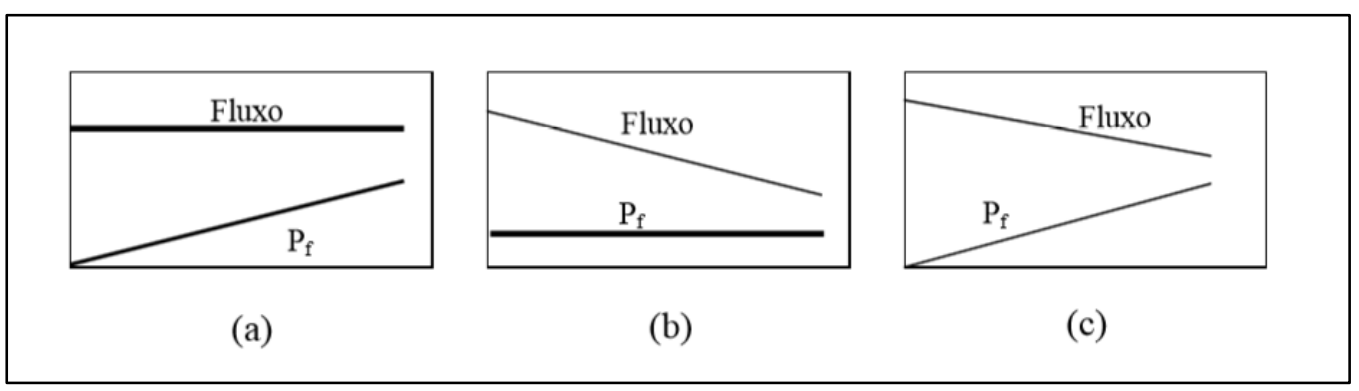

Figura 3.15 - Representação gráfica cronológica para três modos de operação: (a) Fluxo constante, (b) Pressão transmembrana constante e (c) Pressão transmembrana e fluxos variáveis (adaptado de: Metcalf e Eddy, 2007).

Na Figura 3.15 e no segundo modo (b), com a pressão mantida constante, o fluxo resultante varia de forma a diminuir com o tempo. A última opção (c) opera tanto com o 
fluxo como com a pressão transmembrana variáveis, sendo inversamente proporcionais, ou seja, com o tempo de operação, o aumento de pressão irá resultar numa diminuição do fluxo de permeado.

As condições de operação na microfiltração por membranas são importantes, tanto para minimização da formação da torta (incrustação), quanto pelo aspecto econômico, uma vez que o consumo de energia aumenta com o aumento de pressão, com a velocidade tangencial e a frequência de limpeza ou retrolavagem. Estas variáveis operacionais são consideradas as principais nos sistemas de separação por membranas de microfiltração (Schneider e Tsutiya, 2001).

Em uma operação característica de separação por microfiltração, a alimentação geralmente consiste de água como solvente e um ou mais solutos, o fluxo divide-se em duas correntes com diferentes concentrações - permeado (baixo teor de soluto) e concentrado (alto teor), como representado na Figura 3.16.

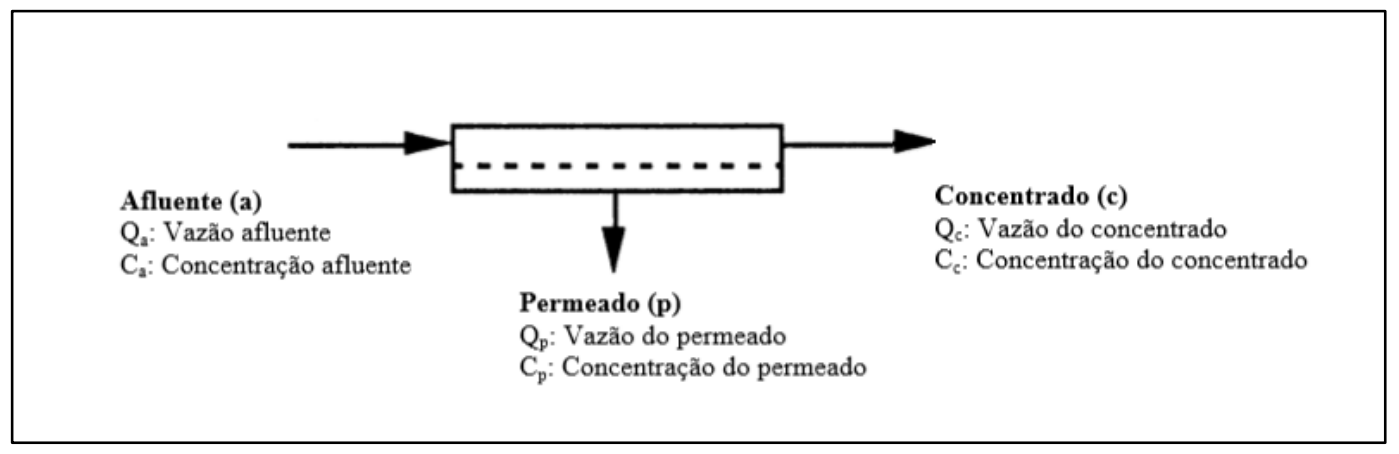

Figura 3.16 - Desenho esquemático de um sistema de microfiltração (adaptado de: Metcalf e Eddy, 2007).

O coeficiente de rendimento ou recuperação (S) é definido como a fração da alimentação que permeia a membrana, como representado pela Equação 3.2.

$$
\mathrm{S}=\frac{\mathrm{Q}_{\mathrm{p}}}{\mathrm{Q}_{\mathrm{a}}} \quad \text { ou } \quad \mathrm{S}=100 \cdot \frac{\mathrm{Q}_{\mathrm{p}}}{\mathrm{Q}_{\mathrm{a}}}(\%)
$$

Onde: $Q_{p}$ é a vazão do permeado e $Q_{a}$ é a vazão de alimentação.

O rendimento pode variar de 0 a 1 , ou de $0 \%$ a $100 \%$, e consiste num parâmetro importante do ponto de vista econômico e, de maneira geral, as membranas comerciais são projetadas 
com um rendimento tão alto quanto possível, ou seja, quanto mais próximo de $100 \%$, melhor (Mulder, 1992; Cheryan, 1998).

$\mathrm{O}$ rendimento típico em sistemas de membranas filtrantes utilizados em saneamento básico, segundo Schneider e Tsutiya (2001), é de 90 a 100\%, para membrana de microfiltração com poros de 0,1 a $0,2 \mu \mathrm{m}$.

Outro parâmetro importante na operação da microfiltração por membranas é o coeficiente de rejeição ou de retenção, ou simplesmente rejeição de um determinado soluto $(R)$, que corresponde à fração desse soluto retido na membrana, como representado pela Equação 3.3 .

$$
\mathrm{R}=\frac{\mathrm{c}_{\mathrm{a}}-\mathrm{c}_{\mathrm{p}}}{\mathrm{c}_{\mathrm{a}}}=1-\frac{\mathrm{c}_{\mathrm{p}}}{\mathrm{ca}} \text { ou } \mathrm{R}=\left(\frac{\mathrm{c}_{\mathrm{a}}-\mathrm{c}_{\mathrm{p}}}{\mathrm{c}_{\mathrm{a}}}\right) \cdot 100=\left(1-\frac{\mathrm{c}_{\mathrm{p}}}{\mathrm{c}_{\mathrm{a}}}\right) \cdot 100(\%)
$$

Onde: $c_{a}$ e $c_{p}$ são concentrações de um determinado soluto na alimentação e no permeado, respectivamente.

Schneider e Tsutiya (2001) relatam que a determinação exata deste parâmetro em sistemas de separação por membranas é praticamente impossível, pois seria necessário medir com precisão a concentração do soluto rejeitado na faixa da subcamada laminar em contato com a superfície da membrana.

\subsubsection{2 - Mecanismos de Rejeição de Solutos por Membranas}

Na prática, as características de rejeição de membrana indicada por fornecedores são feitas sempre com água limpa, sendo que a rejeição de solutos pela membrana é influenciada por fatores como: (i) massa e estrutura molecular dos solutos, (ii) distribuição dos tamanhos dos poros da membrana, (iii) carga elétrica da membrana e dos solutos, (iv) rugosidade e propriedades químicas da superfície da membrana, (v) propriedades químicas da corrente alimentada, (vi) condições hidráulicas na superfície da membrana (tensão de arraste e forças de cisalhamento) e (vii) grau de compactação da torta na superfície da membrana (Schneider e Tsutiya, 2001). 
Baker (2004) relata que as membranas de microfiltração filtram partículas a partir de líquidos e são categorizadas de duas maneiras: (i) filtração de superfície ou por peneiramento e (ii) filtração em profundidade. Na Figura 3.18 demonstram-se essas duas categorias, ilustrando a estrutura específica da superfície da membrana.

A filtração de superfície (a) da Figura 3.17 ocorre em membrana com superfície de poros bem menores do que os diâmetros das partículas a serem removidas, sendo que a fração retida fica acumulada na estrutura rígida da superfície da membrana.

A filtração de profundidade, (b) da Figura 3.17, acontece no interior dos poros da membrana por meio de fenômenos, como: adsorção eletrostática, captura inercial, difusão Browniana ou exclusão de tamanhos (Baker, 2004).

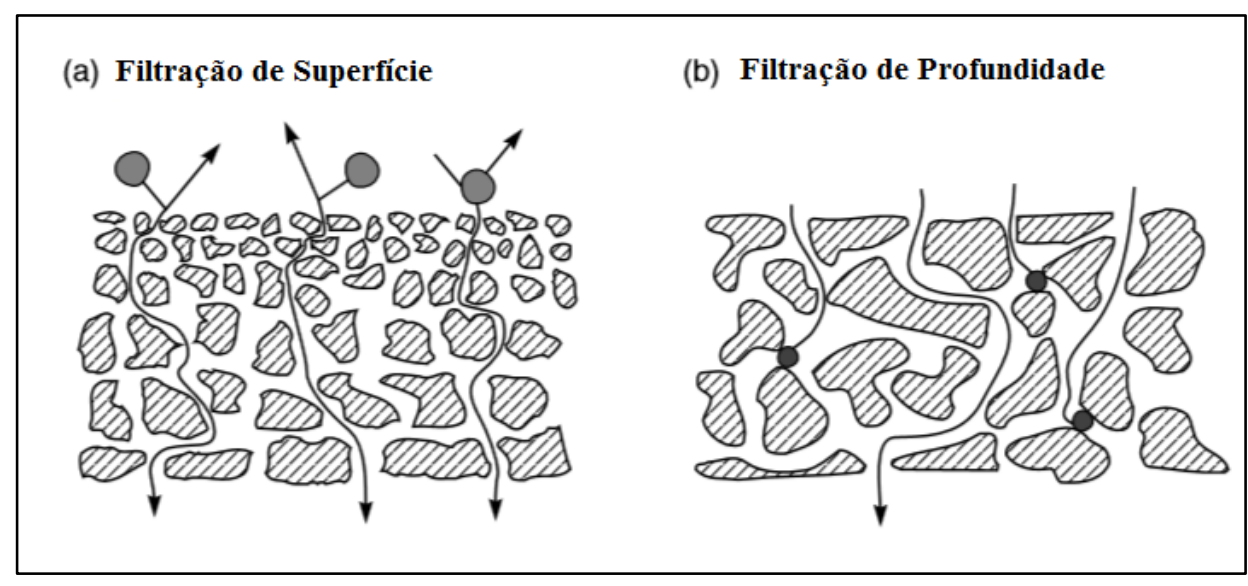

Figura 3.17 - Desenho esquemático das duas categorias de filtração: (a) filtração de superfície e (b) filtração de profundidade (adaptado de: Baker, 2004)

Na Figura 3.18 ilustram-se os mecanismos envolvidos na filtração de profundidade na microfiltração. Observa-se na Figura 3.18 que na trajetória do fluxo ocorrem os seguintes fenômenos para a retenção das partículas: adsorção eletrostática (potencial Zeta), captura inercial, difusão browniana e exclusão de tamanho. 


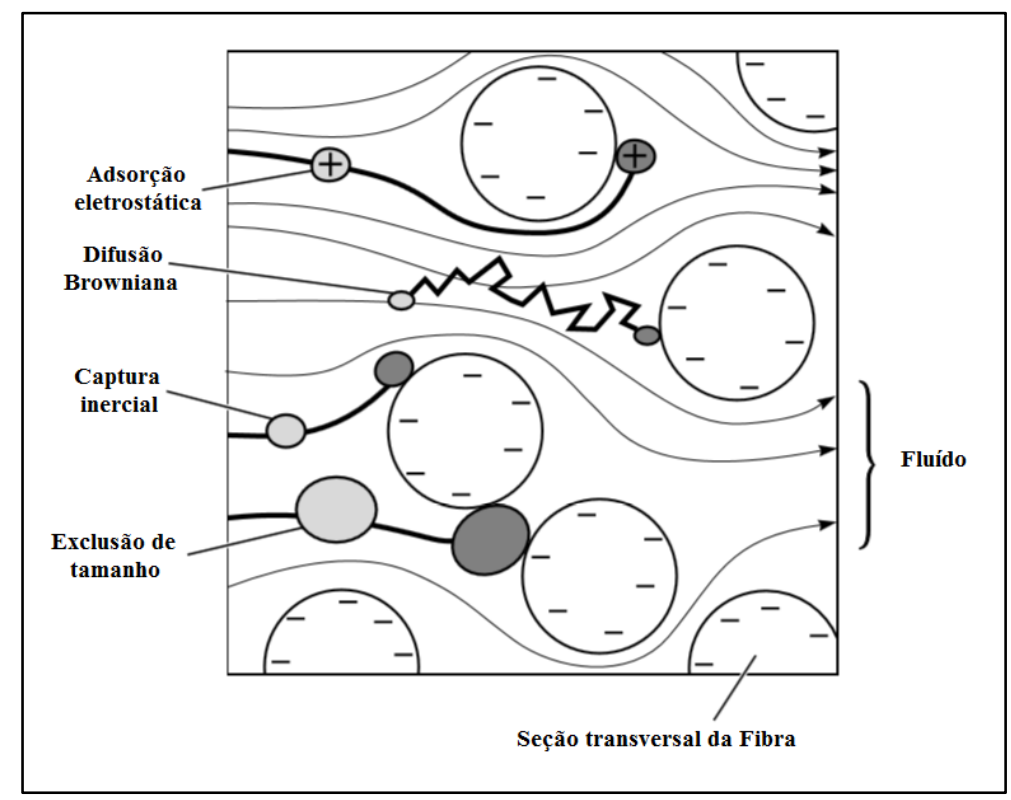

Figura 3.18 - Esquema dos mecanismos envolvidos na retenção de partículas em filtração de profundidade na microfiltração por membranas (adaptado de: Baker, 2004)

\subsubsection{3 - Modelos Matemáticos para Predizer o Fluxo em Microfiltração}

Existem diversos modelos para simular o fluxo como função das variáveis operacionais e das propriedades físicas envolvidas na microfiltração por membranas, mas nenhum deles é completamente satisfatório para descrever o fenômeno (Cheryan, 1998).

Cheryan (1998) relata que o maior problema aparece na imprecisão do entendimento do que ocorre perto da superfície da membrana e nas imperfeições dessa superfície.

Numa situação idealizada, em que exista a distribuição uniforme dos diâmetros dos poros e uniformidade nestes diâmetros na membrana, sem ocorrência de incrustação e desconsiderando a formação do perfil de concentração, acredita-se, geralmente, que a melhor descrição do fluxo através das membranas porosas é dada pela Lei de HagenPoiseuille (Cheryan, 1998).

A Lei de Hagen-Poiseuille, originalmente desenvolvida para descrever a relação da vazão e a queda de pressão, viscosidade, densidade e dimensão de um canal (por exemplo, diâmetro de um tubo), pode ser escrita e usada para explicar matematicamente a filtração em membranas de microfiltração, como é apresentado pela Equação 3.4. 


$$
\mathrm{J}=\frac{\varepsilon \cdot \mathrm{d}_{\mathrm{p}}^{2} \cdot \mathrm{P}_{\mathrm{TM}}}{32 \cdot \mu \cdot \Delta \mathrm{x}}
$$

Onde: J é o fluxo através da membrana, isto é, fluxo em unidades de volumes por área e por tempo; $\varepsilon$ é a porosidade da membrana; $d_{p}$ é o diâmetro médio dos poros da membrana, $\mu$ é a viscosidade dinâmica do líquido permeado; $\Delta x$ é a espessura da camada da pele filtrante da membrana e $\mathrm{P}_{\mathrm{TM}}$ é a pressão transmembrana.

Na Figura 3.19 ilustram-se as variáveis envolvidas na equação de Hagen-Poiseuille aplicada ao escoamento do permeado através da superfície da membrana de microfiltração. Reforça-se que a expressão matemática relaciona o fluxo diretamente proporcional à pressão transmembrana, como observado na Equação 3.4.

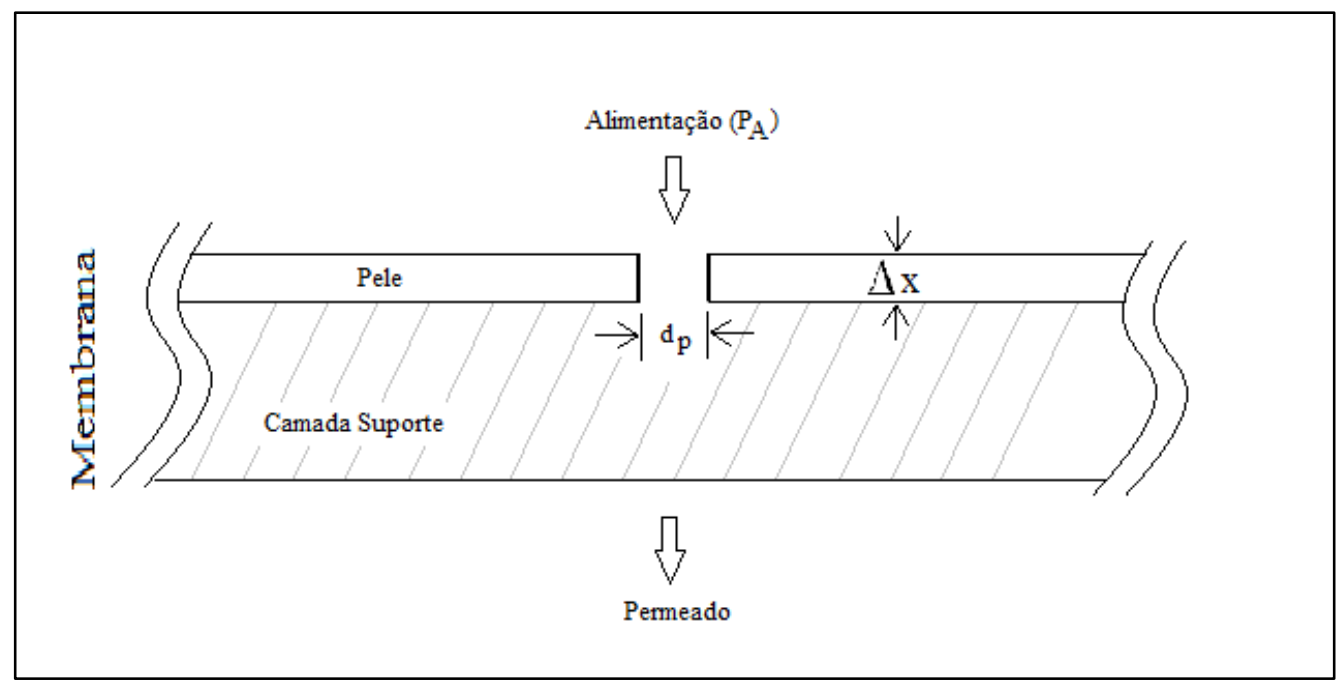

Figura 3.19 - Representação Esquemática de um corte na seção de uma membrana assimétrica de microfiltração e suas características morfológicas (adaptado de: Cheryan, 1998)

Porto (2006) conceitua que, pelo princípio da aderência, uma partícula do fluido em contato com a parede do tubo tem velocidade nula e existe uma camada delgada de fluido, adjacente à parede, na qual a flutuação de velocidade não atinge os mesmos valores que nas regiões distantes da parede. A região onde isto acontece é chamada de camada limite, especificamente subcamada limite laminar, e caracteriza-se por uma variação praticamente linear da velocidade na direção principal do escoamento. 
Assim como no escoamento através do conduto forçado, o fluxo do permeado através dos poros da membrana desenvolve uma camada limite, sendo uma camada limite de concentração. Este fenômeno de desenvolvimento desta camada limite é conhecido como polarização da concentração, no qual a atração das partículas de um determinado soluto pela superfície da membrana cria um perfil de concentração, sendo um valor superior próximo à superfície da membrana e diminuindo até atingir a concentração uniforme da alimentação no seio do líquido, como pode se observar na Figura 3.20.

A Polarização de Concentração é uma complicação adicional no processo de filtração por membrana e é potencializada principalmente quando a corrente de alimentação possui hidrocolóides, macromoléculas (como as proteínas), solutos de moléculas relativamente grandes ou partículas. Alguns solutos, ao serem retidos, tendem a formar uma camada sólida na superfície da membrana. Dependendo do tipo de sólidos aderidos nesta camada, essa região se caracterizará por apresentar uma razoável viscosidade e forma gelatinosa. Esta formação pode ser visualizada na Figura 3.21 e a esta camada denomina-se de camada gel, torta ou camada de polarização (Cheryan, 1998).

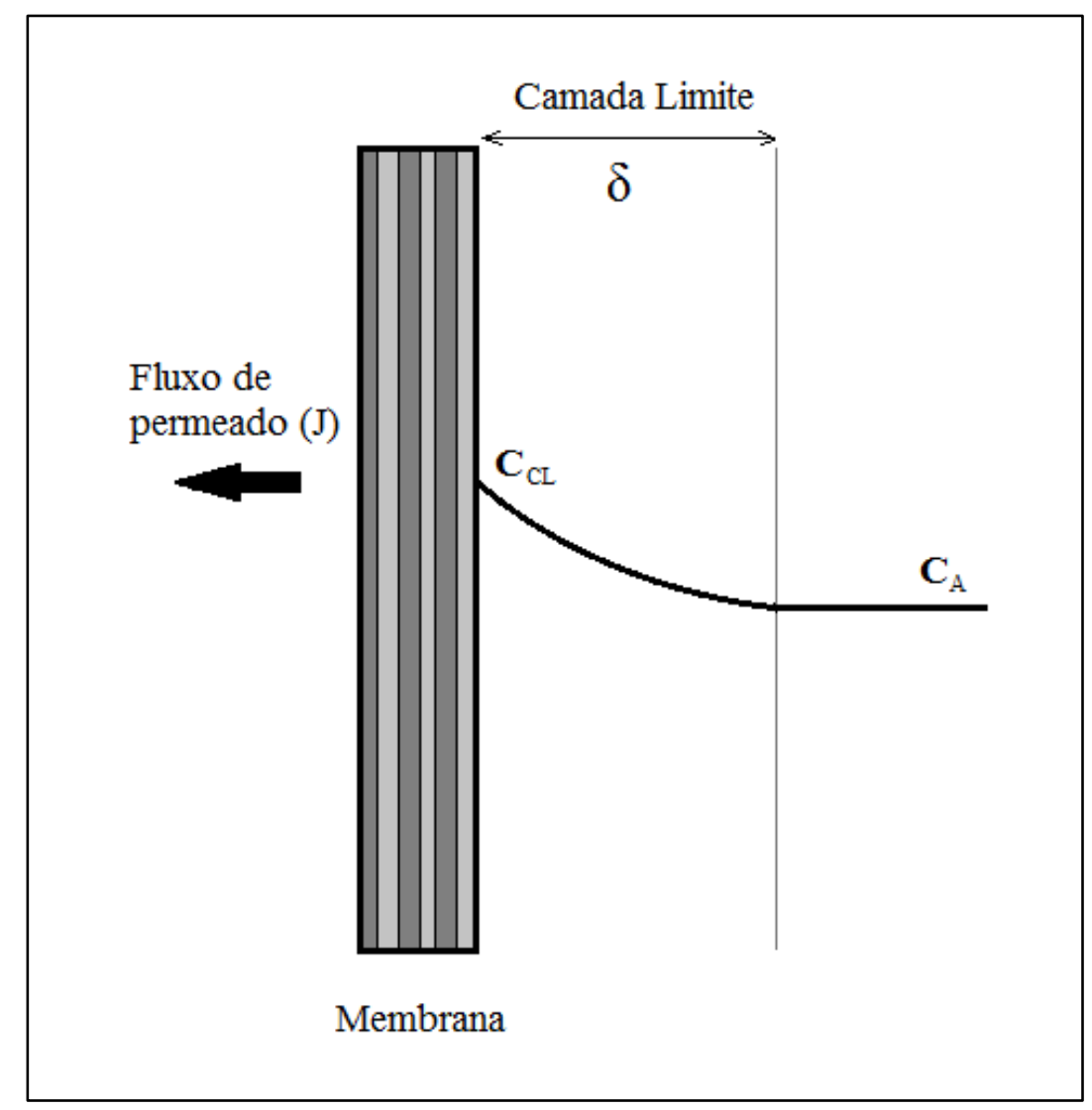

Figura 3.20 - Representação da polarização de concentração do soluto no processo de separação por microfiltração (adaptado de: Cheryan, 1998) 
Como observado na Figura 3.21, a consolidação da formação da torta cria um potencial para transferência de massa, fazendo com que o soluto retorne para o meio, pelo chamado fluxo difusivo de retorno.

Por outro lado, a formação e a presença de uma camada gel pode resultar em aumento na seletividade da membrana, uma vez que os géis são estruturas poliméricas entrelaçadas, o que auxilia na rejeição de solutos de tamanhos menores ou até mesmo de partículas com tamanhos aquém dos diâmetros originais da própria membrana (Silva, 2009).

O balanço de massa na Camada de Polarização pode ser representado matematicamente pela Equação 3.5 .

$$
\mathrm{J} \cdot \mathrm{c}_{\mathrm{sp}}=\mathrm{J} \cdot \mathrm{c}_{\mathrm{sa}}-\mathrm{D}_{\mathrm{i}} \cdot \frac{\mathrm{dc} \mathrm{c}_{\mathrm{s}}}{\mathrm{dx}}
$$

Onde: J é o fluxo volumétrico de alimentação por área da membrana, $\mathrm{c}_{\mathrm{sp}}$ é a concentração de um determinado soluto no permeado, $\mathrm{c}_{\mathrm{sa}}$ é a concentração do mesmo soluto na alimentação e $D_{i} \cdot \frac{d c_{s}}{d x}$ é fluxo difusivo do soluto expressado pela Lei de Fick.

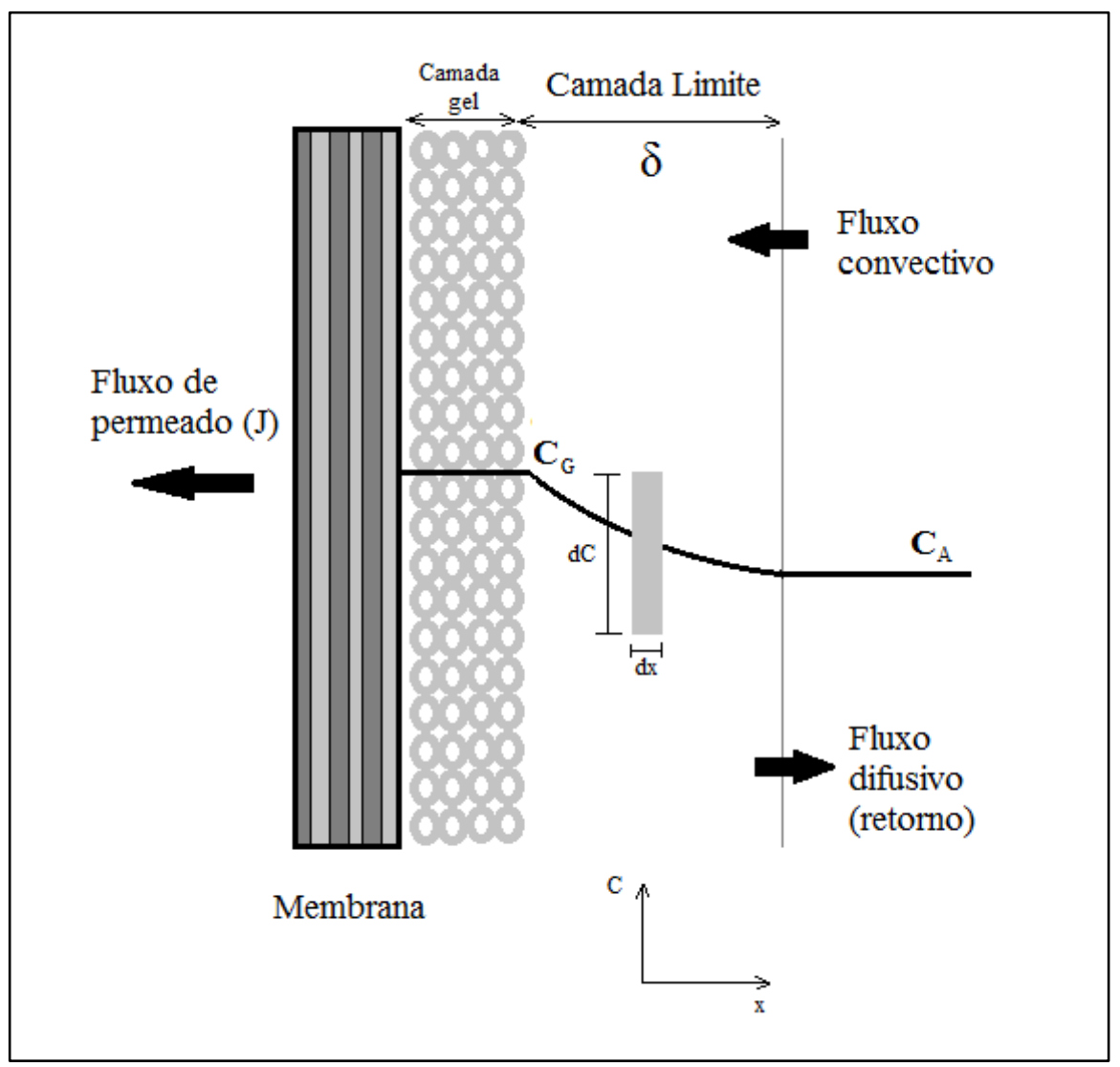

Figura 3.21 - Representação esquemática da polarização da concentração durante a filtração por membranas em microfiltração de solutos coloidais e macromoléculas, mostrando a formação da camada gel ou torta (adaptado de: Cheryan, 1998) 
Adotando-se a hipótese de que, no permeado, o soluto de interesse deve ser rejeitado completamente pela membrana, tem-se que $\mathrm{c}_{\mathrm{sp}}$ é nulo, e integrando a equação diferencial com as condições de contorno de variação de concentração entre $\mathrm{c}_{\mathrm{A}} \mathrm{e} \mathrm{c}_{\mathrm{G}}$, concentração do soluto na alimentação e na torta, respectivamente, tem-se a Equação 3.6.

$$
\mathrm{J}=\frac{\mathrm{D}_{\mathrm{i}}}{\delta} \cdot \ln \frac{\mathrm{c}_{\mathrm{G}}}{\mathrm{c}_{\mathrm{A}}}=\mathrm{k} \cdot \ln \frac{\mathrm{c}_{\mathrm{G}}}{\mathrm{c}_{\mathrm{A}}}
$$

Onde o k é o coeficiente de transferência de massa e $\delta$ é a espessura da camada limite.

A Equação 3.6 representa o modelo matemático da transferência de massa em filtração de membranas de microfiltração denominada de Modelo da Teoria do Filme, um dos mais simples e também mais utilizados para simular o sistema de transferência de massa. Nesse modelo, ressalta-se que o fluxo é uma função direta da relação das concentrações da camada gel e da alimentação e é independente da pressão aplicada (Cheryan, 1998).

\subsection{3 - Fluxo Crítico}

Compreende-se que o transporte de massa do material coloidal para a superfície da membrana é diretamente relacionado com o fluxo para qualquer sistema de separação por membrana. O fluxo no qual ocorre a deposição coloidal é referido com o Fluxo Crítico.

Abaixo deste valor crítico, o fluxo é diretamente proporcional à pressão transmembrana e a operação em estado estacionário é mantida. O Fluxo Crítico é uma função das condições hidráulicas, sendo que este fluxo tende a aumentar com o fluxo cruzado, e tem forte dependência com a natureza da membrana, das espécies envolvidas e das interações entre estas (Stephenson et al., 2000).

No gráfico representado na Figura 3.22, ilustra-se a relação do fluxo (J) versus a pressão transmembrana (PTM) para algumas variações crescentes de condições operacionais, tais como: (i) fluxo, (ii) temperatura e (iii) concentração.

Pode-se observar que a água pura se comporta conforme a Equação 3.4, do modelo de Hagen-Poiseuille, no qual o fluxo é diretamente proporcional à pressão aplicada (PTM). Já 
as outras três curvas, esboçadas na Figura 3.22, representam soluções alimentadas com coloides, e é notório que as curvas dos fluxos $(\mathrm{J})$ em determinado momento da pressão aplicada (PTM) atingem um platô para todas elas, onde os fluxos se tornam independentes da PTM. O gráfico caracteriza as duas regiões de interesse: (i) a controlada pela pressão, a primeira do lado direito da linha tracejada; e a (ii) controlada pela transferência de massa, a do lado esquerdo da mesma linha de referência (Singh, 2015).

Singh (2015) considera que o fluxo do regime permanente em que ocorre a independência da pressão aplicada, região controlada pela transferência de massa, é chamado de Fluxo Limitante ou Fluxo Limitado pela Camada Gel.

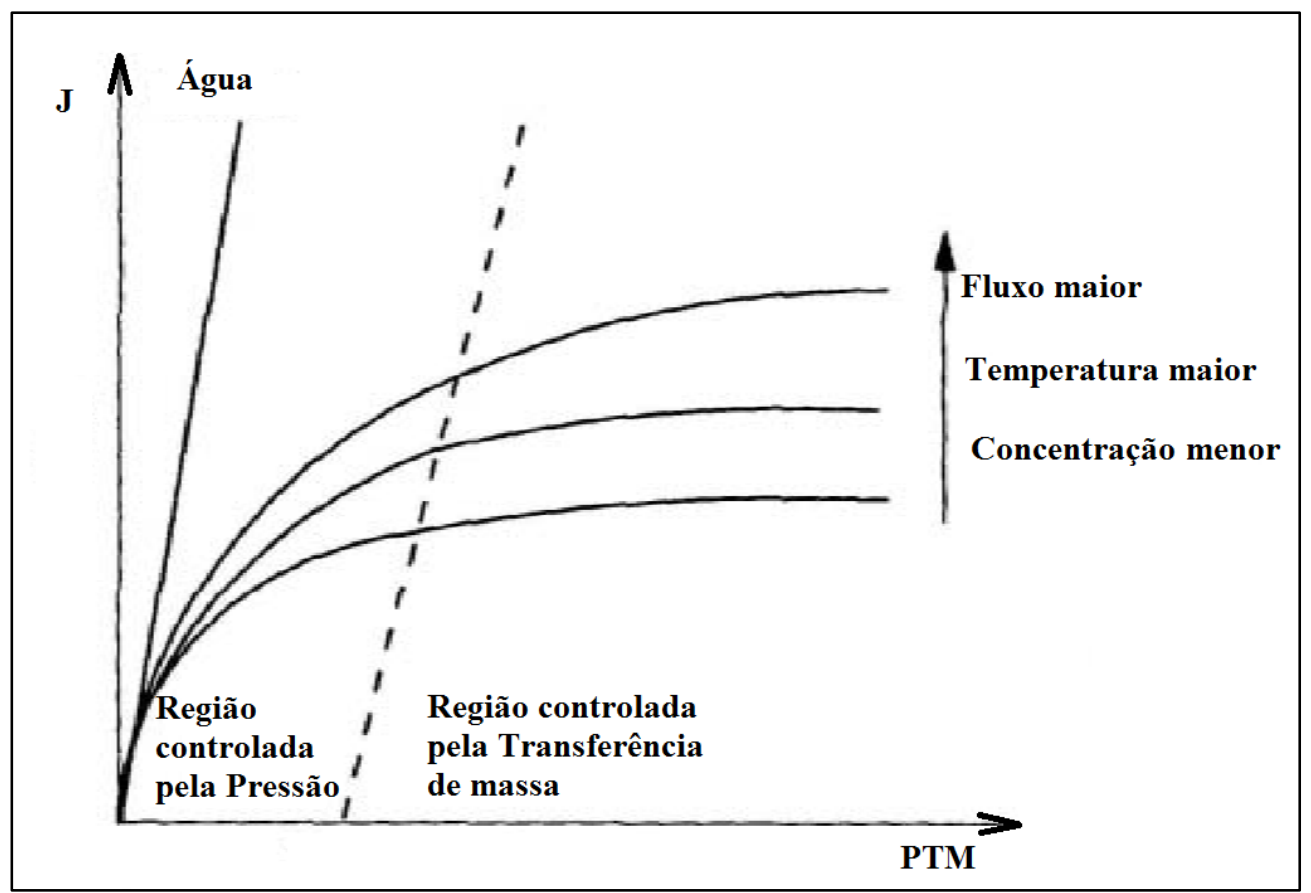

Figura 3.22 - Gráfico representativo da correlação generalizada entre parâmetros operacionais e o fluxo, indicando as áreas de controle da pressão transmembrana e de controle da transferência de massa (adaptado de: Cheryan, 1998)

Com o propósito de minimizar a formação da camada gel, os sistemas de membranas devem ser operados na chamada região abaixo do fluxo crítico, a região controlada pela pressão da Figura 3.22, que também pode ser denominada de subcrítica. Então, o fluxo crítico é definido como o limite abaixo do qual não ocorre o declínio do fluxo ao longo do tempo. Os fluxos críticos aumentam com a velocidade mais elevada de fluxo cruzado (número de Reynolds superior) e menor concentração de soluto na corrente de alimentação (Singh, 2015). 
Outra definição interessante, muito simples e microscopicamente precisa é a seguinte: o fluxo crítico equivale ao fluxo abaixo do qual não ocorre a deposição da matéria coloidal na superfície da membrana em processos de separação por membranas (Stephenson et al., 2000).

\subsection{4 - Incrustações em Membranas (Fouling)}

Segundo Hai e Yamamoto (2011), a incrustação, também denominada em inglês de fouling, é e continua sendo o "calcanhar de Aquiles" da tecnologia de membranas nos biorreatores com membranas, fator limitante na aplicação generalizada de BRMs, devido às consequências em termos de manutenção da planta e os custos operacionais derivados.

O fenômeno da incrustação é muito complexo e difícil de descrever teoricamente. Mesmo para uma determinada solução, a incrustação irá depender de parâmetros físicos e químicos, tais como concentração, temperatura, $\mathrm{pH}$, força iônica e interações específicas (por pontes de hidrogênio e por dipolo-dipolo). No entanto, o valor confiável do declínio do fluxo é essencial para a concepção de qualquer processo de separação por membranas de microfiltração, e por isso deve ser conhecido antecipadamente (Mulder, 1992).

Com o fenômeno da polarização da concentração, o fluxo em um tempo infinitesimal maior $(\mathrm{J} x \mathrm{t})$ é sempre menor do que o valor original, quando $\mathrm{t}=0$. Ao atingir o regime permanente, uma redução ainda maior no fluxo não será mais observada, isto é, o fluxo torna-se constante em função do tempo. O fenômeno da polarização da concentração é um processo reversível, mas, na prática, frequentemente pode ser observado um declínio contínuo no fluxo. Isto é mostrado esquematicamente na Figura 3.24. Tal declínio contínuo do fluxo é o resultado de entupimento da membrana, o que pode ser definido como uma deposição irreversível de partículas retidas, coloides, emulsões, suspensões, sais de macromoléculas sobre ou na membrana (Mulder, 1992).

Mulder (1992) cita que a incrustação ocorre principalmente em membranas porosas, usadas na microfiltração e na ultrafiltração, que são implicitamente suscetíveis à incrustação. Em geral, três tipos de incrustantes podem ser distinguidos: (i) precipitados orgânicos (macromoléculas, substâncias biológicas, etc.), (ii) precipitados inorgânicos (hidróxidos de metal, sais de cálcio, etc.) e (iii) partículas. 


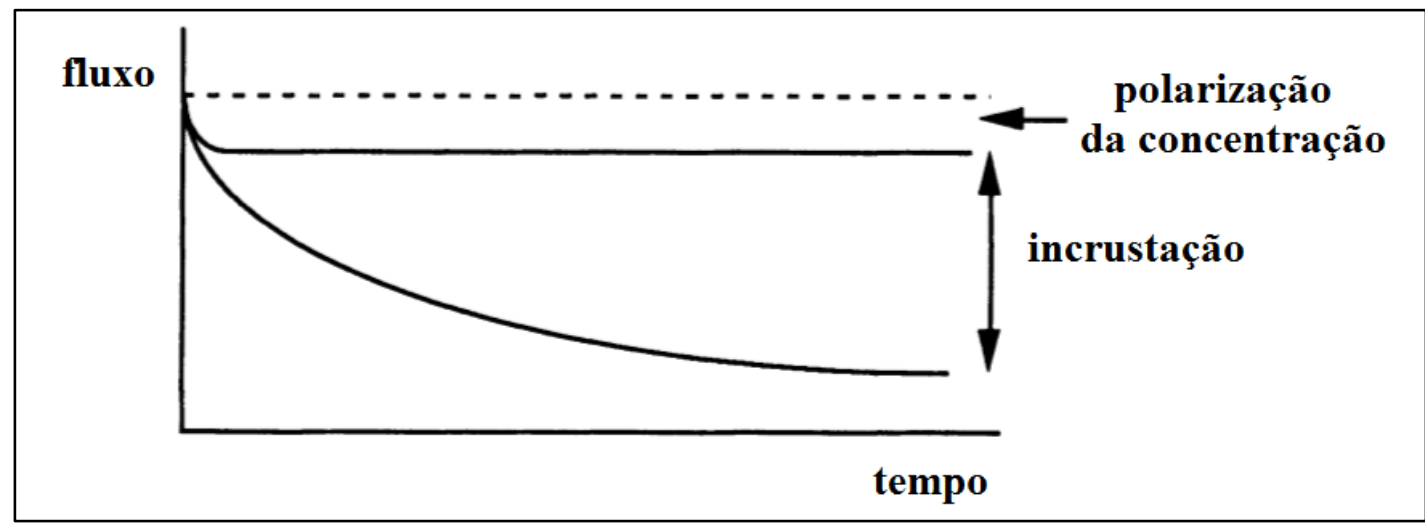

Figura 3.23 - Gráfico ilustrando o fluxo (J) em função do tempo (t), distinguindo a polarização da concentração da incrustação (adaptado de: Mulder, 1992)

Então, a incrustação da membrana pode ser definida como a deposição indesejável e acúmulo de microrganismos, coloides, solutos e os restos celulares dentro dos poros ou na superfície da membrana (Hai e Yamamoto, 2011).

Na Figura 3.24 ilustra-se a incrustação das membranas, de forma gradual, levando, na operação de fluxo constante, ao aumento da pressão transmembrana (Dezotti et al., 2011).

Segundo Amaral (2008) e Dezotti et al. (2011), e ainda como pode ser observado na Figura 3.24, pode-se dizer que a incrustação ocorre em três estágios, a saber: (i) obstrução de poros - condicionamento da membrana limpa juntamente com o aumento da PTM por um curto período de tempo, ilustrado na letra (a); (ii) obstrução dos poros - incrustação lenta durante o qual a PTM cresce linearmente ou apresenta fraco crescimento exponencial, esboçado na letra (b) e (iii) formação da torta - incrustação rápida com abrupto aumento da PTM, como desenhado na letra (c) dessa figura.

Diversos atores auxiliam para a ocorrência dos estágios visualizados na Figura 3.24. Os flocos da biomassa, as substâncias poliméricas extracelulares (EPS, sigla em inglês para Extracellular polymeric substances) e os produtos microbianos solúveis (SMP, sigla em inglês para Soluble microbial products) são atores essenciais para o acontecimento da incrustação, propriamente dita (Dezotti et al., 2011). 


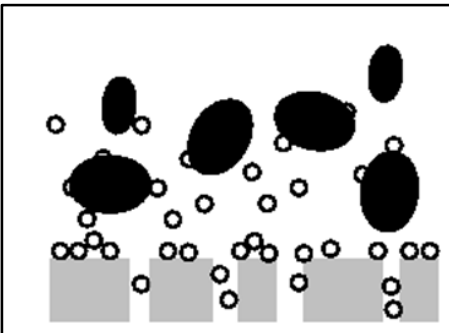

a)

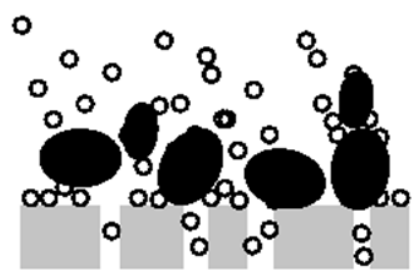

b)

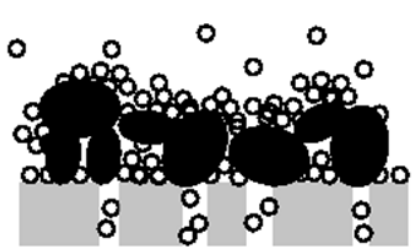

c)

Figura 3.24 - Ilustração do gradual bloqueio dos poros pela ação de macromoléculas (círculos vazados) e flocos microbianos (elipses escuras)

(fonte: Dezotti et al., 2011).

Segundo Dezotti et al. (2011), os eventos sequenciais, visualizados na Figura 3.24, podem ser descritos da seguinte forma:

a. As macromoléculas acondicionam-se na superfície da membrana, formando uma camada que atrai os microrganismos, principalmente os que não fazem parte dos flocos (células planctônicas). Os flocos podem também chegar à superfície e a ela aderir de forma reversível, deixando, ao sair, traços de material exopolimérico, que contribuem para o condicionamento da membrana. Neste momento, o bloqueio dos poros inicia;

b. Várias ocorrências acontecem, como: restrição e bloqueio de poros; depósitos de flocos em regiões onde há pouca tensão de cisalhamento; formação de biofilme fino e de torta em algumas regiões da membrana. A incrustação ocorre mesmo quando se opera na condição subcrítica e, nesse momento, a contribuição dos EPSs é significativa e

c. Neste momento a incrustação se torna autoacelerada. Poros são totalmente bloqueados e o fluxo em poros ainda abertos se torna muito elevado, além do fluxo crítico, o que leva ao bloqueio desses canais. A incrustação não é uniforme na superfície das membranas e pode haver crescimento mais acentuado de torta em alguns locais, com possibilidade de colapso da própria torta e dispersão de debris sobre a membrana. $\mathrm{O}$ resultado é o rápido e, praticamente, exponencial aumento da PTM, como ilustrado anteriormente na Figura 3.22.

Yoon (2016) afirma que, em se tratando de esgotos sanitários e em processos biológicos, o desempenho com relação às incrustações das membranas submersas não melhora muito diminuindo o valor do SST, o que é devido, em grande parte, a que os principais contaminantes na incrustação das membranas não são as maiores partículas, de tamanho na faixa de microns, que são a grande maioria dos SST dos sistemas biológicos, mas as partículas e macromoléculas finas de tamanho submicron chamadas de SMP (Soluble 
microbial products), que se originam a partir da lise de células de microrganismos e biopolímeros extracelulares. Além de que as concentrações de partículas finas não diminuem proporcionalmente ao SST, sendo que baixos valores de SST não garantem menor entupimento da membrana.

Além disso, o efeito da retrolavagem da membrana incrustada por flocos microbianos diminui com a diminuição do SST, devido à escassez de flocos grandes. Por exemplo, embora o efluente secundário tenha valores baixos de SST, menores do que $50 \mathrm{mg} / \ell$, a taxa de entupimento da membrana não é necessariamente baixa durante o processo de filtração (Yoon, 2016).

As partículas finas e macromoléculas contidas no líquido a ser permeado podem facilmente ser adsorvidas na superfície, sem ocorrer interrupção pela formação da camada gel pelos flocos maiores. A velocidade de transporte de volta das partículas finas e das macromoléculas não é afetada pela retrolavagem, tanto quanto no caso dos grandes flocos. No caso de efluentes secundários ou primários avançados, com valores baixos de SST, aproximadamente 10 a $50 \mathrm{mg} / \ell$, feixes de membrana de fibras ocas são tipicamente utilizados no modo de filtração de fora para dentro.

Stuckey (2012) esclarece, que intuitivamente, tamanhos menores de poros levam a fluxos e qualidade de permeado melhores, mas isto não se verifica na maioria das vezes, devido à formação da incrustação ("camada gel”) na superfície da membrana.

Em curto tempo, a camada gel comporta-se como uma membrana secundária, passando a controlar o fluxo e a remoção de DQO. Mudanças nos tamanhos dos poros nem sempre levam a variações significativas no fluxo do permeado e no desempenho do processo de separação (Stuckey, 2012).

\subsubsection{1 - Quantificação do Fluxo na Incrustação}

Cheryan (1998) afirma que nenhum dos dois modelos discutidos anteriormente, no item 3.2.3, descreve na totalidade o comportamento do fluxo de permeado e da pressão transmembrana durante a operação de separação típica por membranas em microfiltração e 
ultrafiltração, isto é, a região controlada pela pressão aplicada (baixa PTM) e a região independente da pressão (alta PTM).

A melhor abordagem e comumente adotada para explicar a queda de fluxo de permeado com o tempo operacional causado pela incrustação é o da resistência em série, conceito utilizado na transferência de calor (Cheryan, 1998).

AWWA (2005) usando a lei de Darcy como base teórica explica que a diminuição do fluxo pode ser simplesmente determinada pela Equação 3.7.

$$
\mathrm{J}=\frac{1}{\mathrm{~A}} \cdot \frac{\mathrm{dV}}{\mathrm{dt}}=\frac{\Delta \mathrm{P}}{\mu \cdot\left(R_{m}+R_{T}\right)}
$$

Onde $\mathrm{J}$ é o fluxo de permeado, A é a área da superfície da membrana, V é o volume de permeado, $\mathrm{t}$ é o tempo de operação, $\Delta \mathrm{P}$ é a queda de pressão através da membrana, $\mu$ é a viscosidade da água, $\mathrm{R}_{\mathrm{m}}$ é a resistência da membrana, e $\mathrm{R}_{\mathrm{T}}$ é a resistência total causada por todos os mecanismos da incrustação (AWWA, 2005).

A resistência total pode ser obtida pela soma de todas as resistências individuais causadas por cada um dos mecanismos atuantes na incrustação, e computada pela Equação 3.8.

$$
\mathrm{R}_{\mathrm{T}}=\mathrm{R}_{\mathrm{pc}}+\mathrm{R}_{\mathrm{a}}+\mathrm{R}_{\mathrm{p}}+\mathrm{R}_{\mathrm{t}}
$$

Onde $R_{p c}, R_{a}, R_{p}$, e $R_{t}$ são as resistências da polarização da concentração, da adsorção dos poros, do bloqueio dos poros, e da camada da torta, respectivamente (AWWA, 2005).

Com isso a Equação 3.7 pode ser rescrita ao substituir a resistência total da Equação 3.8, calculando o fluxo do permeado de acordo com a Equação 3.9.

$$
\mathrm{J}=\frac{\Delta \mathrm{P}}{\mu \cdot\left(R_{m}+\mathrm{R}_{\mathrm{pc}}+\mathrm{R}_{\mathrm{a}}+\mathrm{R}_{\mathrm{p}}+\mathrm{R}_{\mathrm{t}}\right)}
$$

Um amplo espectro de causas contribui para a incrustação em membranas de microfiltração e ultrafiltração, incluindo o tamanho das partículas, a qualidade da matéria 
orgânica e o crescimento biológico. O conceito de resistência em série oferece um meio simples para agrupar os diversos parâmetros que influenciam o desempenho da membrana, permitindo o entendimento do efeito de cada parâmetro a ser determinado individualmente (AWWA, 2005).

A Figura 3.25 apresenta de forma ilustrativa e resumida os mecanismos individuais envolvidos no fenômeno da incrustação.

A incrustação depende de três aspectos principais: (i) as condições operacionais (PTM e hidráulica), (ii) características do efluente alimentado e (iii) características das membranas. Supõe-se que a distribuição granulométrica das partículas no efluente alimentado determina a maior parte do mecanismo de incrustação, sendo que a filtração pela camada de torta será predominante quando as partículas forem maiores que os diâmetros dos poros da membrana, o que é ilustrado pela $\mathrm{R}_{\mathrm{t}}$ da Figura 3.25, enquanto o estreitamento e bloqueio dos poros será causado pelos componentes dimensionalmente comparáveis com os diâmetros dos poros da membranas, o que é ilustrado pelas $R_{a}$ e $R_{p}$ da Figura 3.25. Ressalta-se que a resistência pela polarização da concentração $\left(\mathrm{R}_{\mathrm{pc}}\right)$ não existe quando o mecanismo de rejeição for por superfície ou peneiramento, na micro e ultrafiltração (Ravazinni et al., 2012).

Ao considerar todos os mecanismos incrustantes, o fluxo crítico, $\mathrm{J}_{\mathrm{c}}$, foi desenvolvido e conceituado para a condição de nenhuma incrustação, ou seja, onde só a resistência da membrana $\left(R_{m}\right)$ é a única a ser considerada na Equação 3.9, sendo o fluxo apenas função linear em relação à pressão aplicada. Quando todos os mecanismos são aplicados na Equação 3.9, o fluxo passa a ser avaliado computando todas as resistências envolvidas, então a curva fluxo do permeado versus a PTM começa a desviar-se da linearidade, o que é principalmente justificado pela preponderância da Resistência da torta $\left(\mathrm{R}_{\mathrm{t}}\right)$, como pode ser observado anteriormente no gráfico da Figura 3.22 (AWWA, 2005). 


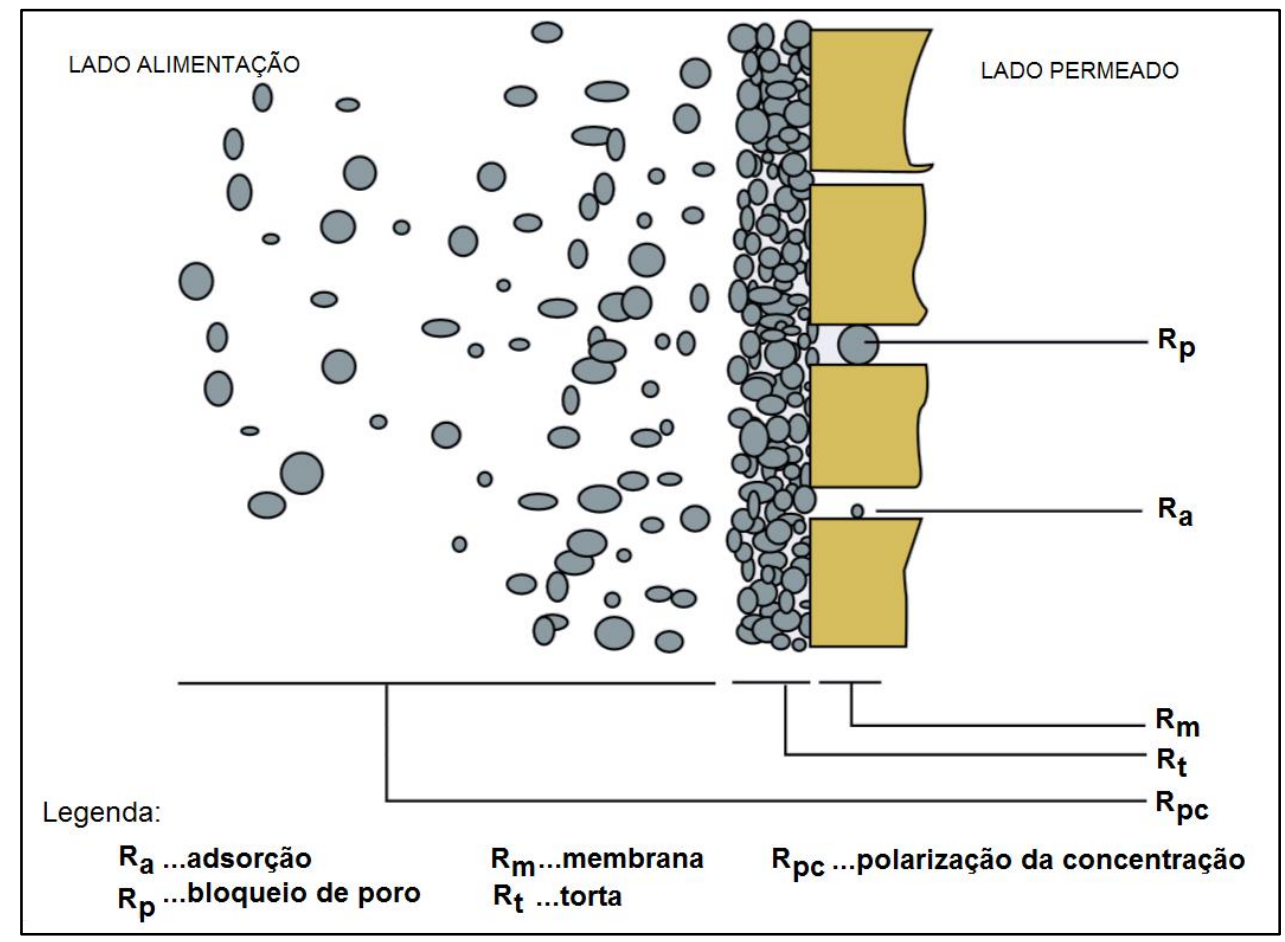

Figura 3.25 - Ilustração esquemática resumida das resistências atuantes, na superfície e dentro dos poros da membrana, durante a filtração (adaptado de: Pinnekamp, 2003)

Portanto, o modelo matemático da filtração pelas resistências em série, incluindo o entendimento do fluxo crítico, $\mathrm{J}_{\mathrm{c}}$, fica esboçado de acordo com as Equações 3.10 e 3.11, ressaltando que Equação 3.10 representa a região controlada pela PTM e Equação 3.11, a outra região que independe da pressão aplicada como já ilustrado no gráfico da Figura 3.22 (AWWA, 2005).

$$
\begin{aligned}
& \mathrm{J}<\mathrm{J}_{\mathrm{c}}=\frac{\Delta \mathrm{P}}{\mu \cdot\left(\mathrm{R}_{\mathrm{m}}\right)} \\
& \mathrm{J}>\mathrm{J}_{\mathrm{c}}=\frac{\Delta \mathrm{P}}{\mu \cdot\left(\mathrm{R}_{\mathrm{m}}+\mathrm{R}_{\mathrm{pc}}+\mathrm{R}_{\mathrm{a}}+\mathrm{R}_{\mathrm{p}}+\mathrm{R}_{\mathrm{t}}\right)}
\end{aligned}
$$

O fluxo crítico pode ser determinado por vários métodos, sendo que mais utilizado é o do fluxo etapalizado ou passo desenvolvido por Le Clech et al. (2003).

\subsubsection{2 - Métodos de Redução da Incrustação}


Devido à complexidade do fenômeno de incrustação, os métodos para redução abordam as interações entre a superfície da membrana e os componentes da alimentação. Diversos fatores estão envolvidos e afetam este fenômeno (Mulder, 1992).

Cada processo de separação por membrana requer um tipo específico de tratamento e algumas destas abordagens podem ser descritas, como: (i) Pré-tratamento da alimentação, (ii) Propriedades das membranas, (iii) Condições operacionais dos módulos e (iv) Limpeza.

- Pré-tratamento da alimentação

Os métodos empregados para pré-tratamento incluem: tratamento térmico, ajuste do $\mathrm{pH}$, adição de agentes complexantes (EDTA e outros), cloração, adsorção em carvão ativado, coagulação e peneiramento $(1$ a $3 \mathrm{~mm})$. A redução das incrustações começa no desenvolvimento e aplicação de um método de pré-tratamento adequado. Por muitas vezes, muito tempo e esforço é gasto na limpeza da membrana enquanto o pré-tratamento é esquecido.

Às vezes podem ser tomadas medidas muito simples, como por exemplo, o ajuste do $\mathrm{pH}, \mathrm{o}$ que é muito importante em se tratando de proteínas. Neste caso, a incrustação é minimizada alterando o valor de $\mathrm{pH}$ para o correspondente ponto isoelétrico da proteína, isto é, no $\mathrm{pH}$ em que a proteína se torna eletricamente neutra.

Assim, os métodos de filtração ou peneiramento clássicos podem ser utilizados para prevenir a entrada de partículas nas fibras estreitas das membranas (fibras ocas) ou mesmo nos canais do lado da alimentação, principalmente na microfiltração.

- Propriedades da membrana

A mudança em alguma das propriedades da membrana pode reduzir as incrustações. Incrustações em membranas porosas (microfiltração e ultrafiltração) são geralmente muito mais graves do que em membranas densas (osmose inversa). Além disso, uma distribuição de tamanho de poros mais estreita pode reduzir a incrustação (embora esse efeito não deva ser superestimado). 
O uso de membranas hidrofílicas, em vez de hidrofóbicas também pode ajudar a reduzir incrustações. Geralmente as proteínas são adsorvidas mais fortemente em superfícies hidrofóbicas e que torna sua remoção mais difícil do que em superfícies hidrofílicas.

Membranas carregadas negativamente podem também ajudar, especialmente na presença de coloides de mesma carga presentes na alimentação.

- Condições operacionais dos módulos

O fenômeno da incrustação enfraquece com a redução da polarização da concentração. A polarização da concentração pode ser reduzida por meio do aumento do coeficiente de transferência de massa (alta velocidade de fluxo) e usando membranas de baixo fluxo. $\mathrm{O}$ uso de vários tipos de promotores de turbulência reduz a incrustação, embora os sistemas que utilizem a fluidificação de leitos e módulos rotativos não sejam viáveis do ponto de vista econômico para aplicações em grande escala.

\section{- Limpeza}

Embora todos os métodos anteriores possam reduzir a incrustação, os mais utilizados na pratica são os de limpeza. A frequência com que as membranas devem ser limpas pode ser estimada a partir da otimização do processo.

Três métodos de limpeza podem ser empregados: (i) limpeza hidráulica, (ii) limpeza mecânica e (iii) limpeza química. A escolha do método de limpeza depende principalmente da configuração do módulo, da resistência química da membrana e do tipo de incrustação encontrada.

\section{a. Limpeza Hidráulica}

Neste método se incluem os seguintes métodos: a retrolavagem (aplicável apenas à microfiltração e em algumas de ultrafiltração), o método de pressurização e despressurização alternativa, o método da mudança de direção do fluxo em uma determinada frequência, e o método de relaxamento com borbulhamento de gás. 
No gráfico da Figura 3.26, fornece-se uma representação esquemática de uma experiência de filtração com e sem retrolavagem.

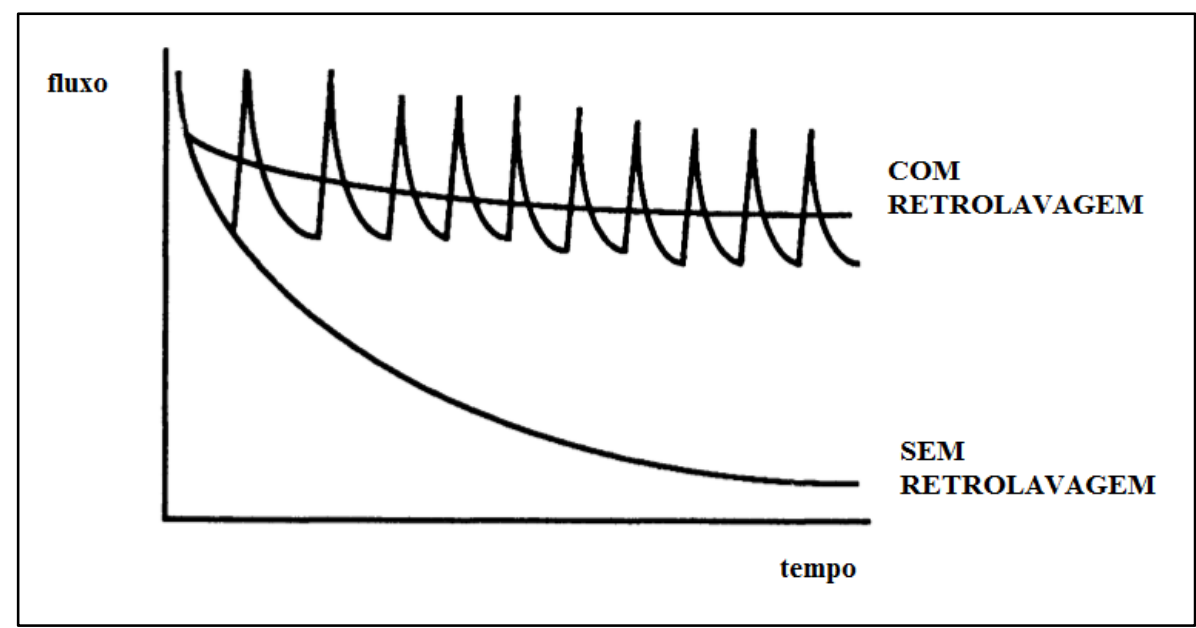

Figura 3.26 - Gráfico do Fluxo em função do tempo de uma microfiltração, linha superior com retrolavagem e inferior sem (adaptado de: Mulder, 1992).

O princípio de lavagem a refluxo, retrolavagem ou contralavagem é representado na Figura 3.27. Este método é o apresentado neste texto por ser o mais utilizado.

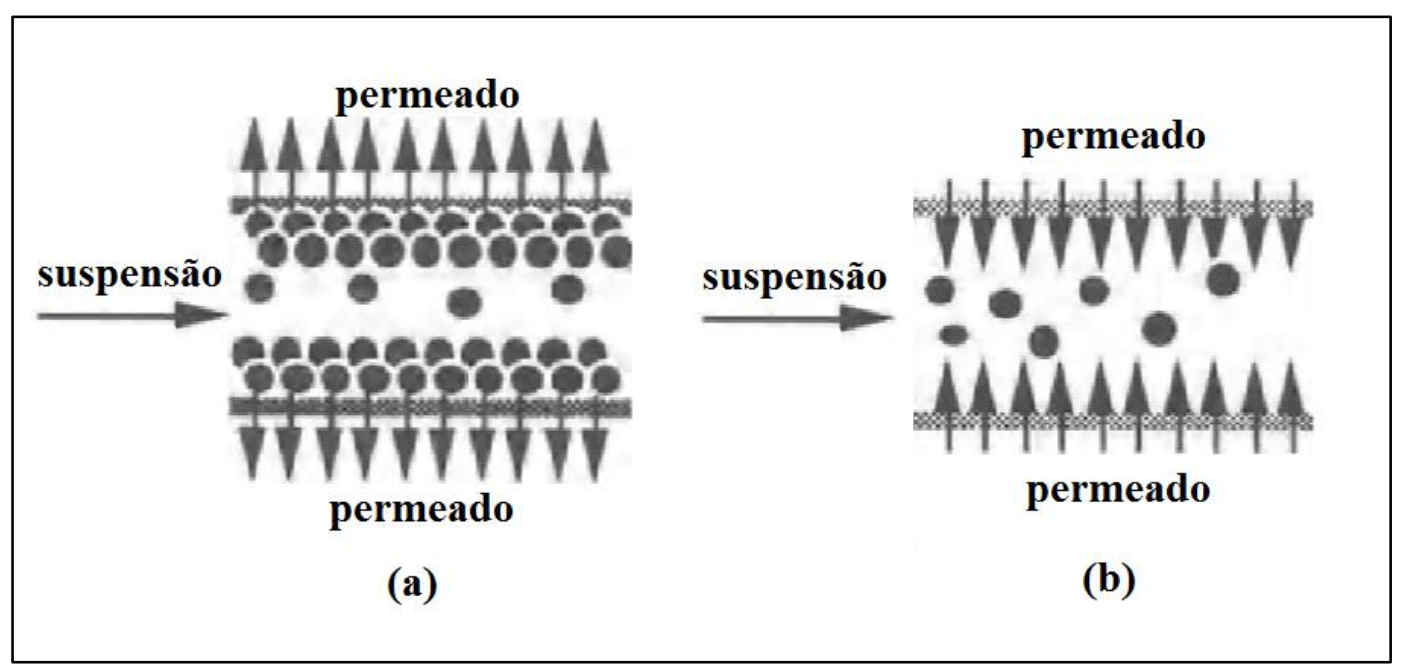

Figura 3.27 - Desenho esquemático para microfiltração em fibras ocas nas condições (a) fluxo de permeado em operação normal e (b) em retrolavagem (adaptado de: Mulder, 1992).

Observa-se na ilustração da Figura 3.27 um sistema de microfiltração (dentro para fora) em fibra oca, na condição filtrando e retrolavando. Depois de um dado período de tempo, a pressão de alimentação é liberada e a direção do permeado revertida a partir do lado do 
permeado para o lado de alimentação, a fim de remover a camada de incrustações dentro da membrana ou na superfície da membrana.

\section{b. Limpeza Mecânica}

Este método baseia-se na fricção de elementos junto à superfície da membrana, muito específico e aplicado nos sistemas tubulares, nos quais se usa um tipo de bolas de esponja de grandes dimensões para efetuar a limpeza (Mulder, 1992).

\section{c. Limpeza Química}

As incrustações que ocorrem nas membranas podem ser classificadas como fisicamente reversíveis, as quais podem ser totalmente eliminadas por limpezas físicas (Mecânica e Hidráulica) ou por algum tipo de pré-tratamento antes da exposição à superfície das membranas, e as fisicamente irreversíveis (Arnal et al., 2011).

As incrustações irreversíveis só podem ser eliminadas pela limpeza química, cuja utilização é limitada a uma certa frequência mínima, pois, se efetuada por repetidas vezes, pode afetar a vida útil das membranas (Arnal et al., 20112).

A limpeza química é o método mais importante para reduzir incrustações, com vários produtos químicos que podem ser usados separadamente ou em combinação.

Mulder (1992) relata que a concentração do produto químico usado e o tempo de limpeza são muito importantes quando se trata da resistência química da superfície da membrana.

A limpeza química é utilizada para recuperar a capacidade de produção das membranas (fluxo ou J). Dois métodos de limpeza química podem ser utilizados, que são: (i) limpeza química convencional e (ii) retrolavagem com adição química (Metcalf \& Eddy, 2016).

Na limpeza química convencional, produtos químicos são utilizados para remover as incrustações responsáveis pela perda de fluxo na membrana $(\mathrm{J}-\mathrm{LMH})$, por meio da imersão das membranas e da passagem dos produtos químicos através das membranas no interior dos módulos (Metcalf \& Eddy, 2016). 
Na retrolavagem com adição química, os produtos químicos são adicionados à água de retrolavagem (permeado) a cada número específico de operações de retrolavagens com água, sendo que o ciclo de retrolavagem com adição química é determinado pela necessidade da operação, geralmente detectada pelo aumento da pressão na alimentação (operação no modo dead end), ou, no caso de membranas submersas, pelas seguintes maneiras: (i) aumento da pressão transmembrana (PTM) operando com fluxo constante ou (ii) diminuição brusca do fluxo operando com PTM constante. Em algumas aplicações, a retrolavagem com adição química é sempre efetuada na operação normal e, quando ocorre a queda de desempenho do sistema abaixo de um determinado nível, a limpeza química convencional é utilizada (Metcalf \& Eddy, 2016).

A seguir mencionam-se algumas das classes de produtos químicos que podem ser aplicados: (i) ácidos (fortes como $\mathrm{H}_{3} \mathrm{PO}_{4}$, ou fraco, como o ácido cítrico), (ii) alcalinos ( $\mathrm{NaOH}, \mathrm{NaClO}$ ), (iii) detergentes (alcalinos, não iônicos), (iv) enzimas, (v) agentes complexantes (EDTA) e (vi) oxidantes $\left(\mathrm{H}_{2} \mathrm{O}_{2}\right.$ e $\left.\mathrm{NaClO}\right)$. Na Tabela 3.2 sumarizam-se os agentes de limpeza mais utilizados e recomendados para diversos incrustantes.

Tabela 3.2 - Soluções de produtos químicos para limpeza de acordo com o tipo de incrustante (adaptado de: Arnal et al., 2011).

\begin{tabular}{|c|c|}
\hline Produto Químico para Limpeza & Material Incrustante \\
\hline $\mathrm{NaClO}$ (Hipoclorito de sódio) & $\begin{array}{l}\text { Biológico, Matéria orgânica natural e polímeros } \\
\text { sintéticos }\end{array}$ \\
\hline $\begin{array}{l}\text { Ácidos (Clorídrico - } \mathrm{HCl} \text {, Sulfúrico - } \\
\mathrm{H}_{2} \mathrm{SO}_{4} \text { e Cítrico }-\mathrm{C}_{6} \mathrm{H}_{8} \mathrm{O}_{7} \text { ) }\end{array}$ & $\begin{array}{l}\text { Depósitos inorgânicos - Carbonato de cálcio, } \\
\text { Óxidos de Metais, Sulfatos de cálcio e bário }\end{array}$ \\
\hline $\mathrm{NaOH}$ (Soda caústica) & $\begin{array}{c}\text { Sílica, Coloides, Matéria orgânica natural e } \\
\text { Biofilmes }\end{array}$ \\
\hline $\mathrm{NaHSO}_{3}$ (Bissulfito de sódio) & Metais redutíveis - Ferro e Manganês \\
\hline $\mathrm{H}_{2} \mathrm{O}_{2}$ (Água Oxigenada) & Matéria orgânica natural \\
\hline $\mathrm{C}_{10} \mathrm{H}_{16} \mathrm{~N}_{2} \mathrm{O}_{8}$ (EDTA) & Metais - Sulfatos de cálcio e bário \\
\hline
\end{tabular}

\subsection{5 - Uso de Membranas em Tratamento de Águas Residuárias}

As membranas, como operação de separação em tratamento de águas residuárias, podem ser utilizadas em reatores biológicos aeróbios e anaeróbios (BRMs) e na filtração de efluentes primário e secundário, sendo que esta última pode ser caracterizada como póstratamento, por meio da micro e da ultrafiltração, podendo eventualmente ser seguida pela osmose inversa (von Voorthuizen et al., 2008). A diferença básica entre os BRMs (aeróbio 
ou anaeróbio) e a filtração, é que, nos primeiros, a interface da membrana é permeada por biomassa e fase líquida, enquanto no último, a alimentação é feita somente pela fase líquida (Metcalf e Eddy, 2007).

No entanto, com exceção da osmose inversa, a separação por membranas é um processo puramente físico e de grande autonomia. Sua aplicação direta no tratamento de esgotos sanitários tem como principal e fundamental característica evitar as limitações típicas do processo biológico (influência da temperatura, estabilidade e toxicidade da alimentação, período de start up, etc.). Os constituintes das águas residuárias seriam de fato "separados" em vez de "removidos". Neste sentido, este processo tem sido referido como Separação Direta por Membranas, ou no caso deste texto, Filtração Direta por Membranas (Ravazinni et al., 2012; Yoon, 2016).

Os Reatores Biológicos com Membranas ou Biorreatores com Membranas referem-se às tecnologias com base na combinação do processo de separação com membranas e os reatores biológicos para o tratamento das águas residuárias. A combinação da separação por membrana com a conversão bioquímica levou a uma série de aplicações de biotecnologia inovadora na área ambiental, ou seja, a separação dos sólidos, a difusão de gás, a extração, a bio-catálise e os reatores biológicos com membrana eletroquímica (Hai e Yamamoto, 2011; Judd, 2011; Hai et al., 2014).

Em reatores biológicos com separação por membranas, as membranas rejeitam os materiais sólidos desenvolvidos pelo processo biológico, para proporcionar um permeado clarificado e desinfetado. Os reatores biológicos com membranas de difusão de gás facilitam o fornecimento/retirada eficaz de um oxidante gasoso ou agente redutor, tal como oxigênio, hidrogênio ou metano. Os reatores biológicos com membrana extrativa têm sido desenvolvidos para a transferência de poluentes orgânicos biodegradáveis a partir de efluentes industriais de difícil degradação, transferindo a substância de interesse para uma membrana de silicone não porosa, para depois a degradação biológica ocorrer em um meio com nutrientes. Os reatores biológicos com membrana bio-catalítica utilizam enzimas ou células microbianas imobilizadas para a degradação de xenobióticos persistentes ou para a síntese de produtos da química fina. Os reatores biológicos com membrana eletroquímica tornam possível a utilização de compostos orgânicos em águas residuárias para a produção de energia ou de outros produtos químicos (Hai et al., 2014). 
Os reatores biológicos ou biorreatores de separação de biossólidos são, no entanto, o tipo mais amplamente estudado e têm encontrado aplicações em escala real em muitos países, principalmente os aeróbios. Revisões abrangentes recentes apontam para a grande maioria das pesquisas sobre aplicações do tipo de separação do biossólido, em paralelo com o sucesso comercial desse processo (Hai et al., 2014).

\subsubsection{1 - Biorreatores Aeróbios com Membranas}

A separação sólido-líquido por membranas em BRM combina as operações de clarificação e a filtração, de um processo convencional de lodos ativados em uma etapa única e simplificada. As membranas são raramente utilizadas para filtrar águas residuárias não tratadas, pelo motivo de que a incrustação impede o estabelecimento de um estado estacionário e também com isto torna a recuperação da água muito baixa e antieconômica. No entanto, quando usado em conjunto com o processo biológico aeróbio, o processo biológico converte matéria orgânica dissolvida em biomassa suspensa, reduzindo o entupimento da membrana e permitindo o aumento da recuperação. Por outro lado, o processo de filtração por membranas introduzidas nos biorreatores não apenas substitui a unidade de sedimentação para a separação sólido-líquido como também forma uma barreira seletiva e absoluta para sólidos e bactérias e os mantêm no tanque de aeração, dando origem a várias vantagens sobre os processos convencionais de lodos ativados (Hai et al., 2014; Hai e Yamamoto, 2011).

Radjenović et al. (2008) observam que, em se tratando de tratamento de águas residuárias, a ideia de integrar os processos de Lodos Ativados Convencional com o de Separação por Membranas foi primeiramente reportada nos Estados Unidos e por pesquisadores do Instituto Politécnico Rensselaer da cidade de Troy no estado de Nova Iorque associados a também empresa americana Dorr-Oliver de Milford no estado de Connecticut.

A integração dos processos de lodos ativados com membranas denominou-se deste então, em inglês, de MBR (Membrane Biological Reactor ou Membrane Bioreactor) ou em português como Reatores Biológicos com Membranas ou Biorreatores com Membranas (Dezotti et al., 2011). A separação da biomassa feita no processo de Lodos Ativados Convencional por meio de sedimentação no MBR foi substituída pelas membranas, trazendo vantagens, das quais, a área menor necessária para a planta de tratamento é uma das maiores. Judd (2011) exemplifica que a área requerida para o tratamento de esgotos da 
cidade alemã de Kaarst, com população equivalente de 80.000 habitantes e vazão afluente de $48.000 \mathrm{~m}^{3} / \mathrm{d}$, foi aproximadamente a metade daquela demandada por uma planta depuradora utilizando o processo de Lodos Ativados Convencional. Atualmente a área para instalação de BRMs pode chegar até o equivalente a $25 \%$ da ocupada para as plantas de Lodos Ativados Convencional (Hespanhol, 2016).

A primeira instalação de MBR, em escala real, foi nos Estados Unidos e projetada pela empresa Dorr-Oliver, a qual não atraiu muito o interesse dos americanos. Só no Japão o processo BRM obteve considerável sucesso nos anos de 1970 a 1980. Até 1990, a maioria dos BRMs instalados foram destinados para tratamento de águas residuárias industriais. Com as mudanças introduzidas pelos japoneses, o mercado de depuração de esgotos sanitários obteve um crescimento acelerado, e na atualidade o processo BRM pode ser configurado até para a remoção biológica de nutrientes, fósforo e nitrogênio (Radjenović et al., 2008).

Na Figura 3.28 são apresentados os esquemas do processo de Lodos Ativados (a) e de forma ilustrativa mostra a diferença causada com a inovação da integração dos processos de separação por membranas (b).

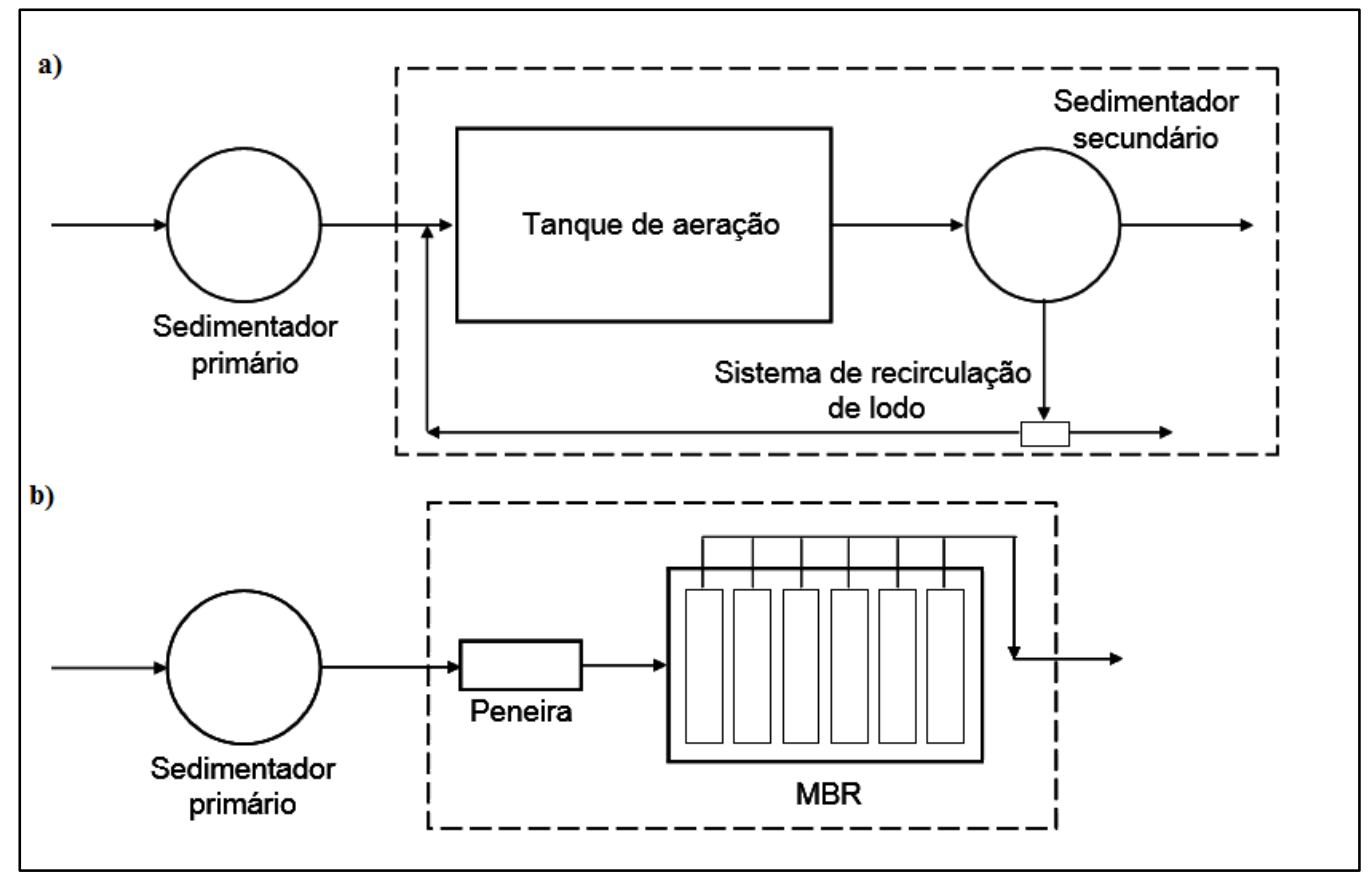

Figura 3.28 - Esquema do processo de Lodos Ativados nas configurações convencional (a) e BRM (b) - a linha tracejada delimita o nível de tratamento denominado de secundário (fonte: Dezotti et al., 2011) 


\subsubsection{2 - Biorreatores Anaeróbios com Membranas}

A digestão anaeróbia é uma alternativa quase que única para o tratamento biológico, especialmente quando deparado com os efluentes orgânicos de elevada resistência à biodegrabilidade e carga orgânica e que são biodegradáveis e não tóxicos para as arquéias metanogênicas (Hai et al., 2014).

A digestão anaeróbia é aplicada ao tratamento de resíduos sólidos e de águas residuárias há mais de cem anos, e existe interesse em que o tratamento anaeróbio possa conseguir, ao mesmo tempo, o controle da poluição e a recuperação de recursos, isto é, a produção de metano, descloração redutiva e da recuperação de enxofre, ao mesmo tempo (Hai et al., 2014).

Já é um fato consolidado que o tratamento aeróbio pode ser facilmente utilizado e é geralmente eficaz na degradação de águas residuárias. No entanto, o custo total do tratamento é elevado, devido a fatores como o consumo de energia para a aeração, volume elevado de produção de lodos, e com isto o alto custo para a disposição dessas biomassas descartadas. Em contrapartida, o processo de tratamento anaeróbio pode gerar biogás e dióxido de carbono e produz menor volume de biomassa. Os custos operacionais do processo anaeróbio são muito menores por causa de suas vantagens competitivas, tais como a ausência de injeção de oxigênio via consumo de eletricidade, o baixo crescimento da biomassa, e a produção de fonte de energia renovável (Hai et al., 2014).

O sucesso do tratamento anaeróbio de águas residuárias, domésticas ou industriais, pode ser atribuído à separação eficaz do tempo de residência celular - TRC (idade do lodo) do tempo de residência hidráulica - TRH, por meio da retenção de biomassa, geralmente realizada pela formação do biofilme (biomassa aderida) e/ou a granulação de lodos biomassa em suspensão (Hai et al., 2014).

Com a estratégia da separação do TRC do TRH, são obtidas altas concentrações de biomassa, levando a capacidades volumétricas elevadas de tratamento para uma grande variedade de águas residuárias. Atualmente, cerca de $80 \%$ das instalações anaeróbias em escala real são reatores de leito de lodo em que a retenção de biomassa é alcançada pela formação de agregados metanogênicos - reator UASB (Hai et al., 2014). 
Não obstante as potenciais vantagens sobre os processos aeróbios, os reatores anaeróbios convencionais têm certas limitações inerentes. A digestão anaeróbia é um processo bioquímico complexo que ocorre em quatro etapas sucessivas, isto é, hidrólise, fermentação/acidogênese, acetogênese, e metanogênese, proporcionadas por vários tipos de micro-organismos. Os estágios da hidrólise e da acidogênese são menos sensíveis às características do meio, quando comparados com a acetogênese e a metanogênese (Hai et $a l ., 2014)$.

Devido à complexidade metabólica dos processos anaeróbios, a relação simbiótica entre todos os micro-organismos é vital para atingir a estabilidade do processo. Quaisquer perturbações no equilíbrio entre a formação dos ácidos, do metano, e os micro-organismos que os formam, poderá causar instabilidade nas condições operacionais do reator. Estes dois grupos têm sensibilidade diferente às condições ambientais e fisiologia, necessidade nutricional e cinética do crescimento diversas. Por exemplo, a faixa de $\mathrm{pH}$ ótima para as arquéias é 6,8 a 7,2, enquanto que um pH mais ácido é desejável para micro-organismos que formam os ácidos. O ajuste do pH é normalmente necessário para manter um ambiente adequado para manter o metabolismo microbiano (Hai et al., 2014).

Assim, a digestão anaeróbia é mais sensível a alterações nas condições operacionais e ambientais, tais como temperatura, $\mathrm{pH}$ e a presença de compostos inibidores nas águas residuárias. Com isto, as atividades biológicas podem ser alteradas e o tempo de recuperação após perturbações pode ser longo. Além disso, o tratamento anaeróbio de águas residuárias apresenta problemas de separação de biomassa, principalmente quando projetado e operado em regime de mistura completa. Em consequência, o pós-tratamento é geralmente necessário para atender aos critérios de qualidade do efluente (Hai et al., 2014).

A formação de grânulos é um processo complexo que envolve interações físicas, químicas bem como biológicas. Em situações onde o biofilme ou a formação de grãos não podem ser garantidos, como no caso da presença da salinidade e de altas temperaturas, ou mesmo quando se deve assegurar a retenção completa da biomassa, a separação física assistida por membrana pode ser usada para atingir a desejada retenção de lodo necessária (Ranade e Bhandari, 2014). 
Nos últimos anos, tem sido dada grande atenção para o uso de tecnologias de membranas em conjunto com reatores anaeróbios, os biorreatores de membrana nomeadamente anaeróbios (BRM-An). Nestes reatores, as membranas podem substituir a unidade de sedimentação por gravidade tradicional (clarificador), simplificando assim as operações múltiplas a uma única operação (Hai et al., 2014).

A tecnologia BRM garante a retenção de biomassa por meio da utilização de membranas de microfiltração ou ultrafiltração. Dado que a biomassa é retida fisicamente no interior do reator, não existe qualquer risco de lavagem de células e a retenção do lodo, então não dependerá da formação de biofilmes ou grânulos. Além disso, os BRMs oferecem a possibilidade de reter microrganismos específicos, os de baixo crescimento microbiológico, mas, nos reatores de fluxo ascendente geralmente aplicados, pode acontecer que esses microrganismos sejam expulsos do reator ou sejam lavados (Ranade e Bhandari, 2014).

Os BRM-An são também adequados para o tratamento de águas residuárias com alto teor de matéria orgânica particulada (como alto teor de sólidos em suspensão), porque as partículas ficarão confinadas no interior do reator, permitindo a sua degradação. Como o permeado é livre de sólidos ou células, a água residuária exigirá menos etapas de póstratamento, quando o interesse em reúso de água for a principal finalidade.

As membranas são utilizadas como unidades de filtração, de modo que a biomassa pode ser totalmente retida no interior do reator. A retenção de biomassa completa elimina os problemas de separação de biomassa, permite a proliferação de microrganismos de crescimento lento no reator, melhorando a qualidade do efluente tornando-o livre de sólidos em suspensão, permitindo concentrações mais elevadas de biomassa e cargas orgânicas desejadas, aumentando assim a estabilidade do sistema e da produtividade (Hai et al., 2014).

Os BRMs anaeróbios (BRM-An) têm mostrado serem uma das tecnologias mais promissoras para o tratamento de águas residuárias de forma sustentável, pois essa tecnologia oferece várias vantagens sobre os BRMs aeróbios, ou seja, não requer energia para aeração, apresenta baixa produção de lodo e permite a geração de recursos energéticos. Em comparação com os processos anaeróbios convencionais, os BRM-An 
podem manter a concentração da biomassa mais elevada, têm maior capacidade de tratamento, produzem efluente com excelente qualidade e uma menor pegada ecológica. Em comparação com os reatores anaeróbios convencionais, eles são relativamente mais robustos para suportar as variações na carga orgânica e condições inibidoras, devido à completa retenção de biomassa pelas membranas (Hai et al., 2014).

Skouteris et al. (2012) acrescentam que, no caso particular de águas residuárias domésticas, os BRMs aeróbios e anaeróbios produzem eficiências similares, em se tratando da remoção de matéria orgânica (DQO solúvel) em condições operacionais idênticas.

A tecnologia BRM-An atualmente está ganhando aceitação por uma ampla gama de indústrias. No entanto, a incrustação da membrana ainda é o principal problema limitando a sua popularidade e desenvolvimento para a comercialização em larga escala. A combinação de BRM-An e outros tratamentos de polimento de efluentes é desejável para fins de reúso de água. Entretanto, o processo é atrativo por ter a vantagem da exploração do recurso energético pelo uso do biogás produzido. O menor custo total do BRM-An em relação aos BRMs aeróbios mostra sua viabilidade econômica (Hai et al., 2014).

Hai et al. (2014) explicam que a separação do efluente final de lodos ativados por uma membrana de ultrafiltração foi relatada pela primeira vez em 1969. A filtração por membranas não foi introduzida para o tratamento anaeróbio de águas residuárias até 1978, quando foi testado um módulo de membrana externa de fluxo cruzado para processar efluentes de fossas sépticas.

Pouco tempo depois, no início de 1980, a empresa Dorr-Oliver desenvolveu o primeiro BRM-An disponível comercialmente para tratar águas residuárias de alta carga orgânica de soro de processamento de leite. No entanto, os primeiros sistemas BRM-An não foram atualizados para a escala real devido ao custo elevado das membranas. Em 1987, um sistema de tratamento anaeróbio com a incorporação de membrana de ultrafiltração foi desenvolvido na África do Sul. Alguns desses sistemas, plantas pilotos e em escala real, ainda estão desempenhando papel importante no tratamento de efluentes industriais (Hai et al., 2014). 
Hai et al. (2014) ressaltam que nos últimos 20 anos houve avanços no entendimento do processo BRM-An, focando sempre na redução de consumo de energia e no reúso de água.

As configurações dos sistemas BRM-An são baseadas em duas configurações principais: biorreator de membrana externa - BRM-EAn, demonstrados nos desenhos "a" e "d" da Figura 3.29, e biorreator de membrana submersa (BRM-SAn), ilustrados nos fluxogramas representados nas letras "b" e "c" da Figura 3.29 (Visvanathan e Abeynayaka, 2012).

Hai et al. (2014) citam que o conceito básico de membranas submersas no mundo foi desenvolvido inicialmente pelo Professor Kazuo Yamamoto, da Universidade de Quioto, no Japão, em 1989.

A membrana pode ser operada pressurizada ou a vácuo. Na primeira abordagem, a membrana é separada do biorreator e uma bomba é necessária para comprimir o efluente do biorreator para a unidade de membrana, que faz com que permeação ocorra. Esta configuração é frequentemente chamada como um biorreator de membrana de fluxo cruzado externo, Figura 3.29 (a). A velocidade de fluxo cruzado do líquido através da superfície da membrana serve como o principal mecanismo para interromper a formação da torta sobre a membrana.

Quando a membrana é imersa dentro do biorreator e operada a vácuo, Figura 3.29 (b), em vez de por pressão direta, a configuração é chamada biorreator de membrana submersa, devido à localização da membrana. Nesta configuração, uma bomba é usada para succionar o permeado ao longo dos poros da membrana. Uma vez que a velocidade do líquido através da membrana não pode ser controlada, a formação da torta pode ser interrompida pelo vigoroso borbulhamento de gás através da superfície da membrana.

Para BRM aeróbios, o ar utilizado também fornece o oxigênio, enquanto que para BRMAn o ideal é utilizar o biogás produzido para uso nobre, como aquecimento e/ou geração de energia elétrica, comparando com o uso deste biogás para auxiliar na remoção da incrustação.

A abordagem da membrana imersa ou submersa operada a vácuo pode ser utilizada em duas configurações, interna ao reator ou em tanque separado, itens "c" e "d" da Figura 
3,29, respectivamente. As aplicações de BRMs submersos para tratamento anaeróbio de águas residuárias ainda são limitadas. As dificuldades de observação, de investigação e de manutenção das membranas no interior de um reator anaeróbio fechado fazem a operação das membranas externas mais favoráveis (Visvanathan e Abeynayaka, 2012).

A membrana pode ser imersa diretamente no biorreator ou numa câmara separada, fluxogramas (b) e (c) da Figura 3.30, respectivamente. Na configuração (d) da Figura 3.30 com a membrana externa será necessário uma bomba para retornar o líquido retido para o biorreator. No entanto, ao contrário da membrana de fluxo cruzado externa, a membrana aqui é operada a vácuo em vez de pressão.

A configuração com câmara externa é usada para estações de tratamento aeróbio de águas residuárias em grande escala, porque ela provê mais fácil a limpeza das membranas sujas, e as câmaras podem ser isoladas, em vez das membranas precisarem ser removidas fisicamente. Este sistema pode funcionar de forma intermitente em modo semifrontal, ou semi-dead-end, para reduzir o custo de bombeamento contínuo e para minimizar os efeitos prejudiciais, tais como a redução da atividade da biomassa e o lodo bombeado.

Para o BRM-EAn, os módulos de membrana são colocados fora do biorreator, e quase sempre é necessária uma bomba de alta potência para comprimir o efluente do biorreator através da unidade de membrana. Até o presente momento, segundo Hai et al. (2014), a maioria dos estudos tem sido realizada com a configuração externa (BRM-EAn), no entanto, esta configuração precisa de elevada velocidade de fluxo cruzado com vistas a evitar a incrustação da membrana, o que pode ocasionar a ruptura dos flocos dos lodos anaeróbios e com isto reduzir a atividade biológica do lodo. O elevado custo de energia gasta para a separação e a frequente e necessária limpeza hidráulica, para manter o desempenho do BRM-EAn tem inviabilizado esta configuração (Hai et al., 2014).

Nos BRM-SAn, a membrana é operada sob uma bomba de vácuo e as condições de operação são muito mais suaves do que nos sistemas externos, devido às velocidades menores. Do mesmo modo, as velocidades tangenciais inferiores provocam uma demanda de energia por esta configuração de até duas ordens de magnitude inferior do que a dos sistemas externos e, como consequência, a tensão de cisalhamento na biomassa associada com a recirculação pode ser reduzida. Além disso, como demonstrado na Figura 3.30, existe a possibilidade do uso do biogás produzido na digestão anaeróbia ser aproveitado 
como gás de limpeza das membranas por meio da recirculação (Visvanathan e Abeynayaka, 2012).

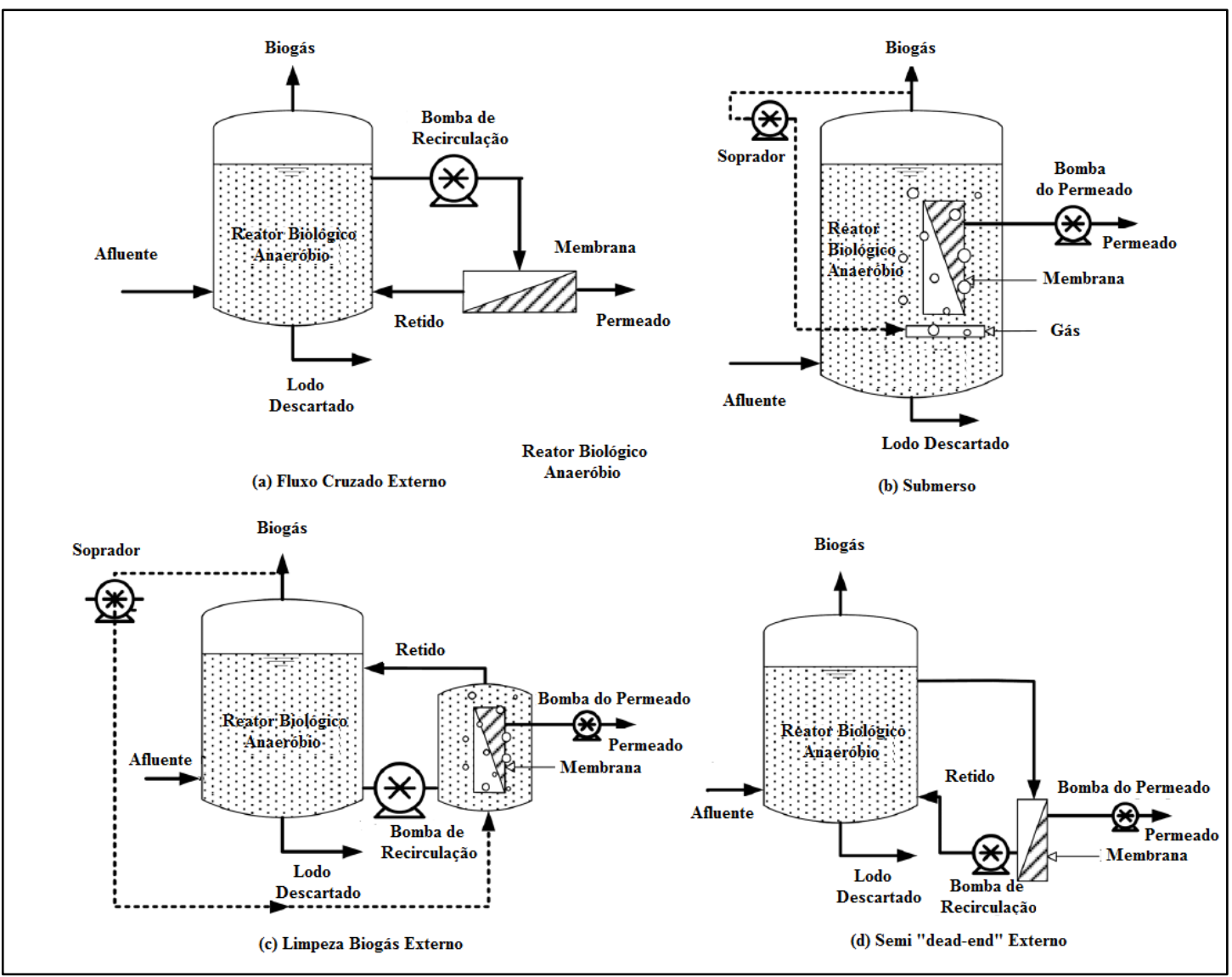

Figura 3.29 - Configurações de Reatores Biológicos Anaeróbios com separação por membranas - BRM-An (adaptado de: Visvanathan e Abeynayaka, 2012).

\subsubsection{3 - Filtração por Membranas}

A Filtração por Membranas pode ser denominada como Filtração Direta por Membranas, em inglês Direct membrane filtration, e tem o propósito de filtrar águas residuárias domésticas (segregadas e não segregadas) diretamente sobre a membrana porosa, sem a etapa de coagulação precedente (Metcalf e Eddy, 2003; Ravazinni et al., 2005; Lateef et al., 2013; Zavala et al., 2014).

A simplicidade da concepção do projeto (design), a manutenção (automação), e a alta qualidade da água que pode ser produzida, seriam as principais vantagens do uso da filtração por membranas no tratamento de esgotos. Em se tratando de filtração direta de esgotos brutos, uma forte queda no fluxo do permeado adicionado a problemas com a 
rápida incrustação podem ser esperados, portanto etapas anteriores a das membranas, como os pré-tratamentos físicos e químicos podem ser adicionadas para melhorar o desempenho da filtração (fluxo e rejeição). Algumas operações unitárias e/ou processos, em particular a sedimentação, a flotação, o micropeneiramento ou até mesmo um tratamento biológico, - o reator $U A S B$ poderia ser apropriadamente adequado -, como tratamento anterior ao da etapa filtração com as membranas (An et al., 2009; Ravazinni et al., 2005; Wen et al., 1999).

No tratamento de esgotos sanitários, dois tipos diferentes de aplicações poderiam ser previstos, o complemento do tratamento ou o tratamento parcial dos despejos. No caso de complemento de tratamento, a filtração direta por membrana seria a etapa de polimento ou o pós-tratamento das águas residuárias, como uma alternativa ao uso de outros processos biológicos usuais (Ravazinni et al., 2005).

Dadas as características do permeado, um tratamento adicional seria necessário, por exemplo, uma filtração mais avançada adicionalmente, de uma sequência micro e ultrafiltração ou ultrafiltração, osmose inversa, adsorção e desinfecção (Ravazinni et al., 2005).

No caso do tratamento parcial, a filtração direta por membranas é instalada próxima à rede de esgotamento, concentrando parcialmente as águas residuárias, extraindo o permeado e devolvendo o concentrado novamente para a tubulação de escoamento de esgotos. Com isto, a água com nutrientes e matéria orgânica, ambos dissolvidos, estariam disponíveis e como consequência reduziriam o consumo de outras fontes hídricas e também economizariam no uso de fertilizantes artificiais, de alto custo (Ravazinni et al., 2005). Este tipo de aplicação é usual nas indústrias, onde as membranas são instaladas em pontos de algumas linhas específicas de resíduos líquidos com objetivo de recuperação do solvente ou de material em suspensão destes resíduos, obviamente com o interesse da fábrica em recuperação de recursos (Baker, 2004; Mulder, 1996).

Outro ponto importante a ser ressaltado é que a proporção das concentrações de nitrogênio e fósforo em esgotos sanitários tem aproximadamente o valor ideal para o uso em cultivo de plantas terrestres, isto é, N:P, 100:7,4-14,8, em base mássica. Como a demanda de água para o uso na agricultura tem aumentado e a quantidade de chuva tem sido mal distribuída 
ao longo do ano, e até muitas vezes diminuída em algumas regiões geográficas, a necessidade de tratamento de águas residuárias com vista à remoção de nutrientes deve ser, em alguns casos, repensada, principalmente pelos custos associados aos processos de remoção biológica de nutrientes. A filtração direta por membrana é uma das formas mais simples de tratamento de águas residuárias para a produção fácil de água recuperada para reúso na agricultura e irrigação paisagística. Várias são as vantagens potenciais sobre os processos de Lodos ativados convencional e BRMs: (i) menor consumo de energia líquida e espaço menor, devido à não utilização de tanques para os reatores biológicos, (ii) menores desafios operacionais devido às variações biológicas, (iii) menores custos de implantação, e (iv) maior valor nutricional da água recuperada, devido à inexistência da remoção biológica de nutrientes (Yoon, 2016).

Pelo fato da filtração direta por membranas, nestes casos, ser uma operação unitária puramente física, com pouca adição de produtos químicos, outros benefícios poderiam ser citados, os quais, em particular, são os seguintes: possibilidade de que as estações de tratamento sejam escalonadas (scale-up), redimensionadas, rapidamente adaptadas por causa da modularidade das membranas, também pela possibilidade da operação ser descontínua ou em batelada e com isto satisfazer as mudanças sazonais da qualidade da água dos esgotos sanitários. Portanto, a filtração direta por membranas parece ser adequada para sistemas de tratamento em pequena escala, principalmente quando a finalidade for o reúso de água, onde eventuais refinamentos no permeado seriam feitos para propósitos específicos (Ravazinni et al., 2005).

As aplicações da filtração por membranas têm sido limitadas ao BRMs, com a prevalência dos aeróbios sobre os anaeróbios, sendo a filtração direta por membranas um conceito novo. Poucos exemplos são encontrados de filtração direta por membranas de efluentes brutos, sendo também relatados alguns casos no tratamento de efluentes primários e secundários por membranas de microfiltração e ultrafiltração (An et al., 2009; Metcalf e Eddy, 2007; Ravazinni et al., 2012; Wen et al., 1999).

Em filtração direta de águas residuárias, dois tipos de configurações são comumente usadas nos módulos de membrana: a pressurizada e a submersa (Metcalf e Eddy, 2007; Yoon, 2016). Na configuração pressurizada, uma bomba é usada para pressurizar a alimentação e efetuar a circulação através da membrana, como ilustrado nos itens (a) e (c) da Figura 3.30. A principal finalidade do vaso de pressão (ou tubo) é acondicionar 
internamente a membrana e manter o isolamento das correntes de alimentação e permeado, sendo que o vaso deve ter estrutura rígida de modo a impedir vazamentos e a perda de pressão. Os materiais mais utilizados são plásticos e fibra de vidro, dependendo da pressão envolvida na filtração. Geralmente, os módulos são fabricados com dimensões de 0,9 a 5,5 m de comprimento e de 100 a 300 mm de diâmetro, são dispostos em racks (suporte tipo prateleiras) ou skids. Um sistema modular de membrana típico pressurizado de microfiltração é mostrado nos itens (a) e (b) da Figura 3.31 (Metcalf e Eddy, 2007). Em membranas de micro e ultrafiltração configuradas sob pressão, existem dois modos de operação: o tangencial e o frontal. No modo tangencial, denominado de cross-flow em inglês, a alimentação flui quase tangencialmente ou paralela à superfície da membrana e a parcela que não permeia as membranas, o retido, recircula de volta e é misturada novamente com a nova alimentação, de forma direta ou em um tanque de mistura (equalização), e todo o escoamento é devido a pressurização da bomba de alimentação. Além disso, durante a filtração, uma fração do retido pode ser descartado (sangria) para tratamento e disposição final, como ilustrado no item (a) da Figura 3.31.

Os módulos de membranas em espiral têm como padrão o modo de operação tangencial (Metcalf e Eddy, 2007). No segundo modo de operação, conhecido como frontal ou alimentação perpendicular ou alimentação direta, dead-end em inglês, não há fluxo transversal ou corrente de retido durante a operação da filtração. Toda alimentação passa pela membrana e o material retido é depositado na superfície da membrana, este modo é muito utilizado em pré-tratamento e na filtração de água para consumo humano direto. Com a formação da torta na superfície da membrana, e com a formação da incrustação, provoca-se um aumento da pressão no lado da alimentação. Com isto, o fluxo de permeado começa a diminuir e também o percentual de rejeição diminui. Quando se alcança o desempenho no momento crítico, os módulos são retirados de operação e assim inicia-se a retrolavagem e a limpeza química. Os itens (b), (d) e (f) da Figura 3.30 ilustram este momento. A limpeza química se faz necessária para restaurar o desempenho das membranas ao seu estado inicial, estado incrustado, que ocorre devido à perda irreversível da permeabilidade da membrana durante a operação da filtração. 


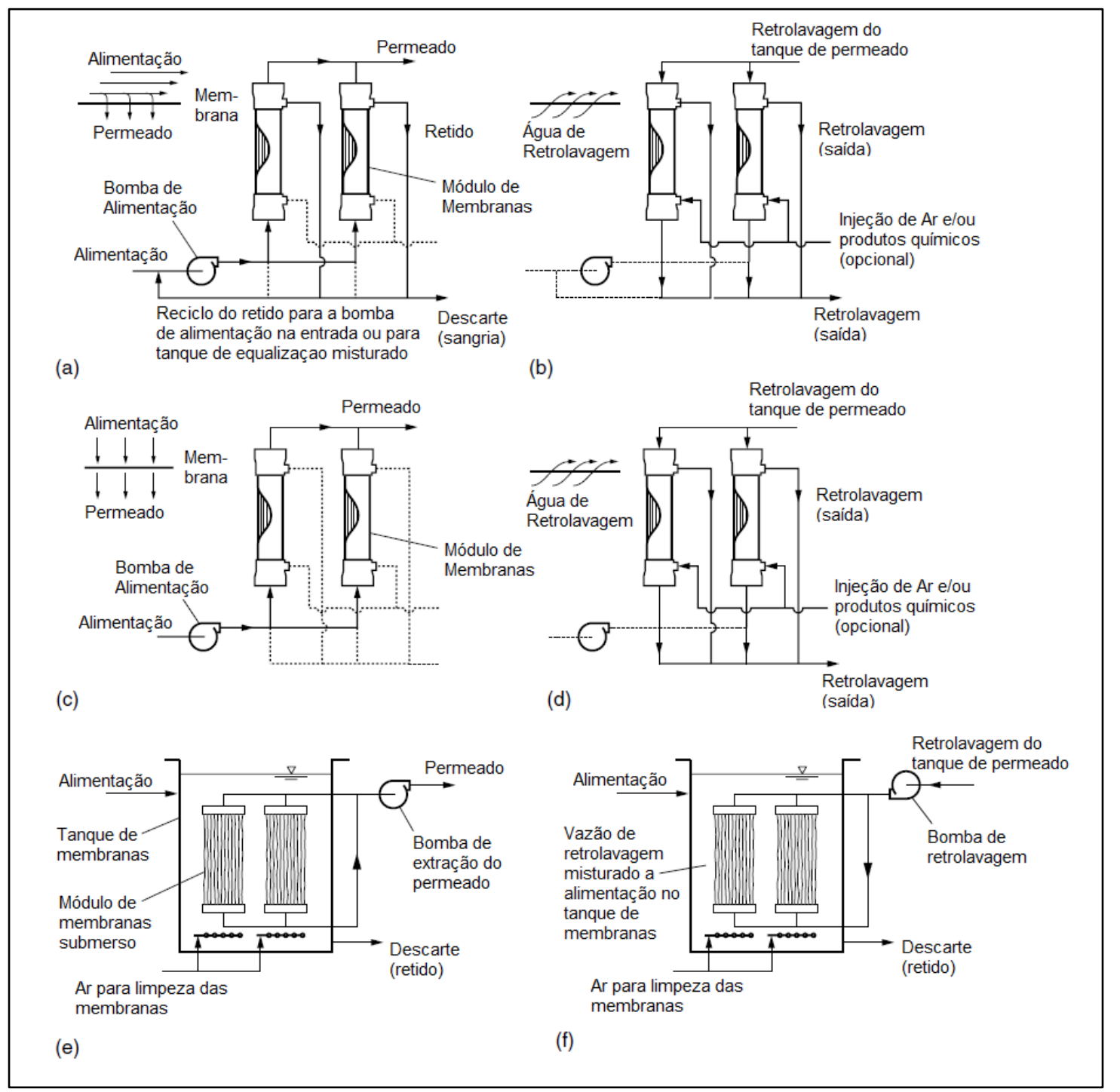

Figura 3.30 - Esboço esquemático da definição das configurações e modos operacionais da filtração por membranas: (a) fluxo tangencial pressurizado, (b) retrolavagem do fluxo tangencial pressurizado, (c) fluxo frontal pressurizado, (d) retrolavagem do fluxo frontal pressurizado, (e) membranas submersas com extração a vácuo e (f) retrolavagem de membranas submersas com extração a vácuo (Adaptado de: Metcalf e Eddy, 2007).

O grau de perda da permeabilidade irreversível depende das condições do material da membrana e do funcionamento, incluindo: (i) o envelhecimento a longo prazo do material da membrana, (ii) da compactação mecânica e da deformação provocadas pelas altas pressões de operação, (iii) reações de hidrólise relacionadas com o pH da solução e (iv) das reações de constituintes específicos da alimentação a membranas. Na configuração submersa, as membranas estão imersas num tanque de águas residuárias da alimentação e o permeado flui através da membrana utilizando-se de vácuo, a pressão é inferior a atmosférica e normalmente a sucção é feita por uma bomba centrífuga, como demonstrado 
no item (e) da Figura 3.31. Ressalta-se que é opcional o uso de ar contínuo para limpeza das membranas, nas etapas filtração (item e) e na retrolavagem (item f). A pressão transmembrana provocada pela sucção da bomba é que promove a passagem do permeado através dos poros da membrana, o NPSH da bomba restringe a máxima pressão para esta aplicação em $50 \mathrm{kPa}(0,5$ bar). Nas fotografias do item (c) da Figura 3.31 ilustra-se um módulo de membranas de fibras ocas içado fora do tanque aberto por um guindaste manual (tifor) e a do item (d) um skid com vários módulos de membranas de placa plana instalados em um tanque aberto, ambas as aplicações com configuração submersa.

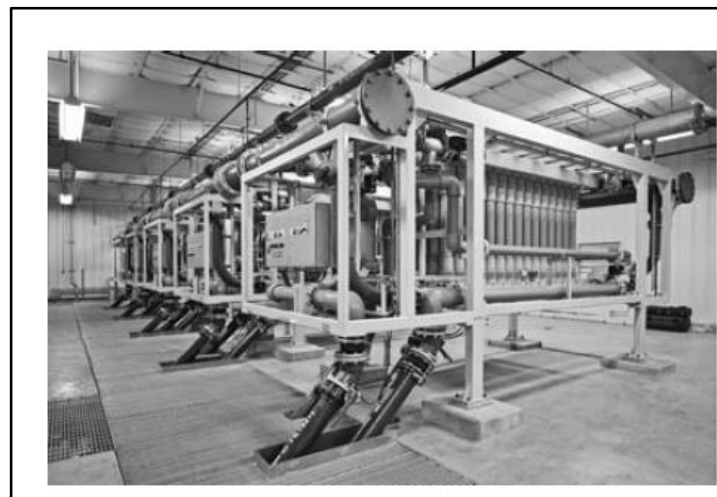

(a)
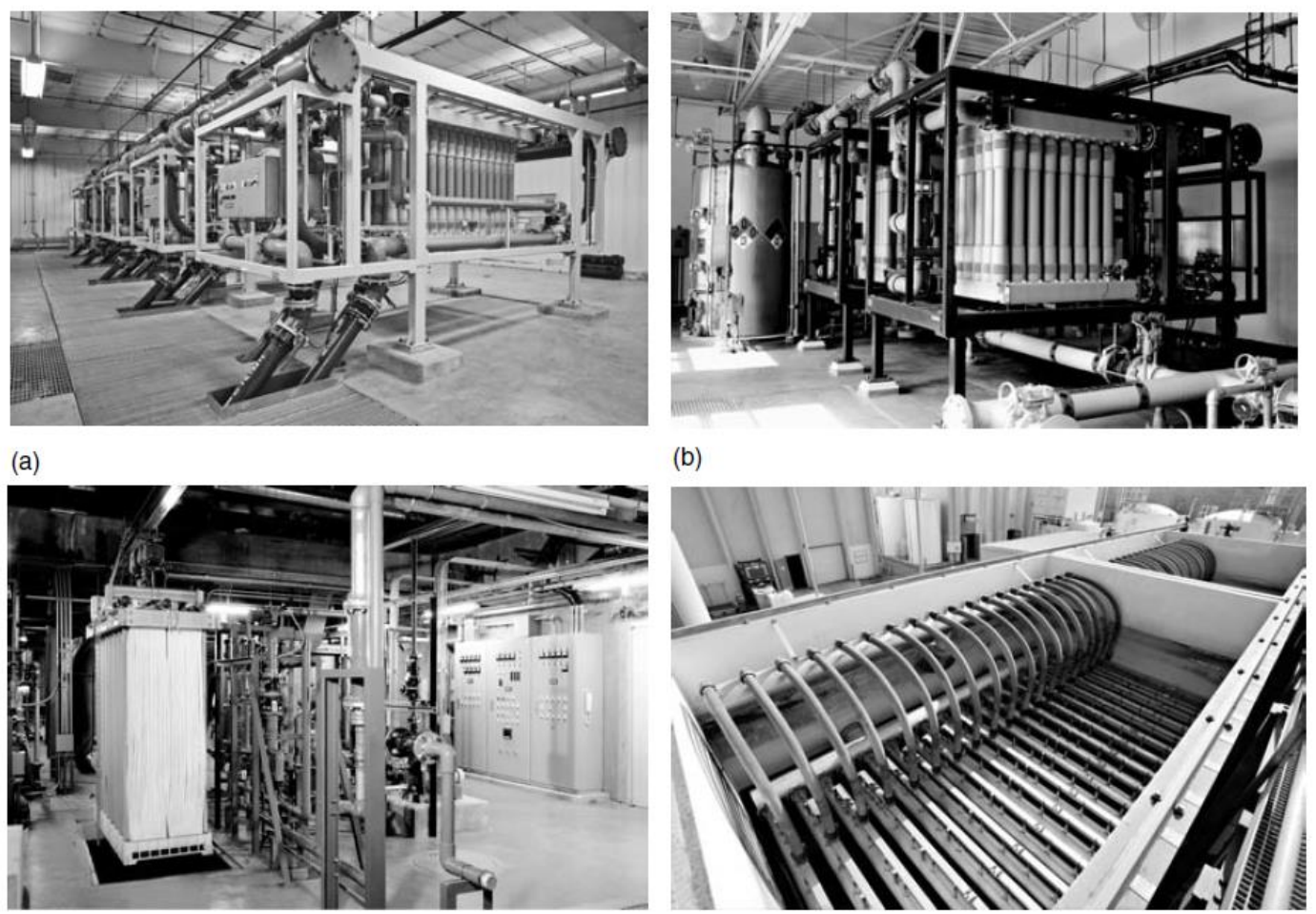

(b)

(c)

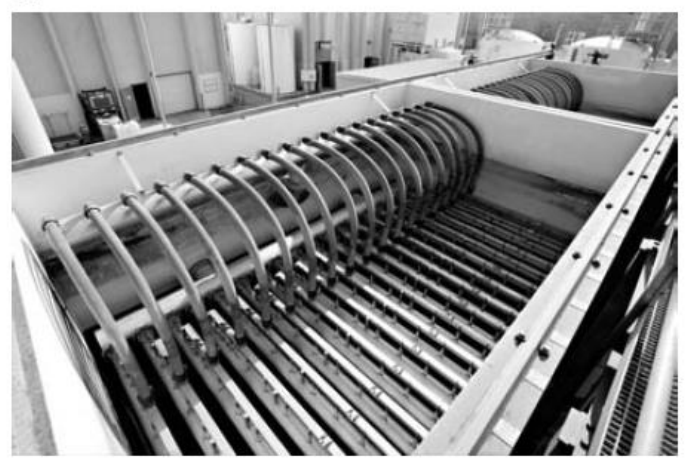

(d)

Figura 3.31 - Fotografias de instalações típicas de configurações de membranas pressurizadas e submersas para filtração de efluentes secundários sedimentados: (a) e (b) microfiltração submersa, (c) módulo de ultrafiltração (fibras ocas) usado em tanque aberto estruturado no solo e (d) módulo de microfiltração (placa plana) instalados em tanque aberto apoiado (adaptado de: Metcalf e Eddy, 2007).

\section{2 - REVISÃO BIBLIOGRÁFICA}

Contextualizando o maior uso de BRMs aeróbios em escala real, Lesjean e Huisjes (2008) registraram a existência de 409 BRMs só na Europa, entre os quais cerca de um quarto foi relacionado ao tratamento de esgotos sanitários (111 plantas) e três quartos para aplicações industriais (298 unidades). O mercado industrial foi o pioneiro, no começo de 1990, 
enquanto o de tratamento de esgotos sanitários começou em 1999. Para ambos, mercado municipal e industrial, observa-se um aumento significativo, como pode ser verificado pelo gráfico da Figura 3.32, resultado do sucesso comercial e da ampla aplicação da tecnologia com BRMs aeróbios submersos (Lesjean e Huisjes, 2008). Lesjean e Huisjes (2008) relataram que é esperado que esta taxa de progressão seja, pelo menos, sustentada nos próximos anos, e que uma maior aceleração da taxa pode ocorrer e dependerá da melhoria da competitividade da tecnologia e da evolução e implementação de regulamentos europeus e dos países integrantes da comunidade europeia.

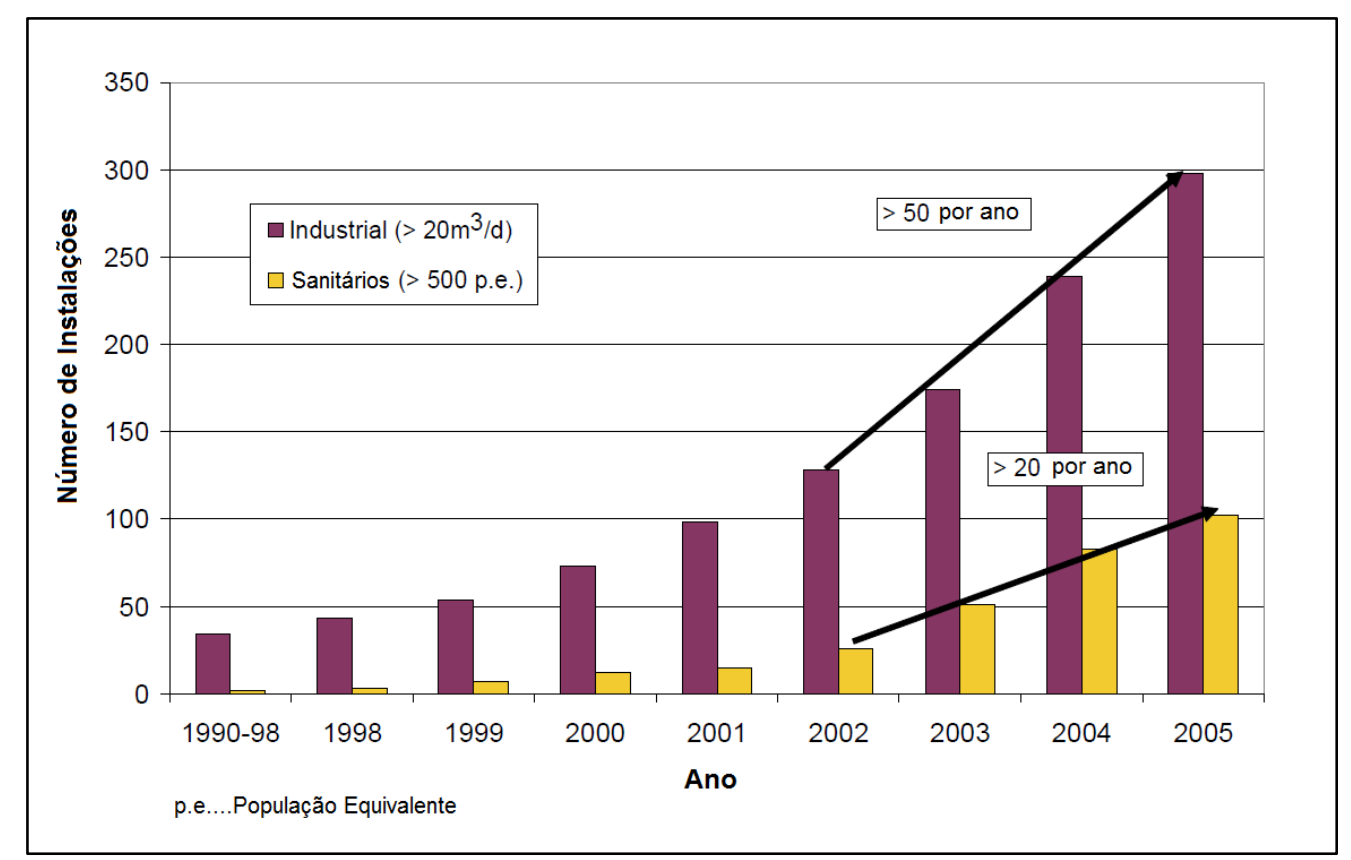

Figura 3.32 - Evolução do mercado por meio do número de instalações de estações de tratamento para tratamento de esgotos industrial e sanitários por BRMs aeróbios na Europa (adaptado de: Lesjean e Huisjes, 2008).

Ainda é ilustrado na Figura 3.32 que em 2002, 85\% do total de 154 unidades de BRMs eram utilizados para tratamento de esgotos industriais. De 2002 a 2005, uma taxa linear média de 20 e 50 unidades por ano, para tratamento de esgotos sanitário e industrial, respectivamente, foi registrado, principalmente pela diminuição dos custos de capital inicial e operacional causado pela tecnologia dos BRMs aeróbio submerso (Lesjean e Huisjes, 2008).

A disseminação do BRM é de tal forma na Europa, que Lesjean e Huisjes (2008) destacaram como conceito pioneiro a produção e venda de estações de tratamento compactas, unidades familiares para 4 até 50 pessoas, tornando-se um mercado 
competitivo com pelo menos oito (8) empresas fornecedoras disponíveis na Alemanha. Em especial, só a empresa BUSSE GT, de Leipzig, que produz BRMs aeróbios utilizando módulos de placa planas com membranas de microfiltração, até dezembro de 2005, já havia comercializado 266 ETEs compactas. No norte da Itália, a empresa EURO-MEC, de Porto Mantovano, também disponibiliza e mantém em seu catálogo unidades compactas de tratamento, de 30 e de $60 \mathrm{~m}^{3} /$ dia, utilizando a tecnologia de membranas.

No Brasil, o mercado para a tecnologia BRM aeróbio ainda é muito pequeno, destacando os exemplos recentes, em escala real, de Campinas e de São Paulo, só no estado de São Paulo.

A SANASA, empresa responsável pelo saneamento básico do município paulista de Campinas, foi a primeira empresa brasileira a construir e operar a partir de 2012 uma estação de tratamento de águas residuárias domésticas com o uso da tecnologia BRM aeróbio, a EPAR Capivari II. A planta combina o processo biológico de remoção de nutrientes do tipo BARDENPHO ${ }^{\circledR}$ ou PHOREDOX modificado de três estágios com a permeação por membranas de ultrafiltração submersas. A EPAR Capivari II, foi concebida em duas etapas, cada uma com a capacidade de tratamento de $182 \mathrm{\ell} / \mathrm{s}$, e está localizada na bacia hidrográfica do Rio Capivari (Andrade et al., 2014).

O exemplo mais recente e implantado na grande São Paulo, é o projeto Estação Produtora de Água Industrial (EPAI) Aquapolo Ambiental, totalmente dedicado à produção de água de reúso para fins industriais, para abastecer o Polo Petroquímico do $\mathrm{ABC}$ paulista, com capacidade de tratamento de população equivalente a 350.000 habitantes. A EPAI Aquapolo é considerada como o maior projeto de água de reúso do hemisfério sul e o $5^{\circ}$ do mundo, tem capacidade de 1.000 l/s com 17 quilômetros de adutora que abastece o polo petroquímico e com fornecimento inicial de $650 \mathrm{\ell} / \mathrm{s}$. O tratamento é baseado na tecnologia de membranas, usando BRM aeróbio com membranas de ultrafiltração, sendo uma parcela do efluente ultrafiltrado tratada por osmose inversa (SABESP, 2010; Koch Membrane Systems, 2014).

Por outro lado, o uso de membranas em sistemas anaeróbios ainda é incipiente, pois, em um relatório da USEPA (2008), apresentava-se a classificação de tecnologias emergentes em tratamento de águas residuárias domésticas dispondo-as em quatro níveis: (i) embrionárias, (ii) inovativas, (iii) estabelecidas e (iv) estabelecidas com inovações. Na 
época, quase nove anos atrás, o uso de filtração por membranas foi classificado como embrionário, ou seja, somente testado em escala de bancada e/ou em plantas pilotos.

Atualmente, as normas de lançamento em corpos receptores de águas residuárias tratadas estão se tornando mais e mais rigorosas e a demanda por água de reúso com qualidade compatível com diferentes finalidades está crescendo. Em tais circunstâncias, processos anaeróbios convencionais são limitados e o crescimento no interesse pelo processo de separação por membranas, especificamente BRM-An, pode ser observado na Figura 3.33, onde esta tendência é obviamente ilustrada pelo número de publicações sobre ambos os processos, $U A S B$ convencional e BRM-An.

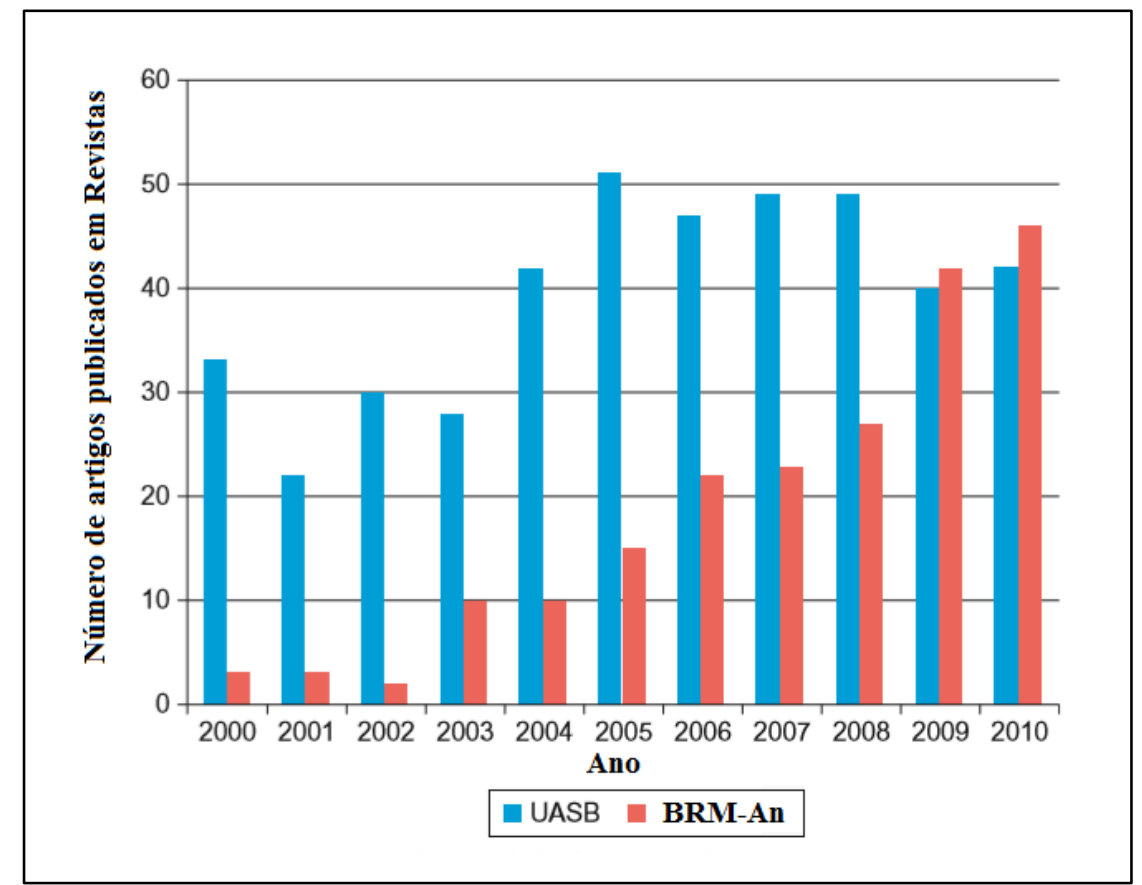

Figura 3.33 - Evolução do número publicações em revistas científicas sobre BRM-An e $U A S B$ (adaptado de: Ranade e Bhandari, 2014).

Ainda na Figura 3.33, observa-se que, a partir do início dos anos 2000, um crescimento contínuo nas publicações em BRM-An, e, por outro lado, o número de estudos sobre UASB teve tendência a se reduzir ao final do período considerado.

A oportunidade em aplicar membranas em BRM-An para tratamento de águas residuárias de baixa carga orgânica pode ser identificada, como demonstrado pelo gráfico da Figura 3.34, e as referências indicam que alguns pesquisadores têm tentado estudar BRM-An para tratamento de águas residuárias de baixa carga orgânica, ou seja, água residuária municipal. A recuperação de energia e o reúso de água são considerações importantes 
quando do interesse em utilizar BRM-An para tratamento desses despejos, caracterizados como domésticos. Mesmo que a recuperação de energia a partir de águas residuárias municipais seja relativamente baixa devido ao pequeno teor de matéria orgânica, a opção do reúso de água é outro interesse imperativo (Ranade e Bhandari, 2014).

As tendências atuais em publicações de pesquisa indicam um grande número de estudos sobre uso de BRM-An em tratamento de águas residuárias industriais de alta carga. Ao mesmo tempo, o número de estudos sobre o tratamento de águas residuárias municipais, também aumentou consideravelmente. O gráfico da Figura 3.34 mostra o número de artigos publicados em periódicos sobre as investigações relacionadas com BRM-An para águas residuárias municipais e industriais.

Dado que os processos anaeróbios têm limitações para a remoção completa de nutrientes, o efluente tratado é composto de concentrações razoáveis em nitrogênio e fósforo. Em tais casos, o efluente tratado pode ser reusado para fins de irrigação na agricultura. Muitos autores comentam que o pós-tratamento de reatores anaeróbios por membranas ou o uso de BRM-An tem vantagens sobre a tecnologia baseada em lodos ativados convencional e que a integração do processo de separação por membranas com os processos anaeróbios, por meio de melhores práticas da engenharia, pode formar sistemas comercialmente viáveis (Ranade e Bhandari, 2014).

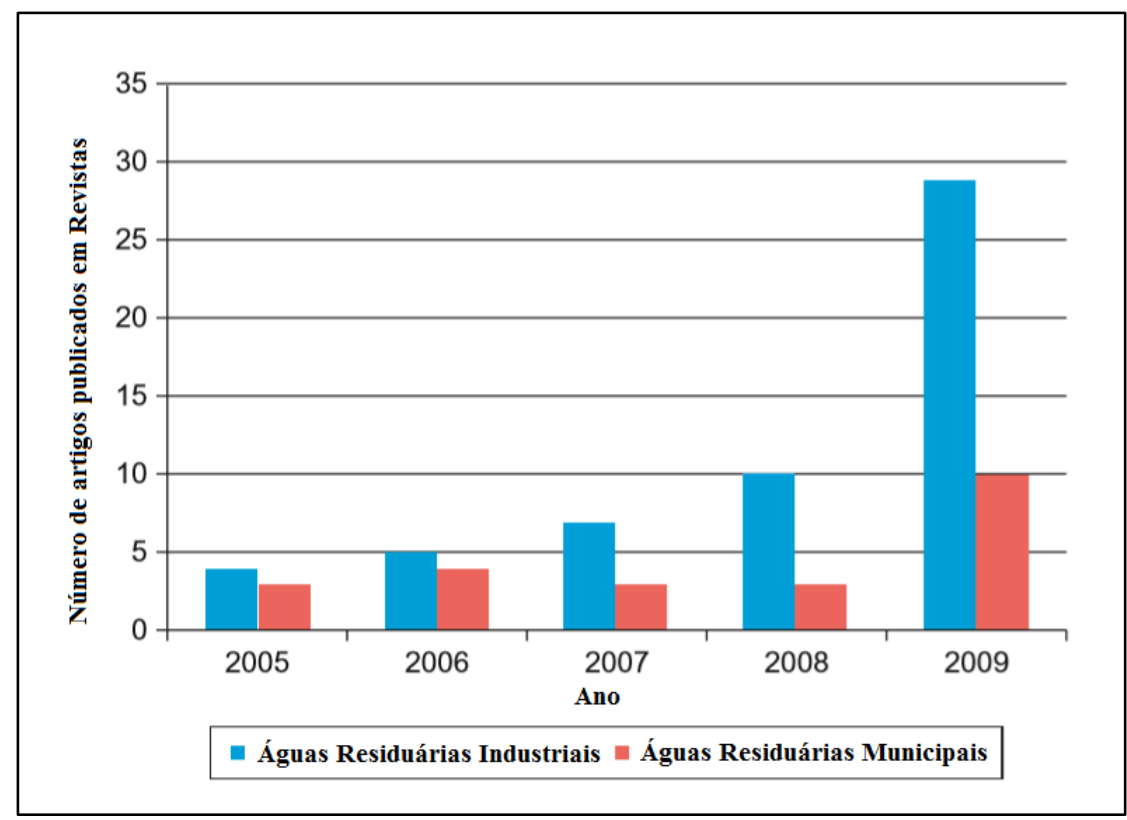

Figura 3.34 - Evolução do número de artigos científicos publicados em revistas sobre o uso de tratamento de águas residuárias industriais e municipais com BRM-An (adaptado de: Ranade e Bhandari, 2014). 
Embora as pesquisas no campo de tratamento de águas residuárias domésticas por filtração por membranas e reatores anaeróbios tenham aumentando nos últimos anos, pouco material encontra-se disponível, o contrário ocorre com os BRMs Aeróbios, que oferece muitas opções de pesquisas, disponíveis e publicadas em diversas referências bibliográficas.

Skouteris et al. (2012) informam que o levantamento de informação sobre a aplicação específica de filtração por membranas em sistemas anaeróbios para o tratamento de águas residuárias indica, especialmente no caso de BRM-An, que somente o desempenho em escala de bancada tem sido completamente estudado, e que a implementação de plantas pilotos é limitada para esta tecnologia, sendo que casos em escala real ou industrial não foram ainda avaliados.

Para melhor sistematização, este item será abordado discorrendo sobre as informações encontradas na literatura, por meio da seguinte sequência de quatro subitens: (i) Prétratamento (Peneiramento Fino), (ii) Configurações experimentais encontradas, (iii) Condições operacionais utilizadas e (iv) Desempenhos obtidos

\subsection{1 - Pré-tratamento (Peneiramento Fino encontrado na literatura)}

Os esgotos sanitários contêm alta quantidade de resíduos grosseiros e fibrosos. Deve ser feito um esforço considerável para proteger as membranas dos efeitos adversos da acumulação de materiais indesejados, adotando-se pré-tratamento mecânico anterior as membranas. No início, a importância desse pré-tratamento foi, de certa maneira, subestimada (Brepols, 2011). Brepols (2011) relata que na Alemanha, a ETE Rödingen, inicialmente possuía uma peneira fina escalar (tipo step-screen) com abertura de $3 \mathrm{~mm}$, mas o uso deste peneiramento levou a sérios problemas de entupimento, aumento da incrustação e danos por materiais abrasivos nas membranas. Com isto, um novo prétratamento foi necessário com a instalação de peneiras ainda mais finas de abertura de 0,5 $\mathrm{mm}$.

Sendo assim, no caso de esgotos sanitários é recomendada a instalação adicional de um peneiramento fino antes do tanque com as membranas, nas configurações externa ou submersa. Este pré-tratamento visa a proteger a membrana dos materiais fibrosos (fios de cabelos, fibras, fiapos, debris, etc.) que, uma vez retidos antes do contato com as 
membranas, isso pode proporcionar o aumento da vida útil destas. Na Tabela 3.3 apresentam-se os valores sugeridos de abertura para as unidades de peneiramento, dados por diversos pesquisadores ou encontrados instalados em plantas pilotos ou em escala real. Observa-se que, especificamente para fibra oca, os valores encontrados variam de 0,8 a 2,0 $\mathrm{mm}$.

A preocupação com a retirada ou remoção de material particulado de origem fibrosa antes que o efluente entre em contato com as membranas é reforçada pelo que foi reportado recentemente por Morgado e Inácio (2014), para um levantamento efetuado do material gradeado na ETE Franca da SABESP, onde os autores informam que o maior volume da ETE é de cabelos, fibras e fiapos, que devem advir do despejo em bacias sanitárias de cabelos, panos de limpeza que se desagregam, pelos de animais como cachorros e gatos, restos de varrição contendo pelos de tapetes, vassouras e escovas e ainda provenientes da lavagem em tanques dos filtros de máquinas de lavar, que retêm os fios dos tecidos.

Tabela 3.3- Abertura da tela do peneiramento fino recomendado/instalado para instalação a montante dos Tanques com Membranas (BRMs aeróbios e anaeróbios e Filtração direta)

Aplicação/Autor $\quad$ Valor $\quad$ Valor

\begin{tabular}{|c|c|c|}
\hline & Recomendado & Encontrado \\
\hline Andrade et al. (2014) & - & $2 \mathrm{~mm}$ \\
\hline $\begin{array}{l}\text { ETE Glessen (9000 População equivalente) - Alemanha } \\
\text { (Brepols, 2011) }\end{array}$ & - & $1,5 \mathrm{~mm}$ \\
\hline $\begin{array}{l}\text { ETE Nordkanal (80000 População equivalente) - } \\
\text { Alemanha (Brepols, 2011) }\end{array}$ & - & $1,0 \mathrm{~mm}$ \\
\hline $\begin{array}{l}\text { ETE Rödingen ( } 3000 \text { População equivalente) - } \\
\text { Alemanha (Brepols, 2011) }\end{array}$ & - & $0,5 \mathrm{~mm}$ \\
\hline $\begin{array}{l}\text { Giménez et al. (2011); Giménez et al. (2012); Robles et } \\
\text { al. }\left(2012^{\mathrm{a}}\right) ; \text { Robles } \text { et al. }\left(2012^{\mathrm{b}}\right) \text {; Pretel } \text { et al. }(2013) ; \\
\text { Robles } \text { et al. }\left(2013^{\mathrm{a}}\right) ; \text { Robles } \text { et } \text { al. }\left(2013^{\mathrm{b}}\right)\end{array}$ & - & $0,5 \mathrm{~mm}$ \\
\hline Koch Membrane Systems (2014) & 1 ou $2 \mathrm{~mm}$ & - \\
\hline Larrea et al. (2014) & 1 a $3 \mathrm{~mm}$ & - \\
\hline Lin et al. (2011) & - & $0,75 \mathrm{~mm}$ \\
\hline Projeto AQUAPOLO - SABESP (2010) & - & $0,4 \mathrm{~mm}$ \\
\hline Radjenović et al. (2007) & $\begin{array}{l}0,8 \text { a } 1,5 \mathrm{~mm} \\
\text { para Fibra } \\
\text { Oca }\end{array}$ & - \\
\hline Radjenović et al. (2007) & $\begin{array}{l}2 \text { a } 3 \mathrm{~mm} \text { para } \\
\text { Placa Plana }\end{array}$ & - \\
\hline Sethi e Juby (2002) & - & $\begin{array}{l}1,2 \mathrm{~mm} \\
(3 / 64 ”)\end{array}$ \\
\hline Sethi e Juby (2002) & - & $0,6 \mathrm{~mm}$ \\
\hline WEF (2006 e 2012) & $1 \mathrm{a} 3 \mathrm{~mm}$ & - \\
\hline Wen et al. (1999) - Fibra oca & - & $1,0 \mathrm{~mm}$ \\
\hline
\end{tabular}


Morgado e Inácio (2014) informam que há também fibras provenientes de processos industriais (fábricas de tecidos) e comerciais (salões de cabelereiros), que lançam efluentes na rede. O material fibroso, cerca de $80 \%$ em peso do material gradeado, é o principal responsável pelo travamento dos dispositivos de limpeza das grades, provocando panes.

\subsection{2 - Configurações Experimentais encontradas na literatura}

Lin et al. (2013), em revisão da aplicação de reatores anaeróbios utilizando membranas, afirmam que os processos de separação normalmente usados são de microfiltração e ultrafiltração, e a maioria dos módulos aplicados são de membranas de fibras ocas, de placas planas e tubulares, sendo que as preferidas são as fibras ocas, pela sua densidade de empacotamento e custos.

As membranas cerâmicas, no início das pesquisas, foram muito aplicadas em sistemas anaeróbios, por apresentarem valores altos de permeabilidade (200 a 250 LMH), cerca de 10 vezes superiores às confeccionadas em polímeros, e com outras vantagens, tais como retrolavagens eficazes e altas resistências à corrosão, à abrasão e às incrustações, e maior controle da polarização da concentração. As membranas metálicas, por sua vez, quando empregadas nos reatores anaeróbios, mostraram melhores resistências aos impactos, melhor recuperação das incrustações, tolerância à oxidação e a altas temperaturas, quando comparadas às poliméricas (Lin et al., 2013).

Segundo Lin et al. (2013), a grande desvantagem das membranas cerâmicas e metálicas é o custo mais elevado quando confrontado às feitas por polímeros, sendo que o custo das membranas poliméricas ao longo dos anos tem diminuído, e portanto, continuam sendo vantajosas em relação ao preço.

Com relação à composição química dos polímeros, os materiais preferidos para as membranas são PVDF (Fluoreto de polivinilideno) e PES (Polieterssulfona), sendo que só estes dois são responsáveis por $75 \%$ dos produtos comercialmente oferecidos no mercado (Lin et al., 2013).

Não foram encontrados muitos registros de reator $U A S B$ acoplado à Filtração por Membranas Submersas (FMS), principalmente alimentados por esgotos sanitários. Foram encontradas somente duas pesquisas tratando do tema associação sequencial de reator 
$U A S B$ e Filtração, ambas chinesas, uma de Wen et al. (1999) e outra de An et al. (2009), sendo que, somente a de Wen et al. (1999) trata especificamente da sequência reator $U A S B / F M S$.

Wen et al. (1999), em escala de laboratório, operaram um sistema composto por reator anaeróbio ilustrado na Figura 3.35, com membranas de fibra oca instaladas na parte superior do reator. O reator anaeróbio apresentava as seguintes características: volume útil de $17,7 \ell$; parte superior com função de zona de sedimentação com volume de $8,8 \ell$ e parte inferior que serve como zona de lodos com volume de 8,9 $\ell$ (diâmetro $90 \mathrm{~mm}$ e altura de $1400 \mathrm{~mm})$.

Como pode ser observado no diagrama esquemático da Figura 3.35, foi instalada uma camada de meio suporte compostas por fibras finas na saída da zona de lodos, para prevenir o carreamento de lodo (a "lavagem") nos momentos de altas cargas hidráulicas alimentadas.

O módulo de membranas utilizadas no estudo de Wen et al. (1999) foi um módulo de fibra oca, feitas de polietileno pela empresa japonesa Mitsubishi Rayon Engineering, com diâmetro médio de poros de $0,03 \mu \mathrm{m}$, área de filtração igual a $0,3 \mathrm{~m}^{2}$ e operado no modo de sucção através de bomba de vácuo para a extração do permeado.

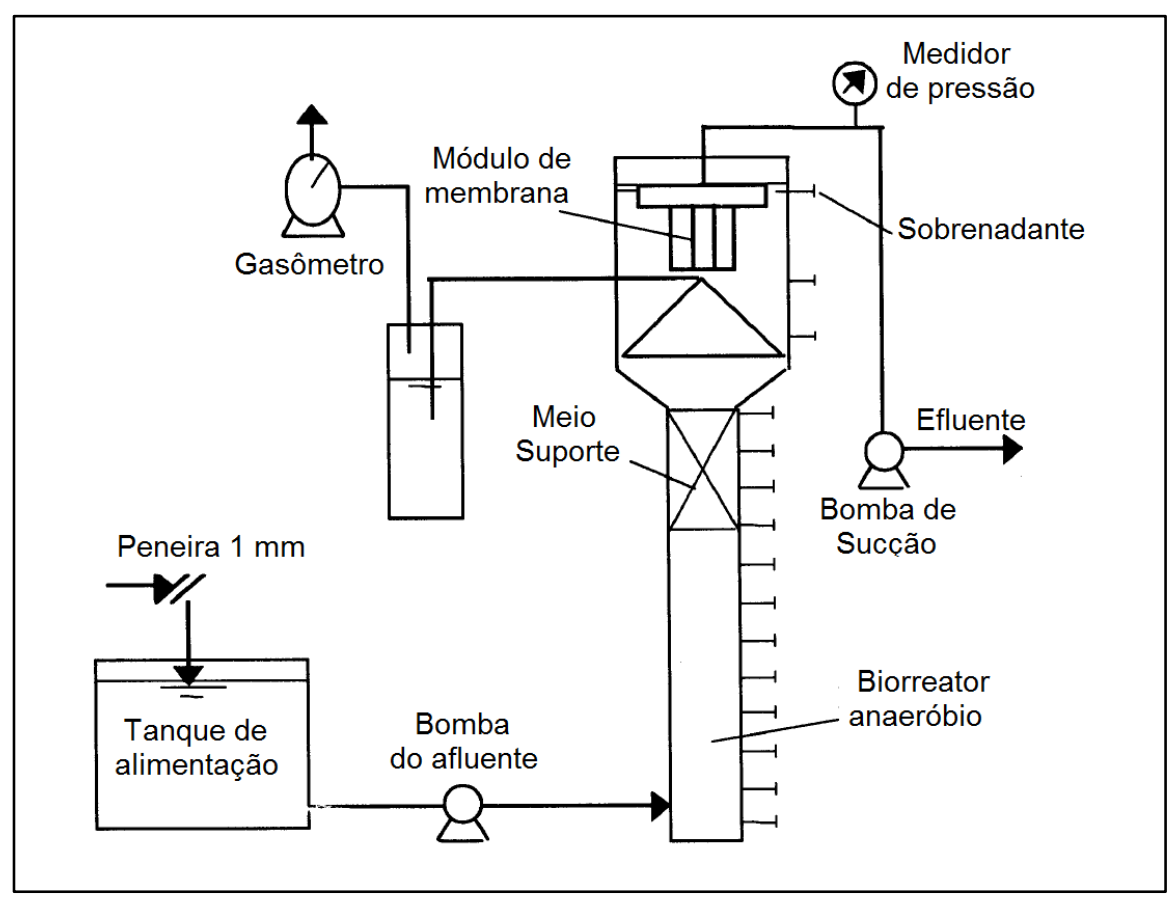

Figura 3.35 - Diagrama esquemático de Biorreator anaeróbio (reator UASB) acoplado ao módulo de membranas de fibra oca submersas (adaptado de: Wen et al., 1999). 
Na pesquisa de Wen et al. (1999), o esgoto sanitário alimentado ao sistema de tratamento era oriundo da Universidade de Tsinghua, o reator foi inicialmente inoculado com lodo proveniente de uma estação de tratamento de esgotos sanitários de Beijing, cidade chinesa onde ocorreu o experimento, e depois foi alimentado com esgotos durante o período de três (3) meses iniciais, e só então se iniciou a etapa de filtração por membranas (Wen et al., 1999).

No trabalho de Wen et al. (1999), sempre os autores referem-se ao sistema biológico como reator anaeróbio, mas pelo diagrama esquemático apresentado na Figura 3.35 e também pela descrição textual, há uma grande semelhança com o reator $U A S B$ da unidade demonstrativa da CETESB (Cia. Ambiental do estado de São Paulo), na capital, em São Paulo, muito utilizado para pesquisa e ensino naquela instituição (Souza e Vieira, 1986 e Vieira et al., 1995).

Na pesquisa de Wen et al. (1999), foram realizados dois ensaios, ou melhor, ensaios com dois tipos de vazão afluente, ocasionando com isto dois Tempos de Detenção Hidráulica no reator, o primeiro de 6 horas e o segundo com tempo menor de $4 \mathrm{~h}$. Uma peneira de $1 \mathrm{~mm}$ foi instalada na entrada do Tanque de Alimentação para prevenir danos e bloqueios nas etapas posteriores (bomba, membranas, etc.), como pode ser observado na Figura 3.35. As condições operacionais experimentadas nas duas corridas estão descritas na Tabela 3.4 (Wen et al., 1999).

Tabela 3.4 - Condições operacionais avaliadas das duas corridas efetuadas no experimento de Wen et al. (1999).

\begin{tabular}{lcc}
\hline \multicolumn{1}{c}{ Itens } & Corrida 1 & Corrida 2 \\
\hline Tempo de operação $(\mathrm{d})$ & 110 & 90 \\
TDH $(\mathrm{h})^{\mathrm{a}}$ & 6 & 4 \\
Vazão afluente $(\ell / \mathrm{h})$ & 1,5 & 2,25 \\
Temperatura do afluente $\left({ }^{\circ} \mathrm{C}\right)$ & $14-25$ & $18,5-22,5$ \\
\hline
\end{tabular}

Legenda: a...TDH no volume da zona de lodo.

Já na pesquisa de An et al. (2009), publicada dez anos após a de Wen et al. (1999), foi analisada a operação de uma planta-piloto que consistia de um reator $U A S B$ sequenciado por módulo de membranas externo (side-stream), operado de forma pressurizada. Os detalhes da planta-piloto utilizada por An et al. (2009) estão demonstrados na Figura 3.36.

O reator $U A S B$ utilizado na pesquisa de An et al. (2009) foi construído em formato cilíndrico, com as seguintes dimensões: diâmetro interno de 19,0 cm e altura total de 120,0 
cm, com um fundo em forma cônica. O separador trifásico foi instalado na parte superior da coluna para separar biogás a partir do sobrenadante. O sedimentador também serviu para separar as grandes partículas elutriadas (lodos) e devolvê-las novamente para o reator, como pode ser observado na Figura 3.36. O biogás foi coletado em um coletor de gás, instalado fora do reator $U A S B$, o efluente do reator alimentava o tanque pulmão, onde parte era recirculada de volta para o reator $U A S B$; a outra parte alimentava o módulo de membrana por meio de uma bomba centrífuga. $\mathrm{O}$ medidor de nível ligado a um controlador lógico programável (CLP) mantinha o fluxo constante por meio da atuação na velocidade da bomba de alimentação, e o CLP também recebia informações de mais cinco sensores: (i) oxigênio dissolvido (OD), (ii) $\mathrm{pH}$, (iii) pressão de sucção da bomba de circulação do módulo das membranas (PM1), (iv) pressão de saída do módulo de membranas (PM2) e (v) pressão de sucção do permeado (PM3).

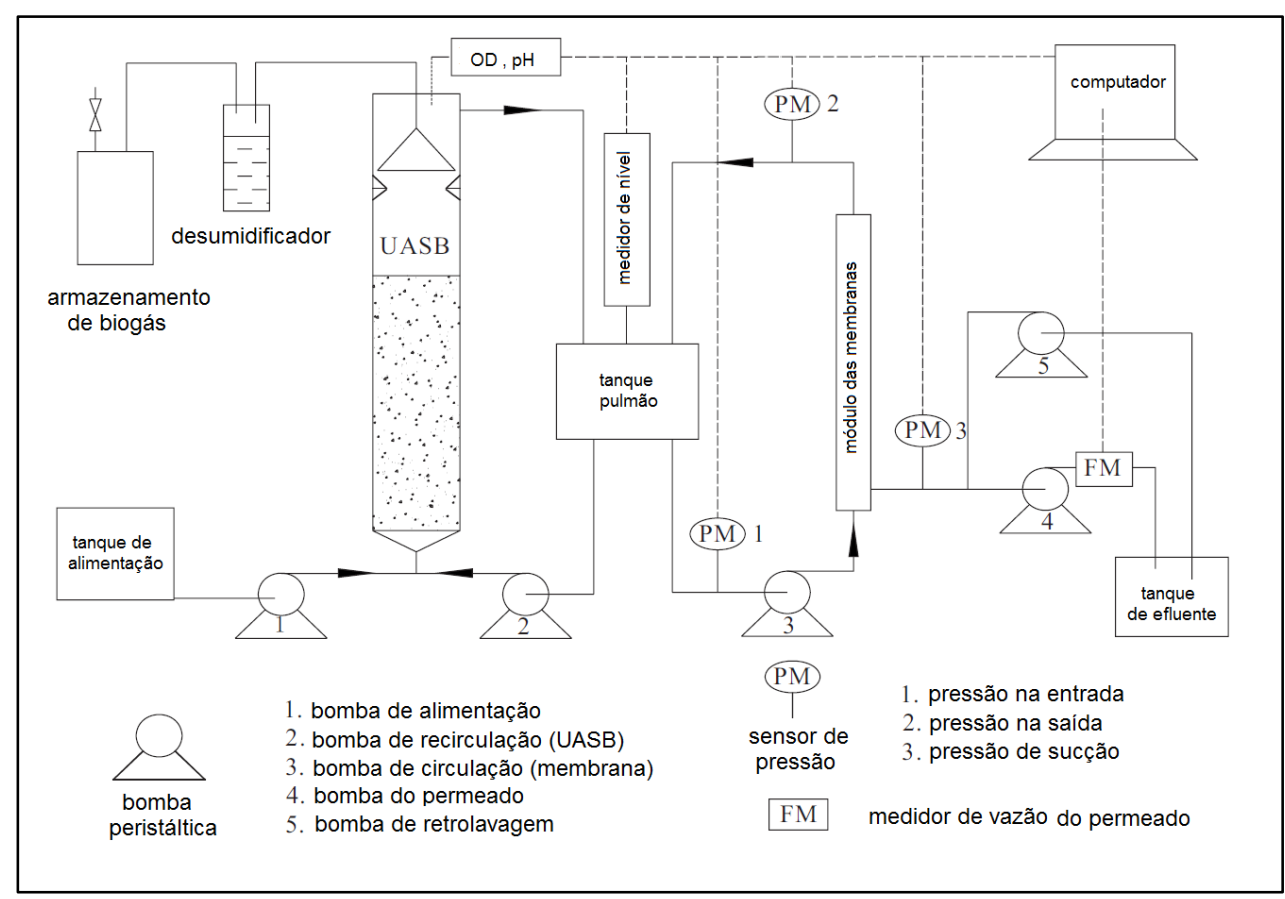

Figura 3.36 - Configuração esquemática da planta-piloto de reator UASB acoplado a módulo de membrana tubular externo (adaptado de: An et al., 2009).

A pesquisa de An et al. (2009) operou com módulos de membranas tubulares, pressurizados, e com três diâmetros diferentes, sendo que as membranas eram feitas de poliacrilonitrila (PAN), hidrofílica, com área útil de membranas de $0,2 \mathrm{~m}^{2}$. Os autores não forneceram informações sobre o diâmetro médio dos poros e o fornecedor/fabricante das membranas. O modo de filtração das membranas nesta pesquisa era frontal (dead-end). 
O lodo inoculado no reator $U A S B$ e o esgoto sanitário alimentado à planta-piloto era procedente da Estação de Recuperação de Esgotos de Ulu Pandan em Singapura. O esgoto era coletado uma vez por semana e mantido sob refrigeração $\left(4^{\circ} \mathrm{C}\right)$, para depois ser transferido e alimentado à planta-piloto.

An et al. (2009) operaram a planta-piloto da Figura 3.36 em dois períodos, também determinados pelo TDH no reator $U A S B, 119$ dias iniciais com TDH igual a 10,0 h e os últimos 92 dias com TDH de 5,5 h.

Schneider e Tsutiya (2001) afirmam que a única configuração viável de acoplamento de membranas a reatores anaeróbios é por meio de um circuito de recirculação externo, ou seja, as membranas devem ser instaladas em um tanque separado, pois a injeção de gases é indispensável para o controle da incrustação, mas em nenhuma das duas pesquisas consultadas, Wen et al. (1999) e An et al. (2009), foi relatado a aplicação de injeção de gases para o "relaxamento" e limpeza.

Ainda, destacam-se as pesquisas do grupo do Prof. Noyola, do Instituto de Engenharia da Universidade Nacional Autónoma do México (Salazar-Peláez et al., 2011; Céron-Vivas et al., 2012). Nesses dois trabalhos, a alimentação de esgotos era sintética, mas no de CéronVivas et al. (2012), o objetivo foi estudar a influência da injeção de gás Nitrogênio na Filtração intermitente para diminuição da incrustações de membranas em módulos tubulares. Na Figura 3.37 demonstra-se a configuração esquemática utilizada. Este trabalho reforça a afirmação de Schneider e Tsutiya (2001) sobre a necessidade de injeção de gases.

Ainda sobre injeção de gases, Stuckey (2012) afirma que o aumento na velocidade de borbulhamento de gases age sobre a tensão de cisalhamento e tem demonstrado piora na remoção de DQO, porém produzindo aumento no fluxo do permeado. O dilema é optar-se por fluxo ou qualidade do permeado em função da alteração da vazão de gás de borbulhamento.

Também, segundo Stuckey (2010), este mesmo dilema traz a discussão o conceito do "turn-up \& turn-down" (sobe/desce), onde as condições operacionais podem garantir o desempenho econômico por meio do controle de incrustação via borbulhamento de gases. Mais pesquisas aplicadas são necessárias para entender melhor a formação da camada de incrustação e o controle da remoção de DQO. 


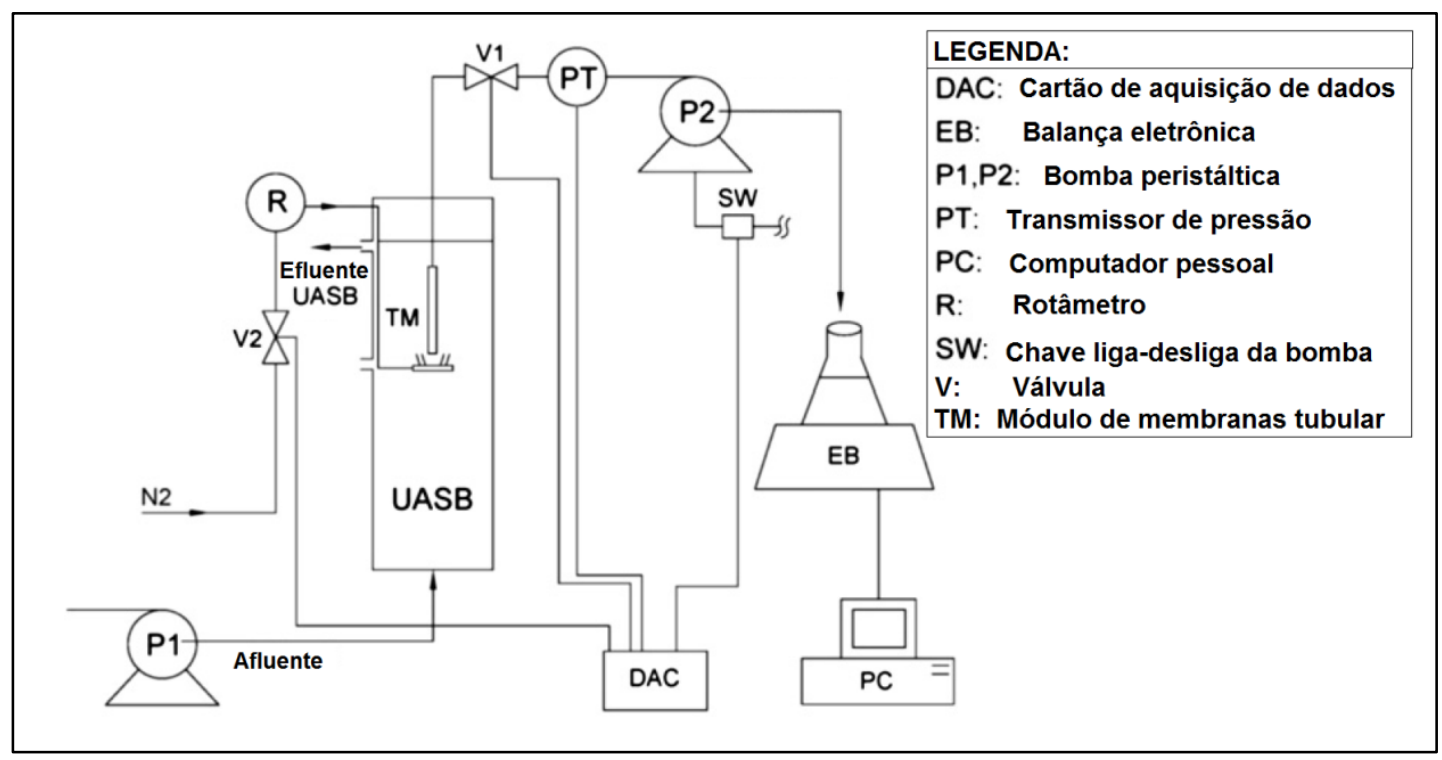

Figura 3.37 - Diagrama esquemático de reator $U A S B$ acoplado a módulo tubular de membranas submerso (adaptado de: Cerón-Vivas et al., 2012).

\subsection{3 - Condições Operacionais encontradas na literatura}

As condições operacionais, no contexto deste trabalho, dizem respeito ao desempenho hidráulico da filtração por membranas, o que geralmente é discutido em termos de algumas variáveis chaves do processo, tais como: (i) tempos de filtração e retrolavagem, (ii) pressões transmembrana aplicadas na filtração e na retrolavagem, (iii) comportamento observado da recuperação, (iv) fluxo específico do permeado, (v) produto químico utilizado e (vi) frequência da limpeza química (Sethi e Juby, 2002).

Para Yoon (2016), os tempos de filtração e retrolavagem variam amplamente e dependem da qualidade da água da alimentação, mas geralmente o tempo de filtração varia de 10 a 30 minutos e o tempo de retrolavagem de 15 a 60 segundos, sendo que a vazão de retrolavagem deve ser compreendida entre 100 e $200 \%$ do fluxo do permeado, para garantir a remoção da torta formada durante cada etapa da filtração à vácuo.

Como valores de referência na filtração à vácuo, Yoon (2016) cita que o fluxo de permeado (J) varia tipicamente entre 20 a 45 LMH para filtração de efluente secundário, e entre 30 a 60 LMH para filtração de água superficial, obviamente, dependendo da qualidade da água alimentada. A utilização do "relaxamento" feito pela injeção de ar auxilia no desempenho das membranas, mas esta melhoria não é suficientemente justificada pelo consumo adicional de energia elétrica, principalmente no caso da fração 
alimentada possuir valores de SST baixos $(<100 \mathrm{mg} / \ell)$. Com relação à PTM na filtração, valores típicos encontrados variam de 30 a $80 \mathrm{kPa}(0,3$ a 0,8 bar).

Wen et al. (1999) revelam que em sua pesquisa o fluxo do permeado operou de forma constante e a PTM aplicada variável, fluxos de 5 e 10 LMH e PTM máxima de $70 \mathrm{kPa}$ (0,7 bar). Periodicamente, o módulo de membranas era retirado do reator UASB e era limpo com água potável e com solução de Hipoclorito de Sódio $(\mathrm{NaClO})$ a 5\%, para a remoção das incrustações da superfície das membranas. A operação estável pôde ser mantida por duas semanas sem limpeza, com o tempo de filtração de 4 minutos e 1 minuto sem filtrar, e alcançando um fluxo de permeado de 5 LMH. Não foi mencionada nenhuma informação sobre a retrolavagem, tempo e PTM utilizados. Ainda com relação à recuperação, para Wen et al. (1999) seria muito difícil o levantamento, pois, com módulo submerso no interior do reator $U A S B$, não é possível medir as vazões de alimentação e do retido, sendo que outro elemento dificultador para a realização do balanço hídrico é a presença da saída de sobrenadante do reator $U A S B$, como pode ser observado no fluxograma da Figura 3.35.

An et al. (2009) operaram a planta-piloto da Figura 3.36 com fluxo do permeado constante de 10,5 LMH e PTM variável. O sistema era composto por três módulos de membranas de diâmetros diferentes (mesma área) e foi utilizada a PTM máxima de $60 \mathrm{kPa}(0,6$ bar). Durante a filtração, quando o valor da PTM aumentava repentinamente, o módulo tubular era retirado de operação para limpeza, com três tipos de lavagens sequenciais: (i) água e ar, (ii) solução de $0,05 \%$ de $\mathrm{NaClO}$ e (iii) solução de $0,30 \%$ de $\mathrm{H}_{2} \mathrm{SO}_{4}$. A operação era efetuada com a filtração ocorrendo de três maneiras: (i) continuamente, (ii) com intermitência (bomba de sucção desligada 20 segundos a cada 10 minutos) e (iii) com retrolavagem (tempo de 20 segundos a cada 10 minutos de filtração). Uma das conclusões de An et al. (2009) foi que a PTM manteve-se em valor mais baixo ( $<15 \mathrm{kPa})$, mantendo o fluxo de 10,5 LMH na opção da retrolavagem com fluxo de $80 \mathrm{LMH}$, que é mais de 5 vezes maior que o fluxo de sucção. Ainda sobre a limpeza, foram testados cinco tempos de duração para cada tipo de limpeza: 5, 10, 20, 30 e 120 minutos. A melhor eficiência ficou com as limpezas químicas, com o retorno de $100 \%$ para o tempo de 2 horas, sendo que a hidráulica atingiu $60 \%$ no mesmo tempo. Nada foi mencionado sobre os valores de recuperação levantados, mesmo porque, no fluxograma da planta-piloto, Figura 3.36, observa-se somente a presença de um medidor de vazão, o do permeado. 
No seu trabalho de revisão, Lew et al. (2009) informaram sobre alguns protocolos de limpeza química usados em aplicações de membranas em sistemas anaeróbios. Lew et al. (2009) reportaram ainda que a limpeza química de melhor resultado de recuperação da membrana $(75 \%)$ foi feita com uma mistura de $\mathrm{NaOH} 0,1 \mathrm{M}$ e $\mathrm{H}_{2} \mathrm{O}_{2} 1 \%$ intercalada com $\mathrm{HCl} 1 \%$

A Tabela 3.5 sumariza os dados levantados por Smith et al. (2012), em sua revisão sobre o uso de sistemas anaeróbios acoplados à filtração por membranas tratando esgotos sanitários, em escala de laboratório, com especial atenção ao controle de incrustação.

Tabela 3.5 - Dados obtidos de pesquisas em escala de bancada para sistemas anaeróbios/filtração por membranas para o controle de incrustação de acordo com o reator, com a membrana e a condição operacional reportado por Smith et al. (2012).

\begin{tabular}{|c|c|c|c|c|c|}
\hline $\begin{array}{c}\mathrm{T} \\
\left({ }^{\circ} \mathrm{C}\right)\end{array}$ & Configuração reator & $\begin{array}{l}\text { Poros ou corte } \\
\qquad(\mu \mathrm{m})\end{array}$ & Controle de incrustação & $\begin{array}{l}\text { Idade } \\
\text { do lodo } \\
\text { (d) }\end{array}$ & $\begin{array}{l}\text { TDH } \\
\text { (h) }\end{array}$ \\
\hline $\begin{array}{r}12- \\
25\end{array}$ & $U A S B+$ BRM-SAn & $0,03 /$ fibra oca & $\begin{array}{r}\text { Limpeza periódica com } \mathrm{NaClO} \text { a } \\
5 \%\end{array}$ & 150 & $4-6$ \\
\hline $\begin{array}{r}11- \\
25\end{array}$ & $E G S B+\mathrm{BRM}-\mathrm{SAn}$ & $0,1 /$ fibra oca & $\begin{array}{r}\text { Retrolavagem e relaxamento, } \\
\text { limpeza periódica com } \mathrm{NaClO} \text { a } \\
0,03 \%\end{array}$ & 145 & $\begin{array}{r}3,5- \\
5,7\end{array}$ \\
\hline 35 & BRM-SAn & 0,4/fibra oca & Borbulhamento de biogás & $\infty$ & $3-48$ \\
\hline 32 & Mistura completa & $\begin{array}{r}0,1 / \text { tubular } \\
\text { externo }\end{array}$ & $\begin{array}{l}\text { Fluxo tangencial, limpeza com } \\
\mathrm{NaOH} \text { a } 0,1 \% \text { semanalmente }\end{array}$ & $\infty$ & $\begin{array}{r}12- \\
48\end{array}$ \\
\hline 37 & $\begin{array}{r}\text { Reator Anaeróbio } \\
\text { com jato de fluxo } \\
\text { (externo) }\end{array}$ & $100 \mathrm{kDa}$ & Fluxo tangencial & $\infty$ & $\begin{array}{r}15- \\
60\end{array}$ \\
\hline 25 & Mistura Completa & $\begin{array}{l}1 / \mathrm{PTFE} \\
\text { tubular } \\
\text { externo }\end{array}$ & $\begin{array}{r}\text { Fluxo tangencial, periodicamente } \\
\text { limpeza com } \mathrm{NaClO}\end{array}$ & $90-360$ & $6-12$ \\
\hline 25 & Mistura Completa & $\begin{array}{r}0,2 / \text { fibra oca } \\
\text { externo }\end{array}$ & $\begin{array}{r}\text { Retrolavagem periódica, limpeza } \\
\text { química com } \mathrm{NaOH} 0,1 \mathrm{M}, \mathrm{H}_{2} \mathrm{O}_{2} \\
\text { a } 1 \% \text { e } \mathrm{HCl} \text { a } 1 \%\end{array}$ & $\infty$ & $\begin{array}{r}4,5- \\
12\end{array}$ \\
\hline $\begin{array}{r}15- \\
25\end{array}$ & Mistura Completa & $\begin{array}{l}1 / \mathrm{PTFE} \\
\text { tubular } \\
\text { externo }\end{array}$ & Retrolavagem periódica & $\infty$ & 9 \\
\hline 30 & $\begin{array}{l}\text { Reator anaeróbio de } \\
\text { fluxo ascendente }\end{array}$ & $\begin{array}{l}100 \mathrm{kDa} \text { de } \\
\text { PVDF e } 30 \\
\text { kDa de PEI }\end{array}$ & Fluxo cruzado & 50 & 24 \\
\hline $\begin{array}{r}25- \\
30\end{array}$ & Mistura Completa & $\begin{array}{r}0,45 / \mathrm{PES} \\
\text { placa plana }\end{array}$ & Borbulhamento de biogás & $\begin{array}{r}30,60 \text { e } \\
\infty\end{array}$ & $8-12$ \\
\hline- & $\begin{array}{r}U A S B+\text { membrana } \\
\text { externa }\end{array}$ & $\begin{array}{r}100 \mathrm{kDa} / \\
\text { PVDF tubular }\end{array}$ & $\begin{array}{r}\text { Fluxo tangencial, limpeza com } \\
\mathrm{NaClO} \text { a cada } 6 \text { horas }\end{array}$ & $\infty$ & $4-12$ \\
\hline 35 & $\begin{array}{r}\text { Leito fluidificado } \\
\text { com dois estágios }+ \\
\text { BRM-An }\end{array}$ & $\begin{array}{r}0,1 / \text { PVDF } \\
\text { fibra oca }\end{array}$ & $\begin{array}{r}\text { Fluidificação com Carvão ativado } \\
\text { granulado, retrolavagem } \\
\text { periódicas e/ou limpeza química } \\
\text { com } \mathrm{NaClO} / \mathrm{NaOH}\end{array}$ & $\infty$ & $\begin{array}{r}4,2- \\
5,9\end{array}$ \\
\hline 15 & BRM-SAn & $\begin{array}{r}0,2 / \text { PES placa } \\
\text { plana }\end{array}$ & $\begin{array}{r}\text { Borbulhamento de biogás e } \\
\text { retrolavagem }\end{array}$ & 300 & 16 \\
\hline
\end{tabular}




\subsection{4 - Desempenhos Obtidos na literatura}

Wen et al. (1999) monitoraram DQO total, DQO solúvel (filtrado em papel de filtro de diâmetros de poros igual a $0,45 \mu \mathrm{m}$ ) e Sólidos Suspensos Totais (SST). No período do experimento, 200 dias, a DQO afluente ao reator $U A S B$ variou de 98 a $2600 \mathrm{mg} / \ell$ e os SST afluente de 100 a 1000 mg/l, como observado na Tabela 3.6. A remoção de DQO no reator $U A S B$ acoplado à membrana submersa foi em média de $97 \%$, sendo que somente no reator $U A S B$ foi em média de $84 \%$ (60 a 95\%) e a rejeição estimada para as membranas submersas de $13 \%$. A concentração de DQO no efluente (permeado) foi sempre menor que $20 \mathrm{mg} / \ell$ e com remoção total de SST, ou seja, $100 \%$.

Tabela 3.6 - Dados da qualidade do afluente das duas Corridas efetuadas no experimento de Wen et al. (1999)

\begin{tabular}{lcc}
\hline \multicolumn{1}{c}{ Itens } & Corrida 1 & Corrida 2 \\
\hline DQO afluente $(\mathrm{mg} / \ell)$ & $97,5-2600$ & $123-1823$ \\
SST afluente $(\mathrm{mg} / \ell)$ & $100-800$ & $100-1000$ \\
pH do afluente & $7,0-7,3$ & $7,0-7,6$ \\
Carga de DQO $\left(\mathrm{kg} / \mathrm{m}^{3} / \mathrm{d}\right)^{\mathrm{a}}$ & $0,39-10,4(3,49)$ & $0,74-11,1(4,21)$ \\
\hline
\end{tabular}

Legenda: a...valor médio entre os parênteses

An et al. (2009) utilizaram DQO total, COT total, e ST (Sólidos Totais) como variáveis para o monitoramento da avaliação do desempenho da pesquisa realizada, a eficiência em remoção global de DQO relatada foi de $77 \%$ (para $\mathrm{TDH}=10 \mathrm{~h}$ ) e de $81 \%$ (para $\mathrm{TDH}=5,5$ h), para COT de 65\% (para TDH=10 h) e 81\% (para TDH= 5,5h) e 91,1\% (para TDH= 10h) e 83,6\% (para TDH= 5,5h) para ST. A composição e as concentrações do esgoto bruto alimentado estão dispostas na Tabela 3.7.

Tabela 3.7 - Características do Esgoto Bruto utilizado na pesquisa de An et al. (2009)

\begin{tabular}{lcc}
\hline \multicolumn{1}{c}{ Variável } & Faixa de variação & Média aritmética \\
\hline COT $(\mathrm{mg} / \ell)$ & $27,8-79,6$ & 50,1 \\
DQO $(\mathrm{mg} / \ell)$ & $58,0-348,0$ & 185,6 \\
$\mathrm{DBO}_{5}(\mathrm{mg} / \ell)$ & $50,0-266,0$ & 139,0 \\
$\mathrm{NH}_{4}{ }^{-}-\mathrm{N}(\mathrm{mg} / \ell)$ & $29,5-47,5$ & 38,0 \\
$\mathrm{PO}_{4}{ }^{-3}-\mathrm{P}(\mathrm{mg} / \ell)$ & $4,6-8,7$ & 6,5 \\
Sólidos Totais $(\mathrm{mg} / \ell)$ & $147,0-240,0$ & 187,0 \\
pH & $6,6-7,8$ & 7,1 \\
\hline
\end{tabular}


Outros resultados obtidos por pesquisas com filtração por membranas microfiltrantes que valem ser ressaltadas e serão usados neste trabalho com fins de comparação são os relatados por Metcalf e Eddy (2007) e Ravazinni et al. (2012), e são descritos nos parágrafos seguintes.

A ETE do munícipio de Orange County, em Santa Ana, Califórnia, testou de maneira extensiva a microfiltração usando membranas submersas tratando efluente primário gradeado, e demonstrou que os resultados dos desempenhos obtidos, tanto para uma planta-piloto quanto para uma unidade demonstrativa, foram muito altos para SST e microrganismos (CF e CT) e satisfatório para matéria orgânica (DBO e DQO). Os resultados de remoções obtidos foram de 94\% para SST, de 5,63 unidades logarítmicas para CT, de 5,57 unidades logarítmicas para CF, de 47\% para DBO e de 52\% para DQO (Metcalf e Eddy, 2007).

Ravazinni et al. (2012) relatam que os resultados das concentrações do permeado para microfiltração de efluente de Tanque Séptico foram $8,8 \mathrm{mg} / \ell$ para DQO, 4,2 $\mathrm{mg} / \ell$ para DBO, $3,8 \mathrm{mg} / \ell$ para COT, $0,2 \mathrm{mg} / \ell$ para SST e $0,15 \mathrm{uT}$ para Turbidez. 


\section{4 - MATERIAIS E MÉTODOS}

\section{1 - CONSIDERAÇÕES INICIAIS}

Na Figura 4.1 esboçam-se as etapas envolvidas nos Materiais e Métodos da pesquisa realizada, distinguindo a construção das postulações e intercâmbio de informações no andamento físico e cronológico da pesquisa desenvolvida na planta-piloto (PP) e como demonstrado na legenda da Figura 4.1.

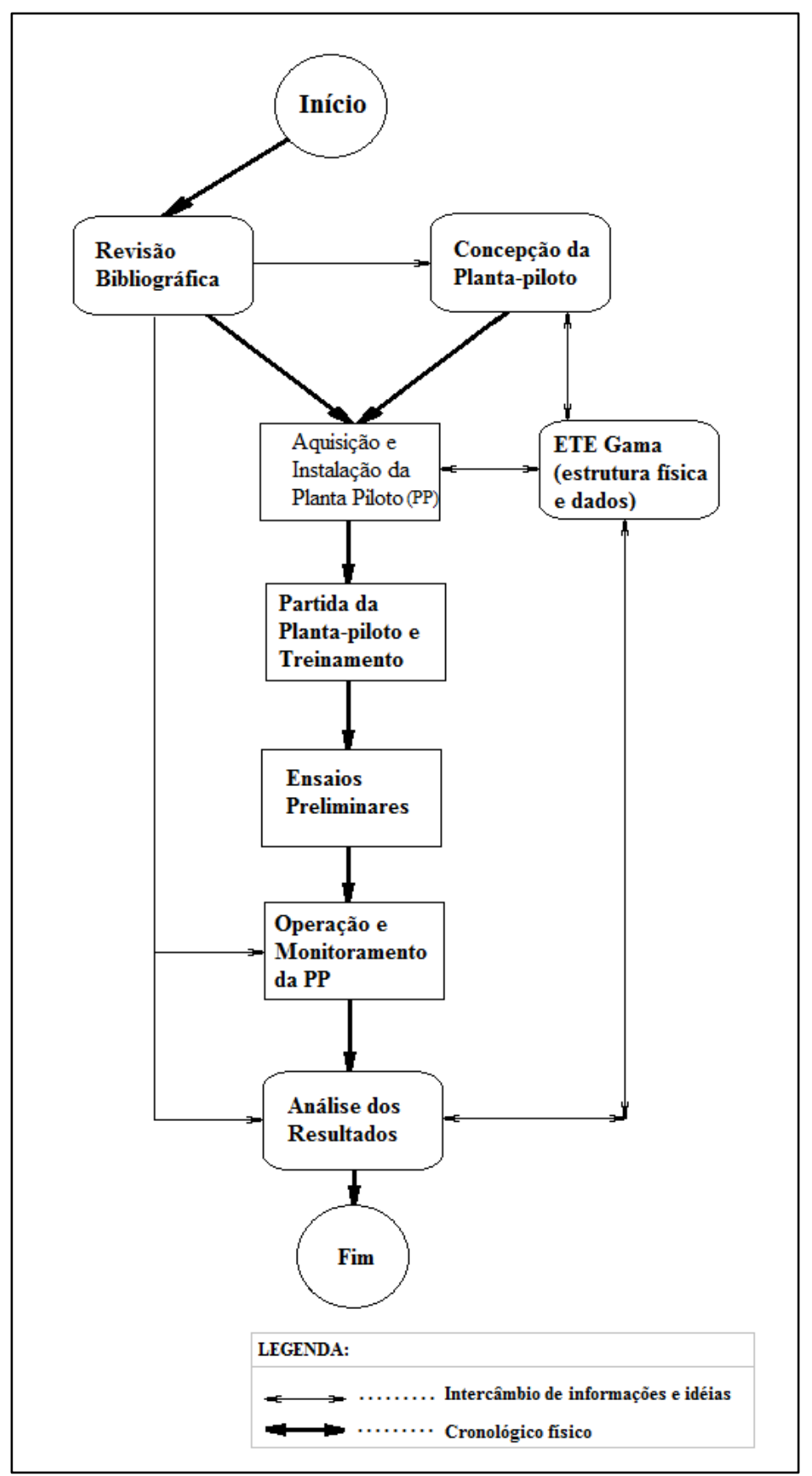

Figura 4.1 - Etapas envolvidas nos Materiais e Métodos desta Pesquisa. 
Na Figura 4.1 é esquematizado como a pesquisa foi realizada, em suas cinco etapas sequenciais, sendo cada fase dedicada a um item da pesquisa, com material e método específicos a serem desenvolvidos, sendo as etapas as seguintes: (i) revisão bibliográfica, (ii) aquisição da planta-piloto (ETE Gama - estrutura e dados), (iii) ensaios preliminares, (iv) partida da planta-piloto e (v) operação e monitoramento da planta-piloto.

Como explicado no esquema da Figura 4.1, algumas etapas do projeto de pesquisa são concorrentes, ou melhor, ocorreram ao mesmo tempo, detalhe da linha mais fina, outras etapas são sequenciais e cronológicas, detalhe da linha mais grossa na Figura 4.1.

As etapas descritas anteriormente geraram ao final de cada uma algum (ns) produto (s), que na Figura 4.1 foram apresentados dentro de caixas com arestas retas. As etapas representadas nas caixas com arestas arredondadas na Figura 4.1, são dedicadas a aquisição, intercâmbio, registros e análises de informações, o que, ao final, também gerou um produto final.

O presente trabalho foi desenvolvido nos seguintes locais:

- Laboratório de Saneamento Ambiental do Programa de Pós-Graduação em Tecnologia Ambiental e Recursos Hídricos, do Departamento de Engenharia Civil e Ambiental, Faculdade de Tecnologia, UnB; onde foram feito as análises laboratoriais.

- Estação de Tratamento de Esgotos do Gama, da CAESB; onde foi montado a planta-piloto de Filtração por Membranas Submersas (FMS) e realizado o experimento.

\section{2 - MATERIAIS}

\subsection{1 - A ETE Gama}

A ETE Gama está localizada no km 20 da rodovia DF $290\left(16^{0} 01,493\right.$ ' Sul e 48 $05,815^{\prime}$ Este), ao sudoeste da cidade do Gama, é uma das 16 ETEs pertencentes ao sistema de esgotamento sanitário do Distrito Federal e operada pela CAESB. A ETE foi projetada para tratar águas residuárias de uma população equivalente de 182.730 habitantes. Na 
Tabela 4.1 são ilustrados alguns dos principais parâmetros utilizados no projeto (CAESB, 2003).

A ETE Gama traz no seu desenho a nova filosofia nacional para tratamento de esgotos sanitários, que associa sequencialmente os processos anaeróbio e aeróbio.

Tabela 4.1 - Principais Parâmetros de Projeto da ETE Gama (fonte: CAESB, 2003)

\begin{tabular}{lll}
\hline Parâmetros & Valores & Unidades \\
\hline Vazão Média $\left(\mathrm{Q}_{\operatorname{med}}\right)$ & 328 & $\ell / \mathrm{s}$ \\
Vazão Máxima $\left(\mathrm{Q}_{\max }\right)$ & 545 & $\ell / \mathrm{s}$ \\
Carga Orgânica Diária & 9.867 & $\mathrm{Kg} \mathrm{DBO} / \mathrm{d}$ \\
Contribuição per capita & 155 & $\ell / \mathrm{hab} . \mathrm{d}$ \\
\hline
\end{tabular}

A ETE Gama lança seu efluente final no Ribeirão Ponte Alta, pertencente à Bacia Hidrográfica do Rio Corumbá. A construção de uma represa a jusante desse lançamento, levou à necessidade do tratamento dos esgotos a nível terciário, por um processo de remoção biológica de nutrientes $(\mathrm{RBN})$ com foco principal no Fósforo.

O reator aeróbio da ETE Gama é classificado como processo BARDENPHO ${ }^{\circledR}$ ou PHOREDOX modificado de cinco estágios (Barnard et al., 1992), com aeração prolongada e co-precipitação, como ilustrado nas Figuras 4.2 e 4.3. Na Figura 4.2 é apresentado um esquema do reator aerado da ETE Gama, onde pode ser verificado que não existe compartimentação física das fases que compõem o processo. Essa configuração não é muito frequente em remoção biológica de nutrientes, mas muito usual em Valos de Oxidação, ou melhor, com hidrodinâmica de fluxo orbital (Qasim, 1999).

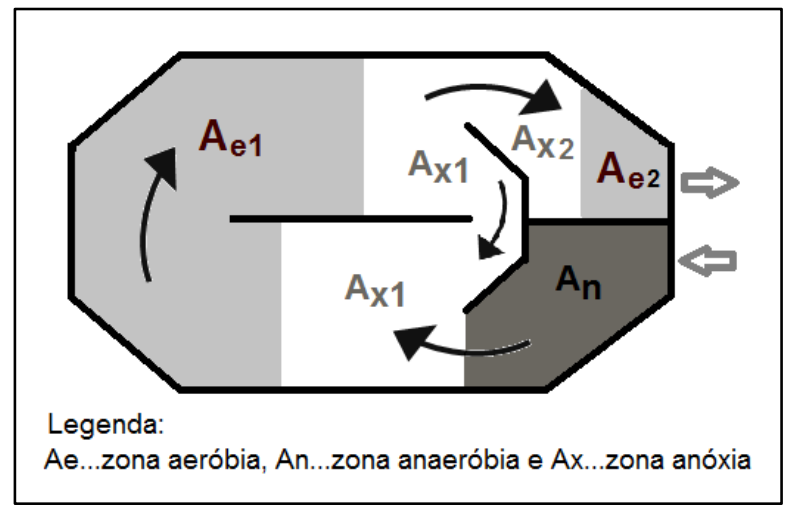

Figura 4.2-Desenho esquemático visto em planta e sem escala do reator aerado da ETE Gama (fonte: Felizatto et al., 2014). 
Na Figura 4.3 apresenta-se o fluxograma de todo o processo de tratamento da ETE Gama, nas suas fases líquida e sólida. Na fase líquida pode-se observar a adição de coagulante metálico, Sulfato de Alumínio líquido, com vistas à coprecipitação de Fósforo.

A configuração das unidades de tratamento da ETE Gama é a seguinte: Tratamento Preliminar (Grade Grosseira de limpeza manual de abertura de 2", três Esteiras de Peneiramento Mecânico de abertura $3 \mathrm{~mm}$ ), quatro reatores UASB e dois reatores aerados com dois clarificadores por reator.

$\mathrm{Na}$ fase sólida, o adensamento do lodo aeróbio descartado é realizado pelo processo de flotação - FAD. Essa etapa ainda possui um reservatório de lodos (anaeróbio e aeróbio adensado), desaguamento mecanizado de lodos por centrifugação e o decantador e adensador de lodo (DAD). O lodo de esgotos desaguado produzido é estocado temporariamente em galpão coberto.

O projeto da ETE Gama estipulou as características das águas residuárias em cada etapa do processo de tratamento, conforme demonstrado na Tabela 4.2; observa-se como características químicas: matéria carbonácea (DQO, DBO e SST) e nutrientes $\left(\mathrm{P}_{\mathrm{T}}, \mathrm{N}_{\mathrm{T}}\right.$, $\mathrm{NH}_{4}{ }^{+}$e $\mathrm{NO}_{3}{ }^{-}$); características físicas ( $\mathrm{pH}$ e Temperatura) e microbiológica (CF).

Tabela 4.2 - Características da Qualidade da Água preconizadas no projeto da ETE Gama (fonte CAESB, 2003)

\begin{tabular}{lllll}
\hline Variáveis & Unidade & Afluente & $\begin{array}{l}\text { Efluente } \\
\text { UASB }\end{array}$ & $\begin{array}{l}\text { Efluente } \\
\text { Final }\end{array}$ \\
\hline $\mathrm{DQO}$ & $\mathrm{mg}-\mathrm{O}_{2} / \ell$ & 580 & $246-333$ & $\leq 125$ \\
$\mathrm{DBO}$ & $\mathrm{mg}-\mathrm{O}_{2} / \ell$ & 348 & $148-200$ & $\leq 50$ \\
$\mathrm{SST}$ & $\mathrm{mg} / \ell$ & 290 & $74-100$ & - \\
$\mathrm{N}_{\mathrm{T}}$ & $\mathrm{mg}-\mathrm{N} / \ell$ & 56,0 & $38-51$ & $\leq 10,0$ \\
$\mathrm{P}_{\mathrm{T}}$ & $\mathrm{mg}-\mathrm{P} / \ell$ & 8,20 & $5,20-7,10$ & $\leq 1,00$ \\
$\mathrm{NH}_{4}{ }^{-}$ & $\mathrm{mg}-\mathrm{N} / \ell$ & 35,0 & s.v. & s.v. \\
$\mathrm{NO}_{3}{ }^{-}$ & $\mathrm{mg}-\mathrm{N} / \ell$ & 0,04 & s.v. & s.v. \\
$\mathrm{pH}$ & $\mathrm{s.v}$ & s.v. & s.v. & $5,0-9,0$ \\
$\mathrm{~T}$ & ${ }^{\circ} \mathrm{C}$ & s.v. & s.v. & $\leq 40$ \\
$\mathrm{CF}$ & $\mathrm{NMP} / 100 \mathrm{~m} \ell$ & $10^{7}$ & s.v. & s.v. \\
\hline
\end{tabular}

Legenda: s.v....sem valor especificado 


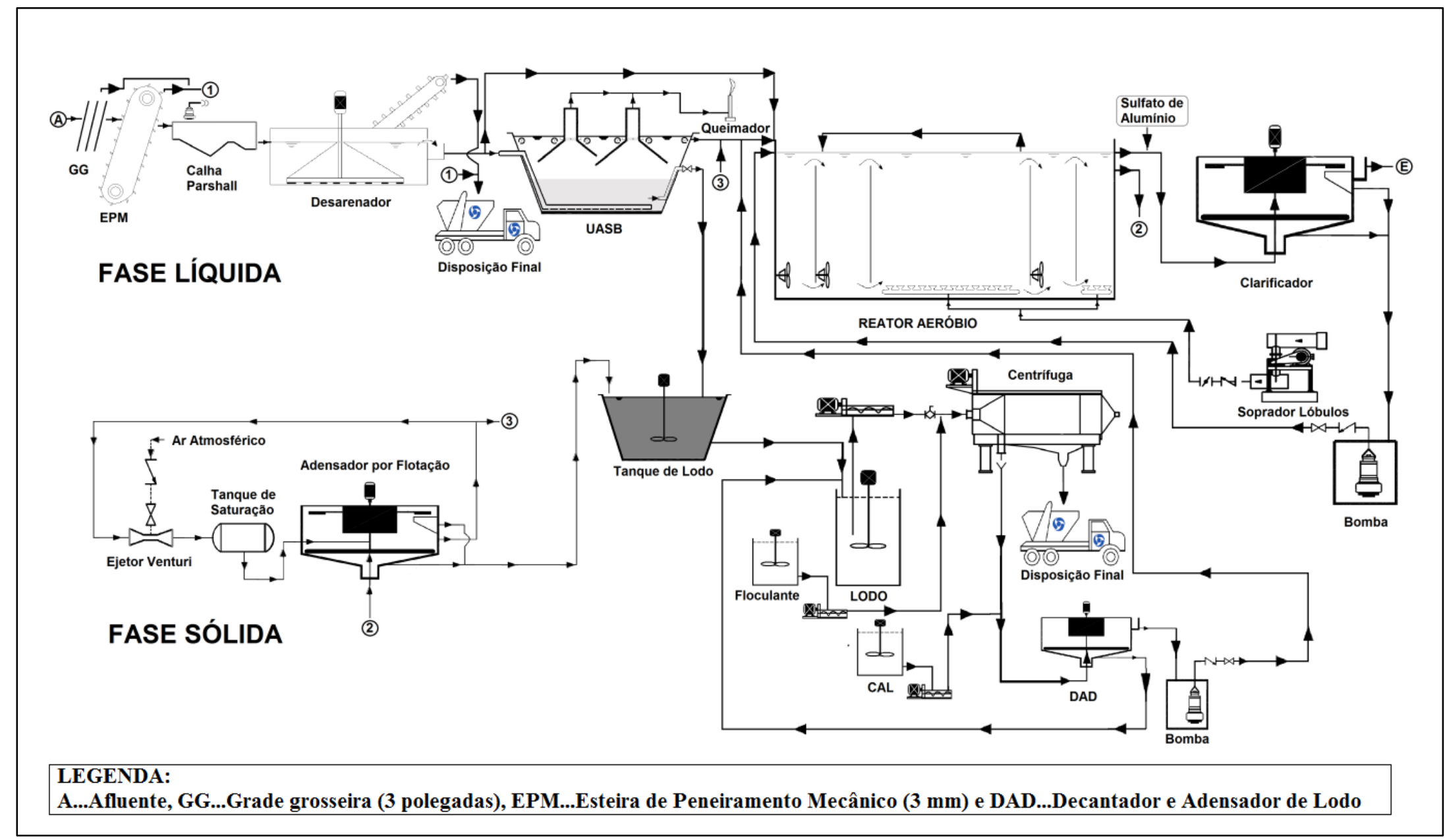

Figura 4.3 - Fluxograma da Estação de Tratamento de Esgotos do Gama (fonte: Felizatto et al., 2014). 
O programa de monitoramento do desempenho operacional é efetuado duas vezes por semana, por meio de coletas compostas realizadas durante 24 horas, com alíquotas tomadas de duas em duas horas, destacando algumas variáveis, conforme é descrito na Tabela 4.3. Todas as marchas analíticas utilizadas seguem o preconizado pela APHA/AWWA/WPCF (2005).

Tabela 4.3 - Variáveis de controle operacional e métodos empregados na avaliação da ETE Gama (fonte: Felizatto et al., 2014).

\begin{tabular}{ll}
\hline Variáveis & Método \\
\hline DBO $\left(\mathrm{mg}-\mathrm{O}_{2} / \ell\right)$ & Manométrico \\
DQO $\left(\mathrm{mg}-\mathrm{O}_{2} / \ell\right)$ & Digestão em refluxo fechado - leitura titulométrica \\
Sólidos em Suspensão totais $(\mathrm{mg} / \ell)$ & Gravimétrico \\
$\mathrm{NTK}(\mathrm{mg}-\mathrm{N} / \ell)$ & Método Micro-Kjeldähl \\
$\mathrm{NO}_{\mathrm{x}}(\mathrm{mg}-\mathrm{N} / \mathrm{l})$ & Filtração/Método da coluna de Cádmio \\
$\mathrm{P}_{\mathrm{T}}(\mathrm{mg}-\mathrm{P} / \ell)$ & Digestão Persulfato de Potássio/ $\mathrm{H}_{2} \mathrm{SO}_{4}$, Redutor \\
& Cloreto Estanoso \\
$\mathrm{CF}(\mathrm{NMP} / 100 \mathrm{~m} \ell)$ & Método dos Tubos Múltiplos (Substrato A1) \\
\hline
\end{tabular}

Na Tabela 4.4 apresenta-se o histórico dos dados de desempenho só para o efluente dos reatores $U A S B$ da ETE Gama, onde se observam as remoções de $81 \%$, 67\% e 30\%, para DBO, DQO e SST, respectivamente. Os dados apresentados na Tabela 4.4 confirmam que nos reatores anaeróbios não ocorre a remoção de nutrientes, Nitrogênio e Fósforo, como já esperado.

Tabela 4.4 - Histórico do desempenho dos reatores tipo UASB da ETE Gama do período de janeiro/2007 a julho/2014

\begin{tabular}{|c|c|c|c|}
\hline Variáveis* & Afluente & Efluente $U A S B$ & Remoção Média \\
\hline $\mathrm{DBO}$ & $\begin{array}{c}403 \\
(100-960)\end{array}$ & $\begin{array}{c}77 \\
(10-160)\end{array}$ & $81 \%$ \\
\hline DQO & $\begin{array}{c}778 \\
(62-2.464)\end{array}$ & $\begin{array}{c}255 \\
(55-820)\end{array}$ & $67 \%$ \\
\hline SST & $\begin{array}{c}252 \\
(83-680)\end{array}$ & $\begin{array}{c}117 \\
(14-590)\end{array}$ & $30 \%$ \\
\hline NTK & $\begin{array}{c}58,5 \\
(17,5-117,7)\end{array}$ & $\begin{array}{c}59,5 \\
(19,1-94,2)\end{array}$ & - \\
\hline $\mathrm{P}_{\mathrm{T}}$ & $\begin{array}{c}8,93 \\
(2,70-30,63)\end{array}$ & $\begin{array}{c}10,14 \\
(3,00-30,63)\end{array}$ & - \\
\hline $\mathrm{PO}_{4}^{-2}$ & - & $\begin{array}{c}6,24 \\
(1,5-12,96)\end{array}$ & - \\
\hline $\mathrm{CF}^{* *}$ & $\begin{array}{c}4,95 \cdot 10^{+7} \\
\left(3,3 \cdot 10^{+6} \text { a } 1,6 \cdot 10^{+9}\right)\end{array}$ & - & - \\
\hline
\end{tabular}




\subsection{2 - A Planta Piloto}

\subsubsection{1 - Local da instalação}

A unidade de filtração por membranas submersas (FMS) foi instalada na Casa de Química da ETE Gama, como pode ser observado na Figura 4.4, em particular a instalação de uma janela e de uma porta metálica confeccionada com chapa "moeda" (material vasado) com a possibilidade de limitar o acesso por trancamento (via cadeado).

A edificação foi escolhida de propósito por ter o espaço necessário para instalar a unidade FMS, por estar em nível topográfico abaixo da caixa de saída do efluente dos reatores $U A S B$ A e B da ETE Gama, por possuir quadro elétrico para ligação e fornecimento de energia elétrica e também por fornecer estruturas básicas de segurança como pode ser visualizado na Figura 4.4, por meio de: (i) lava-olhos instalados, (ii) extintor de incêndio em local de fácil acesso e (iii) quadro do sistema elétrico protegido por para-raios, além de possuir fornecimento de água potável da CAESB.

Toda a instalação hidráulica e elétrica foi feita por equipe de funcionários da CAESB lotados na ETE Gama.

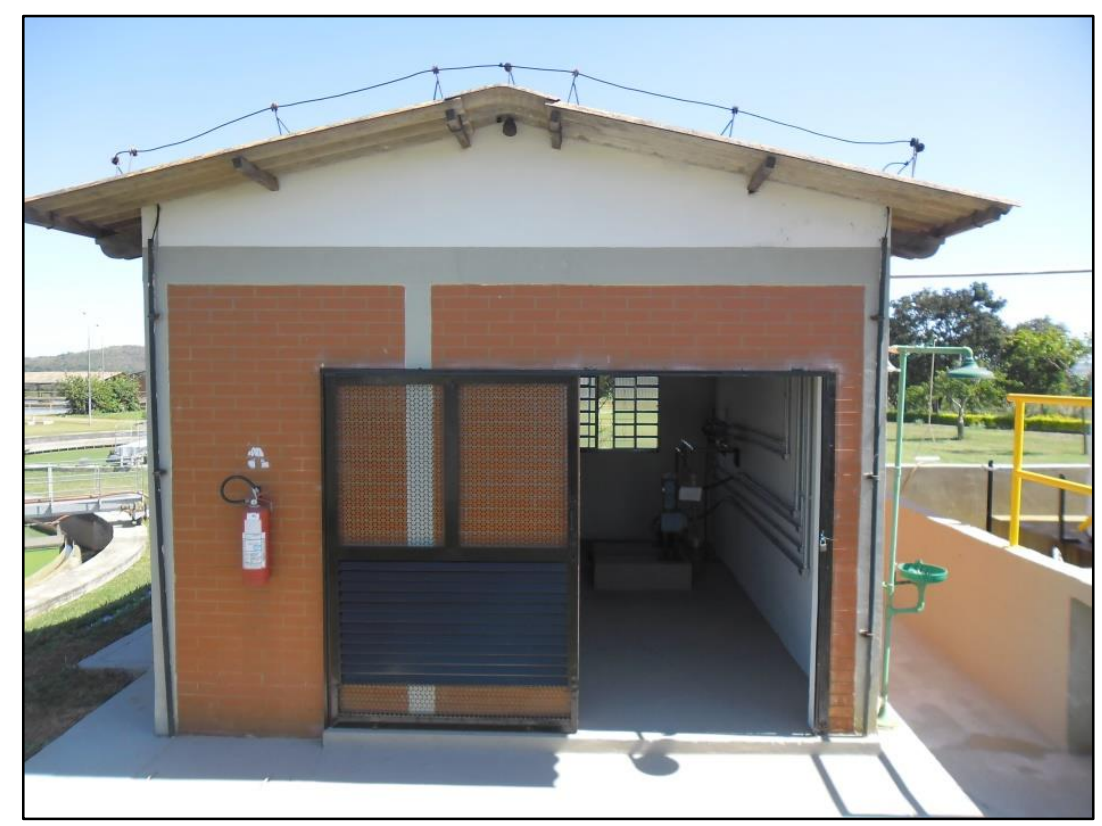

Figura 4.4 - Edifício de instalação da Planta-piloto FMS-PTARH/UnB/RENTED/CAESB Casa de Química da ETE Gama. 
A Figura 4.5 apresenta a fotografia na qual pode ser verificado onde ocorreu a instalação da unidade FMS, no interior da Casa de Química da ETE Gama.

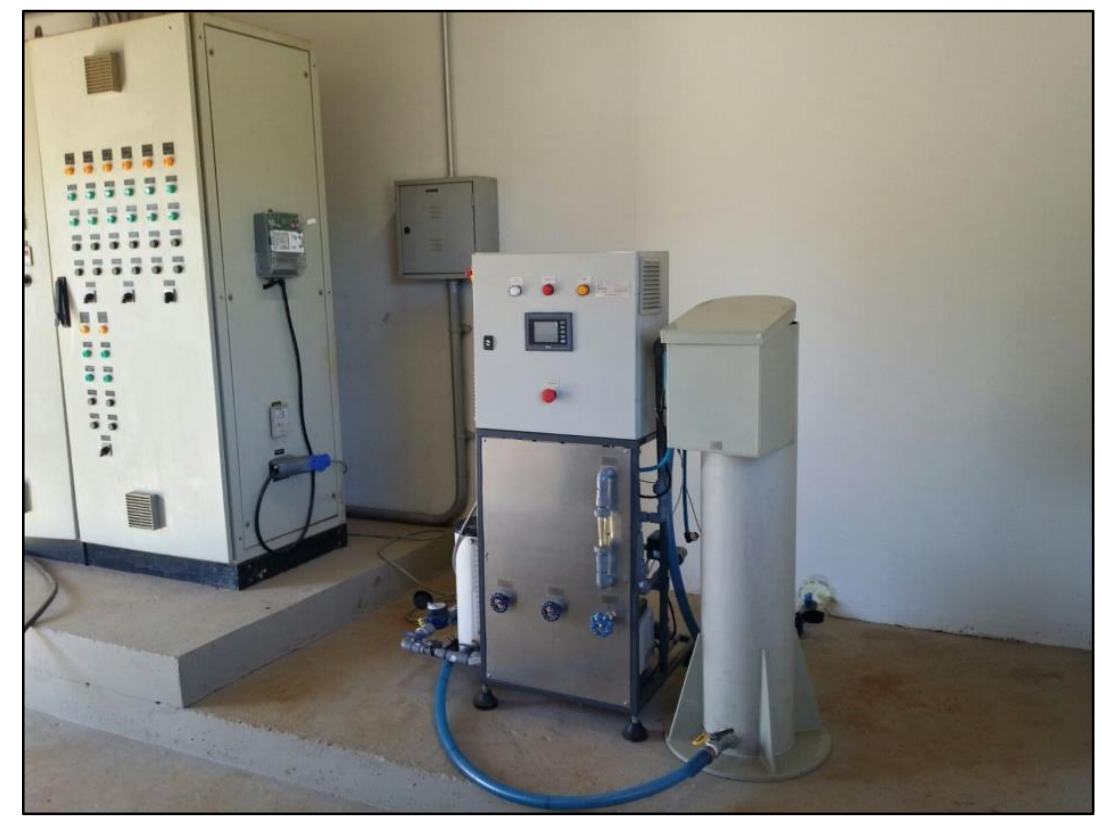

Figura 4.5 - Planta-piloto FMS PTARH-UnB-RENTED/CAESB instalada no interior da Casa de Química da ETE Gama. Detalhe do Medidor de energia elétrico instalado na lateral do console do quadro elétrico já existente.

\subsubsection{2 - Rede de recalque}

A bomba utilizada foi a do tipo submersível modelo XKS-401PW de marca Ferrari, vazão de $3.600 \mathrm{l} / \mathrm{h}$ e altura manométrica de $6 \mathrm{~m}$, que, segundo especificações do fabricante em seu catálogo da bomba, é ideal para esgotamento, drenagem ou transferência de água turva em porões, reservatórios, caixas e cisternas, podendo conter partículas de até $3 \mathrm{~mm}$. A bomba pode ser visualizada na Figura 4.6.

A bomba vem acompanhada dos seguintes itens instalados: sensor de nível automático integrado, protetor térmico, cabo elétrico com 10 m, sucção inferior, corpo leve em PVC, rotor d’água em Noryl, alça e motor IP-68 que funciona em 220 V monofásico e potência de $0,5 \mathrm{cv}(370 \mathrm{~W})$.

A vazão bombeada, em torno de $1,1 \mathrm{~m}^{3} / \mathrm{h}$, foi importante para simular a instalação do módulo de membrana no interior do clarificador do reator $U A S B$ ou em um tanque próximo a saída do efluente a ser permeado. 


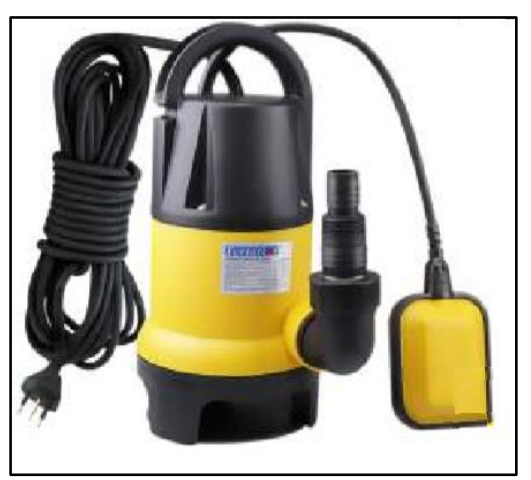

Figura 4.6 - Bomba submersível modelo XKS-401PW do fabricante Ferrari.

Para o pré-tratamento (peneiramento fino), foi idealizado e concebido o uso de filtros em "Y" (abertura 0,5 mm) da marca DECA, de diâmetro de 64 mm.

Na Figura 4.7 apresenta-se o desenho em corte do Filtro em "Y", com as seguintes especificações: (i) aplicado em indústrias para uso de filtração para óleo e vapor saturado em alta pressão, (ii) fornecido em diâmetros de $1 / 2$ " à 3", (iii) fabricado em bronze (corpo, tampa e tampão) e aço inox (tela metálica) e (iv) tela metálica cilíndrica com 95 furos por $\mathrm{cm}^{2}$ e diâmetro do furo de $0,5 \mathrm{~mm}$. Como adaptação, o Filtro "Y" foi utilizado na pesquisa para desempenhar o pré-tratamento, com a função do peneiramento fino. A etapa de peneiramento é efetuada por dois Filtros em "Y", operando em paralelo ou não, como pode ser verificado na Figura 4.4. A ideia e a montagem do "trem" com os dois Filtros "Y" foram da equipe da ETE Gama.

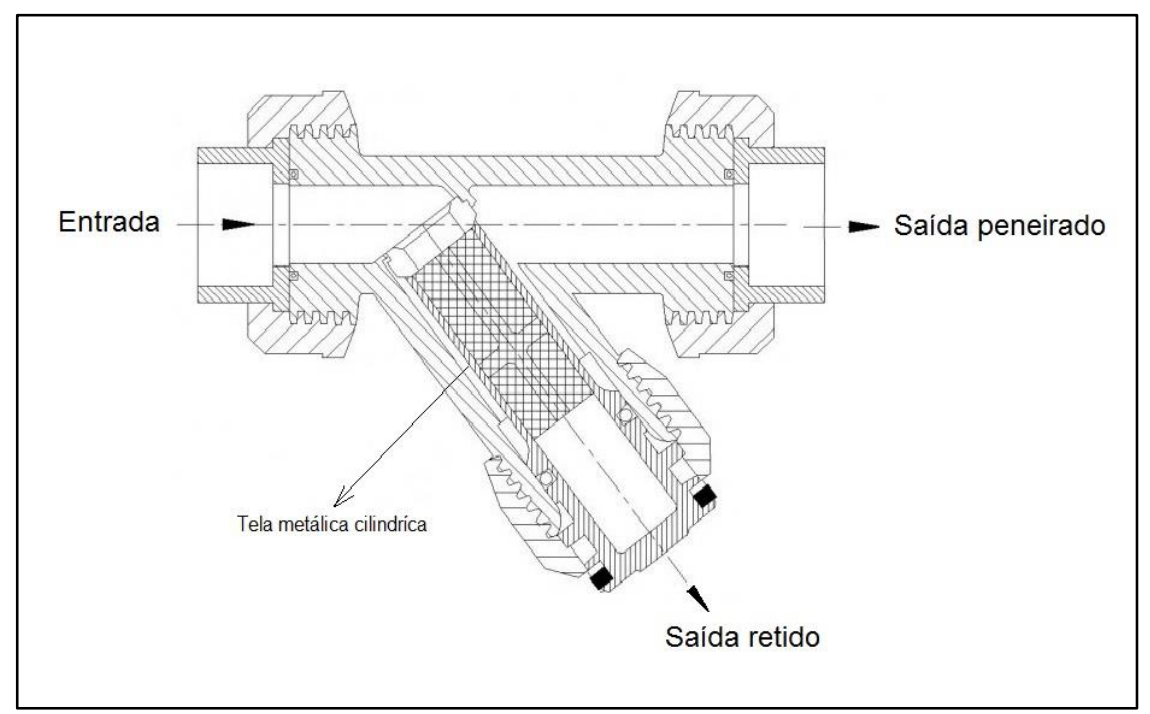

Figura 4.7 - Croqui (sem escala) em corte do Filtro em "Y", fabricante DECA, em destaque a tela metálica cilíndrica perfurada com diâmetros dos furos de 0,5 mm. 
Os filtros foram instalados em dois tramos independentes e iguais, como se pode verificar, o tramo "A", no lado direito da fotografia mostrada na Figura 4.8, e o tramo "B" do lado esquerdo. A instalação do peneiramento fino foi localizada próxima ao poço de bombeamento da rede de recalque da planta-piloto, como ilustrado na Figura 4.8.

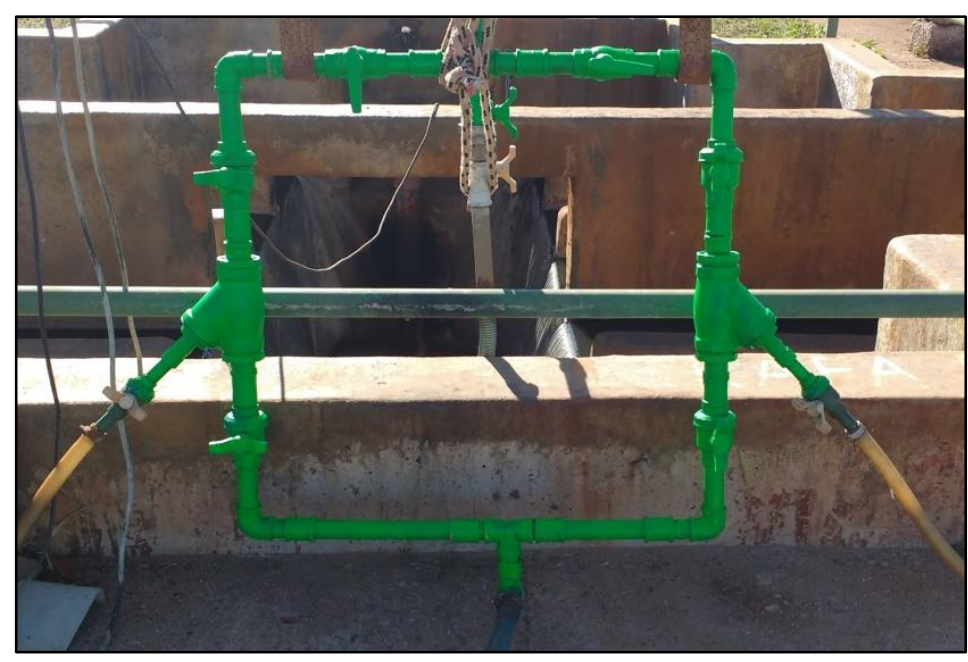

Figura 4.8 - Fotografia do local do poço de bombeamento da rede de recalque da Plantapiloto FMS - PTARH/UnB/RENTED/CAESB e da instalação do pré-tratamento (peneiramento fino). Caixa de passagem do efluente do reator anaeróbio A e B da ETE Gama.

Todos os tubos e acessórios (registros, válvulas, cotovelos, juntas de união e tês) usados na rede de recalque foram de PVC de $32 \mathrm{~mm}$, soldável.

Em algumas partes da rede de recalque, a tubulação utilizada foi a mangueira de plástico corrugado de $32 \mathrm{~mm}$ para facilitar a manipulação, e os pontos da rede onde esse tipo de mangueira foi montado são: (i) saída da bomba submersa até o "trem" de peneiramento fino, (ii) saída do "trem" de peneiramento fino até o início do tubo enterrado de PVC, (iii) na alimentação ao TQ01 (Tanque com membranas submersas) após o hidrômetro ultrassônico e (iv) no descarte localizado no fundo do TQ01 (Tanque com membranas subemersas). Esses detalhes podem ser verificados nas Figuras 4.8 e 4.9. Na Figura 4.9 pode ser visto em detalhe os dois hidrômetros ultrassônicos instalados na alimentação ao TQ01 (Tanque com membranas submersas) e na saída no descarte de fundo do mesmo tanque. 


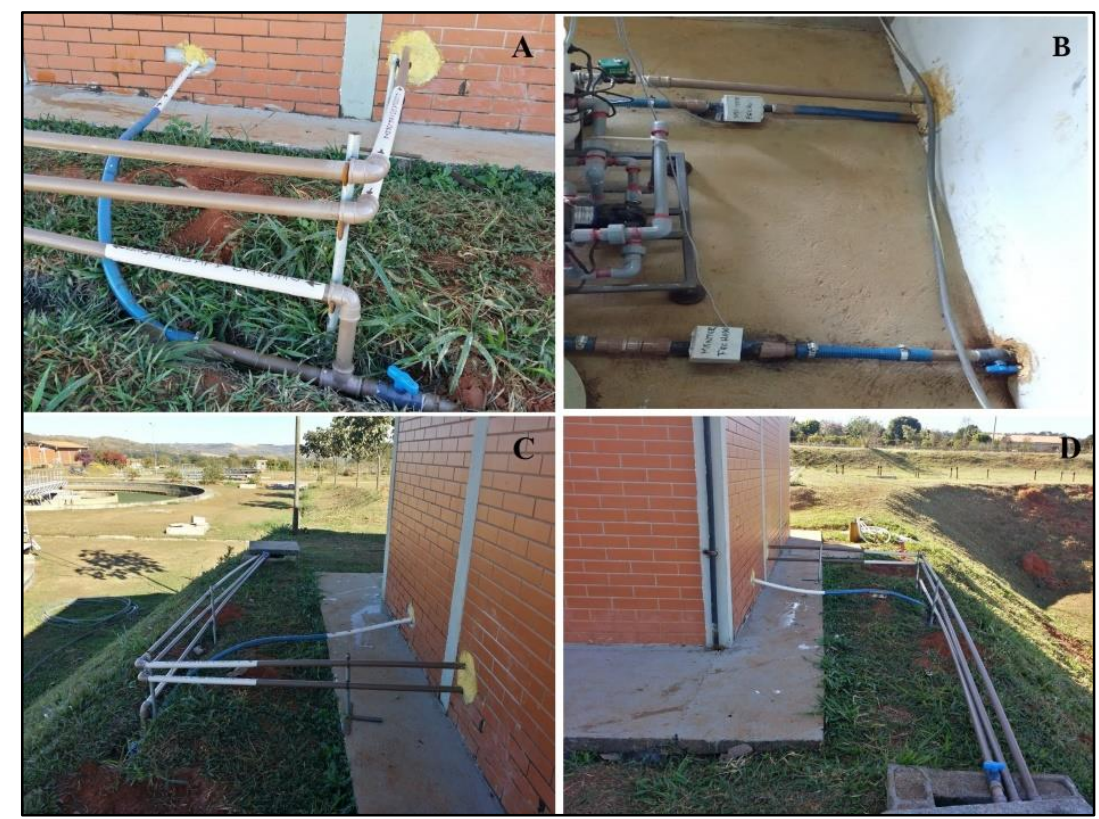

Figura 4.9 - Redes de alimentação e saída (permeado e descarte de fundo do Tanque 01-

Tanque com membranas) da FMS - PTARH/UnB/RENTED/CAESB.

Legenda das fotos: A...vista externa em frente a parede da Casa de Química; B...vista interna em frente a parede no interior da Casa de Química no sentido do Clarificador D; D...vista externa lateral a parede da Casa de Química no sentido dos reatores anaeróbios $U A S B$ C...vista externa lateral a parede da Casa de Química no sentido do Clarificador D; D...vista externa lateral a parede da Casa de Química no sentido dos reatores anaeróbios $U A S B$.

\subsubsection{3 - Medidor de Energia Elétrica}

Para a medição de energia elétrica, foi instalado o Medidor eletrônico de energia elétrica, ativa e reativa, polifásico e unidirecional, modelo E650 8602-B da marca LANDIS+GYR com classe de exatidão B. Segundo o fabricante, as características metrológicas do medidor são: (i) tensões nominais de $120 \mathrm{~V}$ e $240 \mathrm{~V}$; (ii) corrente nominal de $15 \mathrm{~A}$; (iii) corrente máxima de 120; (iv) frequência nominal de $60 \mathrm{~Hz}$; (v) número de elementos de 2 e 3; (vi) número de fios: de 3 e 4; (vii) número de fases de 2 e 3; (viii) constante de calibração de 4,0 W-h/pulso e 4,0 var-h/pulso; (ix) constante eletrônica de 2,0 W-h/pulso e 2,0 varh/pulso. O medidor possui transmissão de dados acumulados via infravermelho por cabo USB, para transmissão das informações para computador portátil. O medidor já instalado é ilustrado na fotografia da Figura 4.5. 


\subsubsection{4 - Unidade de Filtração por Membranas Submersas}

A Planta Piloto projetada, configurada, e instalada na ETE Gama, é constituída de um sistema de microfiltração submersa com capacidade nominal do fabricante de $60 \mathrm{l} / \mathrm{h}$ de permeado (efluente final) e é de fornecimento da empresa brasileira PAM Membranas Seletivas Ltda. (www.pam-membranas.com.br).

São características das membranas utilizadas no sistema: (i) tipo fibra oca, (ii) cilíndricas, (iii) material poli(éter imida), (iv) diâmetro externo de 0,9 a $1,0 \mathrm{~mm}$, (v) fibras com camada seletiva externa e (vi) tamanho médio dos poros de $0,4 \mu \mathrm{m}$, segundo o fabricante.

Foram fornecidos dois módulos de cabeçotes duplos de fibras ocas de área de membrana igual a $6 \mathrm{~m}^{2}$, um sem identificação e outro identificado como 716 . O certificado de qualidade do módulo 716, $\mathrm{N}^{\mathrm{o}} 1451$ - Anexo 1, fornece o valor da permeabilidade hidráulica (K) de 167,0 LHM/bar com testes executados com água da concessionária de abastecimento do Rio de Janeiro (CEDAE), previamente microfiltrada. O teste de integridade efetuado pela PAM Membranas no módulo 716 foi feito de maneira indireta por filtração de solução de amido de milho a $1,0 \mathrm{~g} / \ell$, por meio da medição da turbidez da alimentação e do permeado, com rejeição certificada de 99,9\% (3 unidades logarítmicas).

A Figura 4.10 demonstra o sistema em um fluxograma de processo, apresenta a instrumentação da planta-piloto e os pontos de coleta de amostras que foram utilizados. O efluente do reator tipo $U A S B$, depois de recalcado, passa pelo peneiramento fino, onde é filtrado através de telas metálicas com abertura de 0,5 mm do Filtro em "Y".

A planta-piloto de Filtração direta por Membranas Submersas (FMS), como pode ser observado no fluxograma da Figura 4.10, é composta pelos seguintes elementos principais:

1. Tanque onde está instalado o módulo de membranas (TQ01), com volume de $30 \ell$;

2. Chaves de níveis do TQ01 (LSH e LSL);

3. Módulo de membranas com $6 \mathrm{~m}^{2}$;

4. Bomba de sucção do permeado e de retrolavagem dotada de dispositivo eletrônico para controle de rotação do motor (BC01);

5. Medidores de vazão das correntes do processo (FI);

6. Medidor de pressão (PI); 
7. Soprador de ar com controle e medição de vazão (SP01);

8. Válvulas solenoides de três vias (duas - VT01 e VT02), com acionamento elétrico, controladoras de fluxo que permitem alteração automática das operações de filtração e retrolavagem do módulo de membranas submersas

9. Válvula solenoide de duas vias com acionamento elétrico para controle de fluxo (VS01);

10. Tanque de limpeza, onde é armazenado o permeado (TQ02), com volume de $10 \ell$; $\mathrm{e}$

11. Chaves de níveis do TQ02 (LSLL, LSL, LSH e LSHH).

A etapa de separação origina duas correntes: concentrado e permeado. A corrente de permeado, que flui pelos poros da membrana é direcionada para um tanque de armazenamento da unidade (TQ02).

A unidade contém uma bomba (BC01) de dupla função: filtração e retrolavagem (limpeza das membranas). Na filtração, a bomba succiona o efluente microfiltrado, sendo parte acumulado em um tanque para o processo de limpeza. Na função de limpeza, a bomba succiona o líquido microfiltrado e o bombeia no sentido de dentro para fora das membranas, no procedimento da retrolavagem, o que permite a remoção de particulados que possam obstruir os poros da membrana.

A planta-piloto foi confeccionada para operar como um biorreator aeróbio com membranas, pois possui um soprador que é sempre acionado seja na operação manual ou automática. Esta aeração com bolhas grossas pode também servir como alternativa para a etapa de relaxamento, a fim de minimizar as incrustações, se for utilizada na etapa de retrolavagem, ou garantir maior eficiência na etapa de limpeza periódica das membranas.

A unidade conta com transmissor de pressão, transmissor de vazão, chaves de nível, válvulas, controlador de velocidade, CLP (controlador lógico programável) e IHM (Interface Homem Máquina), pela qual ela pode ser monitorada e controlada. 


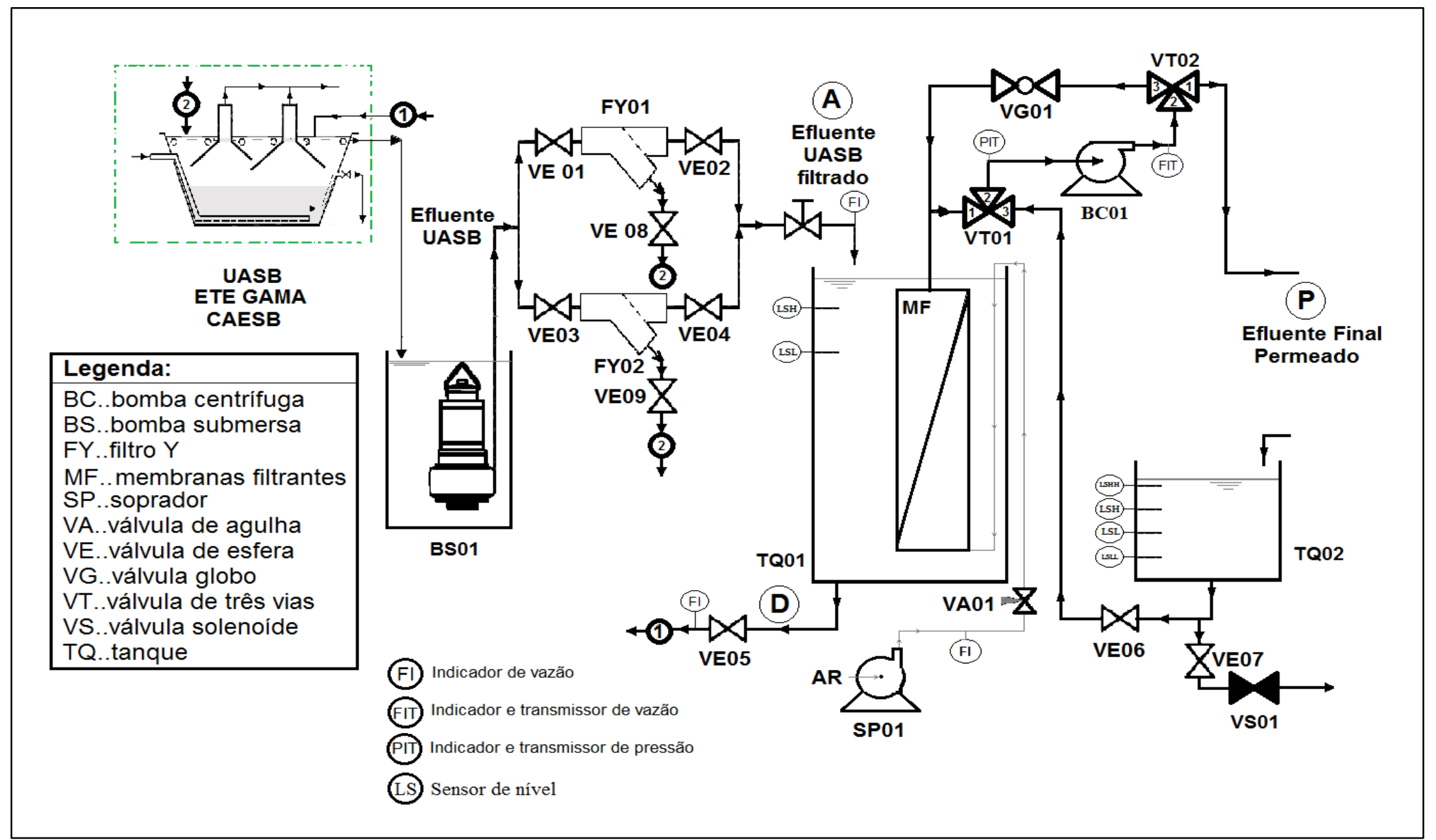

Figura 4.10 -Fluxograma da Planta-piloto FMS - PTARH-UnB/CAESB.

Legenda dos Pontos de coleta de amostras: A. Alimentação ao TQ01 (Efluente UASB filtrado), P. Permeado ou Efluente Final e D. Descarte do tanque com membranas submersas - TQ01. 
Todo controle do sistema segue a lógica do diferencial de pressão, conforme a necessidade de operação, que é efetuado pelo transmissor e indicador de pressão (PIT) mostrado na Figura 4.10. Segundo o fabricante, durante a operação (filtração/retrolavagem), deve existir a possibilidade de fixar as pressões pelo operador/programador com valores máximos para filtração de $-1,0$ bar e para retrolavagem de $+1,0$ bar.

O sistema contém intertravamento, visando à manutenção do nível adequado nos tanques, sendo eles:

1- Nível alto e baixo (LSH e LSL) localizados no TQ 01, ilustrados na Figura 4.10, que realizam o acionamento da bomba $\mathrm{BC} 01$, da seguinte maneira:

○ Quando o nível alto é acionado (LSH), a bomba pode ser ligada para filtração e é desligada para retrolavagem, emitindo um alerta de NÍVEL ALTO no TQ01 na tela do sistema supervisório; e

○ Quando o nível baixo (LSL) é acionado, a bomba pode ser ligada para a retrolavagem é desligada para filtração, emitindo um alarme de NÍVEL BAIXO no TQ01 na tela do sistema supervisório.

2- Nível alto e alto-alto (LSHH e LSH) localizados no TQ02, demonstrados na Figura 4.10, que realizam o acionamento da $\mathrm{BC} 01$, da seguinte forma:

○ Quando o nível alto-alto (LSHH) é acionado, a válvula solenoide (VS01) é ligada e ocorre a paralização da operação, na filtração e na retrolavagem; e

○ Quando o nível alto (LSH) é acionado, a válvula solenoide é desligada, sendo apresentado na tela do supervisório o valor acumulado de permeado, somando o valor de $2,5 \ell$ (a confirmar após montagem das chaves de nível) a cada ciclo de abertura/fechamento da válvula. O volume é cumulativo a cada ciclo de abertura e fechamento da VS01 da Figura 4.5.

3- Nível baixo e baixo-baixo (LSL e LSLL) localizados no tanque TQ02, apresentados na Figura 4.10, que realizam o acionamento da bomba BC01 da seguinte forma: 
○ Quando o nível baixo (LSL) é acionado a bomba BC01 pode ser ligada para retrolavagem, emitindo o sinal de NÍVEL BAIXO no TQ02 na tela do sistema supervisório; e

○ Quando o nível baixo-baixo (LSLL) é acionado, a bomba é desligada para a retrolavagem.

\section{3 - MÉTODOS}

A pesquisa foi realizada em cinco etapas: (i) revisão bibliográfica; (ii) aquisição e instalação da planta-piloto (ETE Gama - estrutura física e dados); (iii) partida da plantapiloto e treinamento; (iv) ensaios preliminares e (v) operação e monitoramento da plantapiloto, como já considerado anteriormente e ilustrado na Figura 4.1.

\subsection{1 - Revisão bibliográfica}

A revisão bibliográfica foi efetuada através da leitura de livros impressos, livros digitais e artigos técnicos digitais de revistas especializadas.

Os principais artigos técnicos levantados em revistas especializadas foram obtidos pelo acesso do aluno-UnB no portal de periódicos da CAPES-CNPq e também alguns downloads ocorreram diretamente da rede mundial de computadores.

Os livros consultados foram, em grande maioria, digitais e também baixados da rede mundial de computadores. Alguns livros impressos também foram consultados.

\subsection{2 - Aquisição e instalação da planta-piloto}

$\mathrm{Na}$ concepção desta pesquisa, teve-se a intenção de usar uma planta-piloto de microfiltração com a finalidade de um tratamento posterior ao reator anaeróbio do tipo $U A S B$, para se ter respostas tecnicamente testadas sobre a viabilização da tecnologia de membranas no que diz respeito ao controle da incrustação, e para, por meio de testes, estabelecer protocolo de operação (filtração/retrolavagem) e de limpeza periódica. 
Uma das atividades desta etapa foi pesquisar fornecedores capazes de conceber uma planta-piloto para o tratamento de esgotos sanitários de parte de uma população equivalente de 4 a 5 habitantes, ou melhor, produzindo $60 \mathrm{l} / \mathrm{h}$ de permeado, e sendo uma estação compacta, automatizada, instalada em plataforma e que atendesse aos custos de aquisição para trabalhos realizados em pesquisas acadêmicas.

Outro fato relevante, com relação a escolha da microfiltração, é que se considerou a finalidade do permeado, que, por tal operação, ele possa ter viabilidade técnica e econômica para ser utilizado em reúso de água em irrigação sem restrições. Nesse sentido, destaca-se que a ETE Gama, por estar instalada em zona rural com agricultores irrigantes, já tem atrativos para produção de água recuperada para o reúso em irrigação.

Como o sistema anaeróbio de tratamento não remove nitrogênio e nem fósforo, o projeto de pesquisa ainda traria mais valor ao permeado, uma vez que, para agricultura, este líquido já viria nutrido, no caso do reúso de água em irrigação.

A construção e o fornecimento da planta-piloto couberam à empresa do Rio de Janeiro, PAM Membranas Seletivas Ltda., já referenciada anteriormente.

A instalação da planta-piloto coube a equipe envolvida na pesquisa do quadro de funcionários da CAESB/ETE Gama.

Nesta etapa, executou-se a rede de recalque da planta-piloto e foram desenvolvidas as seguintes atividades: aquisição e instalação dos componentes do sistema de recalque (bomba, peneiramento, tubulação e acessórios) para conduzir o efluente do reator $U A S B$ até a planta piloto, sendo que este efluente passava em primeiro lugar pelo peneiramento fino como ilustrado na Figura 4.4.

Ainda nesta etapa, providenciou-se o sistema de medição do consumo de energia elétrica e foram realizadas as seguintes atividades: (i) levantamento de fornecedores de medidor de kW-h com acesso dos dados via infravermelho, (ii) especificação para a potência instalada da planta-piloto, (iii) aquisição, (iv) instalação do medidor de energia elétrica digital no local escolhido para instalar a planta-piloto e (v) treinamento do uso do programa de aquisição de dados do medidor de energia elétrica. 


\subsection{3 - Partida da planta-piloto e treinamento}

Nesta etapa, foi realizado o estudo do manual de operação, a energização da planta-piloto através da ligação e testes nos principais equipamentos (bomba de sucção, soprador, válvulas solenoides de três vias) que compõem a estação compacta, através de comandos feitos na IHM (Interface Homem Máquina).

Neste estágio, se procedeu ao início de funcionamento da planta-piloto, ou start-up, que ocorreu nos dias 29 e 30 de julho de 2015, com a presença de um engenheiro da empresa fornecedora (PAM Membranas Seletivas Ltda.), quando foi feito o comissionamento da unidade através de um treinamento teórico ocorrido no miniauditório da sede da CAESB e prático no local de instalação da unidade, a ETE Gama.

A partir deste momento, foi feita a abertura do livro de ocorrências, tipicamente usado na operação de tratamento de esgotos sanitários na CAESB, com o propósito de relatar oficialmente os acontecimentos transcorridos ao longo da temporada da realização desta pesquisa.

De 03/agosto a 20/novembro/2015, foi efetuado o treinamento da equipe na operação da planta-piloto, onde se verificou em detalhes quais seriam os melhores procedimentos para otimizar os testes na unidade de filtração por membranas. Neste período, a operação foi efetuada utilizando o módulo fornecido sem identificação e a operação da planta-piloto foi efetuada nos modos automático e manual.

$\mathrm{Na}$ fase de treinamento, foi verificado que: (i) o medidor de vazão, FIT da Figura 4.10, instalado na planta-piloto apresentava variações nas medições na operação filtração, (ii) os valores de vazões medidos e mostrados na tela do supervisório quando confrontados com a medição direta apresentavam erros acima de $40 \%$ e (iii) o fundo de escala do medidor é sempre de 3,2 l/min. Por isso optou-se por efetuar as medidas de vazões neste projeto de pesquisa por medição direta ou também conhecida como "corta-fluxo" ou volumétrica.

A medição direta consiste na determinação do tempo necessário para encher um determinado recipiente de volume conhecido ou previamente aferido. Este método é aplicável a pequenas vazões - Q $\leq 10$ l/s (Porto, 2006). Com isto adquiriram-se recipientes 
de plásticos rígidos e transparentes que foram aferidos através do uso de proveta graduada, com os seguintes volumes: $10 \ell, 7 \ell, 3 \ell$ e $2 \ell$, sendo os três últimos com marcações de litro em litro. Para executar a medição direta, foram adquiridos cronômetros com as funções cronógrafo e timer, também foi adquirido um termômetro digital com duas entradas de medição, com intuito de medir a temperatura do ar e a do líquido dentro do TQ01, principalmente por conta da variação da viscosidade absoluta em função da temperatura.

Durante o período de treinamento, identificou-se que o melhor seria desviar a vazão do permeado do TQ02, ilustrado na Figura 4.10, para evitar-se o intertravamento instalado na planta-piloto e já relatado, com isto otimizando o controle e impedindo a parada do sistema na operação de filtração, quando o TQ02 estivesse no seu nível máximo, sendo a vazão medida por meio do método direto, preenchendo com permeado os recipientes aferidos, como descrito anteriormente.

Neste estágio, também foi verificada a necessidade da troca dos Filtros "Y", de 1", inicialmente instalados, para 2", mudança efetuada com a finalidade de aumentar a área de filtração incrementada pela maior dimensão da tela fina internamente instalada, como ilustrado na Figura 4.8. Esta necessidade decorreu da verificação de entupimentos recorrentes dos Filtros "Y" ocorridos no início do treinamento, causados, principalmente, por partículas de gordura e materiais fibrosos num momento em que a ETE Gama necessitou desviar o lodo aeróbio descartado (idade do lodo) para as caixas de passagens que alimentam os reatores $U A S B$, entre $18 / 08$ a 28/09/2015, necessidade surgida pela parada do desaguamento mecânico (quebra da Centrífuga ou Decanter).

\subsection{4 - Ensaios preliminares (Operação de curta-duração)}

Este estágio iniciou-se com a instalação do módulo de número 716 no dia 23/11/2015 e terminou em 28/03/2016. Foi dividido nas seguintes subetapas: (i) Levantamentos iniciais, (ii) Comportamento do Fluxo versus tempo, (iii) Pesquisa do Fluxo crítico e (iv) Investigação do Tempo de retrolavagem com máxima eficiência.

Foram realizada a caracterização dos módulos das membranas novos, como foi feito por Vidal (2006) e Silva (2009), com a finalidade de identificar as propriedades iniciais das 
membranas, sendo que estas propriedades mudam ao longo das operações de permeações e retrolavagens sucessivas. Fazendo isso tornou-se possível avaliar a situação da membrana ao longo do tempo, pelo confronto entre medições futuras com as inicialmente executadas.

\subsubsection{1 - Levantamentos Iniciais}

De 23 a 24/11/2016, o módulo de membranas foi avaliado por meio dos seguintes levantamentos iniciais: (i) medição da permeabilidade hidráulica com água potável, (ii) medição da permeabilidade hidráulica com água potável previamente microfiltrada, (iii) investigação da rejeição com a filtração de solução de amido de milho $(1 \mathrm{~g} / \ell)$ - integridade (Silva, 2009).

O método para verificar a permeabilidade hidráulica é sempre efetuado para as membranas novas, as submetidas a um período de permeação do efluente e a aquelas membranas usadas após qualquer tipo de limpeza efetuada. A permeabilidade hidráulica foi determinada a partir das medidas do fluxo do permeado obtido em cada PTM (pressão transmembrana), sendo que a PTM pôde variar de 0,1 a 0,5 bar. A partir dos dados do fluxo de permeado (J) contra a PTM, efetuou-se a regressão linear e determinou-se a permeabilidade hidráulica, que é o coeficiente angular da reta ajustada e como já definido pela Equação 3.1 e como levantado por Silva (2009). O teste pôde ser feito diretamente com a solução líquida investigada ou, para fins de comparação, pôde ser feito sempre com um líquido considerado como "branco", que no caso pode ser a água potável ou uma água potável previamente microfiltrada. Nesta pesquisa o "branco" foi sempre considerado a água potável da CAESB, disponível no local onde foi instalada a planta-piloto.

A Integridade medida de forma indireta pode ser investigada pelo monitoramento da turbidez na filtração de uma solução na qual o soluto tenha um diâmetro de partículas conhecido e maior do que os dos poros da membrana filtrante. Uma das soluções utilizadas para isto pode ser a de amido de milho comercial, pois possui como descrição microscópica grãos com diâmetros médios de 10 a $35 \mu \mathrm{m}$. A PAM Membranas certifica a integridade dos módulos de membrana novos aplicando o teste com a filtração de solução de amido de milho comercial com concentração de $1 \mathrm{~g} / \ell$ e o mesmo foi reproduzido nesta pesquisa. 


\subsubsection{2 - Comportamento do Fluxo (J) versus tempo (t)}

Esta etapa foi efetuada de 03/12/2015 a 06/01/2016, quando foram realizados três levantamentos sucessivos para cada pressão de sucção de $0,10,0,15$ e 0,20 bar. A operação foi efetuada com a microfiltração contínua por 180 minutos do efluente do reator UASB, como apresentado nos diversos gráficos para diferentes testes de filtração por Cheryan (1998).

A Tabela 4.5 apresenta as datas de realizações dos levantamentos do fluxo contra o tempo para as pressões testadas, notando-se a pressão de sucção de 0,1 bar foi testada por quatro vezes, pelo fato de terem ocorrido erros no levantamento no primeiro teste $(3 / 12 / 2015)$.

Tabela 4.5 - Datas dos levantamentos do fluxo contra o tempo para diferentes pressões testadas

\begin{tabular}{cc}
\hline Pressões de sucção testadas (bar) & Data \\
\hline$-0,10$ & 3,4 e $7 / 12 / 2015$ e $6 / 01 / 2016$ \\
$-0,15$ & 11,14 e $15 / 12 / 2016$ \\
$-0,20$ & 8,9 e $10 / 12 / 2015$ \\
\hline
\end{tabular}

O levantamento do fluxo versus tempo foi feito em cinco passos sequenciais, da seguinte forma:

1. Filtração durante o tempo de 180 minutos do efluente do reator $U A S B$, com a medição da vazão de forma direta, da seguinte maneira: (i) de minuto a minuto até os 10 minutos iniciais, (ii) de cinco em cinco minutos, dos 10 até os 40 minutos, e (iii) de 10 em 10 minutos, dos 40 até os 180 minutos finais. Aquisição dos dados de consumo de energia elétrica;

2. Medição da vazão do permeado filtrando água potável da CAESB para o levantamento da permeabilidade hidráulica e da resistência total;

3. Primeira limpeza com água potável por 15 minutos do TQ01, uso da vazão em torno de 15 l/minutos, mantendo o nível do TQ01 entre o baixo e o alto. Após medição da vazão do permeado filtrando água potável para o levantamento da permeabilidade hidráulica e da resistência depois desta limpeza; 
4. Segunda limpeza por meio da retrolavagem por 30 minutos com água potável com a PTM (pressão transmembrana) de $+0,30$ bar e vazão em torno de 4,0 $\ell$ /minuto. Após foi feita a medição da vazão do permeado filtrando água potável, para o levantamento da permeabilidade hidráulica e da resistência depois desta limpeza;

5. Terceira limpeza hidráulica e química realizada na seguinte sequência: (i) adição de $0,25 \ell$ de $\mathrm{NaClO}(15 \%)$ para manutenção de concentração de $800 \mathrm{mg} / \ell$ em cloro ativo, conforme recomendação do fabricante, e mantendo aerado (SP01 ligado) para efetuar o relaxamento por 15 minutos, (ii) repouso por 45 minutos, (iii) aerando por mais 15 minutos, (iv) repouso por 45 minutos e (v) limpeza com água potável por 15 minutos do TQ01, vazão em torno de $15 \ell /$ minutos, mantendo o nível do TQ01 entre o baixo e o alto. Após foi feita a medição da vazão do permeado filtrando água potável para o levantamento da permeabilidade hidráulica e da resistência da membrana.

Durante todas as 10 corridas, foram executadas as coletas de amostras compostas nos pontos definidos na Figura 4.5, como sendo: (i) A (a alimentação ao TQ01 - tanque das membranas), (ii) D (o descarte do TQ01) e (iii) P (o permeado). As coletas foram feitas a cada 5 minutos, tendo sido amostrado um volume de $250 \mathrm{m \ell}$ e adicionado em um recipiente de $4,0 \ell$.

Todos os três recipientes permaneceram em caixa térmica resfriadas durante o desenrolar dos testes. As amostras no final dos testes foram sempre agitadas para homogeneização, retirada de 1,0 $\ell$ e levadas no final do dia da ETE Gama até o Laboratório de Saneamento Ambiental do Programa de Pós-Graduação em Tecnologia Ambiental e Recursos Hídricos, do Departamento de Engenharia Civil e Ambiental, Faculdade de Tecnologia, UnB para a realização das análises laboratoriais.

O levantamento da resistência à permeação foi realizado conforme o modelo de resistências em série e determinado pela lei de Darcy por meio da Equação 3.7, anteriormente descrita. O desempenho para este parâmetro foi monitorado ao longo da pesquisa e comparado sempre com o do início da pesquisa (membranas com características de nova) com os conseguidos no decorrer da permeação do efluente (Silva, 2009). Na Figura 4.11 apresenta-se em forma de fluxograma o procedimento descrito anteriormente. 


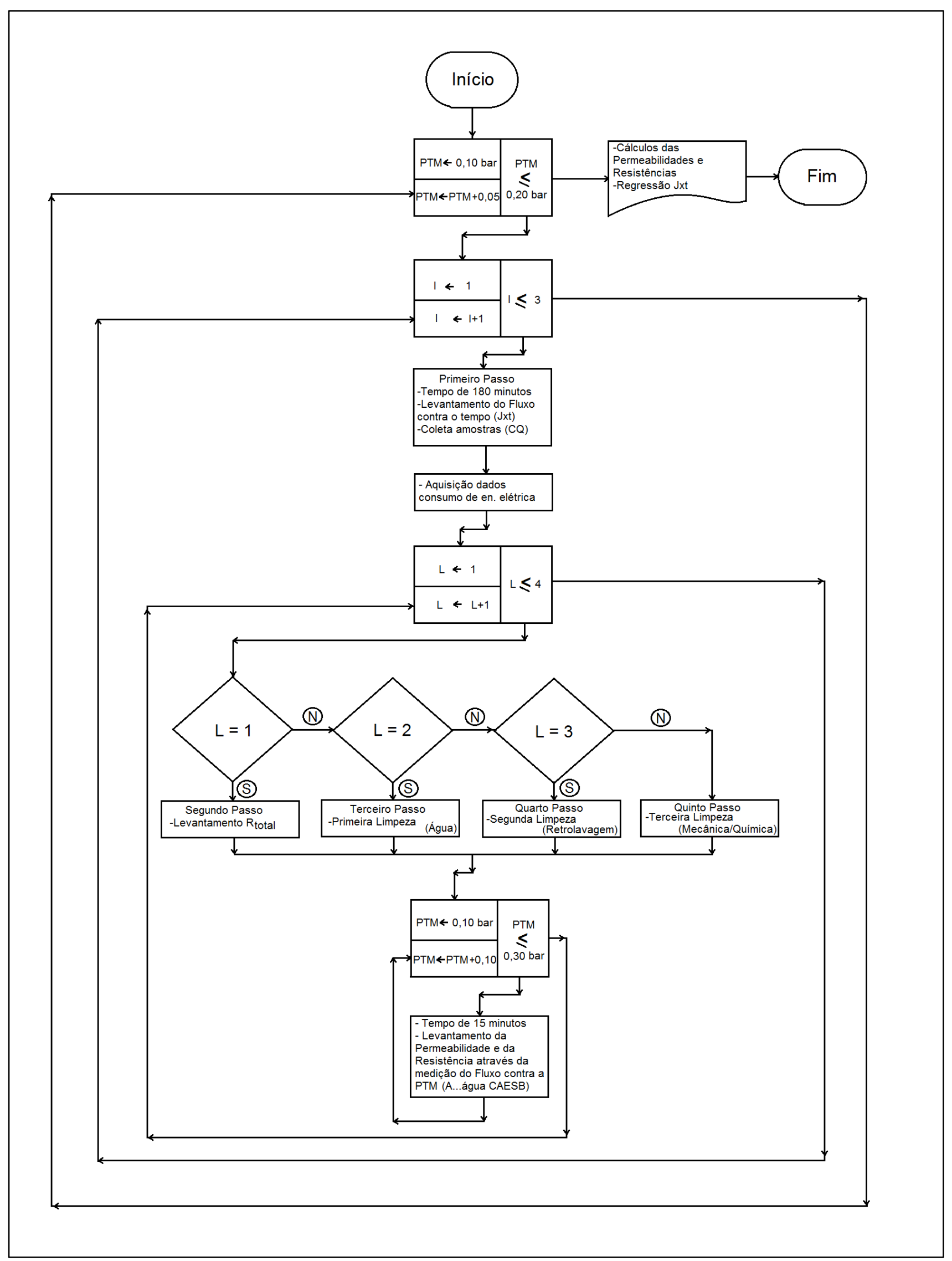

Figura 4.11 - Fluxograma do levantamento do fluxo $(\mathrm{J})$ contra o tempo (t) na filtração direta por membranas de efluente de reator $U A S B$ para PTM de $-0,1,-0,15$ e $-0,20$ bar. 
As análises efetuadas nesta fase foram: (i) DQO sem filtrar - $\mathrm{DQO}_{1}$; (ii) DQO fracionadas - $\mathrm{DQO}_{2}, \mathrm{DQO}_{3}, \mathrm{DQO}_{4}$ e DQO ; (iii) SST fracionados - $\mathrm{SST}_{1}, \mathrm{SST}_{2}, \mathrm{SST}_{3}$ e $\mathrm{SST}_{4}$; (iv) Turbidez fracionadas - $\mathrm{Tu}_{1}, \mathrm{Tu}_{2}, \mathrm{Tu}_{3}, \mathrm{Tu}_{4}$ e $\mathrm{Tu}_{\mathrm{f}}$ e (v) Sólidos Dissolvidos Totais, Sólidos Dissolvidos Totais Fixos e Voláteis, como ilustrado na Figura 4.12. É importante ressaltar que todas as marchas analíticas foram feitas em duplicata.

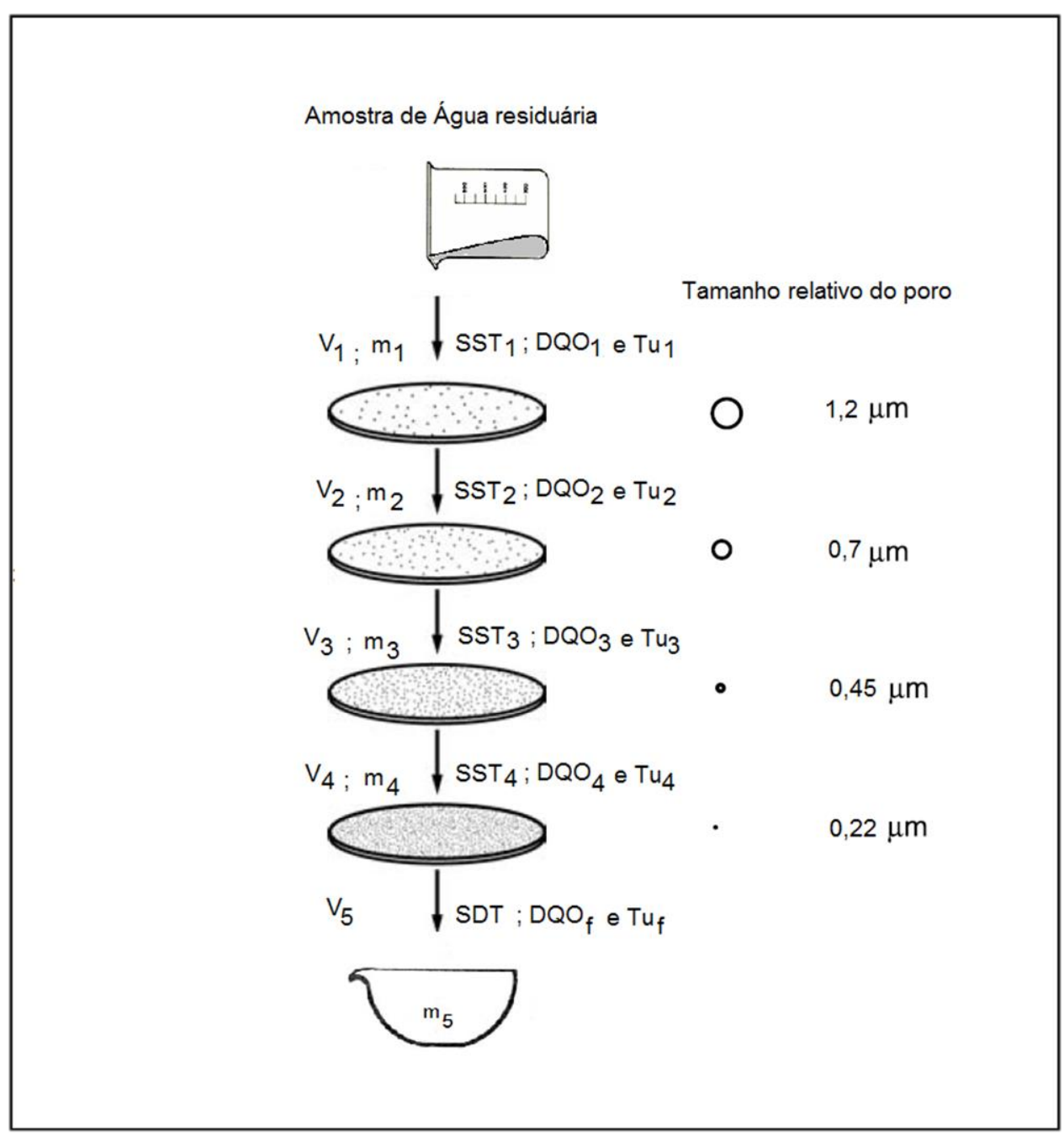

Figura 4.12 - Diagrama esquemático do procedimento para determinação da distribuição do tamanho das partículas (pela massa) usando filtração em série através de membranas filtrantes de diferentes dimensões de poros - 0,22 $\mu \mathrm{m}, 0,45 \mu \mathrm{m}, 0,70 \mu \mathrm{m}$ e $1,2 \mu \mathrm{m}$ (adaptado de Metcalf e Eddy, 2007).

Com os resultados das análises dos quatro fracionamentos dos Sólidos Suspensos Totais de cada amostra, como ilustrado na Figura 4.12, foi calculado o diâmetro médio geométrico em massa $\left(D_{\mathrm{mg}}\right)$, conforme descrito na Equação 4.1. A Equação 4.1 é uma adaptação da usada por Levine et al. (1991). 


$$
D m g=\exp \left(\frac{\sum_{i=1}^{n} S S T i . \ln D i}{\sum_{i=1}^{n} D i}\right)
$$

Onde: Dmg é o diâmetro médio geométrico em massa, SSTi é a concentração de Sólidos Suspensos Totais na fração i e Di é o diâmetro médio calculado pelo diâmetros nominais dos poros dos filtros de membrana sucessivos.

\subsubsection{3 - Pesquisa do Fluxo Crítico}

O Fluxo Crítico foi examinado pelo monitoramento do fluxo permeado para uma dada pressão constante. Este método de determinação é definido com "Transição do Fluxo entre a Dependência e a Independência da Pressão" e é um teste hidráulico realizado pela mudança da PTM para a medição de diferentes fluxos - J (Le Clech et al., 2003).

O levantamento pode ser realizado por 15 minutos para cada pressão avaliada. Este tempo de monitoramento de fluxo de permeado é denominado de "passo", e a cada "passo" ou etapa a pressão será alterada para um valor que pode variar de 0,02 a 0,05 bar superior a anterior. A esta mudança gradativa de pressão aplicada designa-se como "degrau". Os "degraus" podem ser examinados da pressão aplicada de 0,05 a 0,5 bar e verificando o comportamento do fluxo medido. O fluxo crítico será definido como o maior fluxo permeado na qual não se observará uma diminuição no fluxo com o tempo (Silva, 2009).

Esta fase foi realizada do dia 13/01 a 03/02/2016 mediante 5 (cinco) testes com repetição. Cada um dos testes para o levantamento do fluxo crítico foi feito em quatro passos sequenciais, da seguinte forma:

1. Filtração durante o tempo de 180 minutos do efluente do reator $U A S B$, com a medição da vazão de forma direta por 15 minutos por cada PTM variando de $-0,02$ a $-0,20$ bar;

2. Primeira limpeza com água potável por 15 minutos do TQ01, vazão em torno de 15 $\ell /$ minuto, mantendo o nível do TQ01 entre o baixo e o alto;

3. Segunda limpeza por meio da retrolavagem por 30 minutos com água potável com a PTM (pressão transmembrana) de $+0,30$ bar e vazão em torno de 4,0 l/minutos;

4. Terceira limpeza hidráulica e química realizada na seguinte sequência: (i) adição de $0,25 \ell$ de $\mathrm{NaClO}$ (15\%) para manutenção de concentração de $800 \mathrm{mg} / \ell$ em cloro ativo, e mantendo aerado (SP01 ligado) para efetuar o relaxamento por 15 minutos, 
(ii) repouso por 45 minutos, (iii) aerando por mais 15 minutos, (iv) repouso por 45 minutos e (v) limpeza com água potável por 15 minutos do TQ01, vazão em torno de $15 \mathrm{l} /$ minutos, mantendo o nível do TQ01 entre o baixo e o alto. Após foi feita a medição da vazão do permeado filtrando água potável para o levantamento da permeabilidade hidráulica e da resistência da membrana.

A Figura 4.13 apresenta em forma de fluxograma o procedimento descrito anteriormente.

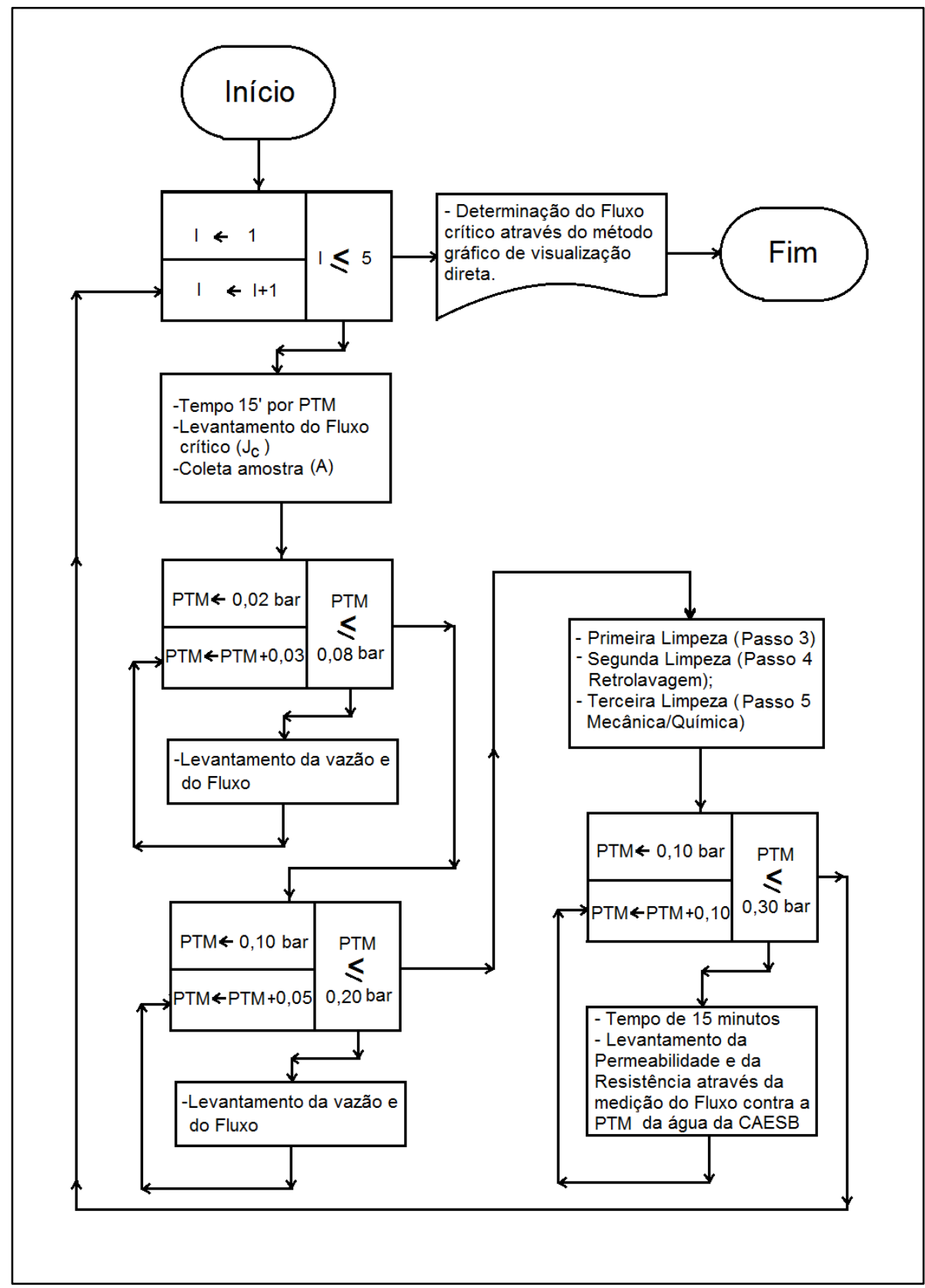

Figura 4.13 - Fluxograma do levantamento do fluxo crítico $\left(\mathrm{J}_{\mathrm{c}}\right)$ na filtração direta por membranas de efluente de reator $U A S B$ para PTM aplicadas de $-0,02 ;-0,05 ;-0,08 ;-0,10$; $-0,15$ e 0,20 bar. 


\subsubsection{4 - Investigação do Tempo de Retrolavagem com máxima eficiência}

Os ensaios para avaliação do tempo de retrolavagem ocorreram de 8/3 a 24/3/2016, quando foram realizados um total de 9 (nove) testes, três corridas com três tempos de retrolavagem de frequência distintas de 30, 60 e 75 segundos, como é ilustrado na Figura 4.14.

Cada teste para o levantamento do tempo de retrolavagem foi feito em quatro passos sequenciais, do seguinte modo:

1. Filtração durante o tempo de 180 minutos do efluente do reator $U A S B$, com a medição da vazão de forma direta com tempo de filtração de 15 minutos e PTM de $-0,1$ bar e o tempo de retrolavagem variando de 30 a 75 segundos e com PTM de +0,20 bar. Aquisição dos dados de consumo de energia elétrica;

2. Primeira limpeza com água potável por 15 minutos do TQ01, vazão em torno de 15 $\ell /$ minutos, mantendo o nível do TQ01 entre o baixo e o alto;

3. Segunda limpeza através da retrolavagem por 30 minutos com água potável com a PTM (pressão transmembrana) de $+0,30$ bar e vazão em torno de $4,0 \ell /$ minutos;

4. Terceira limpeza hidráulica e química realizada na seguinte sequência: (i) adição de $0,25 \ell$ de $\mathrm{NaClO}(15 \%)$ para manutenção de concentração de $800 \mathrm{mg} / \ell$ em cloro ativo, e mantendo aerado (SP01 ligado) para efetuar o relaxamento por 15 minutos, (ii) repouso por 45 minutos, (iii) aerando por mais 15 minutos, (iv) repouso por 45 minutos e (v) limpeza com água potável por 15 minutos do TQ01, vazão em torno de 15 l/minutos, mantendo o nível do TQ01 entre o baixo e o alto. Após foi feita a medição da vazão do permeado filtrando água potável para o levantamento da permeabilidade hidráulica e da resistência da membrana.

A frequência ideal do tempo de retrolavagem foi estabelecida analisando-se o volume líquido médio do permeado, ou seja, o volume total produzido nas etapas de filtração subtraído daquele utilizado nas etapas de retrolavagem, para cada frequência distinta de retrolavagem - 30, 60 e 75 segundos, conforme é ilustrado na Figura 4.14.

Com base nos dados levantados, foi analisado qual o tempo ideal de retrolavagem que fornece a máxima eficiência de produção de permeado, como feito por Rodrigues (2012). 


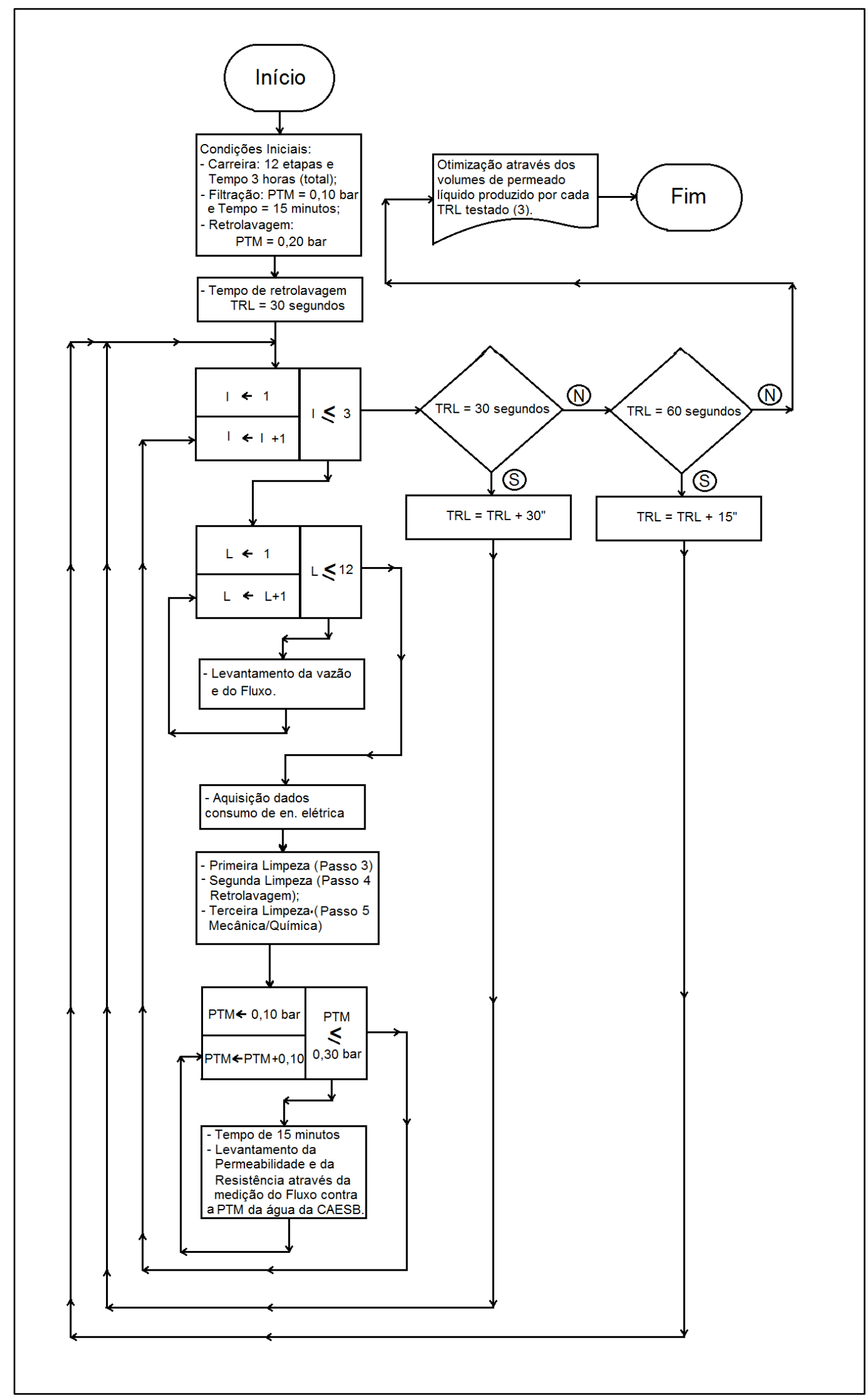

Figura 4.14 - Fluxograma do levantamento do tempo de retrolavagem na filtração direta por membranas de efluente de reator $U A S B$ para tempos de retrolavagem variando de 30 a 75 segundos. 


\subsection{5 - Monitoramento do processo UASB/FSM (Operação de longa duração)}

Esta fase foi desenvolvida em dois períodos, o primeiro de 28/03 a 13/05/2016 e o segundo de 22/08 até 20/10/2016. A operação consistiu em corridas diárias de 6 horas consecutivas de Segunda a Quinta-feira, sendo a Sexta-feira dedicada à manutenção do sistema e limpeza das membranas, executando a segunda (retrolavagem) e a terceira (hidráulica/química) limpezas.

As condições operacionais foram selecionadas a partir dos resultados dos ensaios preliminares, sendo: (i) PTM de filtração, (ii) tempo de filtração e (iii) tempo de retrolavagem.

As condições operacionais sugeridas pelo fabricante da planta-piloto estão indicadas na Tabela 4.6 e serviram de base para os testes realizados nos ensaios preliminares (PAM Membranas Seletivas, 2014).

Tabela 4.6 - Condições operacionais iniciais sugeridas pela fornecedora da unidade de microfiltração (PAM Membrana Seletivas, 2014)

\begin{tabular}{ccc}
\hline Condição Operacional & Valor recomendado & Valor limite \\
\hline $\begin{array}{c}\text { Fluxo permeado }(\ell / \mathrm{h}) \\
\text { Tempo/Duração Retrolavagem } \\
\text { (minutos:segundos) }\end{array}$ & 60 & - \\
PTM (bar) & $15: 30$ & - \\
\hline
\end{tabular}

$\mathrm{Na}$ conclusão desta etapa, a planta-piloto foi operada e avaliada por 61 dias de corridas consecutivas, onde foram investigadas as condições operacionais e efetuado o controle de qualidade do programa de monitoramento.

As condições operacionais foram efetuadas diariamente, a cada corrida, por meio do monitoramento das variáveis descritas na Tabela 4.7 e suas respectivas frequências.

Tabela 4.7 - Condições Operacionais a serem monitoradas e frequências de medições para a Planta-piloto FMS - Filtrando

\begin{tabular}{cc}
\hline Condição Operacional & $\begin{array}{c}\text { Frequência de medição a ser } \\
\text { realizada }\end{array}$ \\
\hline Fluxo permeado $(\ell / \mathrm{h})$ & 15 minutos \\
PTM $($ bar $)$ & 5 minutos \\
Temperatura $\left({ }^{\circ} \mathrm{C}\right)$ & 5 minutos \\
Consumo de Energia Elétrica - Potência útil & Diário \\
$(\mathrm{kW}-\mathrm{h})$ & \\
\hline
\end{tabular}


O esquema de coletas do programa de controle de qualidade da presente pesquisa foi definido para ser feito duas vezes por semana, às Segundas e Quartas-feiras, e as análises foram efetuadas em duplicatas no Laboratório de Saneamento Ambiental do Programa de Pós-Graduação em Tecnologia Ambiental e Recursos Hídricos, do Departamento de Engenharia Civil e Ambiental, Faculdade de Tecnologia da UnB.

As amostragens foram executadas por meio das coletas de alíquotas a cada quinze minutos das amostras do efluente do reator UASB (alimentação), descarte do tanque com membranas (TQ01) e permeado, compondo-as nos testes diários da planta-piloto e analisadas pelas variáveis apresentadas na Tabela 4.8 e suas frequências. As amostras foram preservadas em refrigeração em caixa térmica preenchida por gelo picado, durante as coletas e no transporte da ETE Gama até a UnB.

Tabela 4.8 -Variáveis monitoradas na verificação do desempenho global através das amostras compostas do: efluente do UASB (alimentação), descarte do TQ01 e permeado da Planta-piloto FMS e suas frequências

\begin{tabular}{cc}
\hline Variáveis & $\begin{array}{c}\text { Frequência de medição a ser } \\
\text { realizada }\end{array}$ \\
\hline DQO (total e fracionada) & duas vezes por semana \\
SST (fracionado) & duas vezes por semana \\
SDT & semanal \\
DBO & semanal \\
Agentes surfactantes & semanal \\
Óleos e Graxas & semanal \\
CF & semanal \\
CT & 1 campanha especial \\
\hline
\end{tabular}

Legenda: 1....Análises efetuadas em coletas durante quatro semanas consecutivas (29/08, 12/09, 19/09 e 26/09).

Os resultados obtidos foram analisados, interpretados e comparados servindo-se de três perspectivas:

1- Qualidade da água do permeado como efluente final a ser descartado nos corpos d’água à luz da resolução CONAMA 430/11 (Brasil, 2011);

2- Qualidade da água do permeado como água de reúso com base nas diretrizes da OMS (WHO, 2006) e

3- Desempenho global do sistema UASB-FMS comparando com o PRODES/ANA (Libânio et al., 2007). 
Na Tabela 4.9 apresentam-se os valores padrões para o lançamento direto de efluentes de sistemas de tratamento de esgotos sanitários em corpos d’agua no Brasil, que foram utilizados nesta análise.

Tabela 4.9 - Padrões para Efluentes de Sistemas de Tratamento de Esgotos Sanitários resolução CONAMA 430/11 (Brasil, 2011).

\begin{tabular}{cc}
\hline Variável & Valor \\
\hline DBO & máximo de $120 \mathrm{mg} / \ell$ ou remoção global mínima de $60 \%$ \\
Materiais sedimentáveis & máximo de $1 \mathrm{~m} \ell / \ell$ \\
Óleos e graxas & máximo de $100 \mathrm{mg} / \ell$ \\
pH & 5 a 9 \\
\hline
\end{tabular}

Nas Tabelas 4.10 e 4.11 são apresentados em detalhe as diretrizes recomendadas pela Organização Mundial de Saúde (WHO, 2006) para a qualidade microbiológica da água de reúso quando empregada na irrigação na agricultura.

$\mathrm{Na}$ Tabela 4.10 apresentam-se os valores guia relacionados à remoção e níveis de coliformes fecais (E. Coli), enquanto que na Tabela 4.11 são indicados os valores para garantia da saúde da população.

Tabela 4.10 - Diretrizes para remoção e concentração (E. Coli - NMP/100 m $\ell$ ) para o reúso de água em irrigação irrestrita e restrita de culturas na agricultura, segundo a OMS (WHO, 2006).

\begin{tabular}{|c|c|c|c|}
\hline $\begin{array}{l}\text { Tipo de } \\
\text { irrigação }\end{array}$ & Cultura & $\begin{array}{l}\text { Remoção de } \\
\text { patógenos } \\
\text { requerida } \\
\text { (unidades log) }\end{array}$ & $\begin{array}{l}\text { Nível para monitoramento } \\
\text { de verificação de } E \text {. coli } \\
(\mathrm{NMP} / 100 \mathrm{~m} \ell)^{*}\end{array}$ \\
\hline \multirow{8}{*}{ Irrestrita } & Cultura de raízes & 4 & $\leq 10^{3}$ \\
\hline & Cultura de folhas & 3 & $\leq 10^{4}$ \\
\hline & Irrigação por gotejamento & & \\
\hline & de culturas elevadas & 2 & $\leq 10^{5}$ \\
\hline & Irrigação por gotejamento & & \\
\hline & de culturas rentes ao solo & 4 & $\leq 10^{3}$ \\
\hline & $\begin{array}{l}\text { Depende dos requisitos da } \\
\text { agência reguladora local } \\
\text { Agricultura intensiva }\end{array}$ & 6 ou 7 & $\leq 10^{1}$ ou $\leq 10^{0}$ \\
\hline & $\begin{array}{c}\text { (proteção de adultos e } \\
\text { crianças menores de } 15 \\
\text { anos) }\end{array}$ & 3 & $\leq 10^{4}$ \\
\hline Restrita & $\begin{array}{c}\text { Agricultura altamente } \\
\text { mecanizada }\end{array}$ & 2 & $\leq 10^{5}$ \\
\hline
\end{tabular}

* Média geométrica 
Tabela 4.11 - Diretrizes primárias e metas de qualidade da água de reúso para irrigação para garantia da saúde da população (WHO, 2006)

\begin{tabular}{ccl}
\hline $\begin{array}{c}\text { Tipo de } \\
\text { irrigação }\end{array}$ & $\begin{array}{c}\text { Diretriz primária para patógenos } \\
\text { (bactérias, vírus e protozoários) }\end{array}$ & \multicolumn{1}{c}{$\begin{array}{c}\text { Metas de qualidade para ovos de } \\
\text { helmintos }(\mathrm{OH})\end{array}$} \\
\hline Irrestrita & $\leq 10^{-6}$ DALY perdidos pppa & $\begin{array}{l}\leq 1 \text { ovo por litro (média aritmética); } \\
\leq 0,1 \text { ovo por litro, quando há } \\
\text { exposição de crianças menores que 15 } \\
\text { anos. }\end{array}$ \\
\hline Restrita & $\leq 10^{-6}$ DALY perdidos pppa & $\begin{array}{l}\leq 1 \text { ovo por litro (média aritmética); } \\
\leq 0,1 \text { ovo por litro, quando há } \\
\text { exposição de crianças menores que 15 } \\
\text { anos. }\end{array}$ \\
\hline Localizada & $\leq 10^{-6}$ DALY perdidos pppa & $\begin{array}{l}\text { Culturas rentes ao solo; } \\
\leq 1 \text { ovo por litro (média aritmética). } \\
\text { Culturas elevadas: sem recomendação }\end{array}$ \\
\hline $1 \times 10^{-6}$ DALY (disability adjusted life year) perdidos por pessoa por ano (1 $\mu$ DALY pppa).
\end{tabular}

Nesta pesquisa foi utilizado o PRODES, que é Programa de Despoluição de Bacias Hidrográficas um programa concebido pela ANA (Agência Nacional de Água) em 2001 para estimular a implantação e a operação adequada de ETEs (estações de tratamento de esgotos sanitários) por meio de um processo de certificação de desempenho. As informações periódicas demandadas pelo PRODES/ANA abrangem dados com vazões de esgoto, cargas orgânicas afluentes às ETEs e os resultados de eficiência global de remoção de determinadas variáveis (DBO, SST, NTK, $\mathrm{P}_{\mathrm{T}}$ e $\mathrm{CF}$ ). Este programa também é conhecido como "programa de compra de esgotos tratados". O programa classifica as unidades de depuração em nove categorias (de A até I), sendo "A" aquela de menor complexidade, seguindo em ordem alfabética de acordo com o aumento da complexidade e da capacidade de tratamento do processo. O reator $U A S B$, como tecnologia única de tratamento, é classificado como tratamento primário avançado, "B", com os padrões de remoção de 60\% para DBO e 60\% para SST (Libânio et al., 2007).

A Tabela 4.12 apresenta em detalhes a classificação proposta e praticada pelo PRODES/ANA, indicando os custos de instalações per capita para os diferentes processos de tratamento, e que foram utilizadas nesta pesquisa para análise dos resultados. 
Tabela 4.12 - Valores de referência para classificação dos Sistemas de Tratamento de Esgotos Sanitários para o Programa de Despoluição de Bacias Hidrográficas (PRODES) da Agência Nacional de Água (ANA) segundo os níveis mínimos de remoção para variáveis específicas, incluindo os custos de implantação para cada tipo de sistema (Libânio et al., 2007).

\section{Indicador $^{3}$}

\section{Padrões de Eficiência para Tratamento de Esgotos (em níveis mínimos de remoção)}

\begin{tabular}{|c|c|c|c|c|c|c|c|c|c|}
\hline & $\mathrm{A}$ & $\mathrm{B}$ & $\mathrm{C}$ & $\mathrm{D}$ & $\mathrm{E}$ & $\mathrm{F}$ & $\mathrm{G}$ & $\mathrm{H}$ & $\mathrm{I}$ \\
\hline DBO & $30 \%$ & $60 \%$ & $75 \%$ & $85 \%$ & $85 \%$ & $90 \%$ & $90 \%$ & $90 \%$ & $90 \%$ \\
\hline SST & $40 \%$ & $60 \%$ & $75 \% / 60 \% 1$ & $85 \% / 60 \%{ }^{1}$ & $85 \% / 60 \%{ }^{1}$ & $90 \%$ & $90 \%$ & $90 \%$ & $90 \%$ \\
\hline $\mathrm{CF}$ & & & & & 5 unid. Log. & & 5 unid. Log. & & 5 unid. Log. \\
\hline PT e/ou NTK & & & & & & & & $85 \%$ e/ou $80 \%$ & $85 \%$ e/ou $80 \%$ \\
\hline PE (hab.) $)^{2}$ & \multicolumn{9}{|c|}{ Valores per capita da referência $(\mathrm{R} \$ / \mathbf{h a b} .)^{4}$} \\
\hline até 10.000 & 30 & 50 & 80 & 110 & 120 & 140 & 150 & 170 & 170 \\
\hline de 10.001 a 20.000 & 30 & 40 & 70 & 100 & 100 & 130 & 130 & 150 & 160 \\
\hline de 20.001 a 50.000 & 20 & 30 & 60 & 80 & 90 & 110 & 120 & 140 & 150 \\
\hline de 50.001 a 100.000 & 10 & 30 & 60 & 80 & 80 & 100 & 110 & 130 & 140 \\
\hline de 100.001 a 200.000 & 10 & 30 & 60 & 80 & 80 & 100 & 110 & 130 & 140 \\
\hline acima de 200.000 & 10 & 30 & 60 & 80 & 80 & 100 & 110 & 130 & 140 \\
\hline
\end{tabular}

Observações: 1 60\% somente para os tratamentos que contemplem lagoas produtoras de algas;

2 PE...População Equivalente, em habitantes

2 Carga média diária de DBO de projeto da ETE dividida por uma carga média per capita de 54 g DBO/dia;

${ }^{3}$ DBO...Demanda Bioquímica de Oxigênio, SST...Sólidos Suspensos Totais, CF...Coliforme Fecais, PT...Fósforo Total, NTK...Nitrogênio Total de Kjedähl.

4 Valores referentes ao ano de 2007 (U\$ $1=\mathrm{R} \$ 1,95-$ Valor médio) e 2016 (U\$ $1=$ R\$ 3,59 - Valor médio até Agosto). 


\section{5 - RESULTADOS E DISCUSSÃO}

A discussão e os resultados foram dispostos neste item de acordo com o tempo de duração da operação: (i) curta (Ensaios preliminares) e (ii) longa (Monitoramento do processo $U A S B / F S M)$.

\section{1 - ENSAIOS PRELIMINARES (OPERAÇÃO DE CURTA DURAÇÃO)}

Os resultados apresentados neste item dizem respeito aos seguintes testes efetuados: (i) Levantamentos iniciais, (ii) Comportamento do Fluxo versus tempo, (iii) Pesquisa do Fluxo crítico e (iv) Investigação do Tempo de retrolavagem com máxima eficiência.

\subsection{1 - Levantamentos iniciais}

Os resultados dos levantamentos iniciais são os seguintes: (i) permeabilidade hidráulica inicial filtrando água potável, (ii) permeabilidade hidráulica inicial com água potável previamente microfiltrada e (iii) integridade inicial do módulo de membrana com o monitoramento da turbidez durante a filtração da solução de amido de milho $(1 \mathrm{~g} / \ell)$.

Na Tabela 5.1 são apresentados o valor do certificado do Módulo № 716 PAM Membranas Seletivas e os resultados das permeabilidades hidráulicas após os cálculos dos levantamentos efetuados filtrando água potável da CAESB e água potável da CAESB previamente microfiltrada. Os resultados das permeabilidades hidráulicas testadas para água potável da CAESB e para água potável da CAESB microfiltrada diferem da do certificado, $12 \%$ e $21 \%$, respectivamente. Estes valores são menores que $25 \%$, que segundo Cheryan (1998), é o valor máximo que os resultados das permeabilidades hidráulicas levantadas para membranas não usadas (novas) possam variar.

Tabela 5.1 - Resultados dos testes de levantamento das permeabilidades hidráulicas iniciais executados nos dias 23 e 24/11/2015 e o valor de referência certificado pela fornecedora.

\begin{tabular}{lcc}
\hline \multicolumn{1}{c}{ Operação Microfiltração } & $\begin{array}{c}\text { Permeabilidade hidráulica } \\
- \text { K (LMH/bar) }\end{array}$ & $\begin{array}{c}\text { Coeficiente de } \\
\text { determinação }\left(\mathrm{r}^{2}\right)\end{array}$ \\
\hline Água potável CAESB & 147,94 & 0,9525 \\
Água potável CAESB microfiltrada & 132,89 & 0,9119 \\
Água potável CEDAE microfiltrada & 167,43 & 0,9895 \\
\hline Legenda: a... valor do Certificado de Qualidade de Módulos $\mathrm{N}^{\circ}$ 1451 da PAM Membranas \\
Seletivas - referente ao módulo identificado como 716 (Anexo 1).
\end{tabular}


A Integridade inicial do módulo de membrana foi pesquisada por meio da filtração de 150 $\ell$ de solução de amido de milho $(1 \mathrm{~g} / \ell)$ durante o tempo de filtração de 45 minutos com a pressão aplicada de $-0,10$ bar, sem retrolavagem. Durante o tempo de filtração, foram coletadas amostras da alimentação e do permeado. Após, essas amostras foram levadas ao laboratório local da ETE Gama e executadas as análises da Turbidez da alimentação e do permeado. Os resultados das análises dos testes feitos, do valor de referência certificado (Anexo 1) estão descritos na Tabela 5.2. Observa-se pelos resultados da Tabela 5.2 que a integridade calculada foi inferior ao valor certificado para o módulo de membranas 716 , 2,15 contra 3,00 unidades logarítmicas. Porém, tanto o valor apurado no teste inicial nesta pesquisa quanto o valor de certificado pela fornecedora do módulo foi superior ao relatado por Yoon (2016), que é menor que 1 unidade logarítmica, valor considerado como limite aceitável.

Tabela 5.2 - Resultados do levantamento da integridade pelo monitoramento da Turbidez durante microfiltração de solução de amido de milho $(1 \mathrm{~g} / \ell)$ executado no dia 24/11/2015 e o valor de integridade certificado pela fornecedora.

\begin{tabular}{lccc}
\hline \multicolumn{1}{c}{ Amostras } & Turbidez (uT) & Integridade calculada & Integridade certificada $^{\text {a }}$ \\
\hline Alimentação & 319 & $99,3 \%(2,15$ un. Logs.) & $99,9 \%(3$ um. Logs.) \\
Permeado & 1,90 & & \\
\hline \multicolumn{4}{l}{ Legenda: a...Certificado de Qualidade de Módulos No 1451 (Anexo 1). }
\end{tabular}

\subsection{2 - Comportamento do Fluxo versus tempo}

Os resultados apresentados neste ponto foram decorrentes de três corridas repetidas e sucessivas executadas para cada pressão de sucção (PTM) de 0,10, 0,15 e 0,20 bar (de 03/12/2015 a 06/01/2016). As operações foram conduzidas por meio da filtração contínua por 180 minutos do efluente do reator $U A S B$.

Para a representação do fluxo $(\mathrm{J})$, foi utilizada a uma temperatura de referência, no caso a mais utilizada, é a temperatura padrão de $20^{\circ} \mathrm{C}$. As correções foram feitas pela medição da temperatura e utilizando a viscosidade absoluta ou dinâmica da água $(\mu)$ para a uniformização, ressaltando que, em água e esgotos sanitários, é comum assumir a viscosidade absoluta do permeado como sendo igual à da água pura (Ravazzini, 2008), a qual pode ser calculada em função da temperatura (Huisman, 1996 apud Ravazzini, 2008) e representada pela Equação 5.1. 


$$
\mu=\frac{479.10^{-3}}{(T+42,5)^{1,5}}
$$

Para o cálculo do fluxo padronizado, $\mathbf{J}_{20}$, combinou-se a Equação de Darcy, Equação 3.7, com a Equação 5.1, ficando o fluxo padronizado representado pela Equação 5.2.

$$
J_{20}=\frac{494,11}{(T+42,5)^{1,5}}
$$

Os gráficos das Figuras 5.1 a 5.9 ilustram as condutas com relação ao fluxo padronizado $\left(\mathrm{J}_{20}\right)$ e a resistência desenvolvida $(\mathrm{R})$ ao longo do tempo. As resistências desenvolvidas foram calculadas utilizando a Equação de Darcy, representada pela Equação 3.7. Nas Figuras 5.1 a 5.9 esboçam-se as curvas resultantes dos fluxos e das resistências e também as equações das regressões não lineares decorrentes, equações com os respectivos coeficientes de determinação $\left(r^{2}\right)$.

As unidades de fluxo padronizado e da resistência desenvolvida foram calculadas como $\ell / \mathrm{m}^{2} / \mathrm{h}(\mathrm{LMH})$ e $\mathrm{m}^{-1}$, respectivamente. Nas Figuras 5.1 a 5.9 , a leitura de $\mathrm{J}_{20}$ e R se faz no eixo vertical principal (o da esquerda) e a PTM no eixo vertical secundário (o da direita). As Figuras 5.1 a 5.3 exibem as corridas relacionadas com a pressão de sucção (PTM) de 0,1 bar.

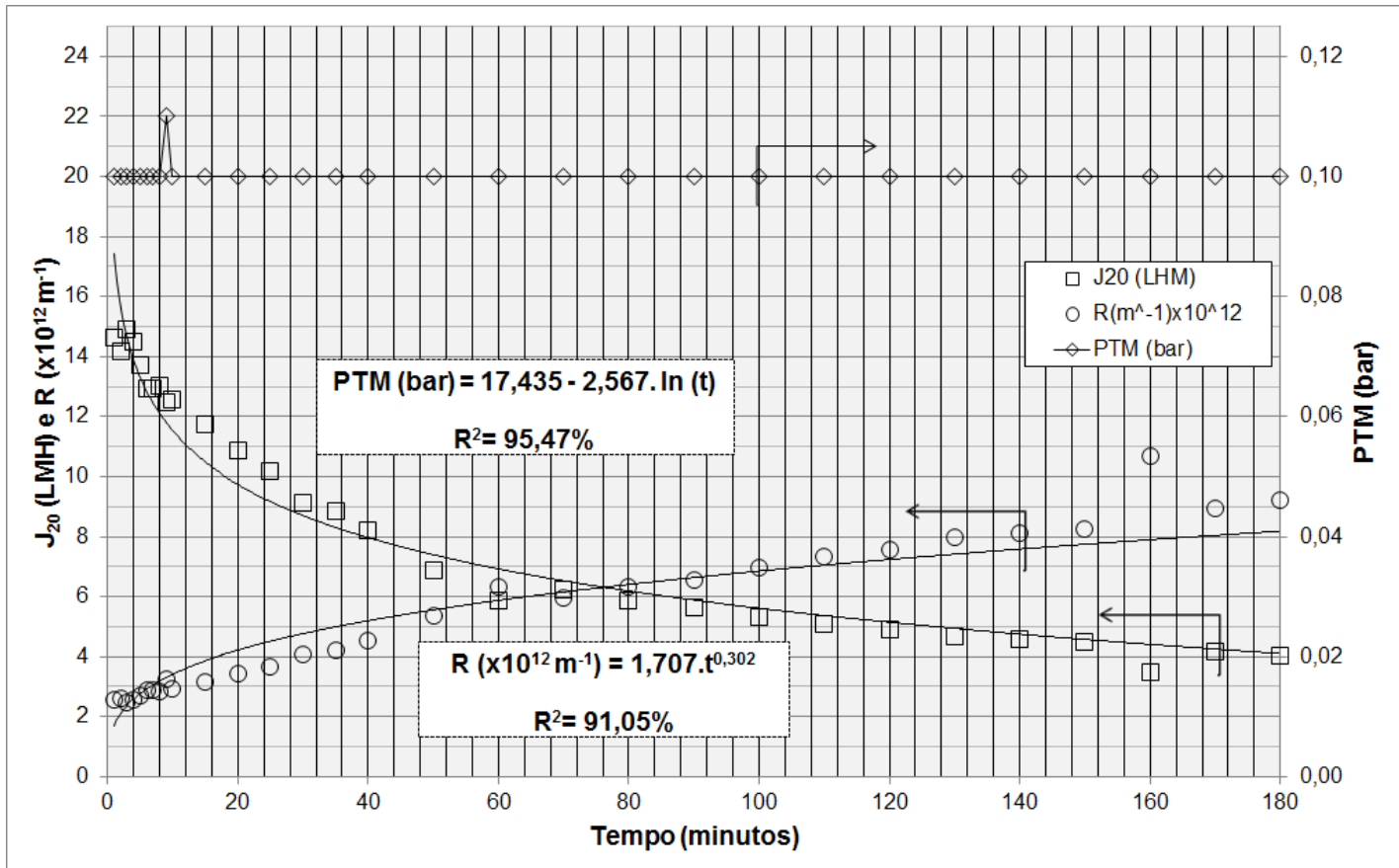

Figura 5.1 - Gráfico do fluxo padronizado, $\mathrm{J}_{20}$, e da resistência desenvolvida ao longo da filtração do efluente do reator $U A S B$ realizada com PTM de -0,1 bar no dia 04/12/2015. 


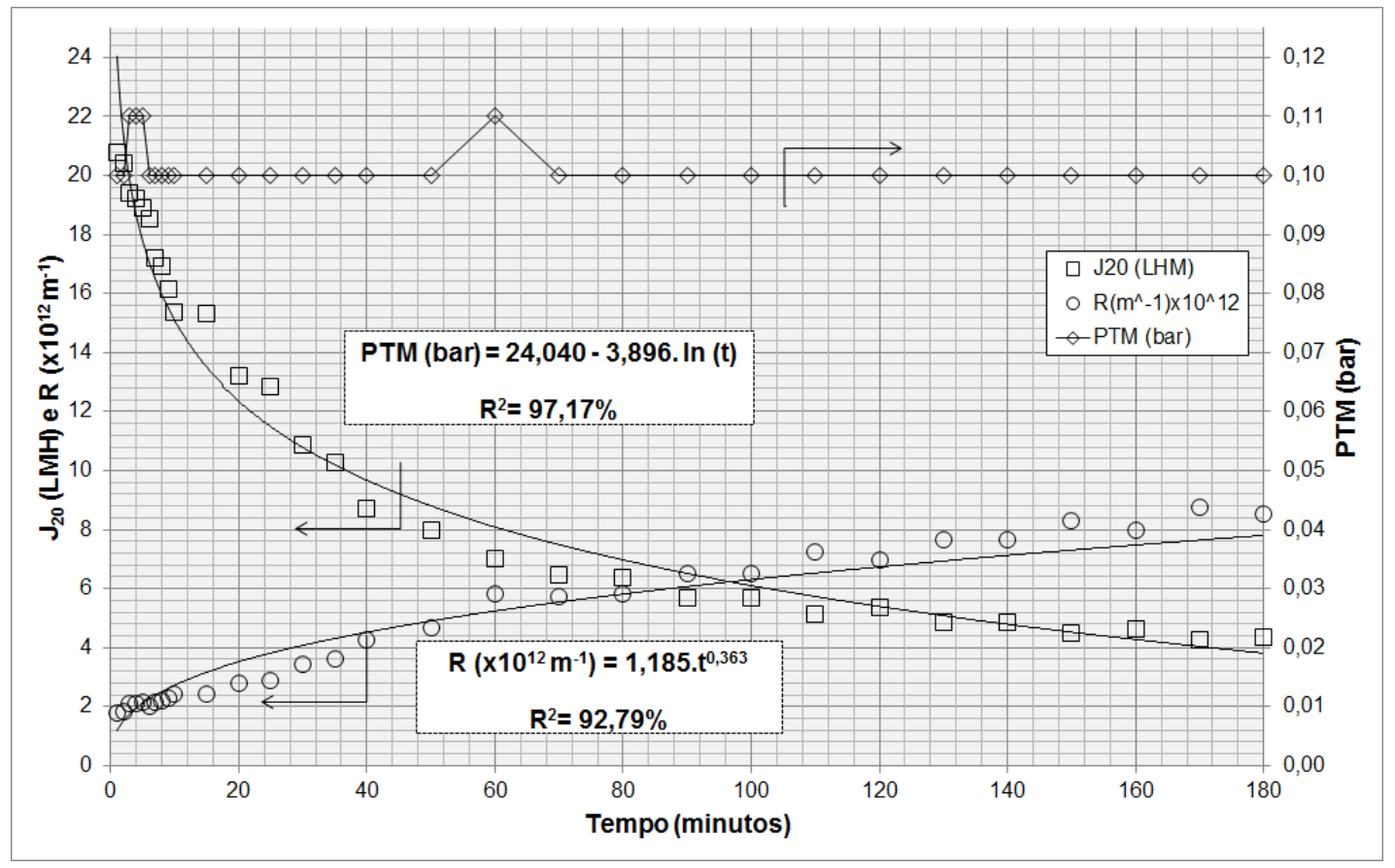

Figura 5.2 - Gráfico do fluxo padronizado, $\mathrm{J}_{20}$, e da resistência desenvolvida ao longo da filtração do efluente do reator $U A S B$ realizada com PTM de $-0,1$ bar no dia 07/12/2015.

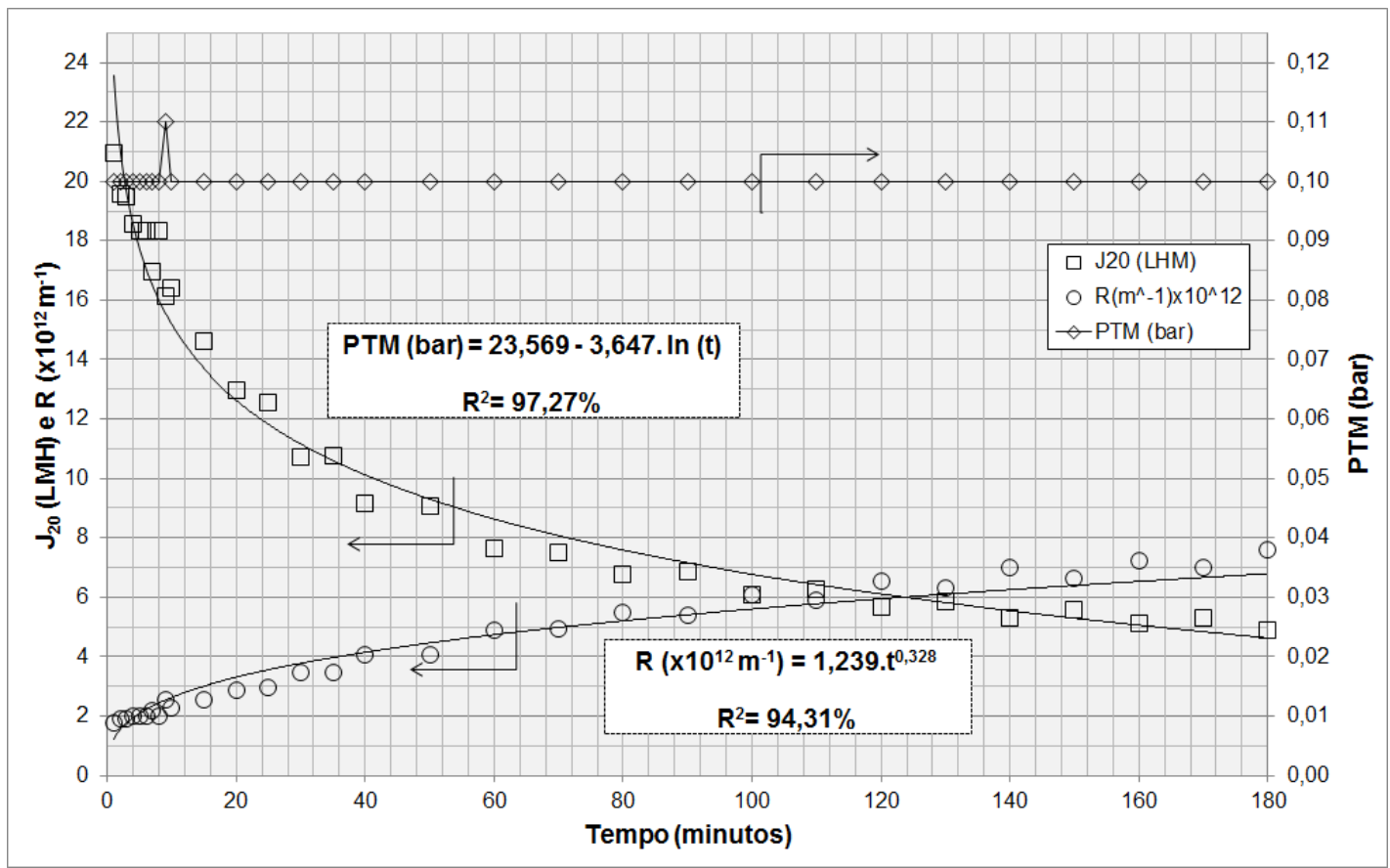

Figura 5.3 - Gráfico do fluxo padronizado, $\mathrm{J}_{20}$, e da resistência desenvolvida ao longo da filtração do efluente do reator $U A S B$ realizada com PTM de -0,1 bar no dia 06/01/2016.

As Figuras 5.4 a 5.6 exibem as corridas relacionadas com PTM de -0,15 bar. 


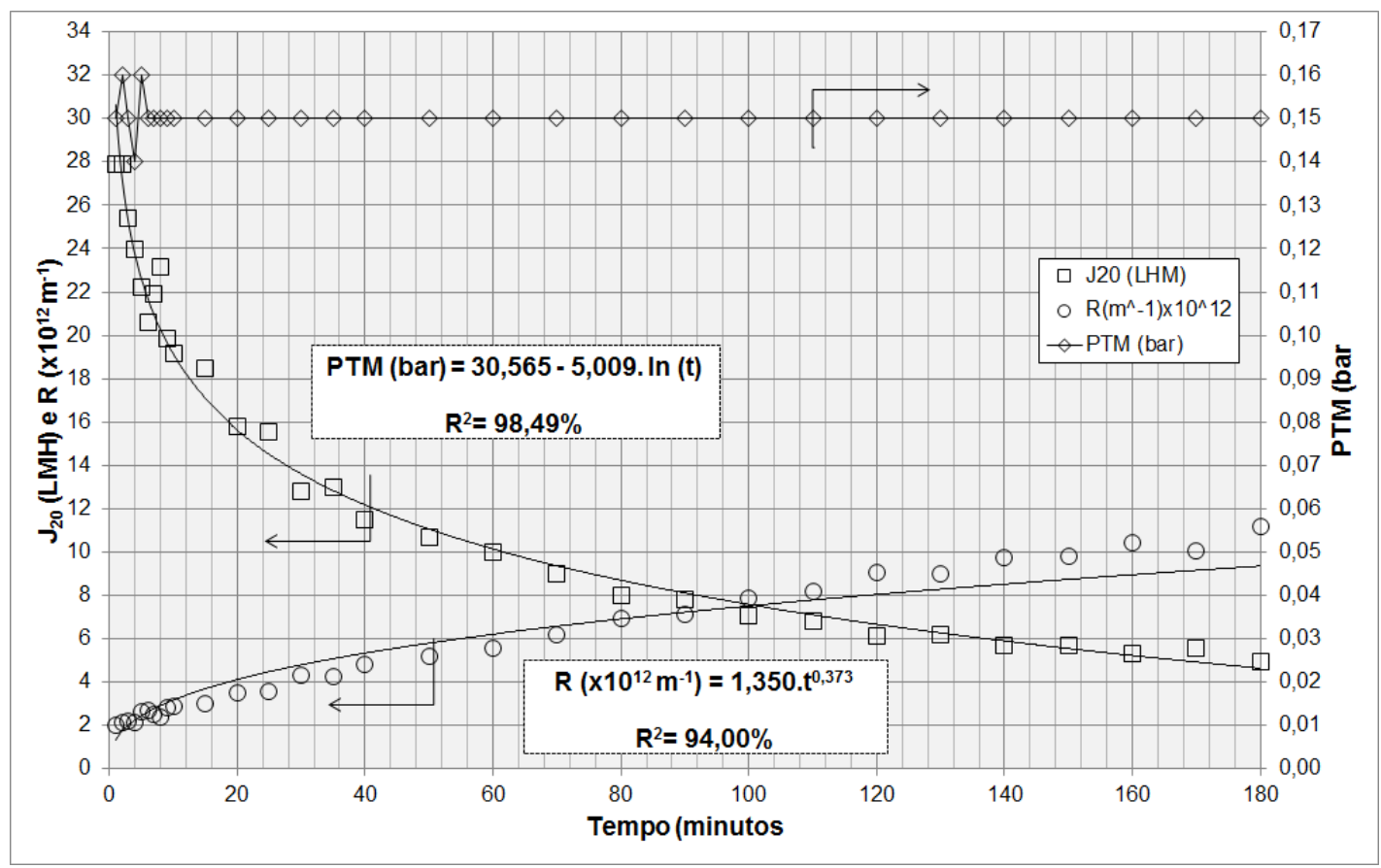

Figura 5.4 - Gráfico do fluxo padronizado, $\mathrm{J}_{20}$, e da resistência desenvolvida ao longo da filtração do efluente do reator $U A S B$ realizada com PTM de $-0,15$ bar no dia 11/12/2016.

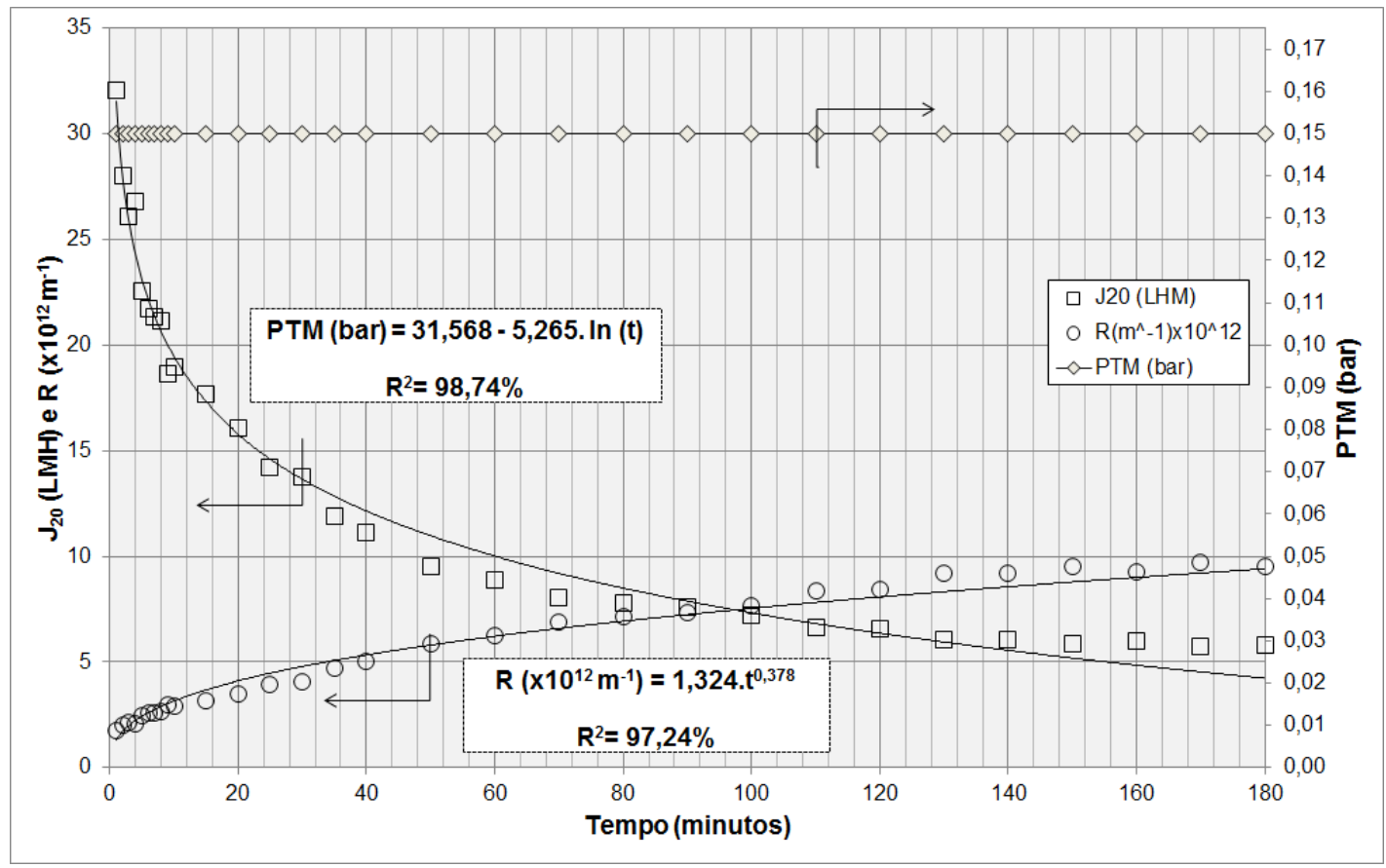

Figura 5.5 - Gráfico do fluxo padronizado, $\mathrm{J}_{20}$, e da resistência desenvolvida ao longo da filtração do efluente do reator $U A S B$ realizada com PTM de -0,15 bar no dia 14/12/2016. 


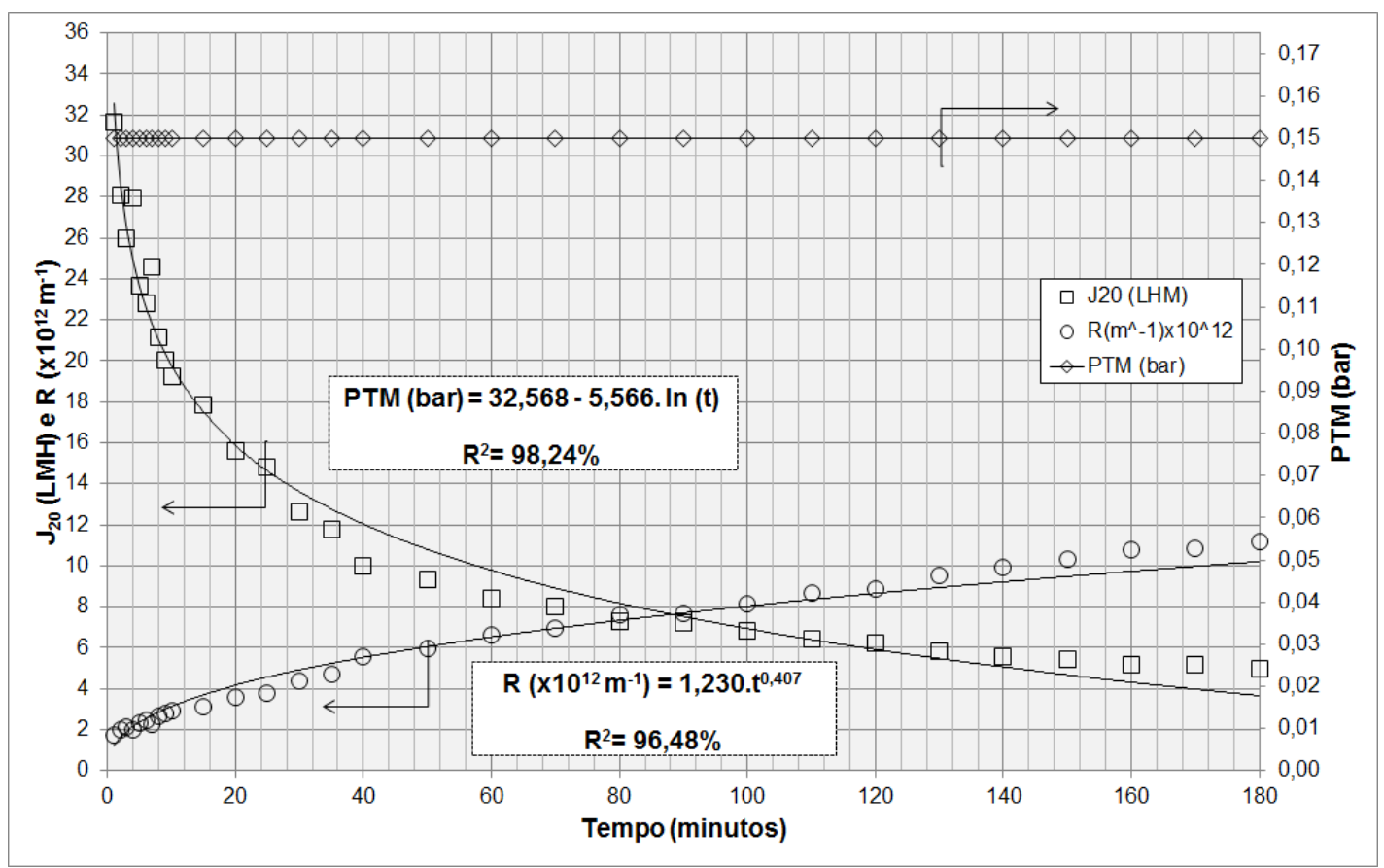

Figura 5.6 - Gráfico do fluxo padronizado, $\mathrm{J}_{20}$, e da resistência desenvolvida ao longo da filtração do efluente do reator UASB realizada com PTM de $-0,15$ bar no dia 15/12/2016.

As Figuras 5.7 a 5.9 exibem as corridas relacionadas com PTM de -0,20 bar.

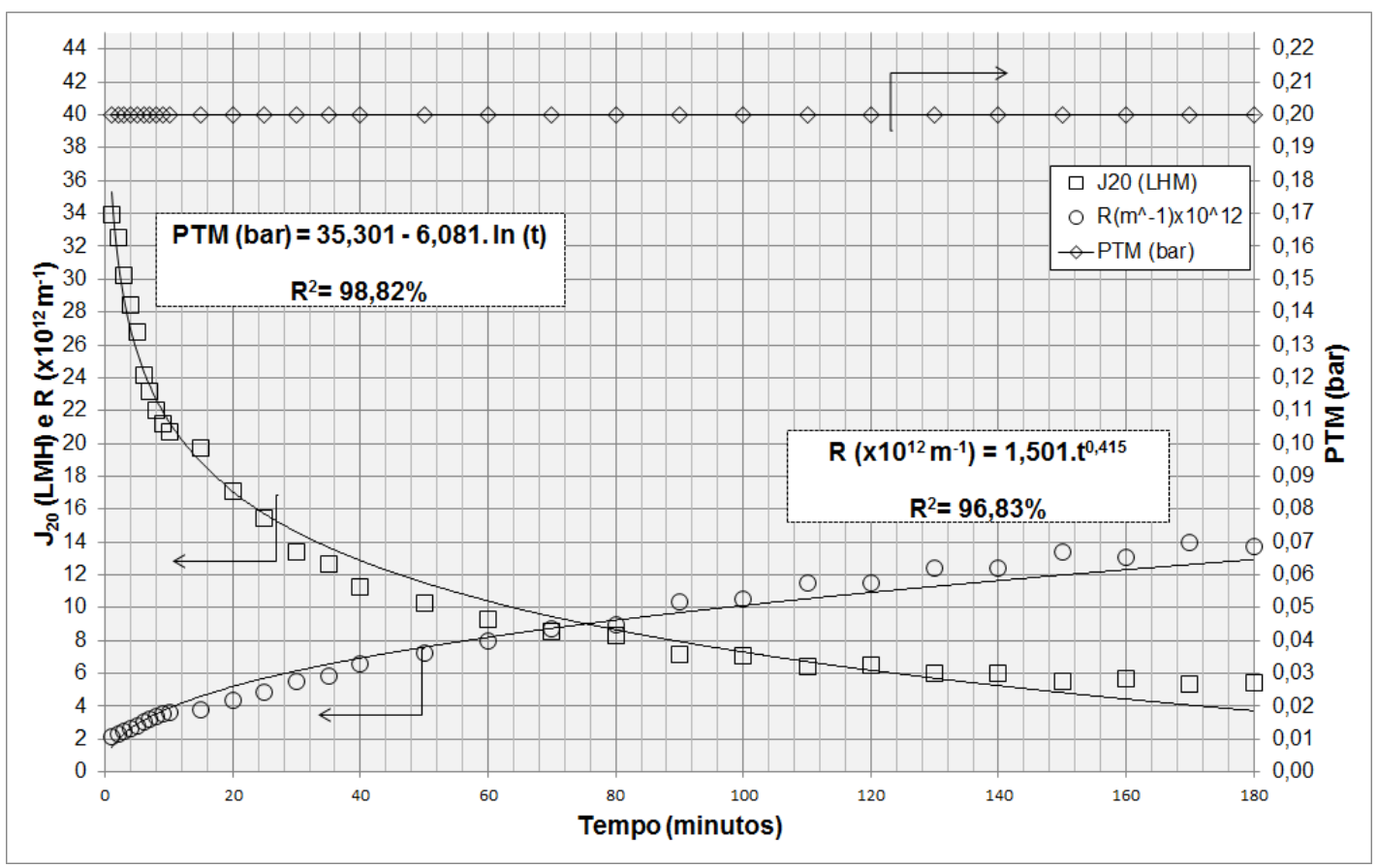

Figura 5.7 - Gráfico do fluxo padronizado, $\mathbf{J}_{20}$, e da resistência desenvolvida ao longo da filtração do efluente do reator $U A S B$ realizada com PTM de -0,20 bar no dia 08/12/2016. 


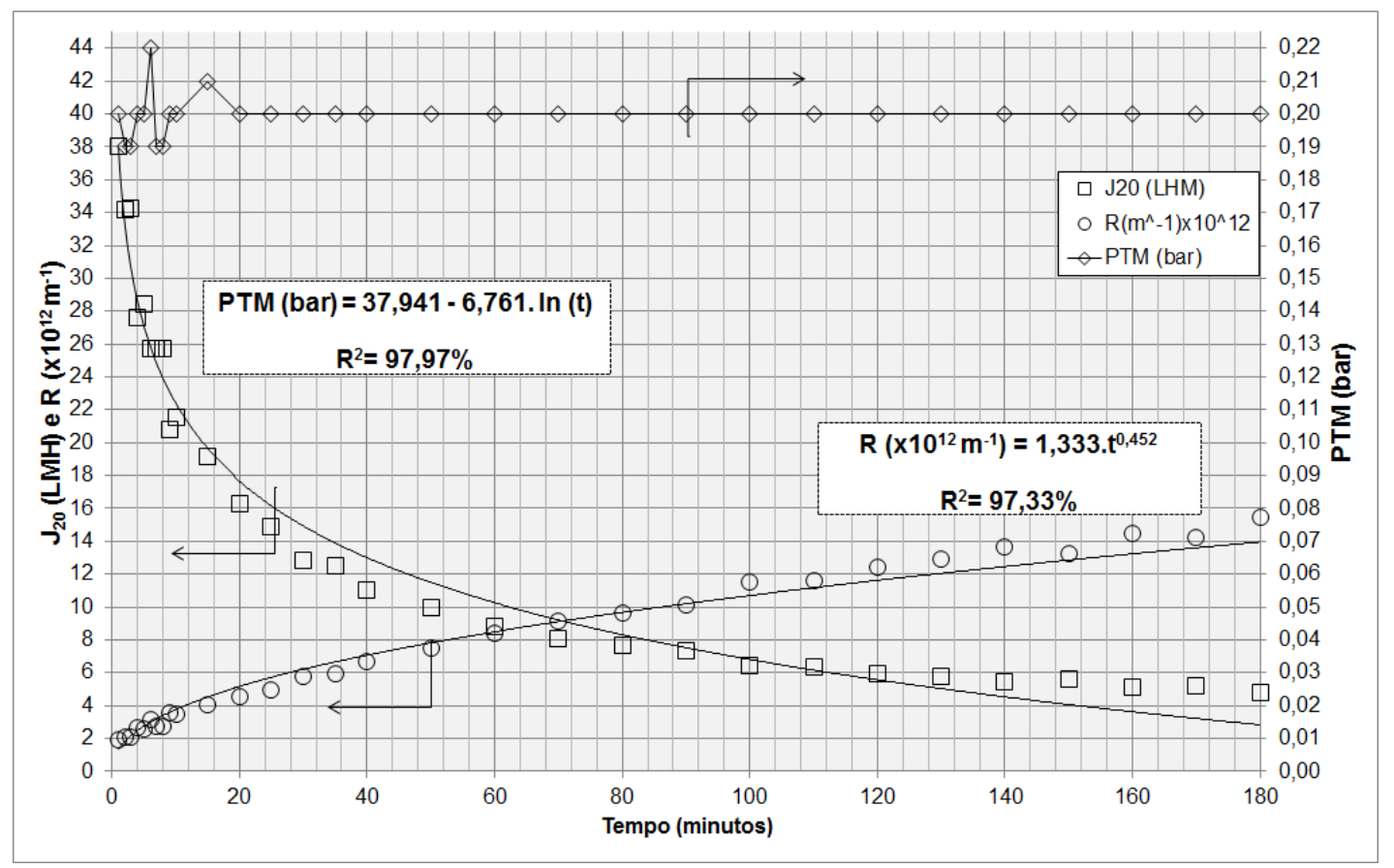

Figura 5.8 - Gráfico do fluxo padronizado, $\mathbf{J}_{20}$, e da resistência desenvolvida ao longo da filtração do efluente do reator UASB realizada com PTM de -0,20 bar no dia 09/12/2016.

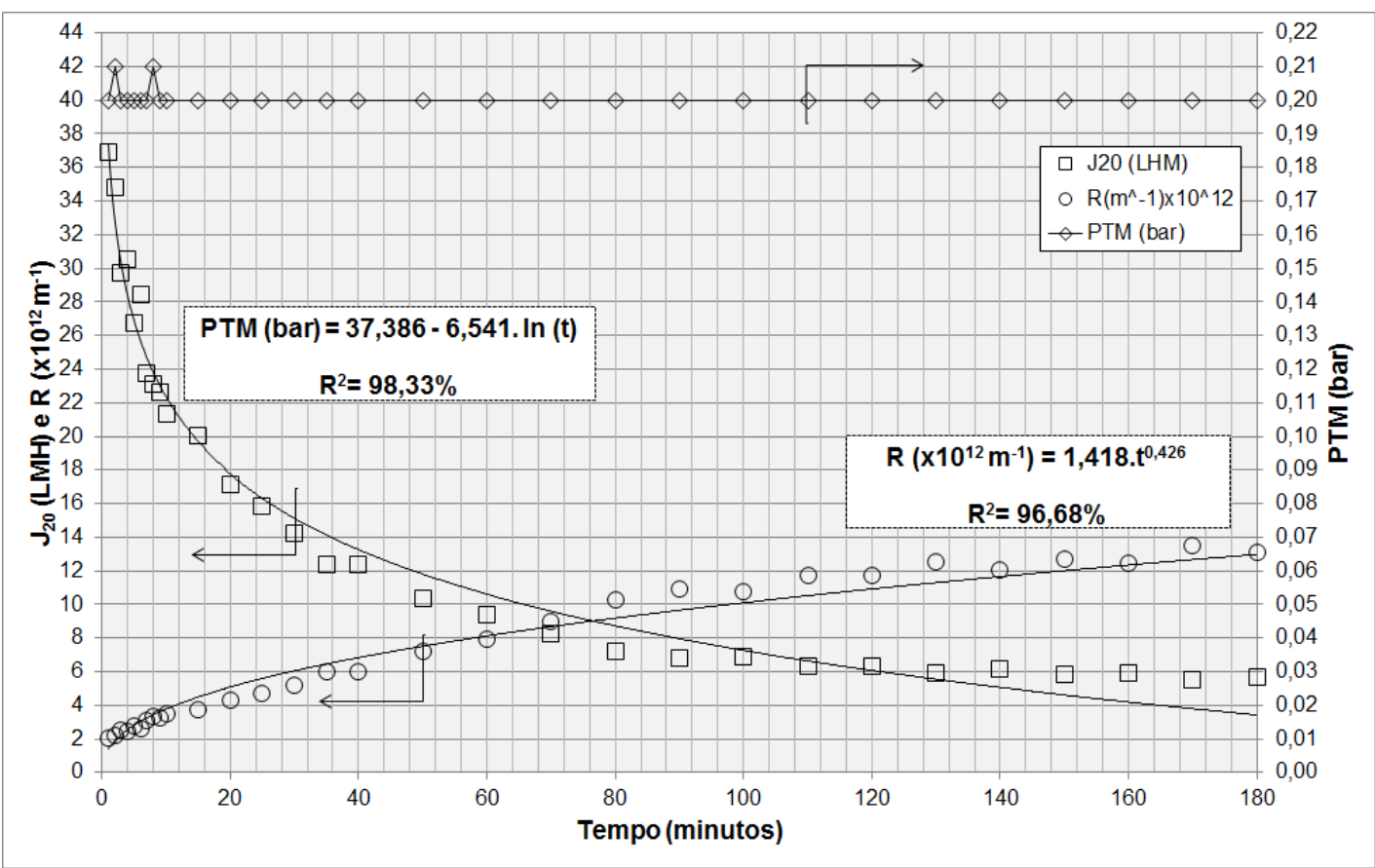

Figura 5.9 - Gráfico do fluxo padronizado, $\mathbf{J}_{20}$, e da resistência desenvolvida ao longo da filtração do efluente do reator UASB realizada com PTM de -0,20 bar no dia 10/12/2016. 
Como verificado pelos gráficos das Figuras 5.1 a 5.9, o modelo que melhor representa o fluxo $\left(\mathrm{J}_{20}\right)$ ao longo do tempo é uma função logarítmica neperiana, ou seja, uma função inversa da exponencial com o número de Neper. Todas as nove equações de tendência descritas nas Figuras 5.1 a 5.9 para $\mathbf{J}_{20}$ apresentaram coeficientes de determinação $\left(\mathrm{r}^{2}\right)$ acima de 0,95 , representando uma relação muito forte entre as duas variáveis $\left(J_{20}\right.$ e t $)$, quando comparado com a referência relatada como padrão informal para coeficiente de determinação dada por Takashi e Inoue (2010), que é 0,81.

Cheryan (1998) reporta que a maioria dos modelos relacionam o fluxo com o tempo ou o volume permeado e geralmente assumem uma forma exponencial, sempre levando em consideração as formas das curvas da incrustação. As Equações 5.3 a 5.6 demonstram os modelos mais comuns encontrados por Cheryan (1998).

$$
\begin{gathered}
J_{t}=J_{0} \cdot t^{-b} \\
J_{t}=J_{0} \cdot e^{-b t} \\
J_{t}=J_{0} \cdot V^{-b t} \\
J_{t}=J_{S S}+k \cdot e^{-b t}
\end{gathered}
$$

Onde: $\mathrm{J}_{0}$ é o fluxo inicial, $\mathrm{J}_{\mathrm{t}}$ o fluxo em um tempo qualquer, $\mathrm{J}_{\mathrm{SS}}$ o fluxo limite ou fluxo no regime permanente, $\mathrm{V}$ o volume do permeado, $\mathrm{k}$ e b são os parâmetros que caracterizam o processo de incrustação (fouling).

De modo inverso, os resultados deste trabalho apontaram para a representação do fenômeno do fluxo em microfiltração de efluente de reator $U A S B$ em função do tempo pela expressão matemática descrita pela Equação 5.7, de forma genérica.

$$
J_{20}=J_{0}-\alpha \cdot \ln t
$$

Onde: $\mathrm{J}_{20}$ é o fluxo padronizado em $\mathrm{LMH}, \mathrm{J}_{0}$ representa o fluxo inicial ou fluxo no tempo zero em LMH e $\alpha$ a constante de decaimento devido ao processo de incrustação, $\mathrm{J}_{0}$ e $\alpha$ dependem da PTM. 
Já a resistência desenvolvida apresentou a aderência a um modelo matemático com uma função potência, ou seja, $\mathrm{R}$ é função potência de $\mathrm{t}$ e com todos os nove resultados dos coeficientes de determinação $\left(\mathrm{r}^{2}\right)$ das equações das tendências superiores a 0,91 , também maior que a referência de 0,81 (Takahashi e Inoue, 2010), descrita pela Equação 5.8, de forma genérica.

$$
R=R_{0} \cdot t^{\beta}
$$

Onde: $\mathrm{R}\left(\mathrm{x} 10^{12}\right)$ é a resistência desenvolvida expressa em $\mathrm{m}^{-1}, \mathrm{R}_{0}$ representa a resistência inicial, resistência no tempo zero ou resistência da membrana limpa e $\beta$ a constante de incremento do processo de incrustação (fouling), que depende da PTM.

Nas Tabelas 5.3 e 5.4 apresentam-se os valores dos componentes das Equações 5.3 e 5.4, já demonstrados no corpo das Figuras de 5.1 a 5.9. Observa-se nas Tabela 5.3 e 5.4, que para o fluxo e a resistência desenvolvida, os valores levantados para as duas Equações 5.3 e 5.4, exceto os da resistência da membrana limpa $\left(\mathrm{R}_{0}\right)$, tendem a aumentar com o aumento da PTM, no caso os valores de $J_{0}$ e de $\alpha$ para $J_{20}=f(t)$ na Tabela 5.3 e o valores $\beta$ para $R=f(t)$ na Tabela 5.4. O valor médio medido para a resistência da membrana limpa $\left(\mathrm{R}_{0}\right)$ apresenta a grandeza de $1,36.10^{12} \mathrm{~m}^{-1}$, determinado nestas nove corridas iniciais.

Tabela 5.3 - Valores dos parâmetros dos modelos que representam o fluxo $\mathrm{J}_{20}$ em função do tempo para microfiltração de efluente de reator $U A S B$ com PTM de -0,10, $-0,15$ e $-0,20$ bar determinados na pesquisa.

\begin{tabular}{lcccccc}
\hline & & \multicolumn{5}{c}{$\mathrm{J}_{20}(\mathrm{LMH})$} \\
\cline { 2 - 7 } PTM & Corrida & $\mathrm{J}_{\mathrm{o}}$ & $\alpha$ & $\mathrm{r}^{2}$ & $\left(\mathrm{~J}_{\mathrm{o}}\right)_{\text {médio }}$ & $(\alpha)_{\text {médio }}$ \\
\hline \multirow{2}{*}{$-0,10$} & 1 & 17,435 & 2,567 & 0,9547 & & \\
& 2 & 24,040 & 3,896 & 0,9717 & 21,681 & 3,370 \\
& 3 & 23,569 & 3,647 & 0,9727 & & \\
\hline \multirow{2}{*}{$-0,15$} & 1 & 30,565 & 5,009 & 0,9849 & & \\
& 2 & 31,568 & 5,265 & 0,9874 & 31,567 & 5,280 \\
& 3 & 32,568 & 5,566 & 0,9824 & & \\
\hline \multirow{3}{*}{0,20} & 1 & 35,301 & 6,081 & 0,9882 & & \\
& 2 & 37,941 & 6,761 & 0,9797 & 36,8760 & 6,461 \\
& 3 & 37,386 & 6,541 & 0,9833 & & \\
\hline
\end{tabular}


Tabela 5.4 - Valores dos parâmetros dos modelos que representam a resistência desenvolvida $(\mathrm{R})$ em função do tempo para microfiltração de efluente de reator UASB com

PTM de $-0,10,-0,15$ e - $-0,20$ bar determinados na pesquisa.

\begin{tabular}{lcccccc}
\hline & & \multicolumn{5}{c}{$\mathrm{R}\left(\mathrm{x} 10^{12} \mathrm{~m}^{-1}\right)$} \\
\cline { 2 - 7 } PTM & Corrida & $\mathrm{R}_{\mathrm{o}}$ & $\beta$ & $\mathrm{r}^{2}$ & $\left(\mathrm{R}_{\mathrm{o}}\right)$ médio & $(\beta)$ médio \\
\hline \multirow{2}{*}{$-0,10$} & 1 & 1,707 & 0,302 & 0,9105 & & \\
& 2 & 1,185 & 0,363 & 0,9279 & 1,377 & 0,331 \\
& 3 & 1,239 & 0,328 & 0,9431 & & \\
\hline \multirow{2}{*}{-15} & 1 & 1,350 & 0,373 & 0,9400 & & \\
& 2 & 1,324 & 0,378 & 0,9724 & 1,301 & 0,386 \\
& 3 & 1,230 & 0,407 & 0,9648 & & \\
\hline \multirow{2}{*}{$-0,20$} & 1 & 1,501 & 0,415 & 0,9683 & & \\
& 2 & 1,333 & 0,452 & 0,9733 & 1,417 & 0,431 \\
& 3 & 1,418 & 0,426 & 0,9668 & & \\
\hline
\end{tabular}

Com os resultados médios dos parâmetros do fluxo versus tempo demonstrados na Tabela 5.3, elaborou-se o gráfico da Figura 5.10, onde é observado o comportamento do fluxo com relação às três PTM dos testes.

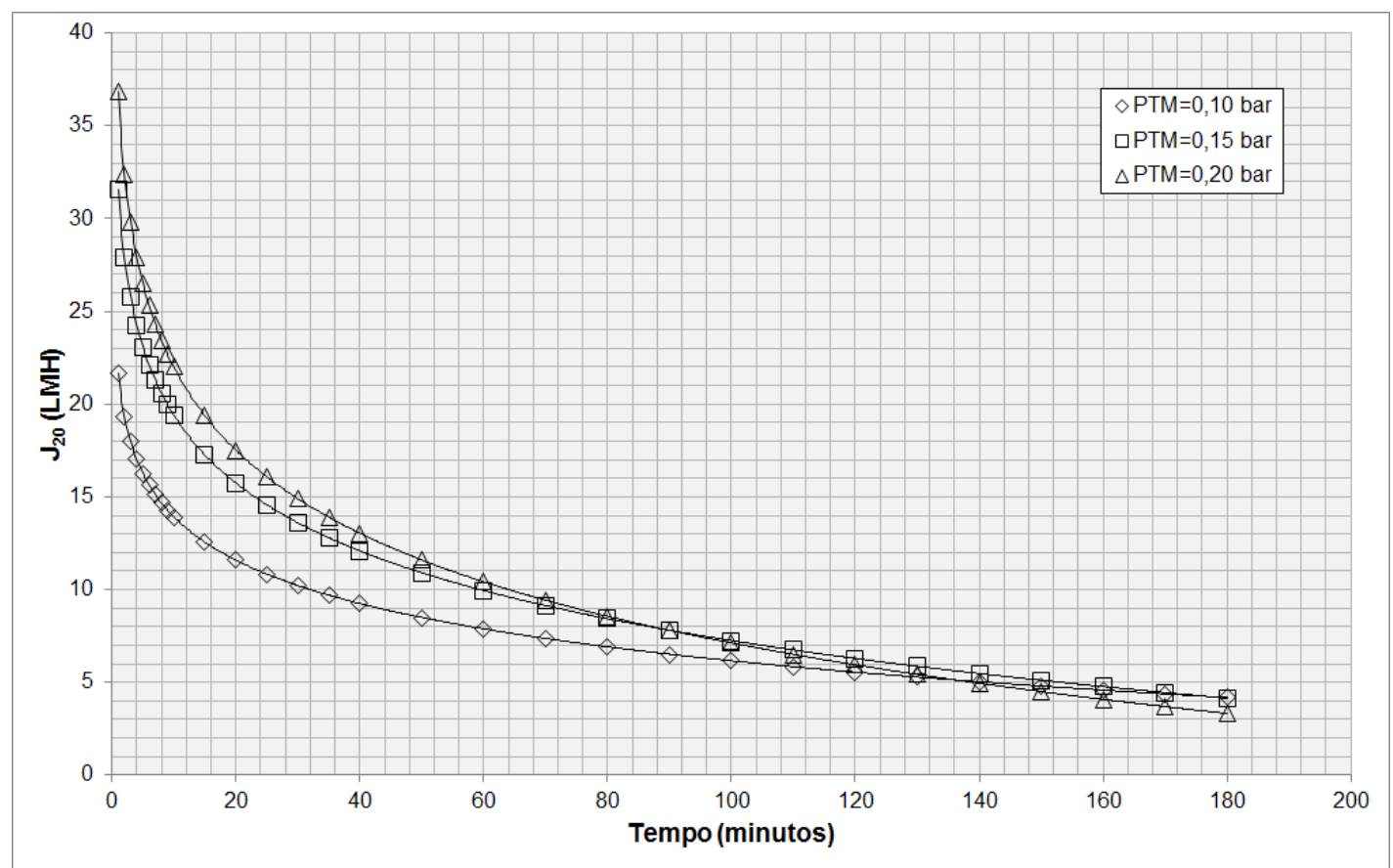

Figura 5.10 - Gráfico do fluxo padronizado, $\mathbf{J}_{20}$, em função do tempo ao longo da filtração do efluente do reator $U A S B$ realizada com PTMs de $-0,10,-0,15$ e $-0,20$ bar. 
Derivando a Equação 5.7, obtém-se a Equação 5.9, que descreve o decaimento do fluxo em relação ao tempo, e substituindo os valores médios dos parâmetros demonstrados na Tabela 5.3 elaborou-se o gráfico da Figura 5.11, onde é observado o comportamento do declínio do fluxo em relação às três PTM ensaiadas.

$$
\frac{-d J_{20}}{d t}=\frac{\alpha}{t}
$$

Onde: $\mathrm{J}_{20}$ é o fluxo padronizado em LMH e $\alpha$ a constante de decaimento devido ao processo de incrustação.

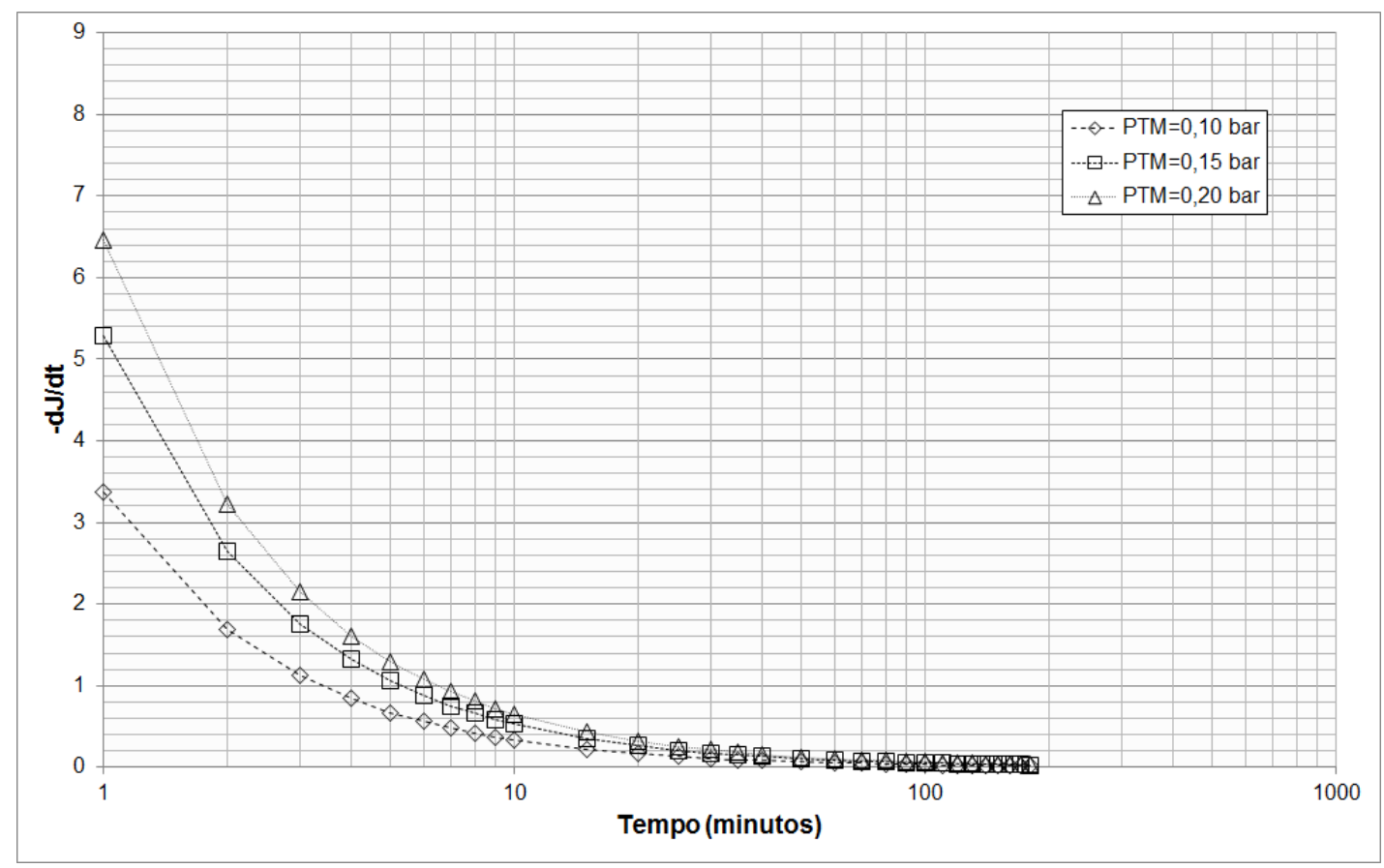

Figura 5.11 - Decaimento do fluxo padronizado $\left(\mathrm{J}_{20}\right)$ em função do tempo ao longo da filtração do efluente do reator $U A S B$ realizada com PTMs de -0,10, -0,15 e -0,20 bar.

Observa-se no gráfico da Figura 5.11, como exemplo, para um tempo de filtração de 15 minutos, que o decaimento é incrementado com os valores de pressões de sucção aplicados e que o menor ocorreu na PTM de $-0,10$ bar. 
Com os resultados médios dos parâmetros da resistência desenvolvida (R) versus tempo demonstrados na Tabela 5.4 elaborou-se o gráfico da Figura 5.12, onde é observado o comportamento da resistência desenvolvida com as três PTM aplicadas nos testes.

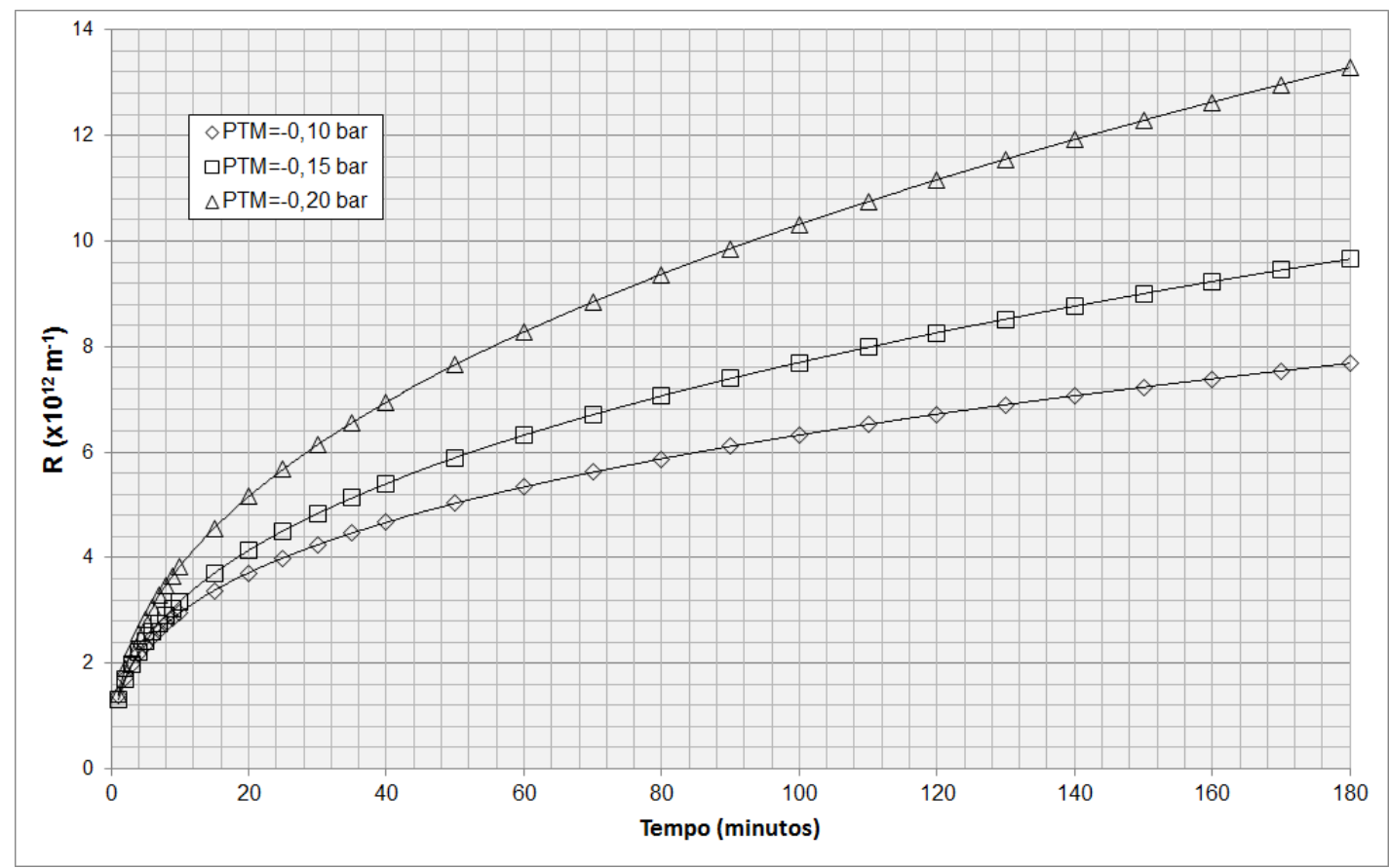

Figura 5.12 - Gráfico da resistência desenvolvida (R) em função do tempo ao longo da filtração do efluente do reator $U A S B$ realizada com PTMs de -0,10, $-0,15$ e $-0,20$ bar.

Observa-se no gráfico da Figura 5.12 que, para o tempo de filtração de 180 minutos, a resistência desenvolvida $(\mathrm{R})$ aumenta com os valores de pressões de sucção aplicados e que o menor resistência desenvolvida ocorreu na PTM de -0,10 bar.

Como descrito no Método (item 4.3) e no fluxograma da Figura 4.11, foi proposto e executado um protocolo de limpeza, consistindo de três ciclos: (i) Primeira limpezaenxague com água potável por 15' com vazão de 15 l/minutos, (ii) Segunda limpeza - a retrolavagem com água potável aplicando PTM de +0,30 bar e vazão de 15 l/minutos por 30’ e (iii) Terceira limpeza (hidráulica/química) - com adição de $\mathrm{NaClO}$ - $15 \%$ para proporcionar uma concentração de $800 \mathrm{mg} / \ell$ no TQ01 (tanque de membrana submersa) e alternando com 15' com relaxamento proporcionado pela injeção de ar soprado e $45^{\prime}$ em repouso e no final outro enxague, como o da Primeira limpeza. 
Antes da primeira limpeza e depois de cada uma das três subsequentes, foi efetuado o ensaio da permeabilidade hidráulica com água potável com intuito de determinar a resistência total $\left(\mathrm{R}_{\mathrm{T}}\right)$ antes da primeira limpeza, a resistência desenvolvida após a primeira limpeza $\left(\mathrm{R}_{1}\right)$, a resistência desenvolvida após a segunda limpeza $\left(\mathrm{R}_{2}\right)$ e, no fím, a resistência da membrana limpa $\left(\mathrm{R}_{0}\right)$ posteriormente a última limpeza, a hidráulica/química.

Estes ensaios foram efetuados para todas as nove corridas de filtração do efluente do reator $U A S B$ e os gráficos das Figuras 5.13 e 5.14 apresentam os dados das resistências desenvolvidas após o rito das limpezas para cada PTM testada $(-0,10,-0,15$ e $-0,20$ bar). A Figura 5.13 apresenta todos os valores calculados das resistências desenvolvidas e a Figura 5.14 exibe somente os valores médios.

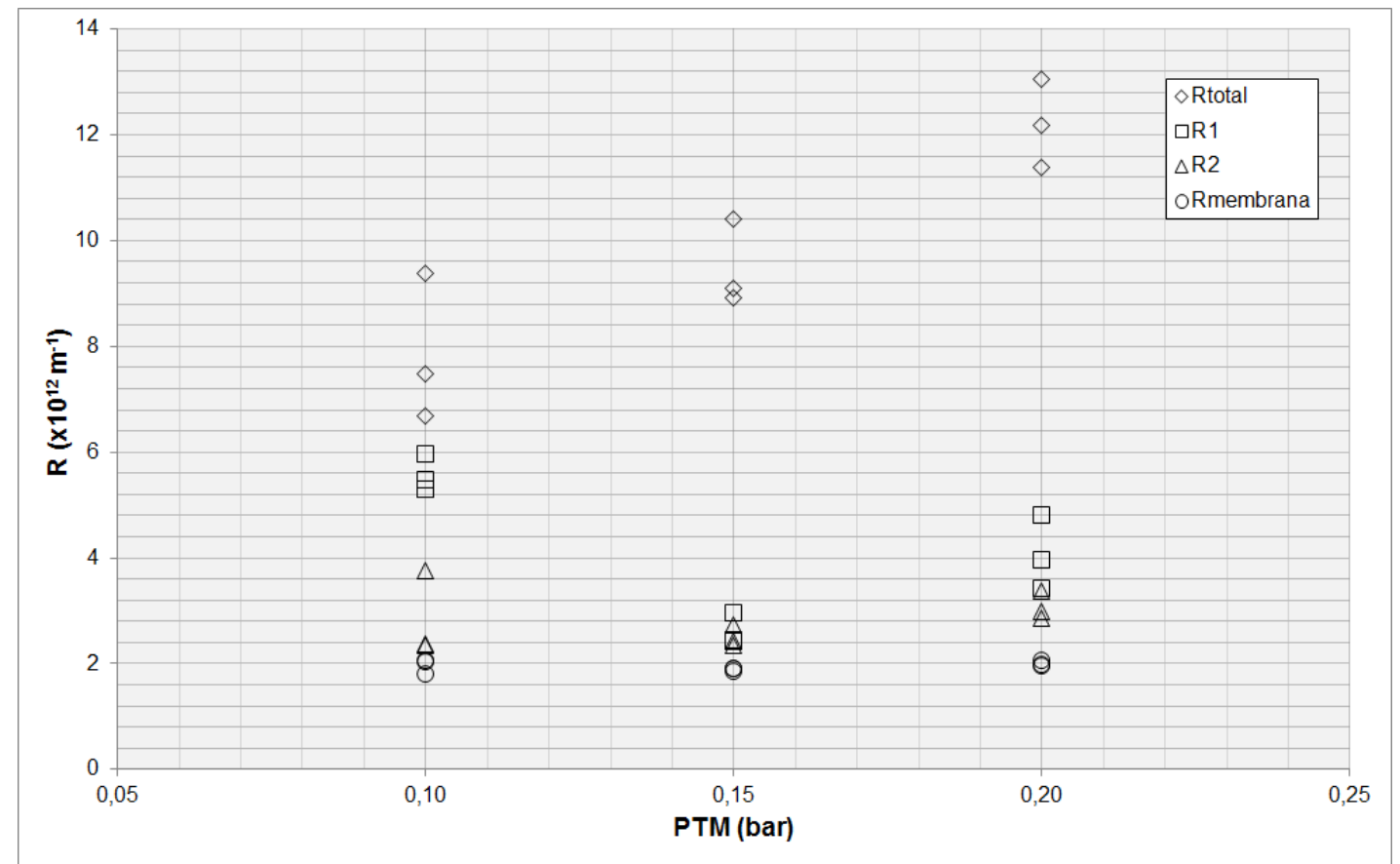

Figura 5.13 - Gráfico das resistências desenvolvidas $\mathrm{R}_{\mathrm{T}}$ (total), $\mathrm{R}_{1}$ (primeira limpeza), $\mathrm{R}_{2}$ (segunda limpeza) e $\mathrm{R}_{0}$ (última limpeza) para todas as PTMs testadas no Levantamento iniciais $(-0,10,-0,15$ e $-0,20$ bar $)$.

Constata-se, pelo que demonstra o gráfico da Figura 5.13 que as resistências desenvolvidas diminuem quando da execução do protocolo de limpeza para todas as PTM testadas e que as $\mathrm{R}_{\mathrm{T}}$ aumentam com o aumento das PTM ensaiadas. 


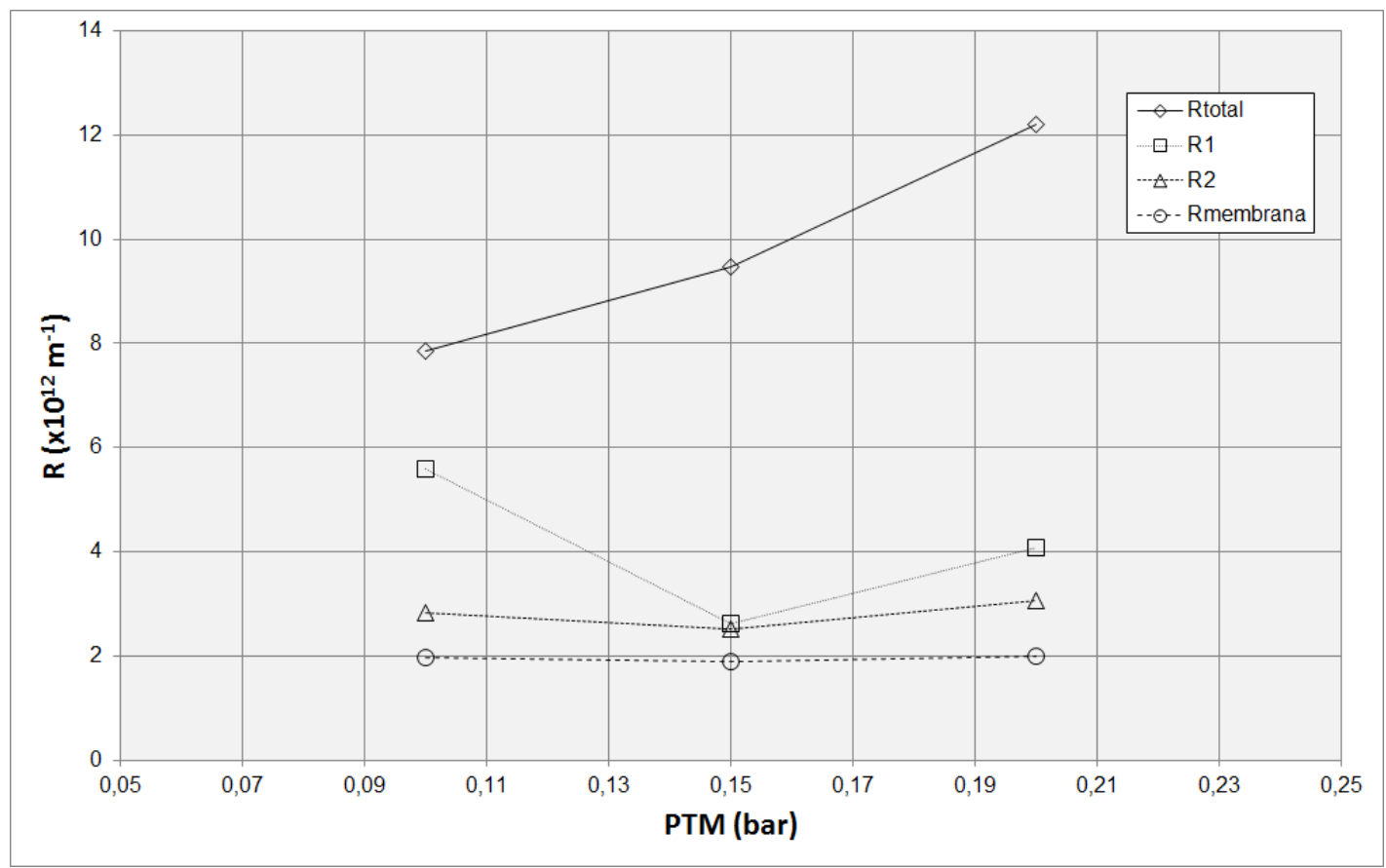

Figura 5.14 - Gráfico das resistências médias desenvolvidas $\mathrm{R}_{\mathrm{T}}$ (total), $\mathrm{R}_{1}$ (primeira limpeza), $\mathrm{R}_{2}$ (segunda limpeza) e $\mathrm{R}_{0}$ (última limpeza) para todas as PTMs testadas no Levantamento iniciais $(-0,10,-0,15$ e $-0,20$ bar).

Nota-se pelo gráfico da Figura 5.14 a confirmação de que, com os valores médios, a $\mathrm{R}_{\mathrm{T}}$ aumenta com a PTM testada. Averígua-se o êxito das segundas (retrolavagem) e terceiras limpezas (hidráulica/química), pois os valores de $\mathrm{R}_{2}$ e $\mathrm{R}_{0}$ independente da PTM testada apresentam valores próximos, porém a força da limpeza hidráulica/química é superior a da retrolavagem. A primeira limpeza (enxague) não possui efetividade na limpeza com valores médios de $\mathrm{R}_{1}$ apresentados sem qualquer relação com a PTM ensaiada.

De acordo com os resultados apurados e expostos, $\mathrm{J}_{20}$ e $\mathrm{R}$ em função do tempo, nesta etapa, que pretendeu verificar o comportamento destas duas variáveis relacionadas às condições operacionais da filtração por membrana submersa do efluente do reator UASB e consonante com Metcalf \& Eddy (2007) e Cheryan (1998), que afirmam que a operação com pressões mais baixas são as desejadas, porque o grau de separação e a qualidade do permeado são melhoradas, decidiu-se operar com a PTM de -0,10 bar. 
Com os volumes produzidos de permeado em cada teste realizado com as três PTMs, elaborou-se o gráfico da Figura 5.15, que apresenta os fluxos médios em função das PTMs testadas.

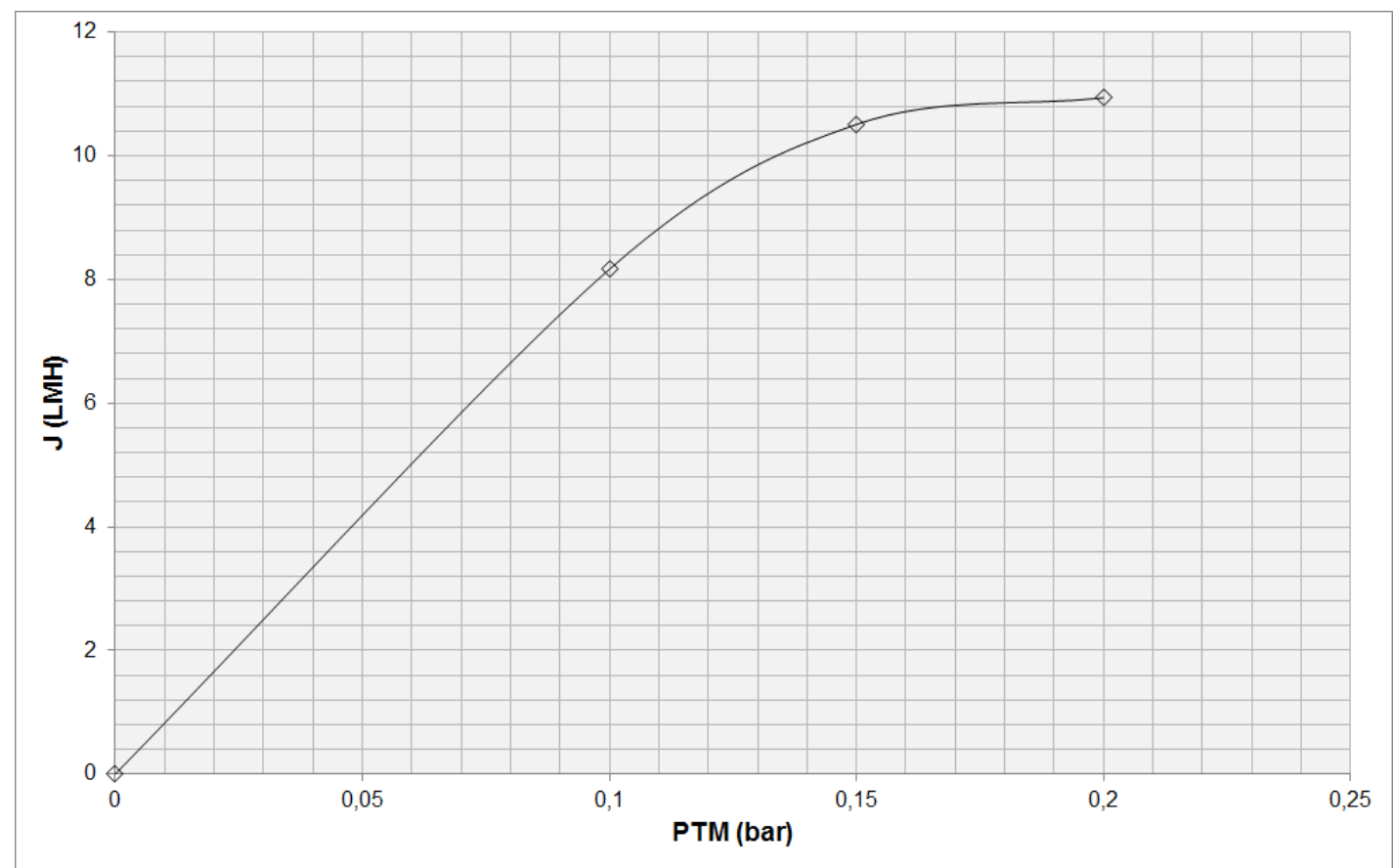

Figura 5.15 - Gráfico do fluxo médio (J em LMH) gerado a partir dos volumes produzidos de permeado nas três corridas sucessivas de cada PTM testada $(-0,10,-0,15$ e $-0,20$ bar).

O gráfico da Figura 5.15 reforçou a decisão de se operar com a menor pressão de sucção ensaiada (PTM), apesar de não terem sido testadas pressões inferiores a $-0,15$ bar nesta etapa da pesquisa, mas pode-se anunciar, com os resultados apurados até este ponto, que os fluxos acima de 10,4 LMH para a microfiltração por membranas submersas de efluente de reator $U A S B$ estão na região controlada pela transferência de massa e não na região controlada pela pressão, que é a situação desejada de se operar, pelo fato de ser uma região na qual se minimiza a formação da camada gel (torta), como explicado anteriormente e mostrado na Figura 3.22.

A escolha para a operação de filtração ser nesta pesquisa de $-0,10$ bar também é reforçada pelo demonstrado no gráfico da Figura 5.15, onde se observa que acima de $-0,15$ bar a operação de microfiltração de efluente do reator $U A S B$ atinge o limite máximo do fluxo (J), considerado como o fluxo crítico. 


\subsection{3 - Fluxo Crítico}

Os testes para investigar o fluxo crítico foram executados por meio do monitoramento do fluxo permeado para PTMs de $-0,02,-0,05,-0,08,-0,10,-0,15$ e $-0,20$ bar, como descrito anteriormente e ilustrado na Figura 4.13. O levantamento foi executado com o tempo de filtração de 15 minutos para cada uma das PTMs avaliadas. Como descrito no procedimento do fluxograma da Figura 4.13, as corridas foram replicadas por cinco (5) vezes e, a cada ensaio executado, no final era realizado o rito de limpeza, com todas as limpezas definidas e descritas anteriormente (enxague, retrolavagem e hidráulica/química), recordando que como última tarefa de cada carreira foi executado o teste para determinação da permeabilidade hidráulica da membrana com água potável.

Com os volumes totais de permeados, produziu-se o gráfico da Figura 5.16, que apresenta o fluxo em função das PTMs avaliadas.

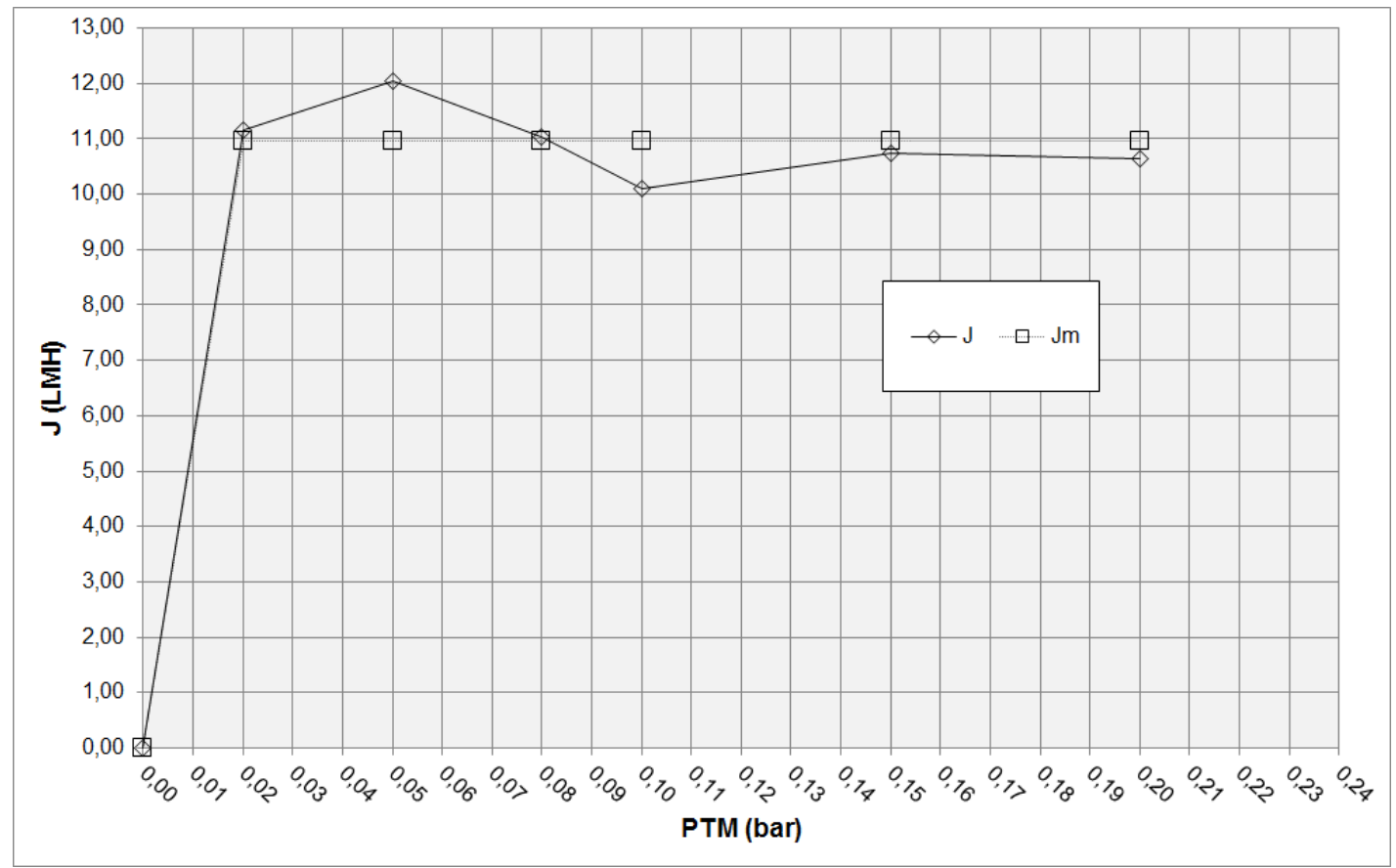

Figura 5.16 - Gráfico do fluxo (J) em função das PTMs aplicadas (-0,02, -0,05, -0,08, $0,10,-0,15$ e $-0,20$ bar) e o fluxo médio $\left(\mathrm{J}_{\mathrm{m}}\right)$ para investigação do Fluxo Crítico para a microfiltração de efluente de reator $U A S B$. 
Observa-se que o fluxo sofreu incremento com a PTM até a o valor aplicado de -0,05 bar, atingindo $12 \mathrm{LMH}$, e a partir desta vazão ocorreu um declínio (10,0 LMH) e estabilizando para as próximas pressões de sucção testadas, em torno de 10,7 LMH. Aplicando a média para todos os valores $\left(\mathrm{J}_{\mathrm{m}}\right)$, o valor de 10,9 LMH é o limite do fluxo contra a PTM e a partir deste, com o aumento da PTM, o fluxo permanece constante. Portanto, após as cinco corridas de microfiltração com efluente do reator $U A S B$, o fluxo crítico pode ser considerado aproximadamente menor que 11,0 LMH.

Ressaltando que o conceito de fluxo crítico é dependente de vários fatores, um dos mais importantes é a qualidade do material alimentado, ou seja, no caso, a composição dos solutos presentes no liquido do efluente do reator $U A S B$, isto pôde ser verificado nesta pesquisa, onde, nas nove (9) primeiras corridas relacionadas com o entendimento do comportamento do fluxo contra o tempo, foi identificado como fluxo crítico o valor de 10,4 LMH. Em um ponto de vista mais restritivo, pode-se afirmar, após 14 corridas de microfiltração de efluente do reator $U A S B$, que o fluxo crítico levantado é inferior a 10 LMH.

\subsection{4 - Tempo de Retrolavagem}

Os ensaios para avaliação do tempo de retrolavagem (TRL) foram realizados perfazendo um total de 9 (nove) testes, três corridas com três tempos de retrolavagem de frequências distintas de 30, 60 e 75 segundos, como ilustra a Figura 4.14, e como proposto e executado por Rodrigues (2012).

As 3 (três) corridas distintas de cada TRL (30", 60" e 75") foram feitas com 12 (doze) etapas de microfiltração de efluente do reator $U A S B$ com tempo de filtração de 15 ' e PTM de $-0,10$ bar e, a cada ensaio executado, no final era realizado o rito de limpeza, com todas as limpezas definidas e descritas anteriormente (enxague, retrolavagem e hidráulica/química), relembrando que como última tarefa de cada carreira foi executado o teste para determinação da permeabilidade hidráulica da água potável.

A Tabela 5.5 apresenta o balanço hídrico de cada corrida executada, onde está registrado, para cada tempo de retrolavagem ensaiado, o volume produzido de permeado (total), o 
volume consumido na retrolavagem, o volume produzido de líquido de permeado, a perda correspondente, e o volume produzido líquido médio de permeado.

Tabela 5.5 - Balanço hídrico do levantamento do tempo de retrolavagem de máxima eficiência para tempos testados de 30", 60" e 75" microfiltrando efluente do reator UASB.

\begin{tabular}{cccccc}
\hline $\begin{array}{c}\text { Tempo de } \\
\text { Retrolavagem } \\
\text { (segundos) }\end{array}$ & $\begin{array}{c}\text { Volume } \\
\text { produzido } \\
\text { de permeado } \\
(\ell)\end{array}$ & $\begin{array}{c}\text { Volume } \\
\text { Consumido na } \\
\text { Retrolavagem } \\
(\ell)\end{array}$ & $\begin{array}{c}\text { Volume } \\
\text { produzido } \\
\text { líquido de } \\
\text { permeado }(\ell)\end{array}$ & $\begin{array}{c}\text { Perda } \\
(\%)\end{array}$ & $\begin{array}{c}\text { Volume } \\
\text { produzido } \\
\text { líquido médio } \\
\text { de permeado } \\
(\ell)\end{array}$ \\
\hline \multirow{2}{*}{$30^{\prime}$} & 185,18 & 16,32 & 168,86 & 8,81 & \\
& 189,55 & 19,76 & 169,79 & 10,42 & 171,30 \\
& 197,26 & 22,00 & 175,26 & 11,15 & \\
\hline \multirow{2}{*}{$60^{\prime}$} & 233,02 & 32,00 & 201,02 & 13,73 & \\
& 202,97 & 29,70 & 173,27 & 14,63 & 179,98 \\
75, & 195,66 & 30,00 & 165,66 & 15,33 & \\
& 213,93 & 48,50 & 165,43 & 22,67 & \\
& 218,61 & 49,00 & 169,61 & 22,41 & 162,97 \\
\hline
\end{tabular}

Com os volumes produzidos líquidos médios de permeado, produziu-se o gráfico da Figura 5.17, em que se apresenta o fluxo em função dos TRLs avaliados.

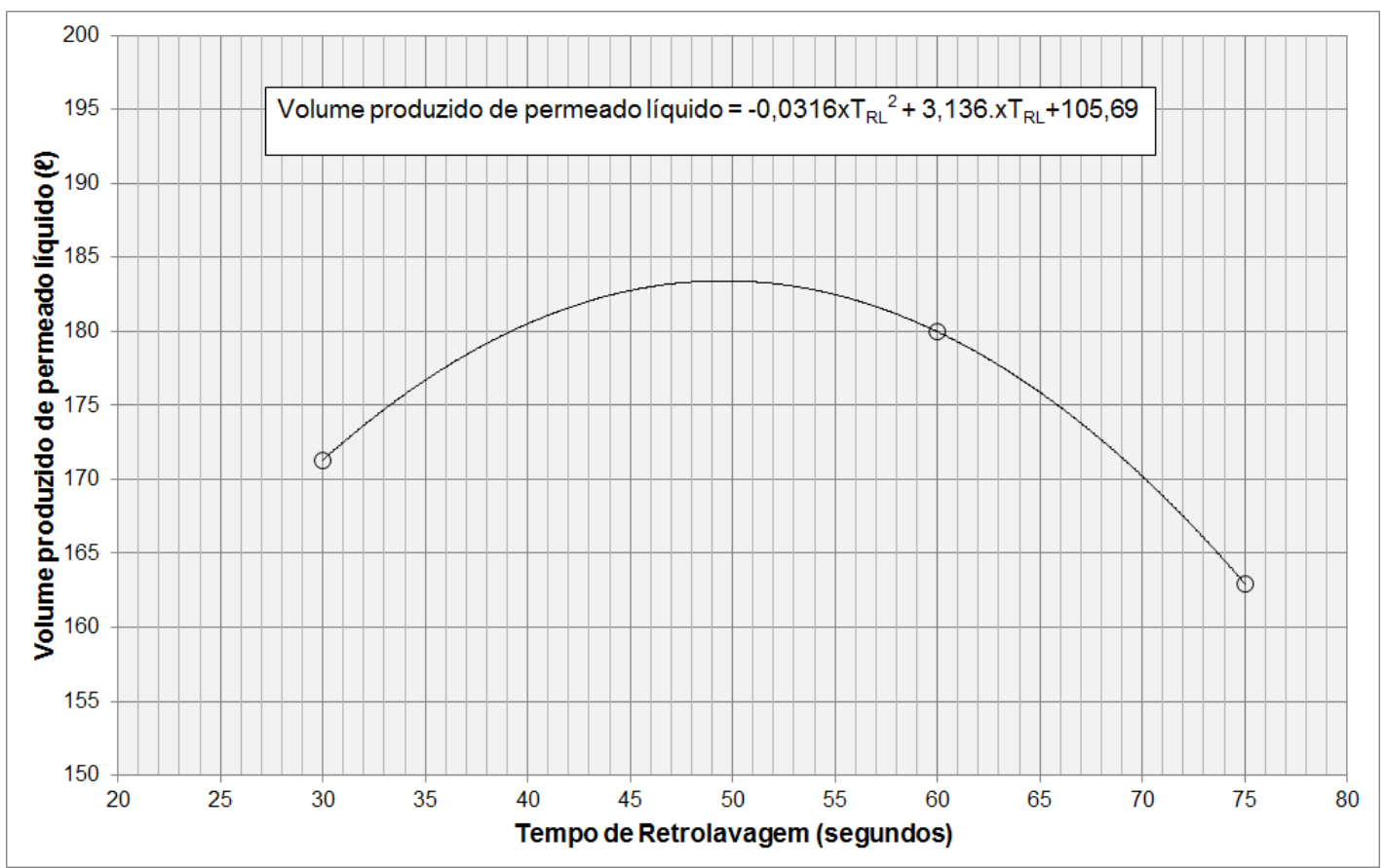

Figura 5.17 - Gráfico do Volume produzido líquido médio de permeado em função dos tempos de retrolavagem testados (30", 45" e 75") para operação de microfiltração de efluente do reator $U A S B$. 
Com base no cálculo do ponto de inflexão (máximo) por meio da derivada primeira da equação da curva demonstrada no gráfico da Figura 5.17 (Rodrigues, 2012), e também, como nota-se no mesmo gráfico, o tempo ideal de retrolavagem que fornece a máxima eficiência de produção de permeado é o tempo de 50 segundos.

A pressão transmembrana (PTM) de -0,10 bar para filtração definida para a próxima fase, de Operação e Monitoramento da Planta-piloto, foi pesquisada e definida na etapa denominada Ensaios Preliminares. O valor é inferior quando comparado com os resultados máximos dos trabalhos de Wen et al. (1999) e An et al. (2009), 0,70 e 0,60 bar, respectivamente. Muito embora, a presente pesquisa operou com PTM de filtração constante e avaliando o declínio do fluxo, e os trabalhos de Wen et al. (1999) e An et al. (2009) foram realizados com fluxo constante e consequente aumento da PTM. O tempo de filtração definido foi o de 15 minutos, considerando o recomendado pela empresa fornecedora da unidade de microfiltração na Tabela 5.6 e com base no decaimento do fluxo observado na Figura 5.11.

O tempo de retrolavagem de melhor eficiência alcançado pelos ensaios efetuados e adotado para próxima etapa foi o de 50 segundos e a PTM usada foi uma unidade absoluta acima do valor definido da PTM de filtração, portanto $+0,20$ bar, como sugerido por PAM Membrana Seletivas (2014).

\section{2 - MONITORAMENTO DO PROCESSO UASB/FSM (OPERAÇÃO DE LONGA DURAÇÃO)}

Esta etapa ocorreu em 16 semanas e foi dedicado à operação de longa duração, cuja execução ocorreu em dois períodos, o primeiro de 28/03 a 13/05/2016 (7 semanas) e o segundo de 22/08 até 20/10/2016 (9 semanas). A operação consistiu em corridas diárias de 6 horas consecutivas por dia, constando de 24 etapas de microfiltração do efluente do reator $U A S B$ (tempo de $15^{\prime}$ e PTM de $-0,10$ bar), intercaladas com a retrolavagem com o permeado (tempo de 50" e PTM de $+0,20$ bar), operando na semana de segunda a quintafeira. E em todas as corridas de operação, foi executada, no fim de cada dia, a limpeza do enxague (segunda no protocolo). Na sexta-feira, último dia da semana, foi dedicada à manutenção do sistema e ao ritual de limpeza das membranas, executando a segunda (retrolavagem) e a terceira (hidráulica/química) limpeza, rememorando que, após a série 
de limpezas, determinação da permeabilidade hidráulica com a água potável, sempre foi o último trabalho executado.

Os resultados deste item foram divididos e apresentados em: (i) Condições operacionais e (ii) Monitoramento Controle de Qualidade.

\subsection{1 - Condições Operacionais}

As 16 semanas de operação foram divididas em quatro períodos de: (i) quatro semanas 28/03 a 20/04, (ii) três semanas - 25/04 a 12/05, (iii) quatro semanas - 22/08 a 15/09 e (iv) cinco semanas - 19/09 a 20/10/2016. Esta divisão foi necessária e com o intuito de que todos os gráficos elaborados se fizessem visualmente mais claros e, consequentemente, esclarecedores.

Os gráficos das Figuras 5.18 e 5.19 ilustram os resultados obtidos nas primeiras quatro semanas de operação microfiltrando efluente do reator $U A S B$. A Figura 5.18 revela o comportamento da variável fluxo padronizado $\left(\mathrm{J}_{20}\right)$ e a Figura 5.19 a evolução da incrustação (fouling) medida por meio da variável resistência desenvolvida, ambas em função do tempo, em minutos.

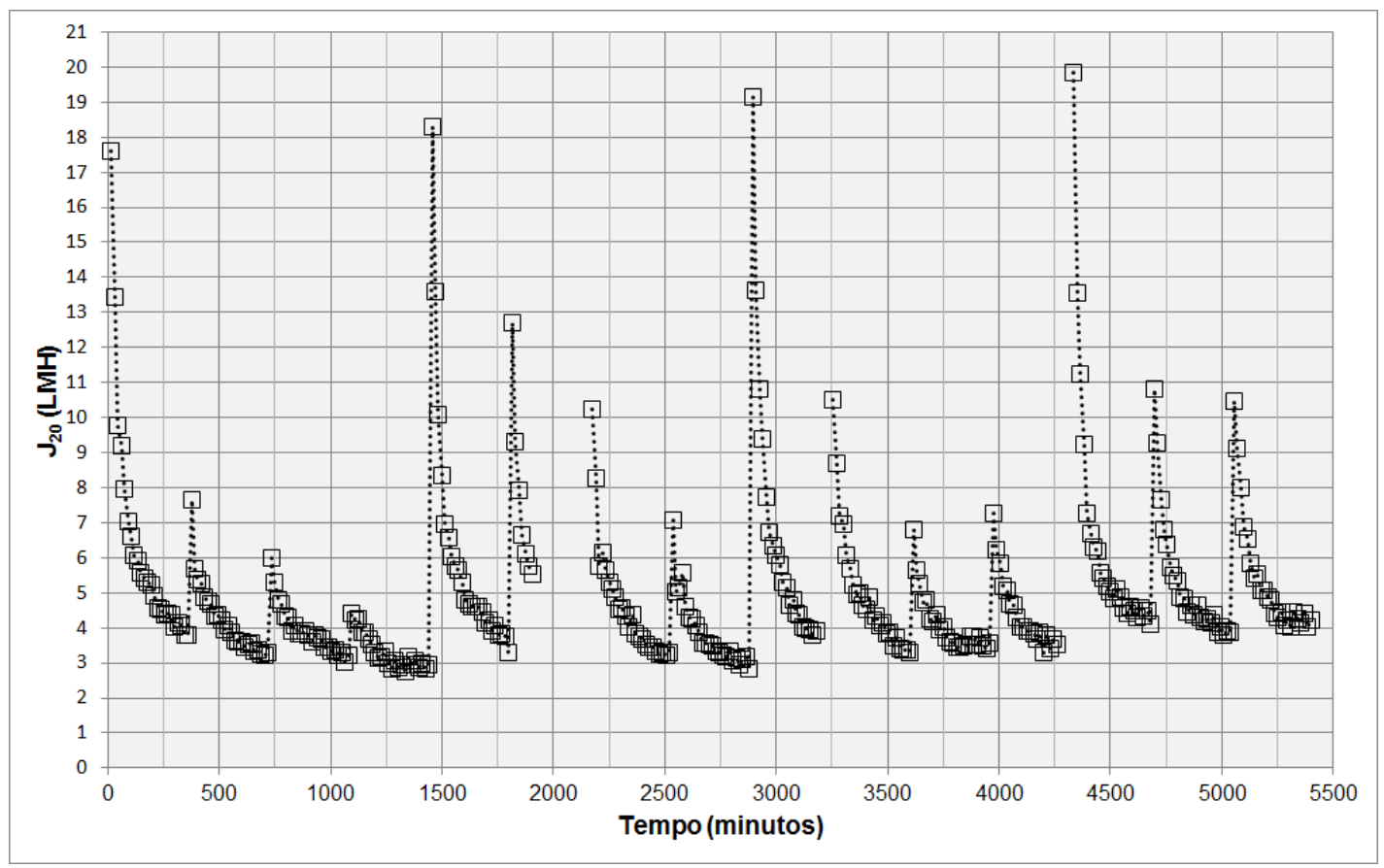

Figura 5.18 - Gráfico do comportamento do fluxo normalizado da operação de microfiltração de efluente de reator $U A S B$ de 28/03 a 20/04/2016 (PTM de -0,1 bar). 


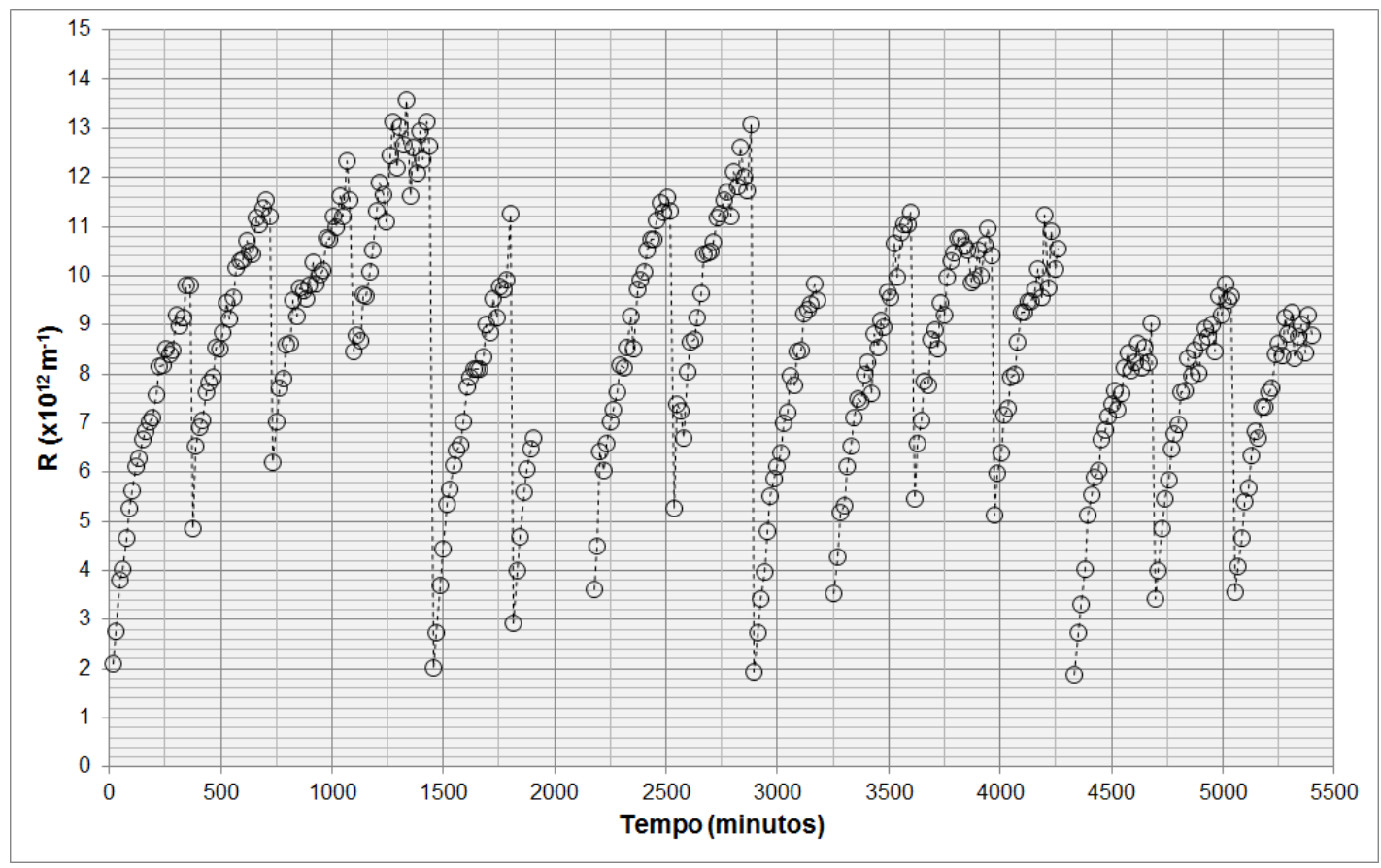

Figura 5.19 - Gráfico da evolução da incrustação medida através da resistência desenvolvida na operação de microfiltração de efluente de reator UASB de 28/03 a 20/04/2016 (PTM de -0,1 bar).

Os gráficos das Figuras $5.20\left(\mathrm{~J}_{20} x \mathrm{t}\right)$ e $5.21(\mathrm{R} x \mathrm{t})$ demonstram o período de 25/04 a $12 / 05 / 16$, as três semanas finais da primeira fase de operação contínua.

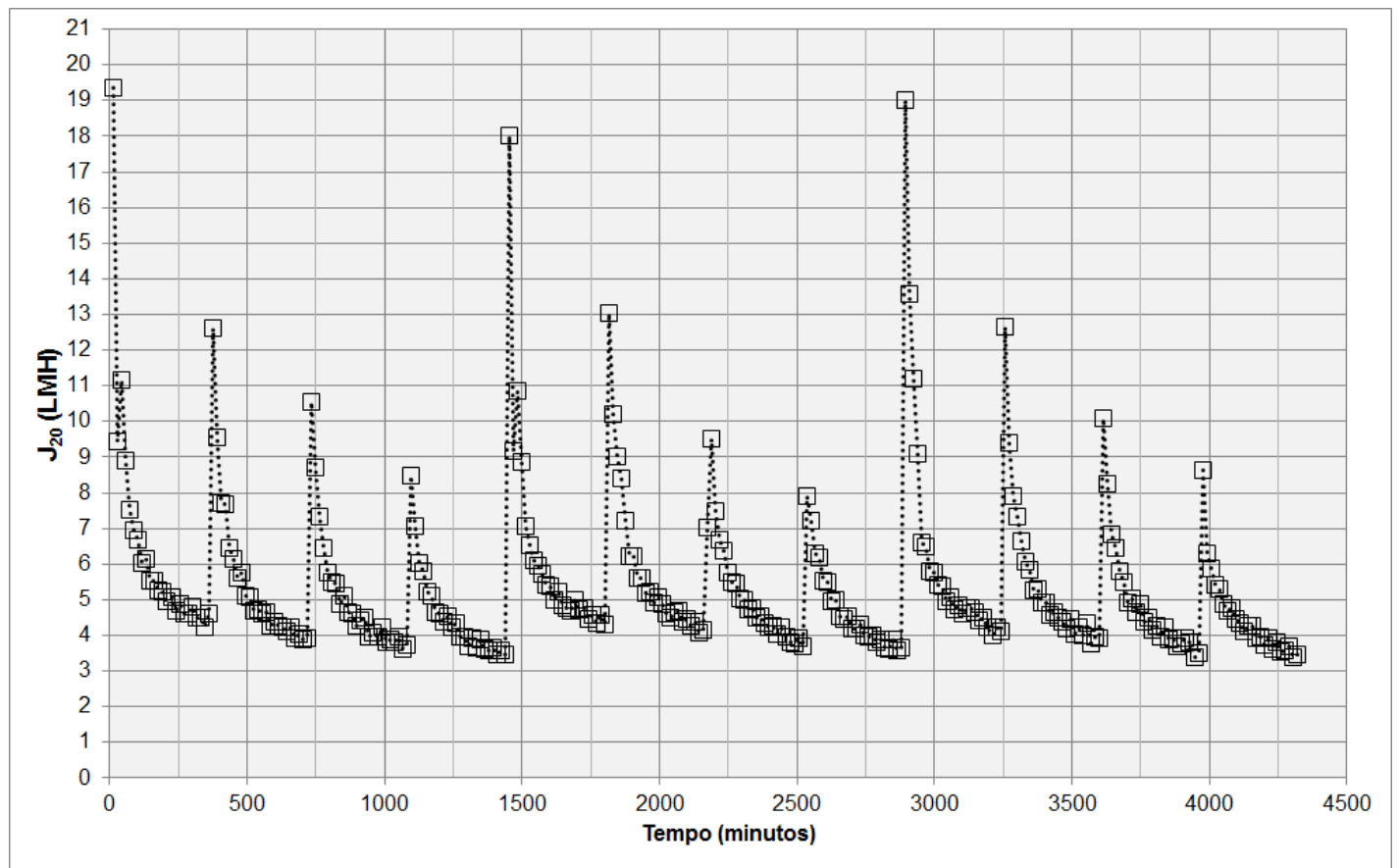

Figura 5.20 - Gráfico do comportamento do fluxo normalizado da operação de microfiltração de efluente de reator $U A S B$ de 25/04 a 12/05/2016 (PTM de -0,1 bar). 


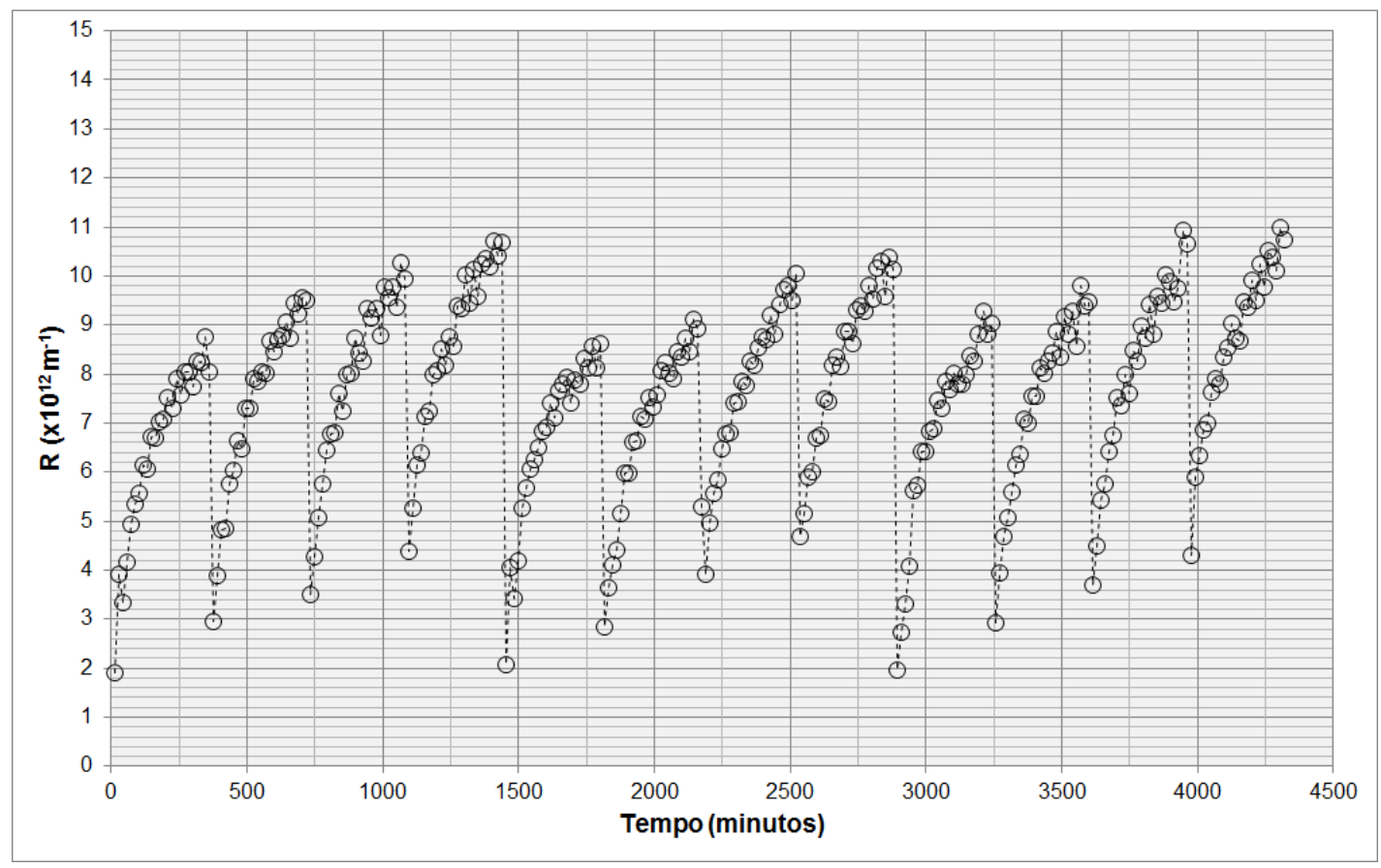

Figura 5.21 - Gráfico da evolução da incrustação medida através da resistência desenvolvida na operação de microfiltração de efluente de reator $U A S B$ de 25/04 a 12/05/2016 (PTM de -0,1 bar).

Os gráficos das Figuras $5.22\left(\mathrm{~J}_{20} x \mathrm{t}\right)$ e $5.23(\mathrm{R} x \mathrm{t})$ demonstram o período de 22/08 a 15/09/16, as quatro semanas iniciais da segunda fase de operação contínua.

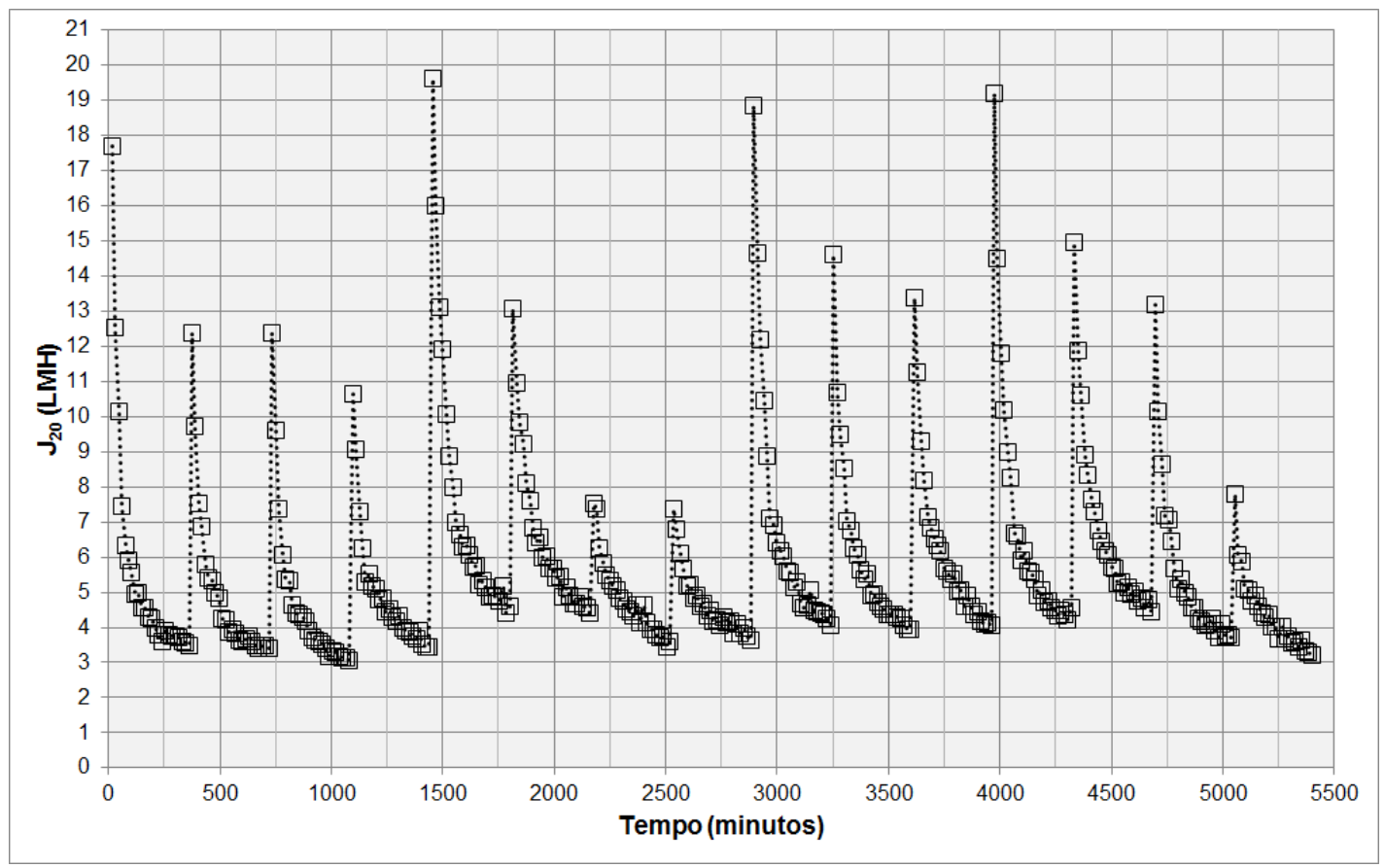

Figura 5.22 - Gráfico do comportamento do fluxo normalizado da operação de microfiltração de efluente de reator $U A S B$ de 22/08 a 15/09/2016 (PTM de -0,1 bar). 


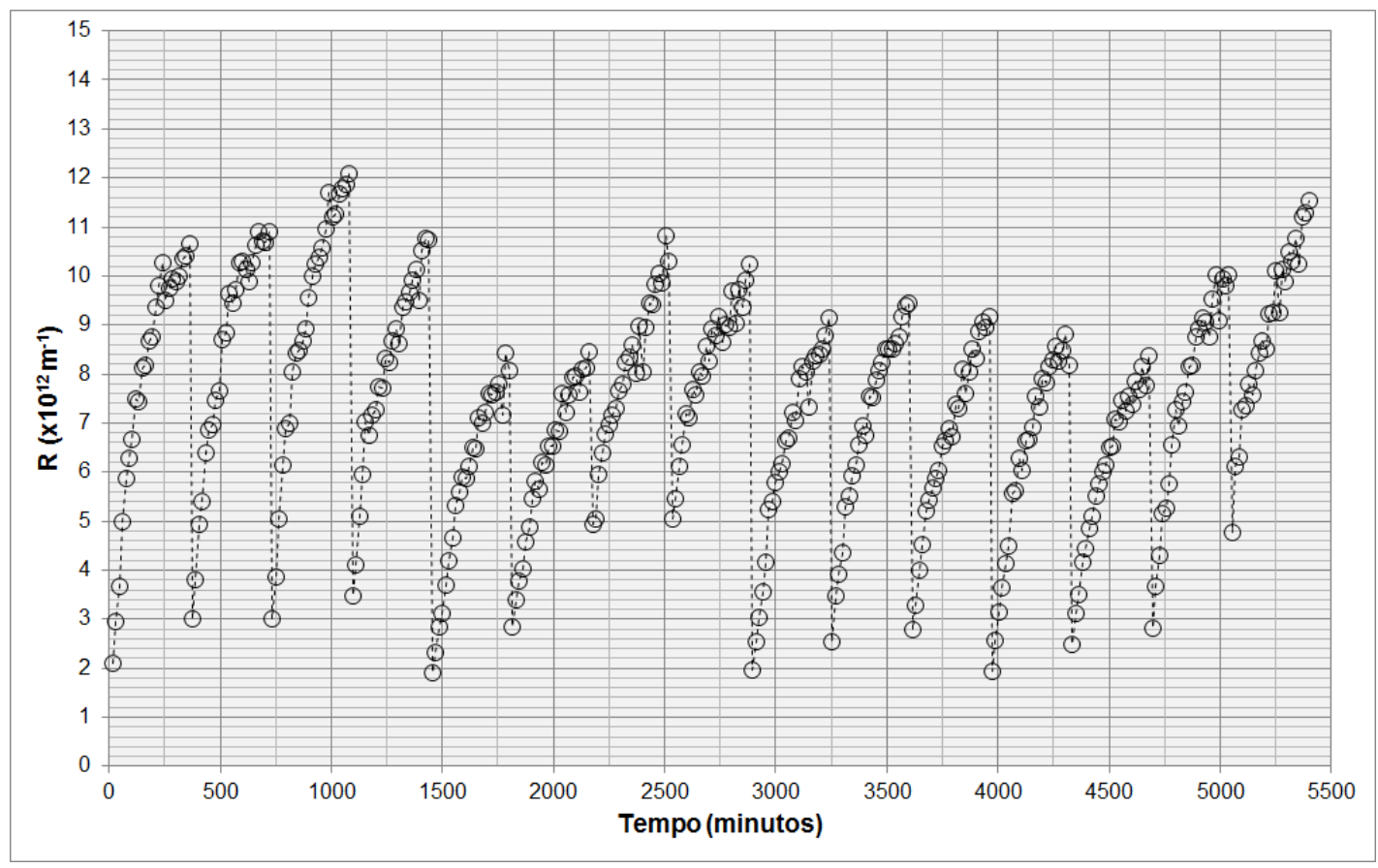

Figura 5.23 - Gráfico da evolução da incrustação medida através da resistência desenvolvida na operação de microfiltração de efluente de reator $U A S B$ de 22/08 a 15/09/2016 (PTM de -0,1 bar).

Os gráficos das Figuras $5.24\left(\mathrm{~J}_{20} x \mathrm{t}\right)$ e $5.25(\mathrm{R} x \mathrm{t})$ demonstram o período de 19/09 a 20/10/16, as cinco semanas finais da segunda fase de operação contínua.

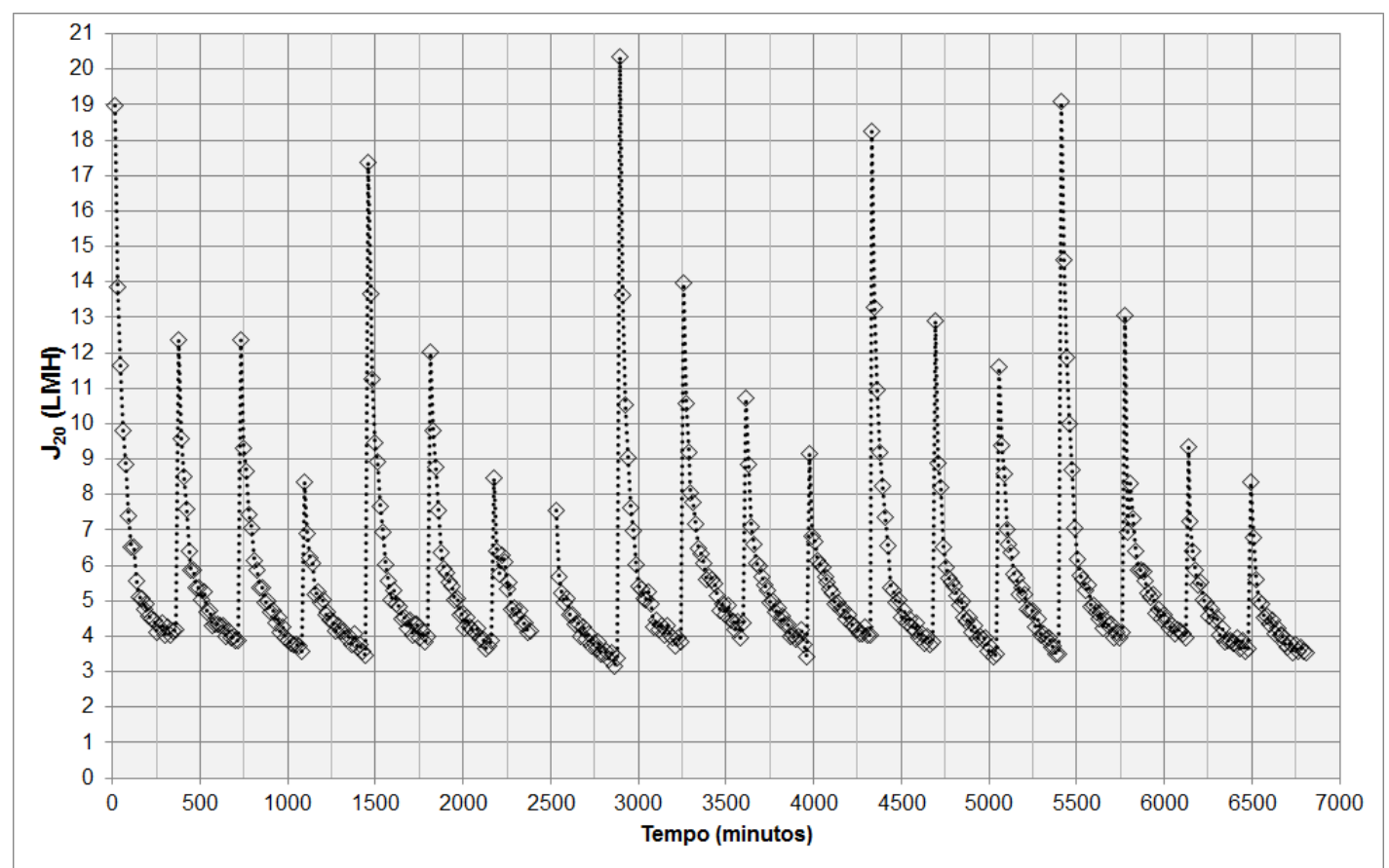

Figura 5.24 - Gráfico do comportamento do fluxo normalizado da operação de microfiltração de efluente de reator $U A S B$ de 19/09 a 20/10/2016 (PTM de -0,1 bar). 


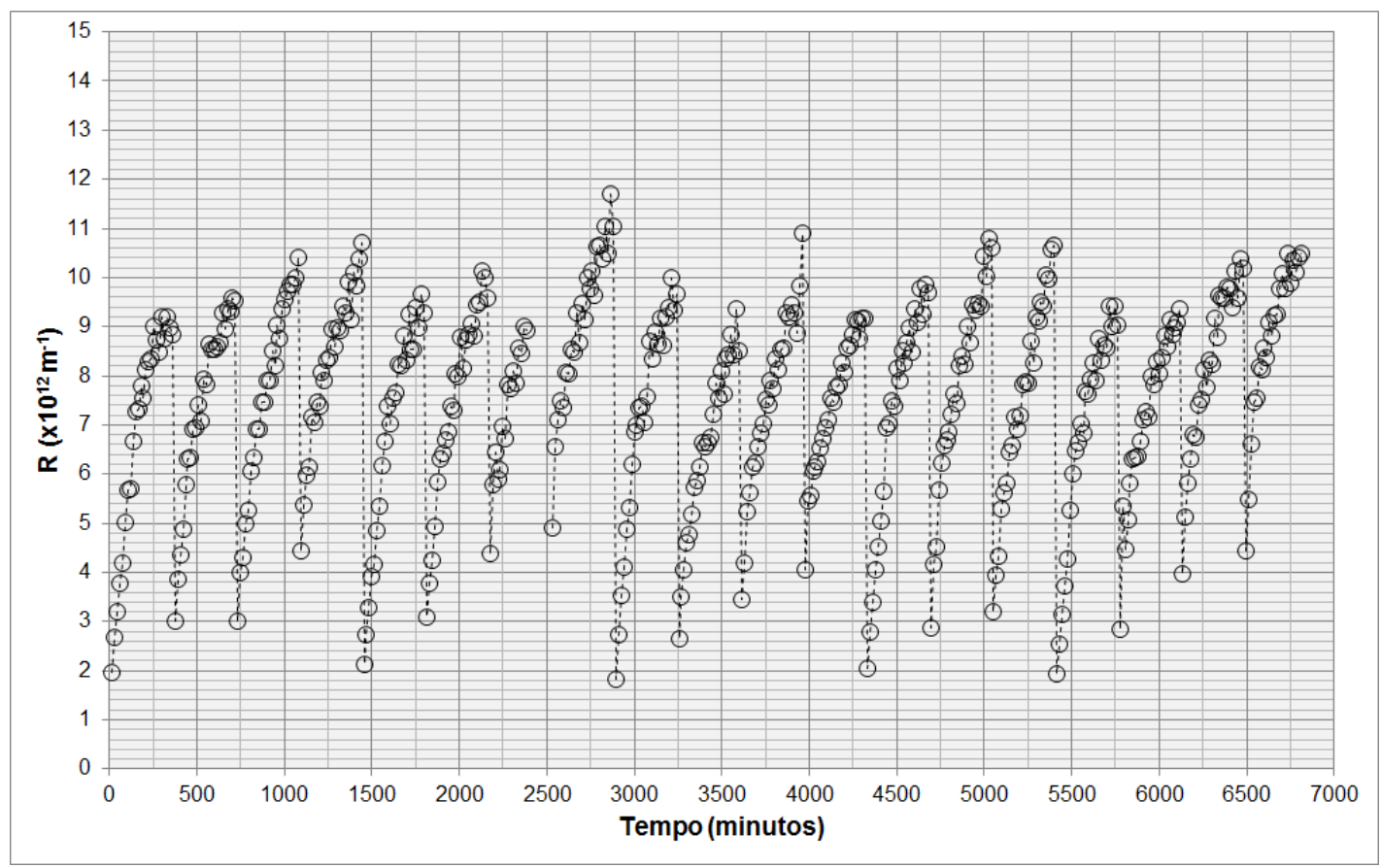

Figura 5.25 - Gráfico da evolução da incrustação medida através da resistência desenvolvida na operação de microfiltração de efluente de reator UASB de 19/09 a 20/10/2016 (PTM de -0,1 bar).

Constata-se, pelas Figuras 5.18, 5.20, 5.22 e 5.24, que o comportamento do fluxo padronizado $\left(\mathrm{J}_{20}\right)$ foi de decaimento ao longo do tempo, com modelo descrito como função potência em relação ao tempo, diferindo do perfil verificado na pesquisa do item dedicado aos Ensaios Preliminares. O valor mínimo, médio e máximo de $\mathrm{J}_{20}$ da série completa apurada a cada etapa de filtração de $15^{\prime}$ foi $2,74,5,42$ e 20,36 LMH, respectivamente.

O valor médio de $\mathrm{J}_{20}$ igual a 5,42 LMH foi abaixo do preconizado no projeto da unidade de filtração, de 10 LMH. Este valor encontrado após os 61 dias de operação passa a ser um parâmetro importante para projetos futuros se tratando de microfiltração de efluente de reator $U A S B$ funcionando num regime semanal de 4 dias operando e 1 dia limpando a unidade de filtração, ou seja, para garantir a vazão de 60 l/h de permeado, a área do módulo de membranas submersas deveria ter quase o dobro da superfície ( 1,8 vezes).

Com os volumes produzidos de permeado diariamente para todas as corridas executadas, foram calculados e separados os fluxo médios por dia da semana (segunda, terça, quarta e quinta-feira), sendo exibidos os valores mínimo, $1^{\circ}$ quartil - 25\%, médio, mediana (50\%), $3^{\circ}$ quartil - 75\% e máximo na Tabela 5.6. 
Tabela 5.6 - Fluxos médios diários (LHM) por dia da semana de operação contínua da microfiltração do efluente do reator UASB (28/03 a 28/10/2016) (*).

\begin{tabular}{ccccc}
\hline Valores & $\begin{array}{c}\text { Fluxo médio } \\
\text { Segunda-feira } \\
\mathrm{J} 2(* 1)\end{array}$ & $\begin{array}{c}\text { Fluxo médio } \\
\text { Terça-feira } \\
\mathrm{J} 3(* 2)\end{array}$ & $\begin{array}{c}\text { Fluxo médio } \\
\text { Quarta-feira } \\
\mathrm{J} 4(* 3)\end{array}$ & $\begin{array}{c}\text { Fluxo médio } \\
\text { Quinta-feira } \\
\mathrm{J} 5(* 4)\end{array}$ \\
\hline Mínimo & 6,46 & 5,12 & 4,77 & 4,17 \\
$1^{\circ}$ Quartil & 7,52 & 6,25 & 5,60 & 5,19 \\
$\begin{array}{c}(25 \%) \\
\text { Médio }\end{array}$ & 7,69 & 6,52 & 5,88 & 5,48 \\
Mediana & 7,69 & 6,57 & 5,96 & 5,41 \\
$\begin{array}{c}(50 \%) \\
3^{\circ} \text { Quartil }\end{array}$ & 7,85 & 6,91 & 6,37 & 5,65 \\
(75\%) & 8,68 & 7,60 & 6,55 & 7,09 \\
Máximo & & &
\end{tabular}

- Número de amostras $(* 1)=16 ;(* 2)=16 ;(* 3)=14 ;(* 4)=15$.

Nota-se que a conduta do fluxo ao longo dos dias da semana também se modifica, pois os valores de mínimo, médio e máximo decaem dia após dia, do primeiro dia (segunda-feira) para o último dia da semana (quinta-feira) da operação contínua, quando observados os gráficos das Figuras 5.18, 5.20, 5.22 e 5.24 e os dados dispostos na Tabela 5.6.

Com os dados do fluxo médio por dia da semana, produziram-se os gráficos tipo box-plot, ou também conhecido como diagramas de caixa e bigodes (Field, 2009), sendo que, neste texto, por preferência, adotou-se o primeiro nome para se referir a este tipo de representação gráfica. Portanto, os gráficos tipo box-plot da Figura 5.26 exibem os fluxos médios diários separados por dia de operação da semana. O Anexo 2 traz uma ilustração esclarecendo como é representada a estatística descritiva por este tipo de gráfico.

Novamente foi verificado que a primeira limpeza, a do enxague, que normalmente foi executada após todas as 61 corridas ensaiadas, não foi eficiente, pois não retirou toda a incrustação da corrida diária e não impediu que o próximo dia retornasse a operar com fluxo semelhante ao dia anterior e sim com valor inferior, como pode ser observado na Tabela 5.6. Também pode ser verificado na Figura 5.26 que somente as limpezas com retrolavagem (segunda) e a hidráulica/química (terceira) foram capazes de retornar o fluxo médio ao valor da situação de membranas limpas, como observa-se no valor superior do fluxo médio no primeiro dia da semana (segunda-feira) através do box-plot da variável J2 da Figura 5.26. 


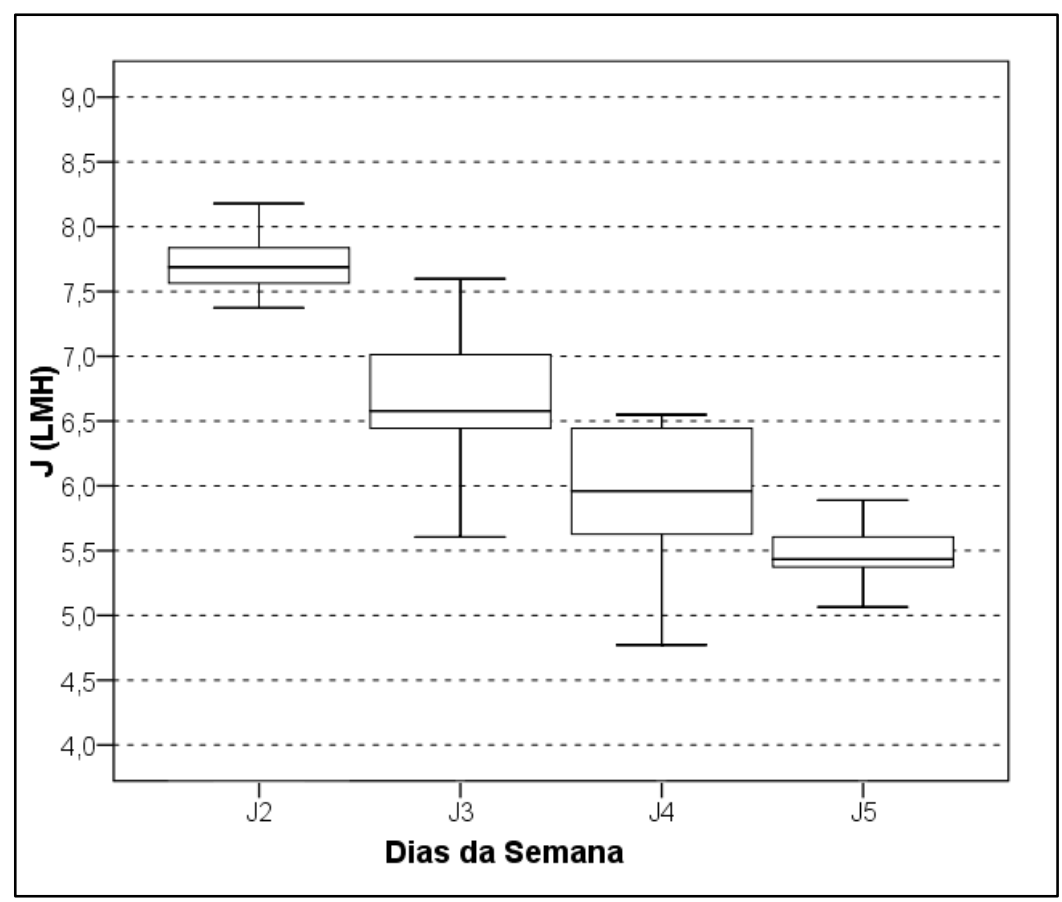

Figura 5.26 - Gráficos box-plot dos fluxos médios desmembrados por dias da semana: J2 (Segunda-feira), J3 (Terça-feira), J4 (Quarta-feira) e J5 (Quinta-feira) da operação contínua de microfiltração do efluente do reator $U A S B(28 / 03$ a 28/10/2016).

Constata-se pelas Figuras 5.19, 5.21, 5.23 e 5.25 que a evolução da incrustação ao longo do tempo e medida através da resistência desenvolvida comportou-se como modelo matemático de função potência em relação ao tempo, mantendo o perfil verificado na pesquisa do item dedicado aos Ensaios Preliminares. Os valores mínimo, médio e máximo de $\mathrm{R}$ da série completa apurada a cada etapa de filtração de $15^{\prime}$ foram $1,82.10^{12}, 7,73.10^{12}$ e $13,57.10^{12} \mathrm{~m}^{-1}$, respectivamente. Sendo que o $\mathrm{R}$ mínimo igual a $1,82.10^{12} \mathrm{~m}^{-1}$ corresponde ao valor da resistência da membrana limpa, com o valor inicial apontado de $1,36.10^{12} \mathrm{~m}^{-1}$ e levantado nos ensaios preliminares, com valor de $\pm 33 \%$ de diferença entre duas medidas, mostrando que, durante 61 dias de operação contínua, ficou evidente a existência de incrustação desenvolvida de forma irreversível nas membranas submersas. $\mathrm{O}$ valor médio de $7,73.10^{12} \mathrm{~m}^{-1}$ equivale ao valor máximo calculado para a PTM de $-0,10$ bar, e o valor máximo $13,57.10^{12} \mathrm{~m}^{-1}$ aproxima-se do correspondente valor máximo calculado para a PTM de -0,20 bar, ambos apontados no gráfico da Figura 5.12.

Os valores da produtividade, que é relacionada aos volumes produzidos de permeado e aos volumes de permeado consumidos na retrolavagem diários, foram dispostos na Tabela 5.7 (valores mínimo, médio e máximo) e ilustrados nos gráficos de barras das Figuras 5.27 e 
5.28, sendo os gráficos divididos de acordo com as duas fases já definidas (28/03 a 13/05 -

7 semanas e 22/08 até 20/10/2016 - 9 semanas).

Tabela 5.7 - Produtividade dos 61 dias de operação contínua da microfiltração de efluente do reator $U A S B$, correspondente aos volumes produzidos de permeado e os volumes de

permeados consumidos na retrolavagem diários (28/03 a 20/10/2016).

\begin{tabular}{ccc}
\hline Valores & $\begin{array}{c}\text { Volumes produzidos de } \\
\text { permeado diários }(\ell)\end{array}$ & $\begin{array}{c}\text { Volumes de permeado consumidos na } \\
\text { retrolavagem diários }(\ell)\end{array}$ \\
\hline Mínimo & 145,00 & 27,76 \\
$1^{\circ}$ Quartil & 201,57 & 50,73 \\
$(25 \%)$ & 230,17 & 53,86 \\
Médio & 232,01 & 55,35 \\
Mediana & & \\
(50\%) & 265,71 & 57,55 \\
$3^{\circ}$ Quartil & 312,52 & 66,73 \\
(75\%) & & \\
Máximo & &
\end{tabular}

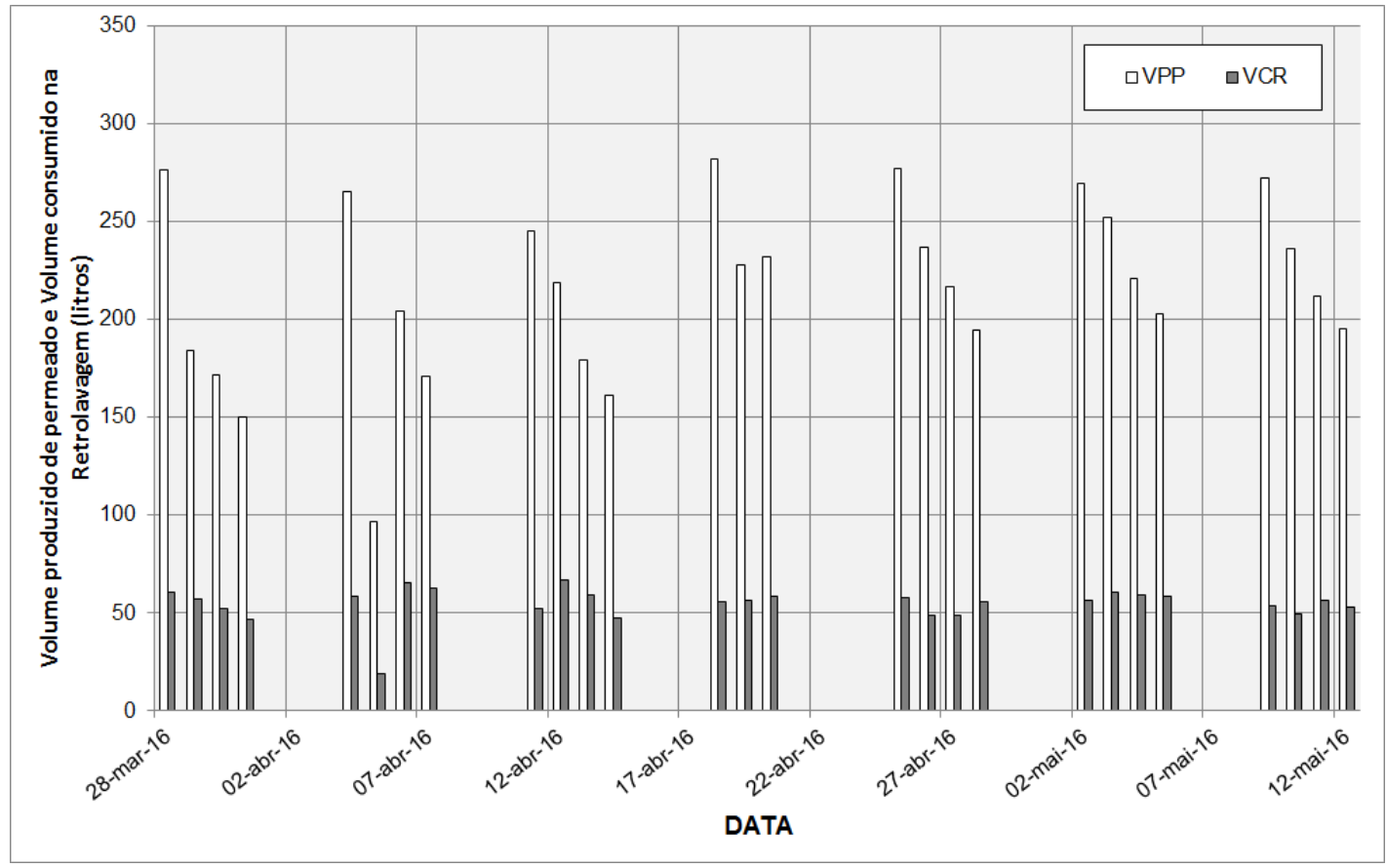

Figura 5.27 - Produtividade das sete (7) semanas iniciais da operação contínua da microfiltração de efluente do reator $U A S B$, correspondente aos volumes produzidos de permeado (VPP) e os volumes de permeados consumidos na retrolavagem (VCR) diários (28/03 a 13/05/2016). 


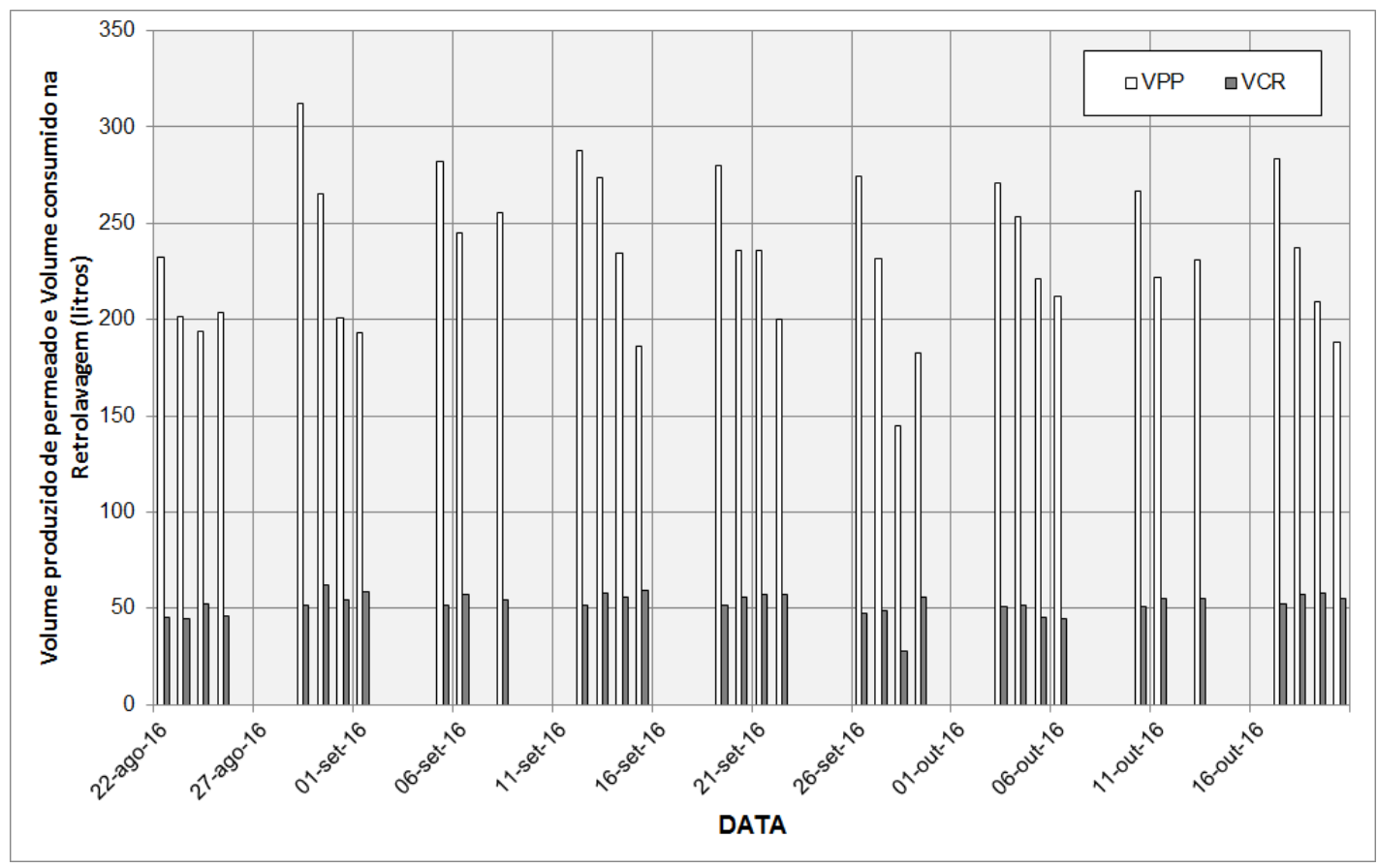

Figura 5.28 - Produtividade das nove (9) semanas finais da operação contínua da microfiltração de efluente do reator $U A S B$, correspondente aos volumes produzidos de permeado (VPP) e os volumes de permeados consumidos na retrolavagem (VCR) diários (22/08 a 20/10/2016).

As perdas calculadas em percentagem (\%), que relacionam os volumes de permeado consumidos na retrolavagem com os volumes produzidos de permeado diários, foram dispostas nos gráficos de barras das Figuras 5.29 e 5.30, sendo divididas de acordo com as duas fases já definidas (28/03 a 13/05 - 7 semanas e 22/08 até 20/10/2016 - 9 semanas).

As perdas na retrolavagem mínima, média e máxima nos 61 dias de operação contínua da microfiltração de efluente do reator $U A S B$ foram $16,57 \%$, 24,26\% e 36,78\%, respectivamente (de 28/03 a 20/10/2016), como demonstrado nas Figuras 5.29 e 5.30.

Como os valores dos volumes produzidos de permeado diários ao longo dos dias da semana tenderam a diminuir e os volumes de permeados consumidos na retrolavagem tiveram a tendência a se manter constante e em torno da média de 54,05 $\ell$, ambas variáveis observadas nas Figuras 5.27 e 5.28, consequentemente nesta pesquisa, foi observado que as perdas diárias percentuais calculadas ao longo da semana sofreram acréscimos do dia anterior para o próximo.

Os valores obtidos neste trabalho com relação às perdas do permeado para o consumo no uso na retrolavagem das filtrações com membranas foram muito superiores a aquela 
definida como referência pela Koch Membrane Systems (2014), que é 6\% para operação com membranas submersas de módulos de fibra-oca.

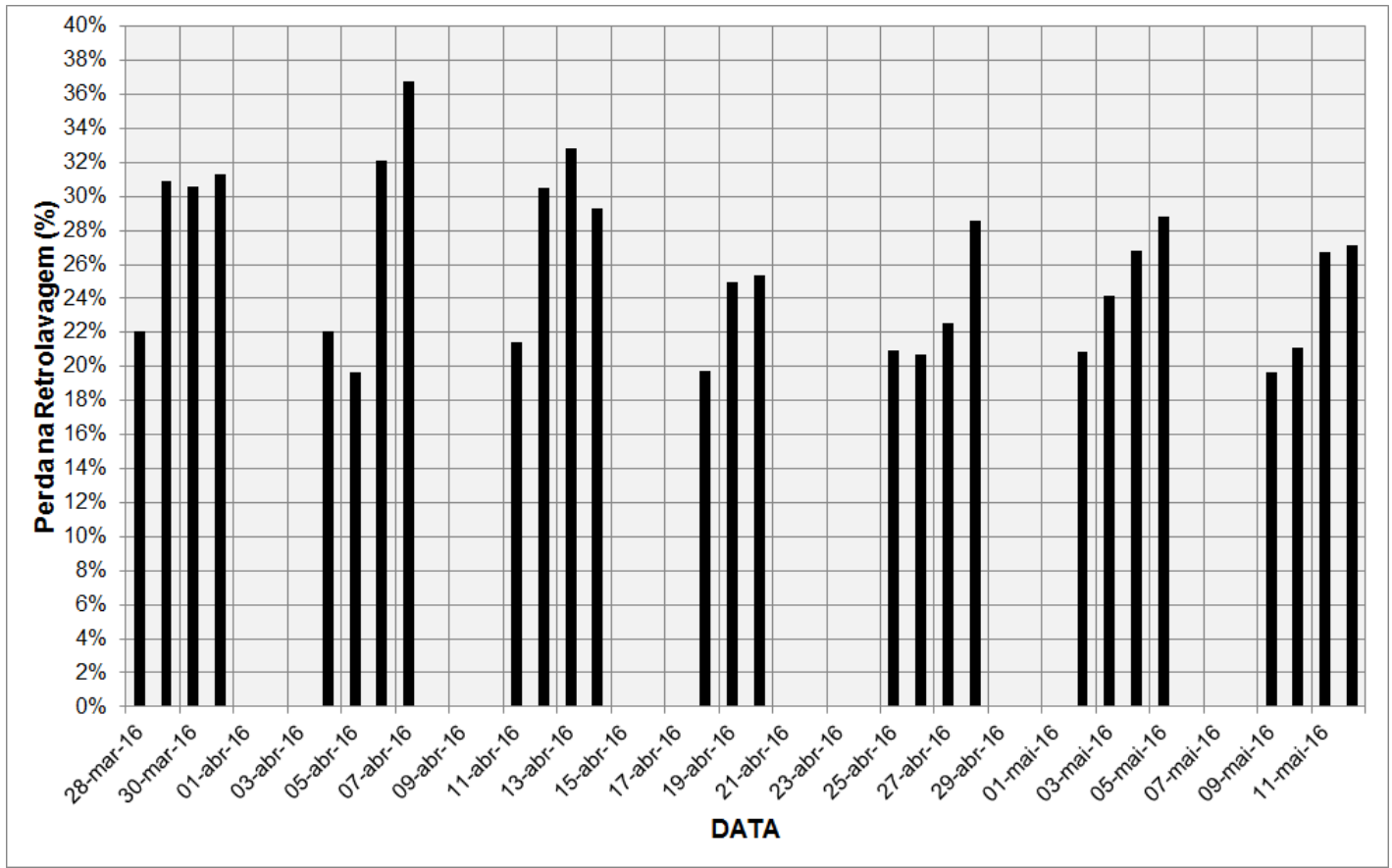

Figura 5.29 - Perdas na retrolavagem das sete (7) semanas iniciais da operação contínua da microfiltração de efluente do reator UASB (28/03 a 13/05/2016).

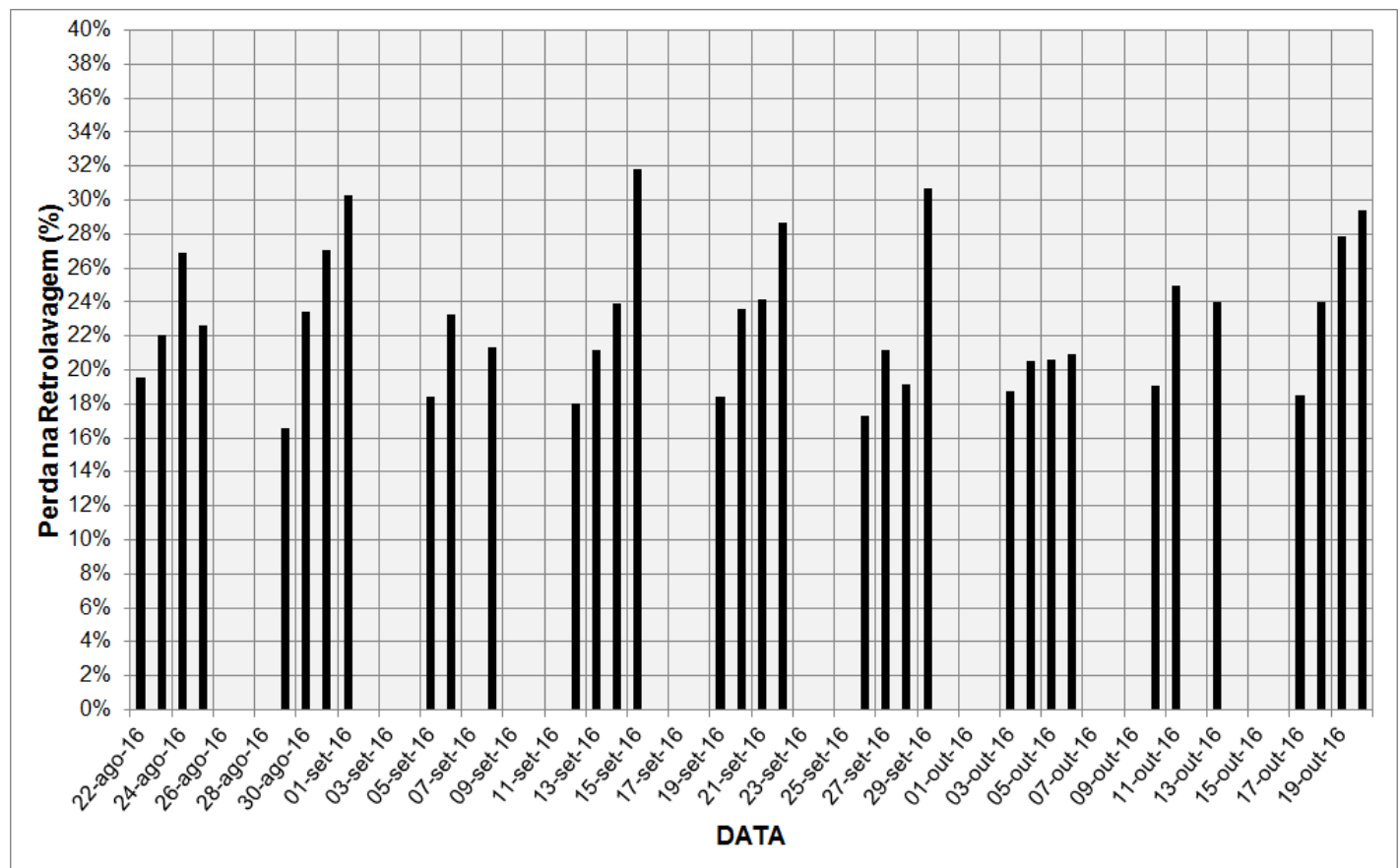

Figura 5.30 - Perdas na retrolavagem das nove (7) semanas finais da operação contínua da microfiltração de efluente do reator UASB (22/08 a 20/10/2016). 
A avaliação do item consumo de energia elétrica foi analisada por meio das medições diárias das potências úteis consumidas (Wh) de todas as 61 corridas da operação de longo termo, sendo que os resultados mínimo, médio e máximo apurados foram 334, 549 e 608 $\mathrm{Wh}$, respectivamente.

Como observado nos gráficos das Figuras 5.27 e 5.28, os volumes produzidos de permeado (VPP) sofreram declínio ao longo dos dias da semana de operação, fato que repercutiu, causando um crescimento no consumo específico de energia elétrica $\left(\mathrm{kWh} / \mathrm{m}^{3}\right)$. A Tabela 5.8 retrata os valores mínimo, médio e máximo constatados para o consumo específico de energia elétrica, por dia da semana da operação de longo termo da microfiltração do efluente do reator $U A S B$.

Tabela 5.8 - Consumos específicos de energia elétrica $\left(\mathrm{kWh} / \mathrm{m}^{3}\right)$ por dia da semana de operação contínua da microfiltração do efluente do reator $U A S B(28 / 03$ a 28/10/2016).

\begin{tabular}{ccccc}
\hline Valores & $\begin{array}{c}\text { Consumo } \\
\text { específico de } \\
\text { energia elétrica } \\
\text { Segunda-feira } \\
\text { P2 }(* 1)\end{array}$ & $\begin{array}{c}\text { Consumo } \\
\text { específico de } \\
\text { energia elétrica } \\
\text { Terça-feira } \\
\text { P3 }(* 2)\end{array}$ & $\begin{array}{c}\text { Consumo } \\
\text { específico de } \\
\text { energia elétrica } \\
\text { Quarta-feira } \\
\text { P4 }(* 3)\end{array}$ & $\begin{array}{c}\text { Consumo } \\
\text { específico de } \\
\text { energia elétrica } \\
\text { Quinta-feira } \\
\text { P5 }(* 4)\end{array}$ \\
\hline $\begin{array}{c}\text { Mínimo } \\
1^{\circ} \text { Quartil }\end{array}$ & 1,34 & 1,70 & 1,96 & 1,75 \\
$\begin{array}{c}\text { (25\%) } \\
\text { Médio }\end{array}$ & 1,89 & 2,25 & 2,55 & 2,35 \\
Mediana & 1,97 & 2,37 & 2,75 & 2,74 \\
$\begin{array}{c}(50 \%) \\
3^{\circ} \text { Quartil }\end{array}$ & 2,09 & 2,41 & 2,70 & 2,92 \\
$(75 \%)$ & 2,16 & 2,45 & 2,84 & 3,00 \\
Máximo & 2,62 & 3,12 & 3,64 & 3,88 \\
\hline
\end{tabular}

- Número de amostras $(* 1)=16 ;(* 2)=16 ;(* 3)=14 ;(* 4)=15$.

Nos gráficos box-plot da Figura 5.31 é exibido o consumo específico de energia elétrica ou potência útil unitária, em $\mathrm{kWh} / \mathrm{m}^{3}$, por dia da semana, para todas as corridas ensaiadas na operação de longo termo. Deve-se observar o acréscimo na Figura 5.31 de uma linha contínua, valor de referência para comparação - 3,10 kWh/m³ (Cheryan, 1998).

O valor médio observado para o consumo específico de energia elétrica $\left(\mathrm{kWh} / \mathrm{m}^{3}\right)$ foi inferior ao relatado por Cheryan (1998), de $3,1 \mathrm{kWh} / \mathrm{m}^{3}$. Note-se que este consumo específico de energia elétrica, informado por Cheryan (1998), refere-se a exemplo de projeto em escala real de uma unidade de ultrafiltração operando em regime de batelada 
por $8.000 \mathrm{~h} / \mathrm{ano}$, constituído de 110 módulos de fibra oca e área total de filtração igual a $154 \mathrm{~m}^{2}$, operando com fluxo (J) de 26 LHM e com eficiência da bomba de sucção de permeado igual a $50 \%$.

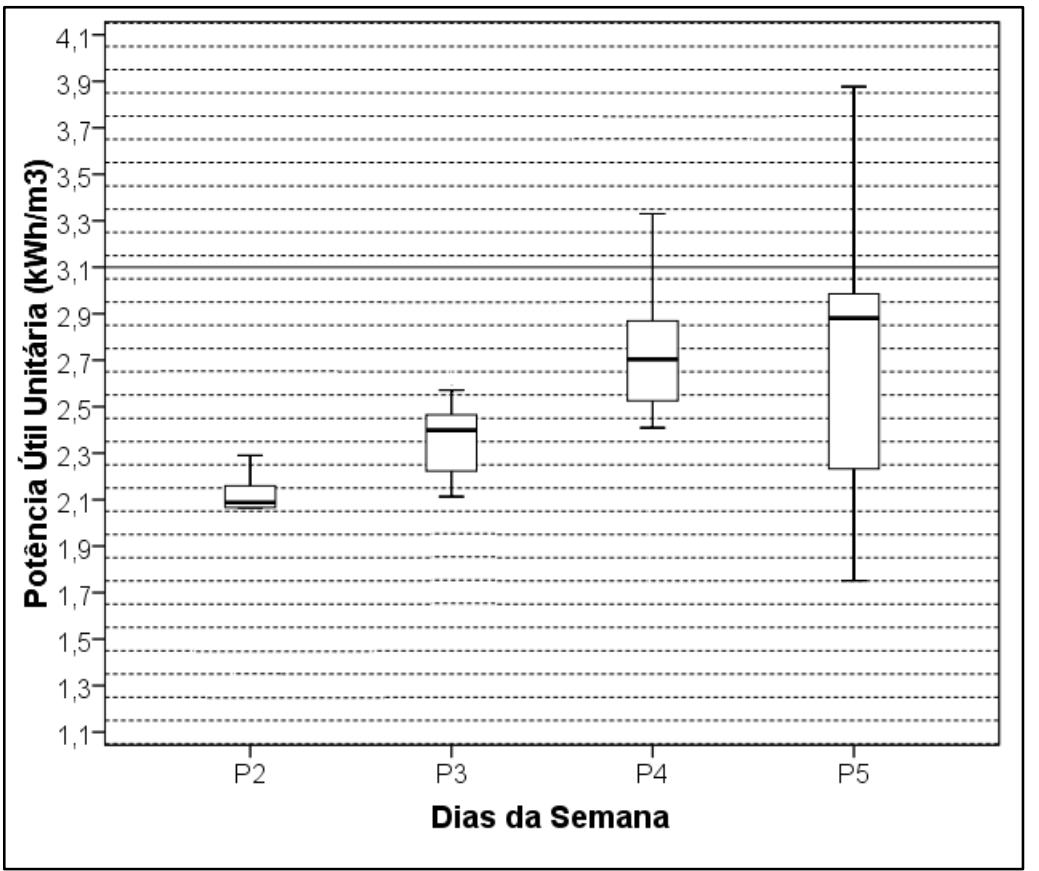

Figura 5.31 - Gráficos box-plot dos consumos específicos de energia elétrica $\left(\mathrm{kWh} / \mathrm{m}^{3}\right)$ por dia da semana: P2 (Segunda-feira), P3 (Terça-feira), P4 (Quarta-feira) e P5 (Quinta-

feira) da operação contínua da microfiltração do efluente do reator $U A S B$ (28/03 a 28/10/2016).

No entanto, todos os valores levantados para os consumos específicos de energia elétrica foram superiores ao valor de referência teórico estipulado para microfiltração/ultrafiltração por Chang et al. (2008), que é de $0,26 \mathrm{kWh} / \mathrm{m}^{3}$.

O valor médio alcançado no presente estudo foi superior ao relatado pela Companhia de Saneamento Ambiental do Distrito Federal (CAESB) para o consumo específico de energia elétrica de todas as dezesseis (16) ETEs, em escala real, que foi de $0,37 \mathrm{kWh} / \mathrm{m}^{3}(0,00 \mathrm{a}$ 1,52), portanto o valor levantado na presente pesquisa foi superior ao médio e ao máximo consumos específicos de energia elétrica informados pela CAESB (2015).

Os dados do balanço hídrico no tanque de membranas submersas (TQ01) envolvem as seguintes variáveis: (i) o volume da alimentação medido pelo hidrômetro ultrassônico, (ii) o volume do descarte medido pelo hidrômetro ultrassônico, (iii) o volume de permeado medido durante a corrida diária por meio da medição direta e (iv) o volume consumido do 
permeado para uso na retrolavagem medida de forma direta. Note-se que a perda, como o nome propriamente diz, também está sendo contabilizada no medidor ultrassônico do descarte, já que entra na corrente do descarte do TQ01, como ilustrado no fluxograma da Figura 4.10, no caso da alimentação e do descarte pelo medidor identificado com FI.

A Tabela 5.9 apresenta os valores mínimo, médio, máximo e o total diário medidos para o volume da alimentação, do descarte e do permeado das séries levantadas durante esta pesquisa operando com a microfiltração de efluente do reator $U A S B$ durante as 61 corridas executadas. Os volumes da alimentação e descarte estão expressos em $\mathrm{m}^{3}$ e o do permeado em $\ell$.

Tabela 5.9 - Volumes diários medidos da alimentação, do descarte e do permeado durante a operação de longo termo da pesquisa de microfiltração de efluente de reator $U A S B$.

\begin{tabular}{|c|c|c|c|}
\hline \multirow{2}{*}{ Valores } & \multicolumn{3}{|c|}{ Volumes medidos diariamente } \\
\hline & Alimentação $^{\mathrm{a}}$ & Descarte $^{\mathrm{a}}$ & Permeado \\
\hline Mínimo & 2,044 & 2,546 & 145 \\
\hline Médio & 6,467 & 6,354 & 228 \\
\hline Máximo & 7,200 & 7,476 & 313 \\
\hline Soma & 394,466 & 387,580 & 13708 \\
\hline
\end{tabular}

Legenda: a...unidade $\mathrm{em}^{3} \mathrm{e}$ b...unidade em $\ell$.

O tempo de detenção hidráulico (TDH) no tanque das membranas submersas (TQ01) foi calculado com a série dos volumes medidos diários da alimentação e do descarte. $\mathrm{O}$ valor considerado alimentado diário no volume de $30 \ell$ do TQ01 foi a média entre os medidos para alimentação e descarte (hidrômetros ultrassônicos). O gráfico da Figura 5.32 ilustra os valores do TDH ao longo das 61 corridas ensaiadas na Filtração por Membranas Submersas (FMS).

Utilizando-se da Equação 3.2 e com as séries dos volumes de permeado e do alimentado ao TQ01, foi produzido o gráfico da Figura 5.33, em que se ilustra a recuperação - S (\%) calculada diariamente para todas as 61 corridas experimentadas.

No intuito de operar o tanque de membranas submersas (TQ01) como uma unidade de microfiltração de efluente do reator $U A S B$, os valores baixos de TDH médio de 1,60 minutos no TQ01 e da recuperação média - $\mathrm{S}$ de 3,55\%, com todas as duas séries completas e expostas nas Figuras 5.32 e 5.33, concretizaram e garantiram que a simulação 
do local de instalação do módulo das membranas submersas ocorresse na zona de sedimentação do reator $U A S B$, como a configuração utilizada na pesquisa de Wen et al. (1999).

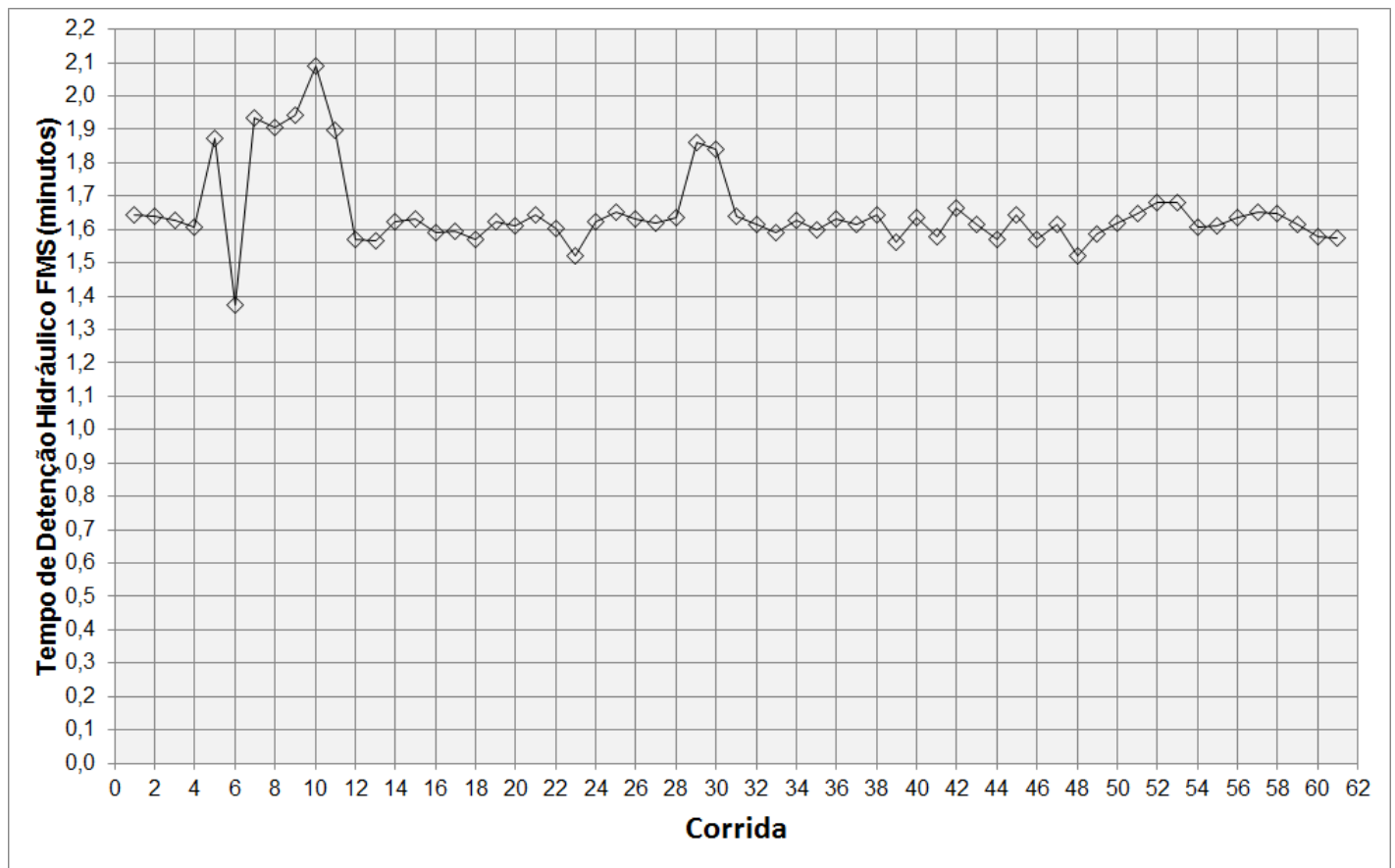

Figura 5.32 - Gráfico do tempo de detenção hidráulico calculado diariamente para todas as corridas da operação contínua da microfiltração do efluente do reator $U A S B$

(28/03 a 28/10/2016).

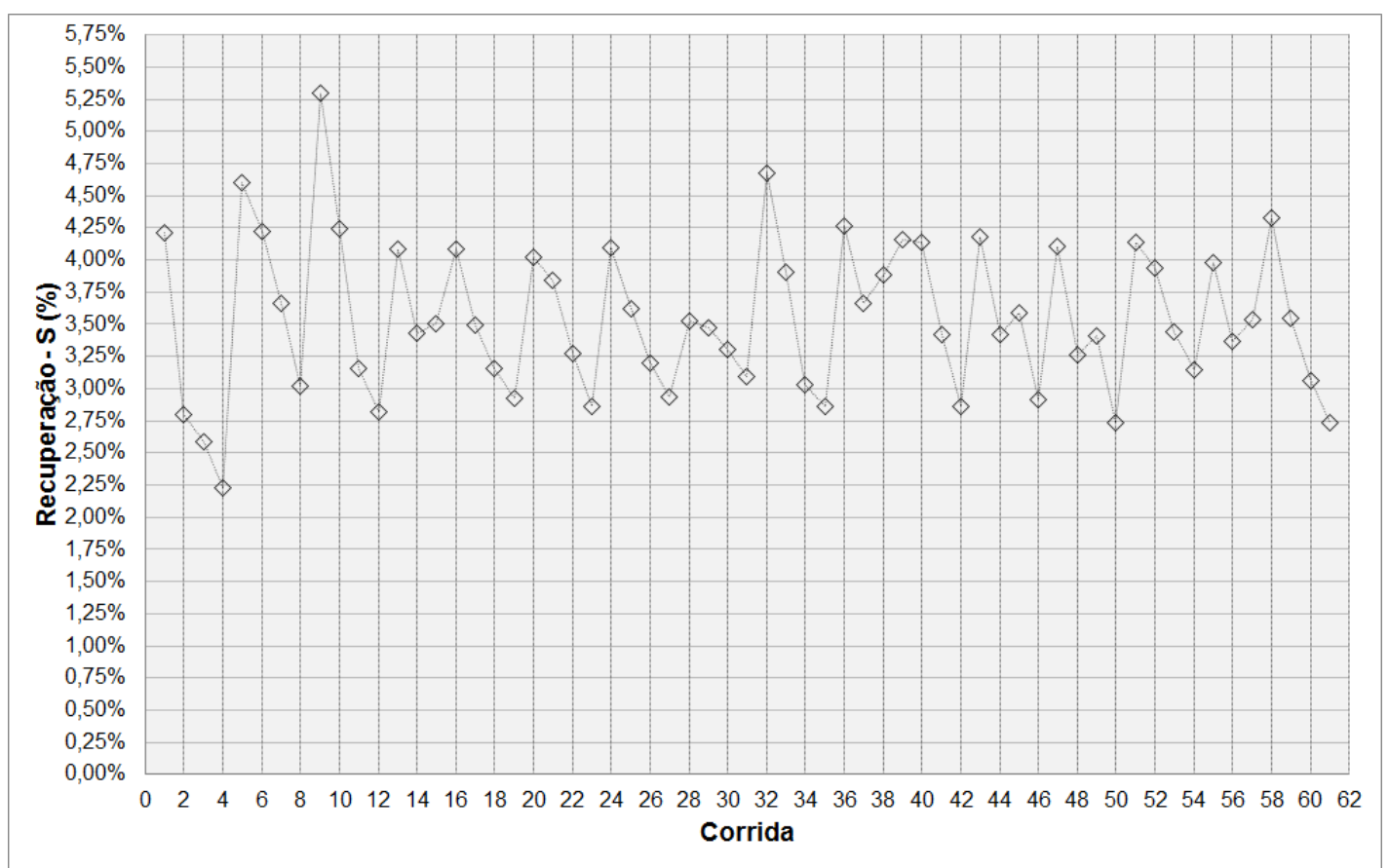

Figura 5.33 - Gráfico da recuperação - S (\%) calculada diariamente para todas as corridas da operação contínua da microfiltração do efluente do reator UASB (28/03 a 28/10/2016). 
Como última etapa a ser discutida e ainda relativo às condições operacionais, apresentamse os gráficos das Figuras 5.34 e 5.35, nos quais se ilustram as sequências dos valores da permeabilidade hidráulica (K) microfiltrando o "branco" (água potável da CAESB) e a resistência do módulo de membranas submersas limpas, sempre após o protocolo de limpeza utilizado nesta pesquisa, segunda limpeza - retrolavagem e terceira limpeza hidráulica/química, como anteriormente descrito. No total, foram ensaiados 28 vezes o levantamento da permeabilidade hidráulica com água potável com 18 (dezoito) primeiros deles na etapa de ensaios preliminares e os outros 20 (vinte) últimos na fase de operação de longa duração desta pesquisa (23/11/2015 a 20/10/2016).

No gráfico da Figura 5.34 demonstra-se que as três primeiras medidas iniciais da sequência dos valores da permeabilidade hidráulica $(\mathrm{K})$ microfiltrando água potável variaram em torno de $134 \mathrm{LHM} /$ bar e, a partir da quarta medida, passou a variar em torno de 240 LHM/bar, ou seja, da terceira medida para a quarta houve um incremento de $42 \%$ no valor da permeabilidade hidráulica do módulo de membranas limpas, mas, a partir da quarta medida em diante, os valores comparativos percentuais absolutos entre uma medida e outra passaram a ser 0,05\%, 4,30\% e 13,93\%, como valores mínimo, médio e máximo, respectivamente. Cheryan (1998) considera normal que as permeabilidades hidráulicas com água potável de membranas novas possam apresentar valores de até $25 \%$ de diferença entre uma medida e outra.

Portanto, duas hipóteses poderiam ser formuladas: ou o protocolo de limpeza a partir da terceira medida teria atingido a sua máxima eficiência, ou a Integridade da membrana teria diminuído no início dos testes no levantamento dos ensaios preliminares. Para a verificação destas duas hipóteses, foi realizado após o final das 61 corridas de microfiltração com o efluente do reator $U A S B$, o segundo e último levantamento da integridade do módulo de membranas submersas. O teste foi executado no dia 14/11/2016, filtrando $500 \ell$ de uma solução de amido de milho $(0,5 \mathrm{~g} / \ell)$ durante $57^{\prime}$ com PTM de $-0,10$ bar na unidade de microfiltração. Foram coletadas as amostras da alimentação (solução de amido de milho $0,5 \mathrm{~g} / \ell$ ) e do permeado, os exames de turbidez foram feitos para alimentação e para o permeado, cujo resultados foram de 164 uT e 1,35 uT, respectivamente. Deste modo, a rejeição da solução de amido de milho $(0,5 \mathrm{~g} / \ell)$ foi de 99,18\%, ou seja, 2,09 unidades logarítmicas. Relembrando que a integridade inicial (alcançada no início desta pesquisa) foi de 2,15 unidades logarítmicas, de maneira que, 
quando comparando a Integridade inicial com a final, a diferença foi menor que $4 \%$. Consequentemente, pode-se afirmar que a hipótese da eficácia da limpeza a partir da quarta medida é a mais provável de ter ocorrido nesta pesquisa.

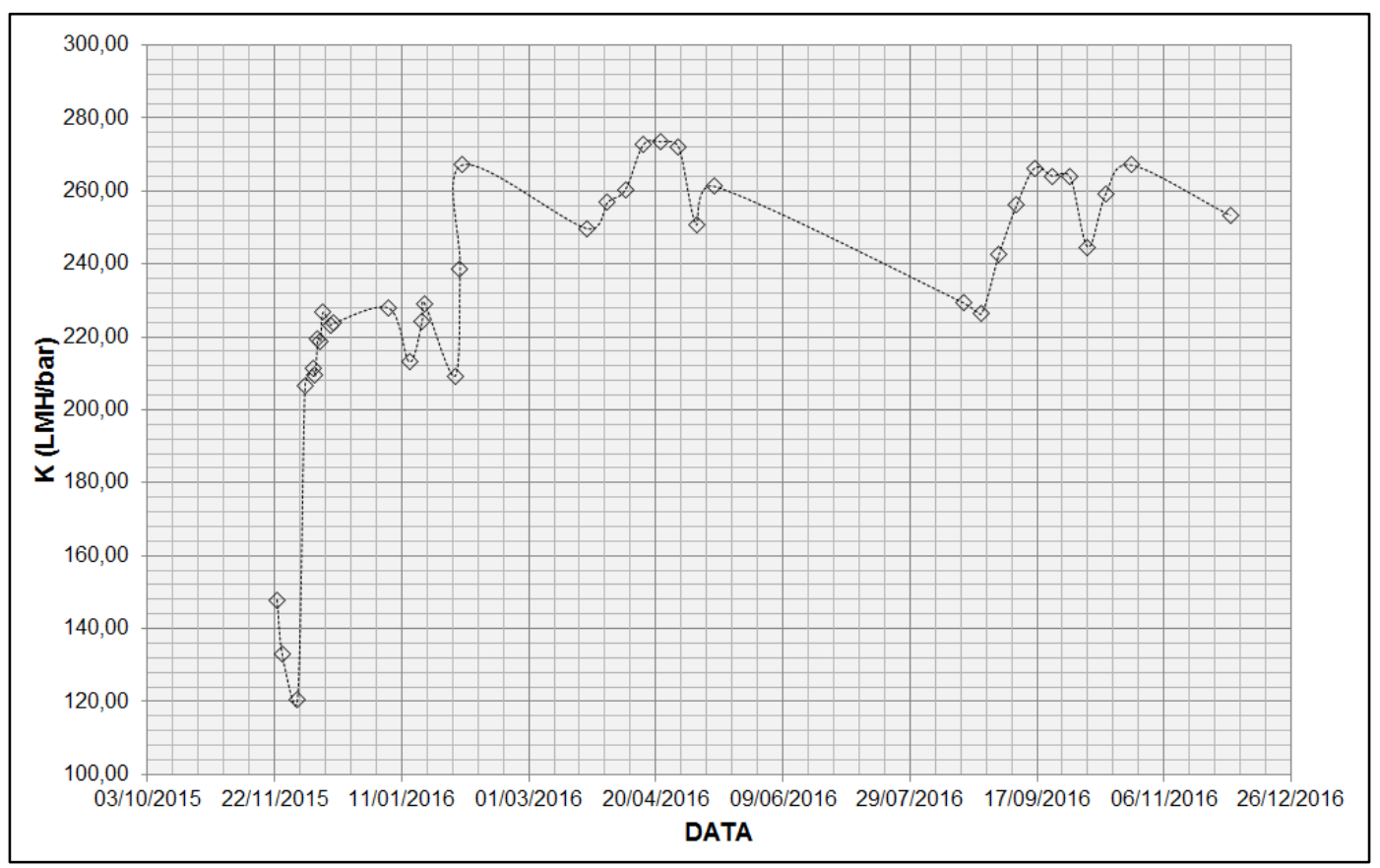

Figura 5.34 - Gráfico da sequência das permeabilidades hidráulicas (K) filtrando água potável da CAESB após o protocolo de limpeza executado na pesquisa: retrolavagem e limpeza hidráulica/química no período de 23/11/2015 a 20/10/2016.

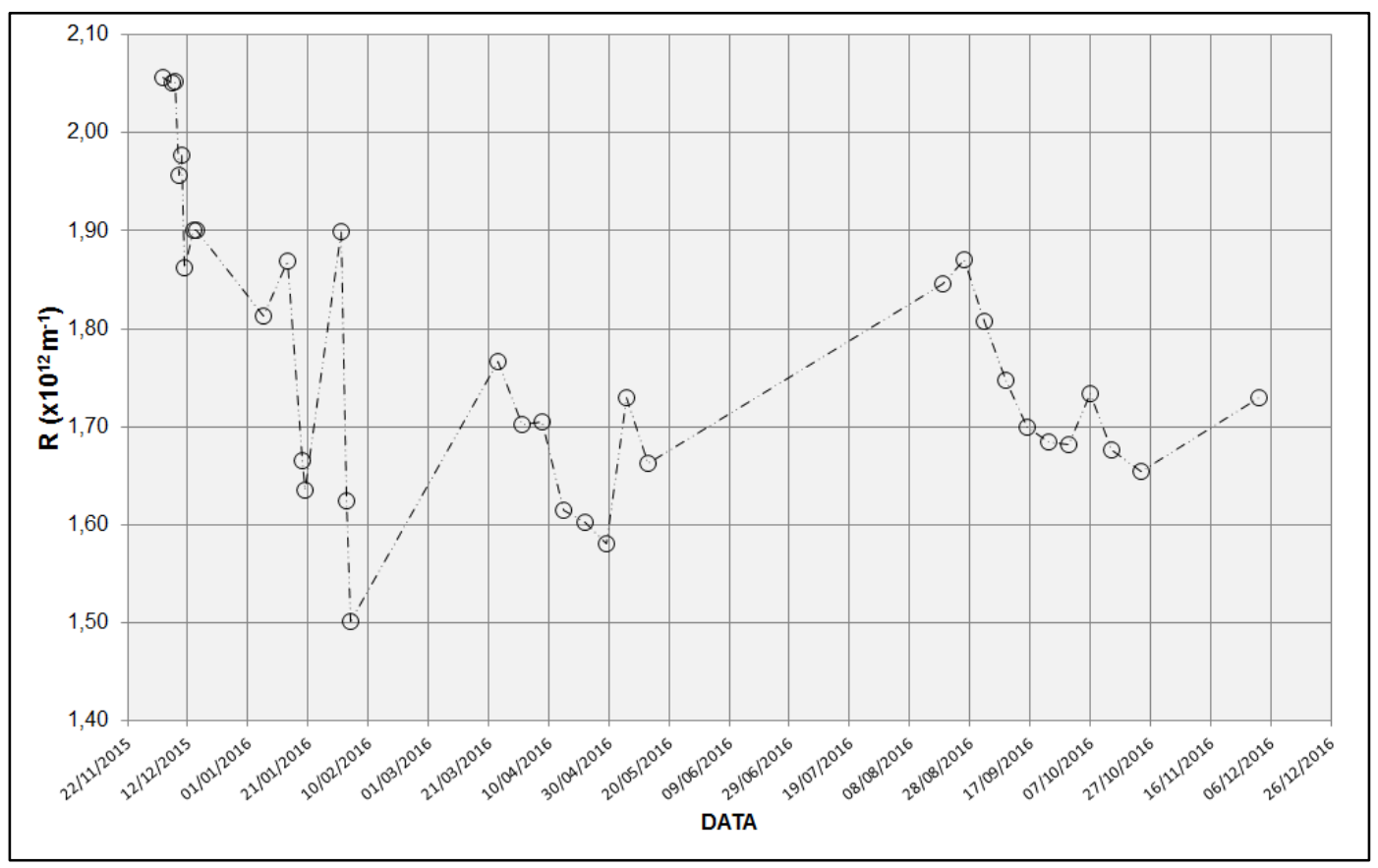

Figura 5.35 - Gráfico da sequência das resistências para membranas limpas (R), filtrando água potável da CAESB após o protocolo de limpeza executado na pesquisa: retrolavagem e limpeza hidráulica/química no período de 23/11/2015 a 20/10/2016. 


\subsection{2 - Monitoramento e Controle de Qualidade}

O programa de monitoramento da microfiltração do efluente do reator $U A S B$, durante as 61 corridas ensaiadas, foi desenvolvido por meio de coletas compostas ao longo dos 24 (vinte e quatro) estágios de filtração executados por dia de operação, com amostragem da alimentação, do descarte e do permeado. Essas coletas aconteciam sempre na segunda e na quarta-feira. As amostragens do programa de monitoramento do desempenho global da ETE Gama sempre acontecem no domingo e na quarta-feira, por isso os resultados de Esgoto Bruto, afluente a ETE, considerados neste trabalho foram os executados pelo planejamento da CAESB, nos domingos e quartas-feiras.

A pesquisa toda foi realizada em 16 (dezesseis) segundas-feiras, 16 (dezesseis) terçasfeiras, 14 (quatorze) quartas-feiras e 15 (quinze) quintas-feiras, portanto foram feitas 30 (trinta) amostragens durante as 61 corridas. As variáveis Demanda Química de Oxigênio (DQO), Sólidos Suspensos Totais e Sólidos Dissolvidos Totais foram analisadas duas vezes por semana, portanto perfazendo um total de 30 dados por variável. As variáveis Demanda Bioquímica de Oxigênio padrão (DBO), Agentes Surfactantes, Óleos e Graxas, Coliformes Fecais e Totais foram medidas uma vez por semana, sempre nas Quartas-feiras, perfazendo um total de 14 resultados para cada uma delas. Para a avaliação da concentração dos ovos de helmintos, foi executada uma campanha especial de quatro semanas consecutivas, utilizando-se das amostras efetuadas nas segundas-feiras (29/08, 12/09, 19/09 e 26/09/2016).

Os resultados do monitoramento do controle de qualidade da microfiltração são abordados desmembrando-os segundo as características avaliadas: (i) físicas, (ii) químicas e (iii) microbiológicas.

As características físicas da qualidade da água pesquisadas no presente trabalho foram: (i) pH, (ii) Sólidos Suspensos Totais (SST), (iii) Turbidez, (iv) diâmetro médio geométrico em massa $\left(D_{\mathrm{mg}}\right)$ e (v) Sólidos Dissolvidos Totais.

A Tabela 5.10 apresenta as medidas estatísticas (valores mínimo, $1^{\circ}$ quartil - 25\%, médio, mediana (50\%), $3^{\circ}$ quartil - 75\%, máximo e o desvio-padrão) das sequências temporais de 
pH monitorados nesta pesquisa de microfiltração de efluente do reator $U A S B$ para as amostras: (i) do esgoto bruto (afluente a ETE), (ii) da alimentação ao TQ 01 (efluente do reator $U A S B$ ), (iii) do descarte do TQ01 e (iv) do permeado durante as 61 corridas executadas.

Tabela 5.10 - Medidas estatísticas das séries temporais de $\mathrm{pH}$ monitorados na pesquisa de microfiltração de efluente do reator $U A S B$ para as amostras: afluente a ETE Gama, da alimentação ao TQ 01, do descarte do TQ01 e do permeado das 61 corridas executadas (28/03 a 20/10/2016).

\begin{tabular}{ccccc}
\hline \multirow{2}{*}{ Valores } & \multicolumn{4}{c}{ Ponto de amostragem } \\
\cline { 2 - 5 } & $\begin{array}{c}\text { Afluente } \\
\text { à ETE Gama } \\
(\mathrm{AfpH})\end{array}$ & $\begin{array}{c}\text { Alimentação } \\
\text { TQ 01 } \\
(\text { AlpH) }\end{array}$ & $\begin{array}{c}\text { Descarte } \\
\text { TQ01 } \\
(\mathrm{DepH})\end{array}$ & $\begin{array}{c}\text { Permeado } \\
\text { produzido } \\
(\text { PepH })\end{array}$ \\
\hline Mínimo & 6,84 & 6,07 & 6,34 & 6,30 \\
$1^{\circ}$ Quartil (25\%) & 7,10 & 6,60 & 6,61 & 6,52 \\
Médio & 7,29 & 7,25 & 7,15 & 6,76 \\
Mediana (50\%) & 7,33 & 7,30 & 7,30 & 6,60 \\
$3^{\circ}$ Quartil (75\%) & 7,45 & 7,90 & 7,50 & 7,01 \\
Máximo & 7,89 & 8,02 & 8,00 & 7,60 \\
Desvio-padrão & 0,22 & 0,61 & 0,47 & 0,33 \\
\hline
\end{tabular}

Legenda: AfpH...pH do afluente à ETE Gama, AlpH...pH da alimentação ao TQ01, DepH...pH do descarte do TQ01 e PepH...pH do permeado.

Nos gráficos box-plot da Figura 5.36 exibem-se todas as quatro sequências temporais monitoradas de $\mathrm{pH}$ das amostras desta pesquisa de microfiltração de efluente do reator $U A S B$ para o afluente à ETE Gama, da alimentação ao TQ 01, do descarte do TQ01 e do permeado das 61 corridas.

Observa-se que os valores médios de $\mathrm{pH}$ ao longo do tratamento ocorrido (reator UASB + microfiltração por membranas submersas) mantiveram-se próximos, do afluente à ETE Gama até a alimentação do tanque de membranas (TQ01) e nas amostras de permeado ocorreu uma diminuta redução $(6,0 \%)$. Porém, destaca-se que todos os valores da série temporal de $\mathrm{pH}$ do efluente final do tratamento, permeado, atendem à resolução CONAMA 430/11 (Brasil, 2011) - $\mathrm{pH}>5,0$.

A Tabela 5.11 apresenta os parâmetros estatísticos (valores mínimo, $1^{\circ}$ quartil - 25\%, médio, mediana (50\%), $3^{\circ}$ quartil - 75\%, máximo e o desvio-padrão) das séries temporais de SST monitorados nesta pesquisa de microfiltração de efluente do reator $U A S B$ para as amostras: (i) do esgoto bruto (afluente a ETE), (ii) da alimentação ao TQ 01 (efluente do 
reator $U A S B$ ), (iii) do descarte do TQ01 e (iv) do permeado durante as 61 corridas executadas.

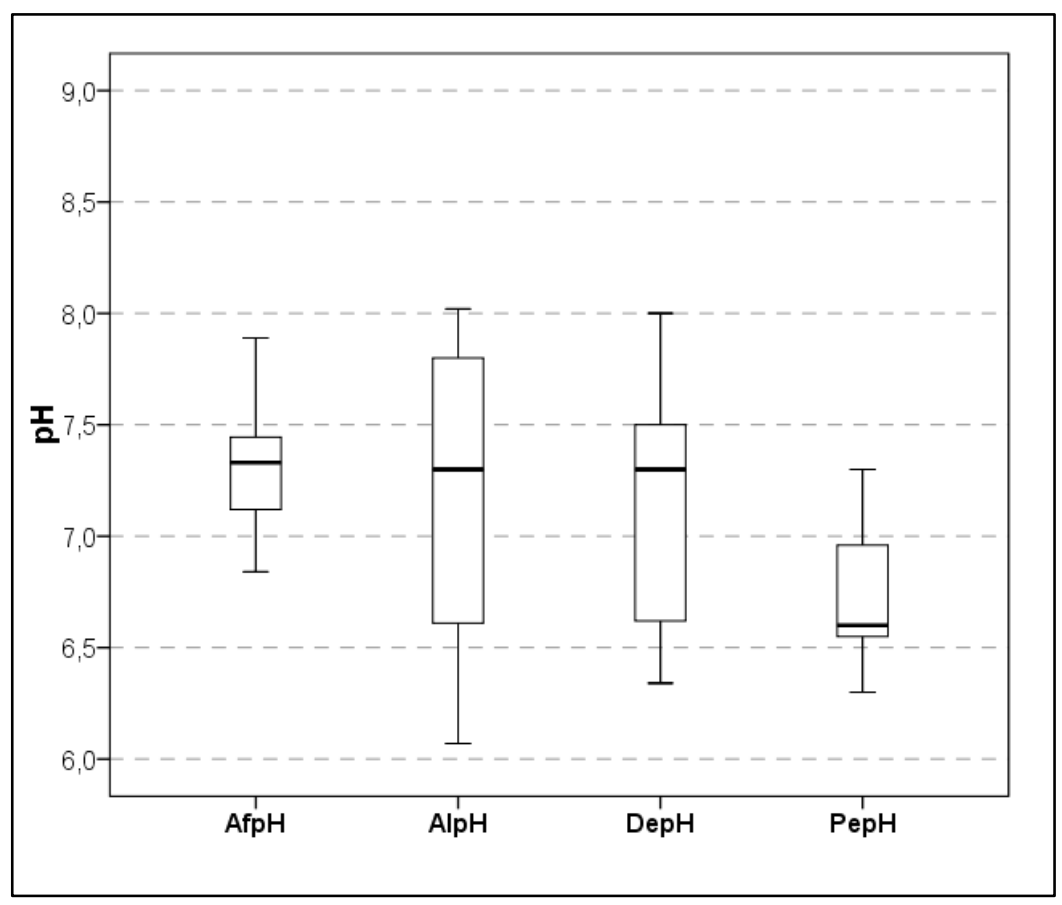

Figura 5.36 - Gráficos box-plot das séries temporais de $\mathrm{pH}$ monitorados na pesquisa de microfiltração de efluente do reator $U A S B$ para as amostras: afluente a ETE Gama, da alimentação ao TQ 01, do descarte do TQ01 e do permeado das 61 corridas executadas (28/03 a 20/10/2016).

Legenda: AfpH...pH do afluente à ETE Gama, AlpH...pH da alimentação ao TQ01, DepH...pH do descarte do TQ01 e PepH...pH do permeado.

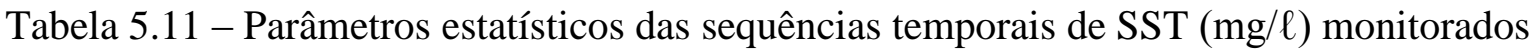
na pesquisa de microfiltração de efluente do reator $U A S B$ para as amostras: afluente a ETE

Gama, da alimentação ao TQ 01, do descarte do TQ01 e do permeado das 61 corridas executadas (28/03 a 20/10/2016).

\begin{tabular}{ccccc}
\hline \multirow{2}{*}{ Valores } & \multicolumn{4}{c}{ Ponto de amostragem } \\
\cline { 2 - 5 } & $\begin{array}{c}\text { Afluente } \\
\text { à ETE Gama } \\
\text { (AfSST) }\end{array}$ & $\begin{array}{c}\text { Alimentação } \\
\text { TQ 01 } \\
\text { (AlSST1) }\end{array}$ & $\begin{array}{c}\text { Descarte } \\
\text { TQ01 } \\
\text { (DeSST1) }\end{array}$ & $\begin{array}{c}\text { Permeado } \\
\text { produzido } \\
\text { (PeSST1) }\end{array}$ \\
\hline Mínimo & 183 & 3 & 2 & 1 \\
$1^{\circ}$ Quartil (25\%) & 235 & 6 & 6 & 2 \\
Médio & 373 & 17 & 15 & 4 \\
Mediana (50\%) & 300 & 10 & 10 & 3 \\
$3^{\circ}$ Quartil (75\%) & 440 & 26 & 25 & 4 \\
Máximo & 968 & 67 & 41 & 14 \\
Desvio-padrão & 259 & 14 & 12 & 3 \\
\hline
\end{tabular}

Legenda: AfSST...SST do afluente à ETE Gama, AlSST1...SST da alimentação ao TQ01, DeSST1...SST do descarte do TQ01 e PeSST1...SST do permeado. 
Nas Figuras 5.37 e 5.38, apresentam-se os gráficos box-plot de todas as quatro séries monitoradas de SST das amostras desta pesquisa de microfiltração de efluente do reator $U A S B$ das 61 corridas. Tendo em conta que ocorreram diferentes intervalos de variação dos valores das séries, na Figura 5.37 ilustra-se a sequência temporal relacionada às amostras do afluente à ETE Gama, enquanto na Figura 5.38 apresentam-se os valores da alimentação ao TQ01, do descarte do TQ01 e os do permeado.

O reator $U A S B$ foi responsável pela maior parcela da remoção de SST, com valor médio levantado de $97 \%$. A unidade de microfiltração acrescentou 69\%, em média, à remoção de SST. Dessa forma, o tratamento completo registrou uma remoção média de SST de 99\%. A remoção global de SST da microfiltração do efluente do reator $U A S B$ elevou o padrão do tratamento de "B" (remoção mínima de 60\%) para o nível "F" (remoção mínima de 90\%) da referência de classificação dos sistemas de tratamento de esgotos sanitários do Programa de Despoluição de Bacias Hidrográficas (PRODES) da Agência Nacional de Água (ANA) (Libânio et al., 2007).

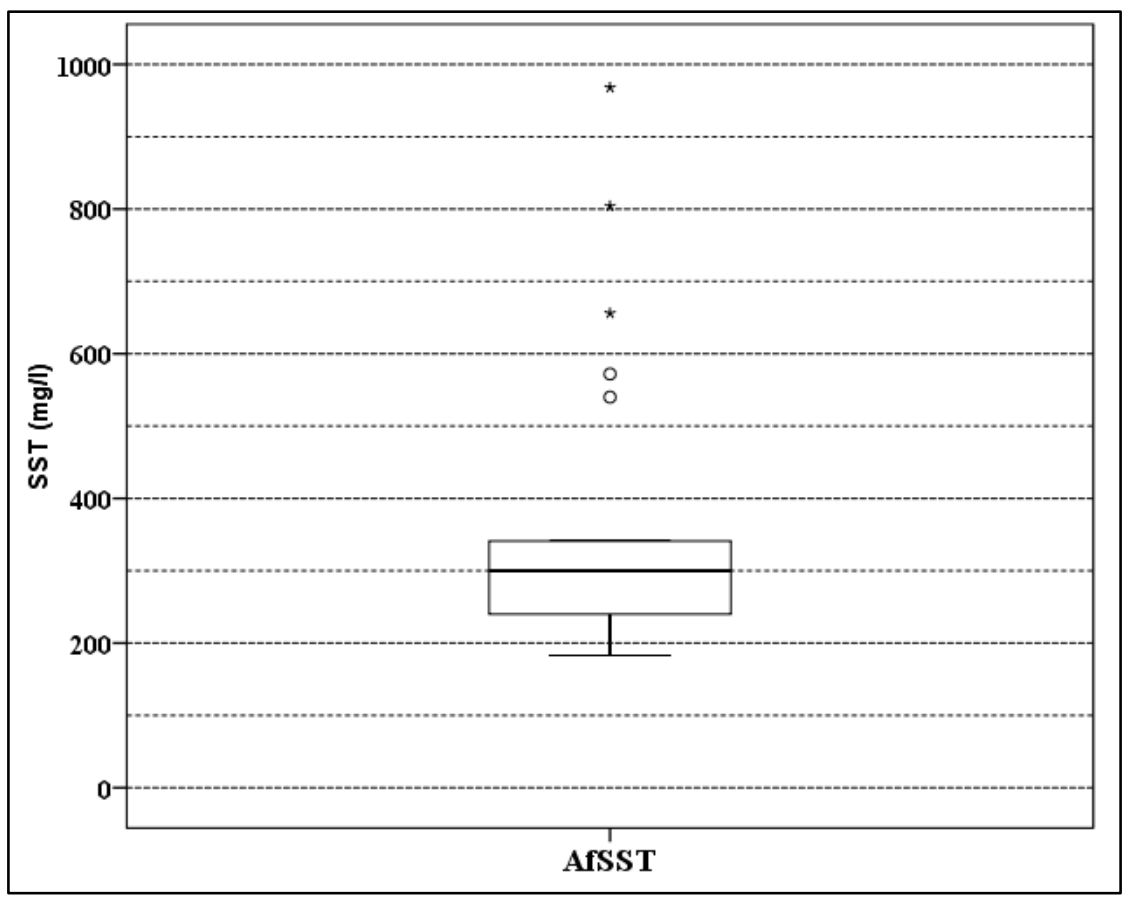

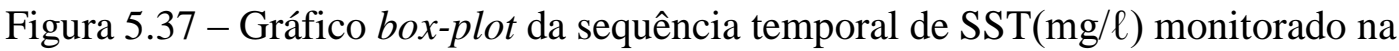
pesquisa de microfiltração de efluente do reator $U A S B$ para a amostra afluente a ETE Gama (28/03 a 20/10/2016).

Legenda: AfSST...SST do afluente à ETE Gama, “o” e “*”...outliers. 


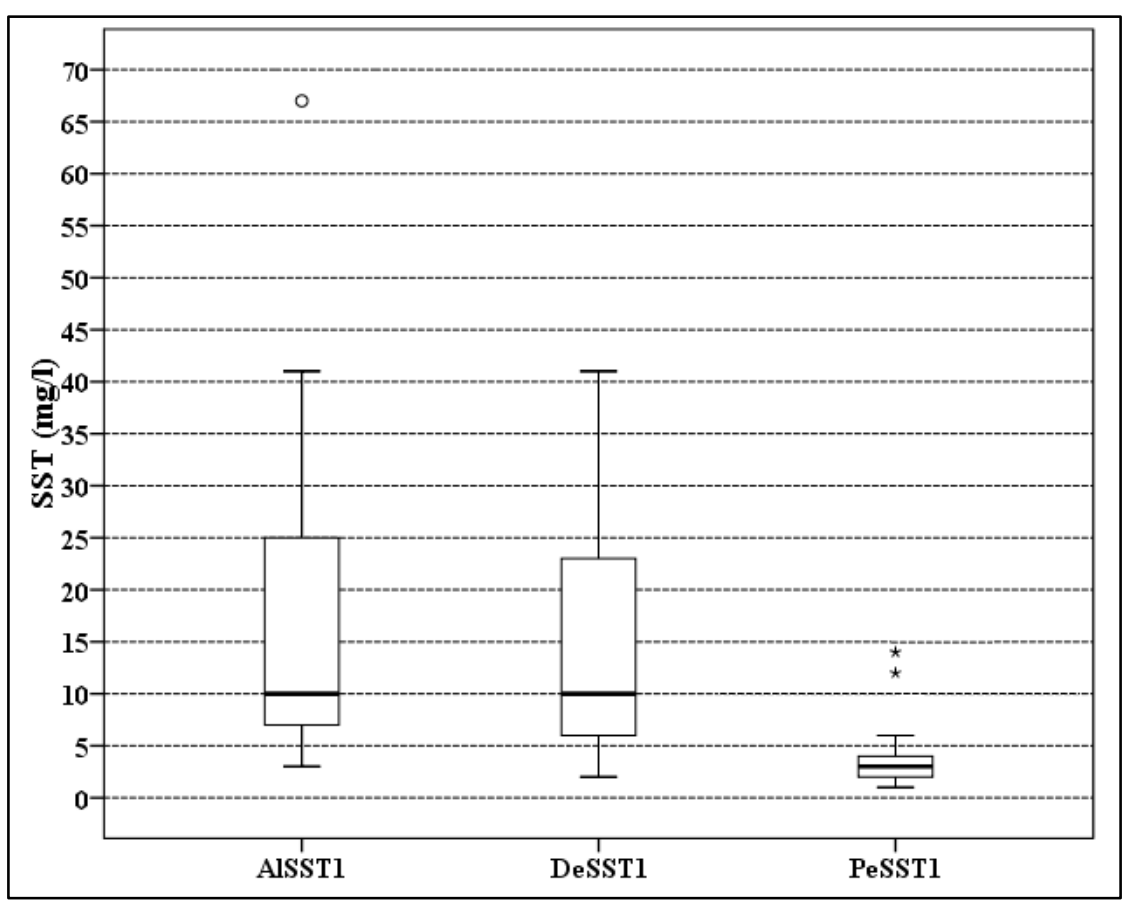

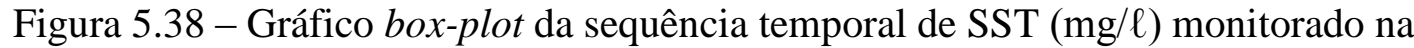
pesquisa de microfiltração de efluente do reator $U A S B$ para a amostra de permeado das 61 corridas executadas (28/03 a 20/10/2016).

Legenda: PeSST...SST do permeado; “o" e “*”...outliers.

Nos gráficos box-plot da Figura 5.39 apontam-se os resultados encontrados para as remoções parciais e para a remoção global de SST no presente trabalho.

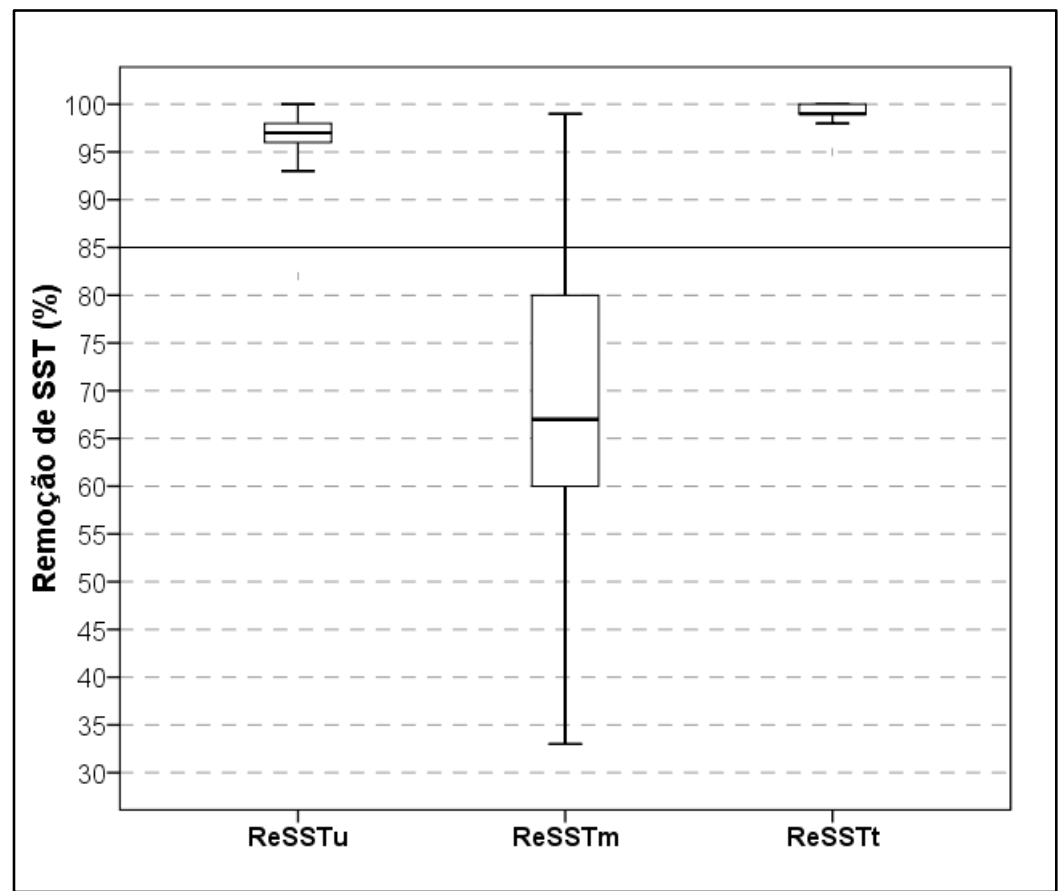

Figura 5.39 - Gráficos box-plot das remoções parciais no reator UASB (ReSSTu) e nas membranas submersas (ReSSTm) e remoção global do tratamento (ReSSTt) da pesquisa de microfiltração do efluente do reator $U A S B$ (28/03 a 20/10/2016). 
Na Tabela 5.12 apresentam-se as medidas estatísticas (valores mínimo, $1^{\circ}$ quartil $-25 \%$, médio, mediana (50\%), $3^{\circ}$ quartil - 75\%, máximo e o desvio-padrão) das sequências temporais de Turbidez verificadas nesta pesquisa de microfiltração de efluente do reator $U A S B$ para as amostras: (i) da alimentação ao TQ 01 (efluente do reator $U A S B$ ), (ii) do descarte do TQ01 e (iii) do permeado durante as 61 corridas executadas.

Na Figura 5.40 ilustram-se os gráficos box-plot de todas as três séries monitoradas de Turbidez desta pesquisa de microfiltração de efluente do reator $U A S B$ das amostras: da alimentação ao TQ 01, do descarte do TQ01 e do permeado das 61 corridas.

Nos gráficos box-plot da Figura 5.41 demonstram-se os valores levantados para a remoções de Turbidez (uT), informando que os valores considerados como os de entrada foram os da alimentação ao TQ01, mesmo porque, pela informação da Turbidez, e como pode ser verificado no gráfico da Figura 5.40, todos os parâmetros das duas amostras, que podem ser vistos na Tabela 5.12, para a alimentação e descarte do TQ01, são equivalentes.

Tabela 5.12 - Parâmetros estatísticos das séries temporais de Turbidez (uT) ensaiados na pesquisa de microfiltração de efluente do reator $U A S B$ para as amostras: da alimentação ao TQ 01, do descarte do TQ01 e do permeado das 61 corridas executadas (28/03 a 20/10/2016).

\begin{tabular}{cccc}
\hline \multirow{2}{*}{ Valores } & \multicolumn{3}{c}{ Ponto de amostragem } \\
\cline { 2 - 4 } & $\begin{array}{c}\text { Alimentação } \\
\text { TQ 01 } \\
\text { (AlTur) }\end{array}$ & $\begin{array}{c}\text { Descarte } \\
\text { TQ01 } \\
\text { (DeTur) }\end{array}$ & $\begin{array}{c}\text { Permeado } \\
\text { produzido } \\
\text { (PeTur) }\end{array}$ \\
\hline Mínimo & 89 & 86 & 35 \\
$1^{\circ}$ Quartil (25\%) & 108 & 115 & 61 \\
Médio & 171 & 169 & 100 \\
Mediana (50\%) & 180 & 170 & 82 \\
$3^{\circ}$ Quartil (75\%) & 202 & 220 & 160 \\
Máximo & 366 & 315 & 190 \\
Desvio-padrão & 65 & 59 & 50 \\
\hline
\end{tabular}

Legenda: AlTur...Turbidez da alimentação ao TQ01, DeTur...Turbidez do descarte do TQ01 e PeTur...Turbidez do permeado. 


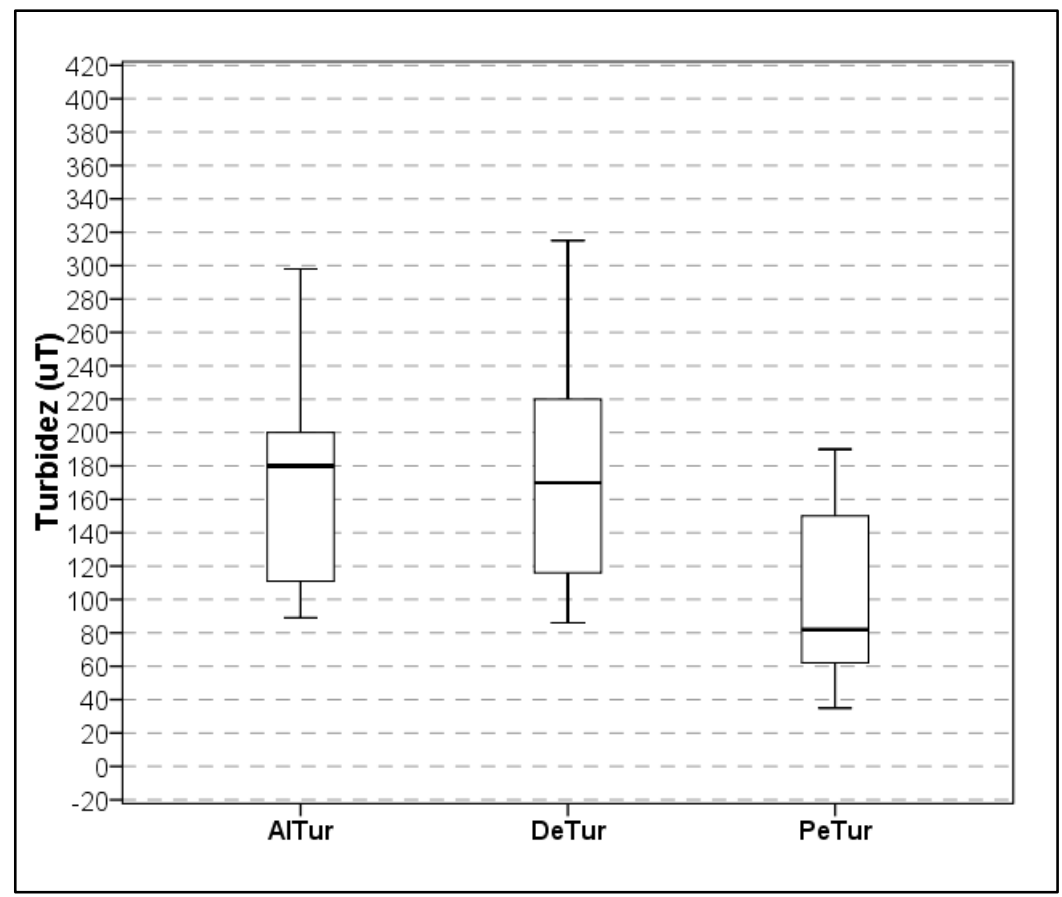

Figura 5.40 - Gráficos box-plot das séries temporais de Turbidez (uT) levantadas na pesquisa de microfiltração de efluente do reator $U A S B$ para as amostras: da alimentação ao TQ 01 e do descarte do TQ01 das 61 corridas executadas (28/03 a 20/10/2016).

Legenda: AlTur...Turbidez da alimentação ao TQ01, DeTur...Turbidez do descarte do TQ01 e PeTur...Turbidez do permeado.

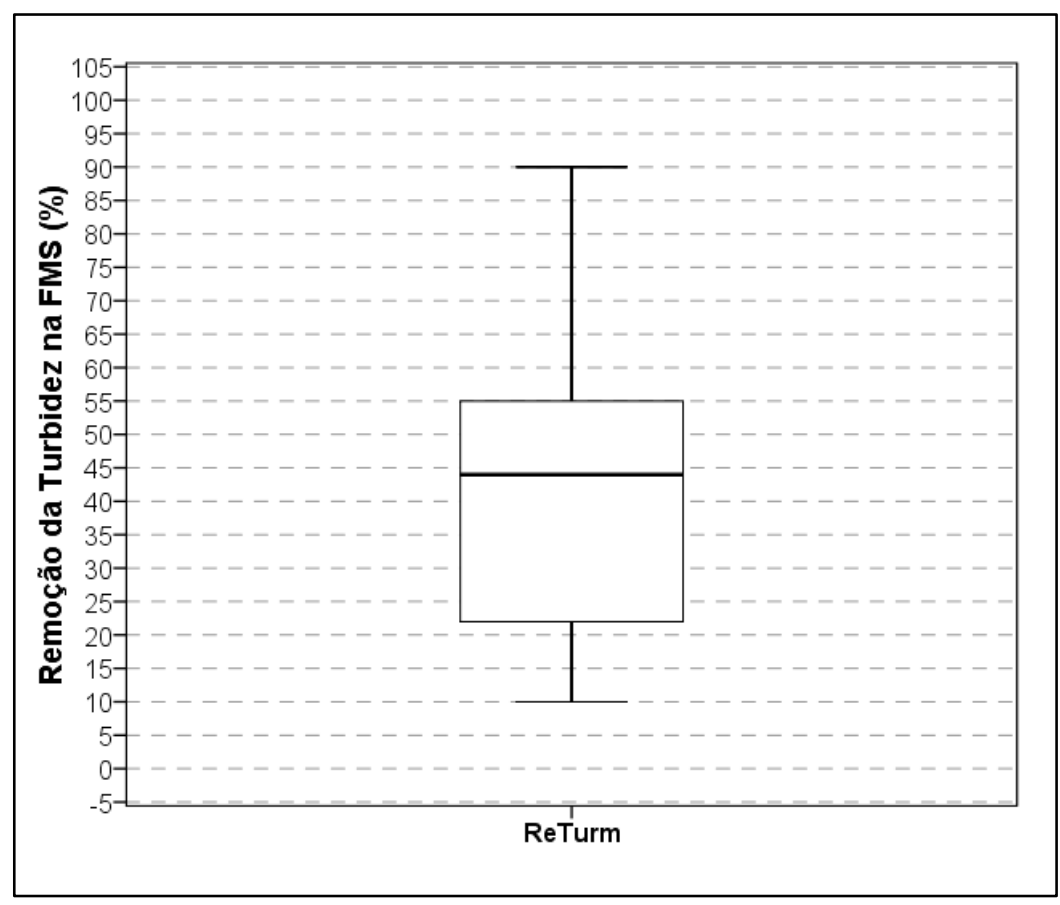

Figura 5.41 - Gráfico box-plot da remoção de Turbidez pela unidade de filtração por membranas submersas (ReTurm) da pesquisa de microfiltração do efluente do reator UASB (28/03 a 20/10/2016).

Legenda: FMS...Filtração por Membranas Submersas. 
Verifica-se que a remoção média da Turbidez foi de 40\%, com o permeado apresentando em média 100 uT como Turbidez e, como verificado no dia a dia da pesquisa, visualmente, apresentava-se com turbidez e cor elevada, quando comparado a água potável da CAESB.

As estimativas dos diâmetros médios geométricos em massa $\left(\mathrm{D}_{\mathrm{mg}}-\mu \mathrm{m}\right)$ a partir dos dados levantados nesta pesquisa de microfiltração do efluente do reator $U A S B$, foram feitas durante as 61 corridas ensaiadas para as seguintes amostras: (i) da alimentação ao TQ 01 (efluente do reator $U A S B$ ), (ii) do descarte do TQ01 e (iii) do permeado. Os valores foram calculados a partir das análises dos quatro fracionamentos dos Sólidos Suspensos Totais de cada uma das amostras, como ilustrado na Figura 4.12 e segundo a Equação 5.1 segundo a forma adaptada da pesquisa de Levine et al. (1991).

$$
D m g=\exp \left(\frac{\sum_{i=1}^{n} S S T i . l n D i}{\sum_{i=1}^{n} D i}\right)
$$

Onde: $\mathrm{D}_{\mathrm{mg}}$ é o diâmetro médio geométrico em massa $(\mu \mathrm{m})$, SSTi é a concentração de Sólidos Suspensos Totais na fração i e Di é o diâmetro médio calculado pelo diâmetros nominais dos poros dos filtros de membrana sucessivos.

Na Tabela 5.13 apresentam-se os parâmetros estatísticos (valores mínimo, $1^{\circ}$ quartil $25 \%$, médio, mediana (50\%), $3^{\circ}$ quartil - 75\%, máximo e o desvio-padrão) das estimativas dos diâmetros médios geométricos em massa $(\mu \mathrm{m})$ verificados nesta pesquisa de microfiltração de efluente do reator $U A S B$ para as amostras: (i) da alimentação ao TQ 01 (efluente do reator $U A S B$ ), (ii) do descarte do TQ01 e (iii) do permeado durante as 61 corridas executadas.

Nos gráficos box-plot da Figura 5.42 ilustram-se os valores estimados para os cálculos dos diâmetros médios geométricos em massa das amostras nesta pesquisa de microfiltração de efluente do reator $U A S B$ para as amostras: (i) da alimentação ao TQ 01 (efluente do reator $U A S B$ ), (ii) do descarte do TQ01 e (iii) do permeado durante as 61 corridas ensaiadas. Nota-se que os valores médios dos resultados das duas amostras são muito próximos. 
Tabela 5.13 - Medidas estatísticas das estimativas dos diâmetros médios geométricos em massa $(\mu \mathrm{m})$ verificados na pesquisa de microfiltração de efluente do reator $U A S B$ para as amostras: da alimentação ao TQ 01, do descarte do TQ01 e do permeado das 61 corridas ensaiadas (28/03 a 20/10/2016).

\begin{tabular}{cccc}
\hline \multirow{2}{*}{ Valores } & \multicolumn{3}{c}{ Ponto de amostragem } \\
\cline { 2 - 4 } & $\begin{array}{c}\text { Alimentação } \\
(\text { DiAl }-\mu \mathrm{m})\end{array}$ & $\begin{array}{c}\text { Descarte } \\
(\mathrm{DiDe}-\mu \mathrm{m})\end{array}$ & $\begin{array}{c}\text { Permeado } \\
(\text { DiPe- } \mu \mathrm{m})\end{array}$ \\
\hline Mínimo & 0,66 & 0,59 & 0,56 \\
$1^{\circ}$ Quartil $(25 \%)$ & 0,80 & 0,75 & 0,68 \\
Médio & 0,87 & 0,85 & 0,73 \\
Mediana (50\%) & 0,85 & 0,85 & 0,71 \\
$3^{\circ}$ Quartil (75\%) & 0,97 & 0,94 & 0,77 \\
Máximo & 1,08 & 1,08 & 1,02 \\
Desvio-padrão & 0,12 & 0,13 & 0,09 \\
\hline Legenda: DiAl... D mg $_{\text {da }}$ da alimentação ao TQ01, DiDe... D D $_{\text {mg }}$ do descarte do TQ01 e DiPe... \\
D $_{\text {mg do permeado. }}$
\end{tabular}

Como se pode notar nos dados da Tabela 5.13 e pelo demonstrado nos gráficos box-plot da Figura 5.42, a flutuação dos valores das variáveis DiAl e DiDe são semelhantes, com valores médios e máximos coincidentes. Com relação ao $\mathrm{D}_{\mathrm{mg}}$ do permeado, o microfiltrado em membranas submersas com diâmetro de poros de 0,40 $\mu \mathrm{m}$ (PAM Membrana Seletivas, 2014), apresentou um declínio em todas as medidas estatísticas da Tabela 5.13 e a estimativa do DiPe médio de $0,73 \mu \mathrm{m}$.

Com estes resultados, a situação constatada parece como o conto do sonho do sábio chinês, em que este sonhará que era uma borboleta ou uma borboleta sonhará que era um sábio chinês, pois, se os resultados estimados do DiPe estiverem corretos, pode-se afirmar que o diâmetro médio dos poros da membrana não é $0,40 \mu \mathrm{m}$, e se o diâmetro de poros da membrana, com certeza, for $0,40 \mu \mathrm{m}$, o valor da integridade de 3 unidades logarítmicas não garante que as partículas do permeado possam ter diâmetros abaixo de 0,40 $\mu \mathrm{m}$, pelos resultados levantados nesta pesquisa. 


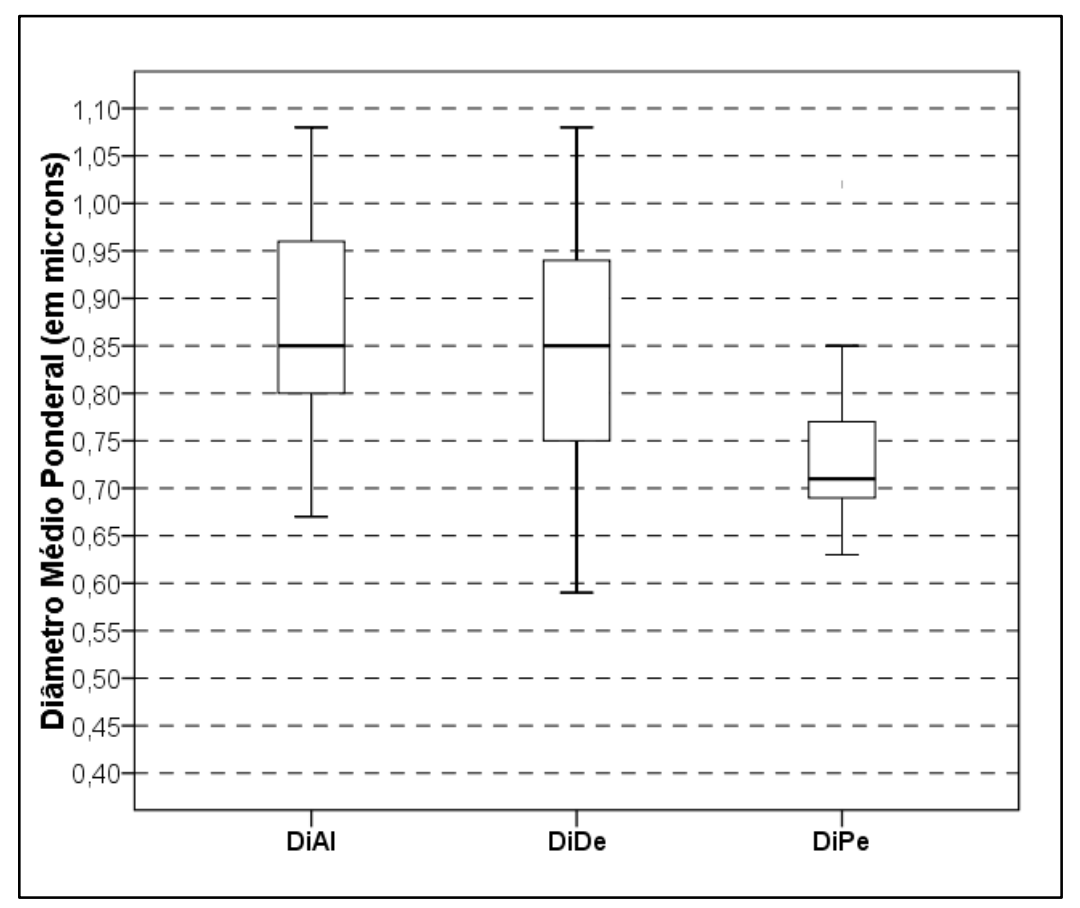

Figura 5.42 - Gráficos box-plot das estimativas dos diâmetros médios geométricos em massa $(\mu \mathrm{m})$ computados na pesquisa de microfiltração de efluente do reator $U A S B$ para as amostras: da alimentação ao TQ 01 e do descarte do TQ01 das 61 corridas executadas (28/03 a 20/10/2016).

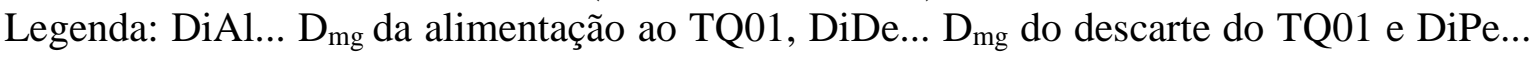
$\mathrm{D}_{\mathrm{mg}}$ do permeado.

Na Tabela 5.14 apresentam-se os parâmetros estatísticos (valores mínimo, $1^{\circ}$ quartil 25\%, médio, mediana (50\%), $3^{\circ}$ quartil - 75\%, máximo e o desvio-padrão) das séries temporais de Sólidos Dissolvidos Totais (SDT), Sólidos Dissolvidos Totais Voláteis (SDTv) e Sólidos Dissolvidos Totais Fixos (SDTf) monitorados nesta pesquisa de microfiltração de efluente do reator $U A S B$ para as amostras: (i) alimentação do TQ 01, (ii) descarte do TQ01 e (iii) do permeado durante as 61 corridas executadas. Ressalta-se que, como ilustrado no desenho da Figura 4.12, os SDT analisados foram a fração filtrável da membrana filtrante de $0,22 \mu \mathrm{m}$. 
Tabela 5.14 - Medidas estatísticas das séries temporais de Sólidos Dissolvidos Totais (SDT), SDT voláteis (SDTv) e SDT fixos (SDTf) monitorados (mg/ $\ell$ ) na pesquisa de microfiltração de efluente do reator $U A S B$ para as amostras: alimentação do TQ 01, descarte do TQ01 e do permeado das 61 corridas executadas

(28/03 a 20/10/2016).

\begin{tabular}{|c|c|c|c|c|c|c|c|c|c|}
\hline \multirow{3}{*}{ Valores } & \multicolumn{9}{|c|}{ Amostras } \\
\hline & \multicolumn{3}{|c|}{ Alimentação ao TQ01 } & \multicolumn{3}{|c|}{ Descarte do TQ01 } & \multicolumn{3}{|c|}{ Permeado } \\
\hline & AlSDT & AlSDTv & AlSDTf & DeSDT & DeSDTv & DeSDTf & PeSDT & PeSDTv & PeSDTf \\
\hline Mínimo & 204 & 2 & 86 & 238 & 3 & 59 & 223 & 2 & 53 \\
\hline $1^{\circ}$ Quartil & 353 & 65 & 159 & 384 & 55 & 232 & 310 & 4 & 158 \\
\hline Médio & 1055 & 191 & 864 & 1201 & 200 & 1001 & 793 & 139 & 654 \\
\hline $\begin{array}{l}\text { Mediana } \\
(50 \%)\end{array}$ & 859 & 177 & 708 & 1057 & 152 & 911 & 574 & 109 & 505 \\
\hline $\begin{array}{c}3^{\circ} \text { Quartil } \\
(75 \%)\end{array}$ & 1889 & 240 & 1587 & 1737 & 314 & 1409 & 1308 & 194 & 1155 \\
\hline Máximo & 2308 & 902 & 2154 & 5320 & 654 & 4847 & 1857 & 405 & 1806 \\
\hline $\begin{array}{l}\text { Desvio- } \\
\text { padrão }\end{array}$ & 756 & 188 & 724 & 986 & 176 & 941 & 531 & 128 & 543 \\
\hline
\end{tabular}

Na Figura 5.43 são exibidos os gráficos box-plot de todas as três séries monitoradas de SDT, SDTv e SDTf desta pesquisa de microfiltração de efluente do reator UASB por amostras: (i) da alimentação ao TQ 01, (ii) do descarte do TQ01 e (iii) do permeado durante as 61 corridas executadas. Todos os valores estão expressos em mg/ $\ell$.

Na Tabela 5.14 e na Figura 5.43 são demonstrados que a maioria dos valores foi inferior a 3,0 g/ $\ell$, sendo que o valor máximo de todas as séries para a concentração de Sólidos Dissolvidos Totais foi 5,32 g/ $\ell$. A fração inorgânica (SDTf) dos Sólidos Dissolvidos Totais (SDT) foi sempre muito superior à orgânica (SDTv), ocorrendo já na corrente da alimentação ao tanque de membranas submersas (TQ01), que é o efluente do reator UASB, o que destaca a eficiência do reator $U A S B$ da ETE Gama na remoção da matéria orgânica. 


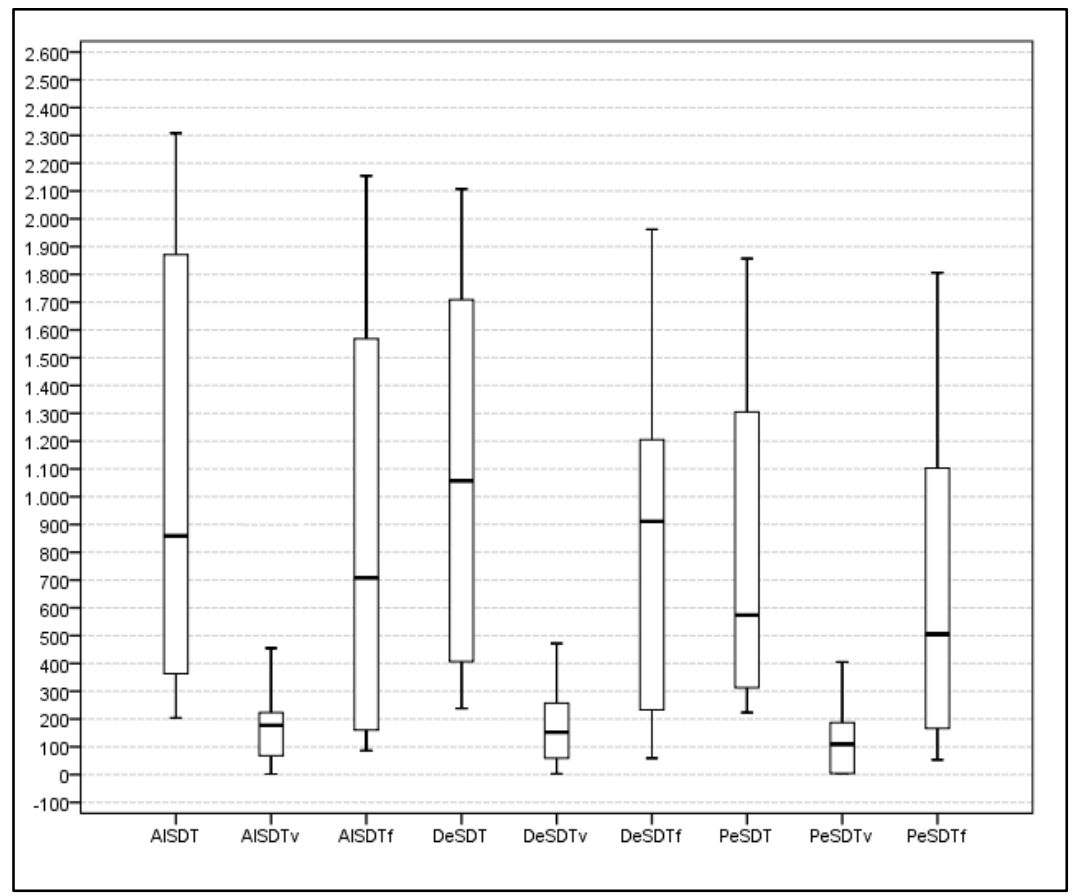

Figura 5.43 - Gráficos box-plot das séries temporais de Turbidez (uT) levantadas na pesquisa de microfiltração de efluente do reator $U A S B$ para as amostras: da alimentação ao TQ 01 e do descarte do TQ01 das 61 corridas executadas (28/03 a 20/10/2016).

Legenda: AlSDT...SDT da alimentação ao TQ01, AlSDTv...SDTv da alimentação, AlSDTf...SDTf da alimentação, DeSDT...SDT do descarte do TQ01, DeSDTv...SDTv do descarte do TQ01, DeSDTf...SDTf do descarte do TQ01, PeSDT...SDT do permeado, PeSDTv...SDTv do permeado e PeSDTf...SDTf do permeado. Todos os valores expressos $\mathrm{em} \mathrm{mg} / \ell$.

As características químicas da qualidade da água exploradas na presente pesquisa foram:

(i) Demanda Bioquímica de Oxigênio padrão (DBO), (ii) Demanda Química de Oxigênio (DQO), (iii) Surfactantes Aniônicos - Detergentes (SA) e (iv) Óleos e Graxas (OG).

Na Tabela 5.15 apresentam-se as medidas estatísticas (valores mínimo, $1^{\circ}$ quartil - 25\%, médio, mediana (50\%), $3^{\circ}$ quartil - 75\%, máximo e o desvio-padrão) das séries temporais da Demanda Bioquímica de Oxigênio (DBO em $\mathrm{mg} / \ell$ ) levantados neste trabalho de microfiltração do efluente do reator $U A S B$ para as amostras: (i) do esgoto bruto (afluente a ETE), (ii) da alimentação ao TQ 01 (efluente do reator $U A S B$ ), (iii) do permeado durante as 61 corridas executadas. 
Tabela 5.15 - Medidas estatísticas das sequencias temporais de Demanda Bioquímica de Oxigênio (DBO em $\mathrm{mg} / \ell$ ) monitorados na pesquisa de microfiltração de efluente do reator $U A S B$ para as amostras: afluente a ETE Gama, da alimentação ao TQ 01 e do permeado das 61 corridas executadas (28/03 a 20/10/2016).

\begin{tabular}{cccc}
\hline & \multicolumn{3}{c}{ Ponto de amostragem } \\
\cline { 2 - 4 } Valores & $\begin{array}{c}\text { Afluente } \\
\text { à ETE Gama } \\
\text { (AfDBO) }\end{array}$ & $\begin{array}{c}\text { Alimentação } \\
\text { TQ 01 } \\
\text { (AlDBO) }\end{array}$ & $\begin{array}{c}\text { Permeado } \\
\text { (PeDBO) }\end{array}$ \\
\hline Mínimo & 200 & 36 & 21 \\
$1^{\circ}$ Quartil (25\%) & 380 & 49 & 34 \\
Médio & 405 & 76 & 53 \\
Mediana (50\%) & 420 & 64 & 44 \\
$3^{\circ}$ Quartil (75\%) & 460 & 100 & 60 \\
Máximo & 500 & 200 & 150 \\
Desvio-padrão & 75 & 39 & 32 \\
\hline Legenda: AfDBO...DBO do afluente à ETE Gama, AlDBO...DBO da alimentação ao \\
TQ01 e PeDBO...pH do permeado.
\end{tabular}

Na Figura 5.44 apresentam-se os gráficos box-plot de todas as três séries temporais monitoradas da Demanda Bioquímica de Oxigênio (DBO em $\mathrm{mg} / \ell$ ) levantados neste trabalho de microfiltração do efluente do reator $U A S B$ para as amostras: (i) do esgoto bruto (afluente a ETE), (ii) da alimentação ao TQ 01 (efluente do reator $U A S B$ ) e (iii) do permeado durante as 61 corridas ensaiadas.

Nos gráficos box-plot da Figura 5.45 apontam-se os resultados encontrados para as remoções parciais, ocorridas no reator $U A S B$ (ReDBOu) e na planta-piloto de microfiltração por membranas submersas (ReDBOm) e da remoção global de todo tratamento (reator $U A S B$ + planta-piloto de microfiltração por membranas submersas) da variável DBO no presente trabalho.

A remoção parcial do reator $U A S B$ foi responsável pela maior parcela da remoção de $\mathrm{DBO}$, com valor médio levantado de $81 \%$. A unidade de microfiltração acrescentou $30 \%$, em média, à remoção de DBO. Dessa forma, o tratamento completo registrou uma remoção média de DBO de $87 \%$. A remoção global de DBO da microfiltração do efluente do reator $U A S B$ elevou o padrão do tratamento de "B" (remoção mínima de 60\%) para o nível "E" (remoção mínima de $85 \%$ ) da referência de classificação dos sistemas de tratamento de esgotos sanitários PRODES/ANA (Libânio et al., 2007). 


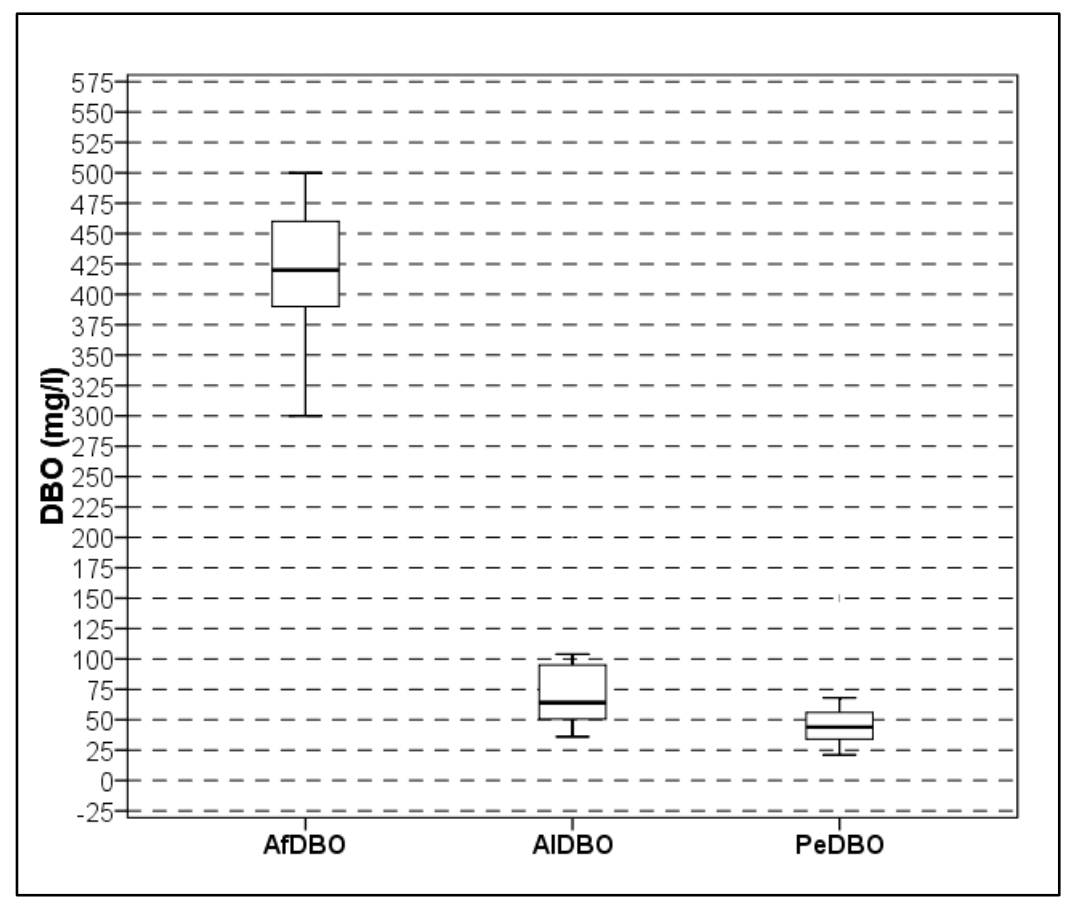

Figura 5.44 - Gráficos box-plot das séries de $\mathrm{DBO}(\mathrm{mg} / \ell)$ monitorados na pesquisa de microfiltração de efluente do reator $U A S B$ para as amostras: afluente a ETE Gama, alimentação do TQ 01 e do permeado das 61 corridas ensaiadas (28/03 a 20/10/2016). Legenda: AfDBO...DBO do afluente à ETE Gama, AIDBO...DBO da alimentação ao TQ01 e PeDBO...DBO do permeado.

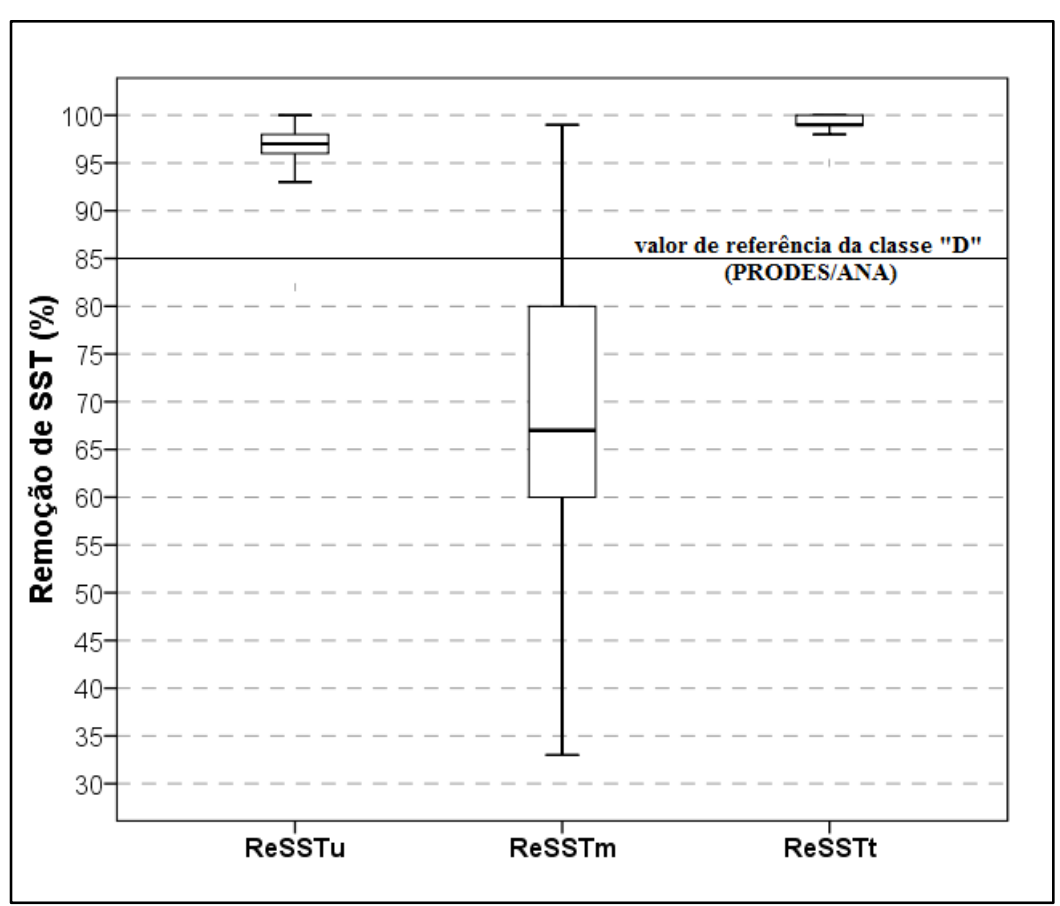

Figura 5.45 - Gráficos box-plot das remoções parciais de DBO no reator UASB (ReDBOu) e nas membranas submersas (ReDBOm) e remoção global do tratamento (ReDBOt) da pesquisa de microfiltração do efluente do reator $U A S B(28 / 03$ a 20/10/2016). Legenda: PRODES...Programa de Despoluição de Bacias Hidrográficas e ANA...Agência Nacional de Água. 
Destaca-se que todos os valores das concentrações das séries temporais da Demanda Bioquímica de Oxigênio (DBO em $\mathrm{mg} / \ell$ ) das amostras do efluente do reator UASB (alimentação do TQ01) e do efluente final do tratamento (permeado) atendem ao valor da resolução CONAMA 430/11 (Brasil, 2011) - DBO < $120 \mathrm{mg} / \ell$.

$\mathrm{Na}$ Tabela 5.16 apresentam-se as medidas estatísticas (valores mínimo, $1^{\circ}$ quartil $-25 \%$, médio, mediana (50\%), $3^{\circ}$ quartil - 75\%, máximo e o desvio-padrão) das séries temporais da Demanda Química de Oxigênio (DQO em $\mathrm{mg} / \ell$ ) levantados neste trabalho de microfiltração do efluente do reator $U A S B$ para as amostras do: (i) esgoto bruto (afluente a ETE), (ii) alimentação ao TQ 01 (efluente do reator $U A S B$ ), (iii) descarte do TQ01 e (iv) permeado durante as 61 corridas executadas.

Tabela 5.16 - Parâmetros estatísticos das séries temporais das concentrações das Demandas Químicas de Oxigênio (DQO em mg/ $\ell$ ) levantadas nesta pesquisa de microfiltração de efluente do reator $U A S B$ para as amostras: afluente a ETE Gama, alimentação do TQ 01, descarte do TQ01 e do permeado das 61 corridas ensaiadas (28/03 a

\begin{tabular}{ccccc}
\multicolumn{5}{c}{ 20/10/2016). } \\
\hline \multirow{4}{*}{ Valores } & $\begin{array}{c}\text { Ponto de amostragem } \\
\text { Afluente } \\
\text { à ETE Gama } \\
\text { (AfDQO) }\end{array}$ & $\begin{array}{c}\text { Alimentação } \\
\text { TQ 01 } \\
\text { (AlDQO) }\end{array}$ & $\begin{array}{c}\text { Descarte } \\
\text { TQ 01 } \\
(\text { DeDQO) }\end{array}$ & $\begin{array}{c}\text { Permeado } \\
\text { (PeDQO) }\end{array}$ \\
\hline Mínimo & 334 & 128 & 109 & 43 \\
$1^{\circ}$ Quartil (25\%) & 628 & 182 & 168 & 77 \\
Médio & 681 & 221 & 220 & 110 \\
Mediana (50\%) & 702 & 200 & 206 & 88 \\
$3^{\circ}$ Quartil (75\%) & 741 & 225 & 221 & 143 \\
Máximo & 930 & 473 & 459 & 190 \\
Desvio-padrão & 127 & 83 & 91 & 44 \\
\hline
\end{tabular}

Legenda: AfDQO...DQO do afluente à ETE Gama, AlDQO...DQO da alimentação ao TQ01, DeDQO...DQO do descarte do TQ01 e PeDBO...pH do permeado.

Na Figura 5.46 apresentam-se os gráficos box-plot de três séries temporais monitoradas da Demanda Química de Oxigênio (DQO em $\mathrm{mg} / \ell$ ) obtidas nesta pesquisa de microfiltração do efluente do reator $U A S B$ para as amostras: (i) do esgoto bruto (afluente a ETE), (ii) da alimentação ao TQ 01 (efluente do reator $U A S B$ ) e (iii) do permeado durante as 61 corridas ensaiadas. 
Nos gráficos box-plot da Figura 5.47 apontam-se os resultados encontrados das remoções parciais, ocorridas no reator $U A S B$ (ReDQOu) e na planta-piloto de microfiltração por membranas submersas (ReDQOm) e da remoção global de todo tratamento (reator UASB + planta-piloto de microfiltração por membranas submersas) da variável DQO obtidos nesta pesquisa.

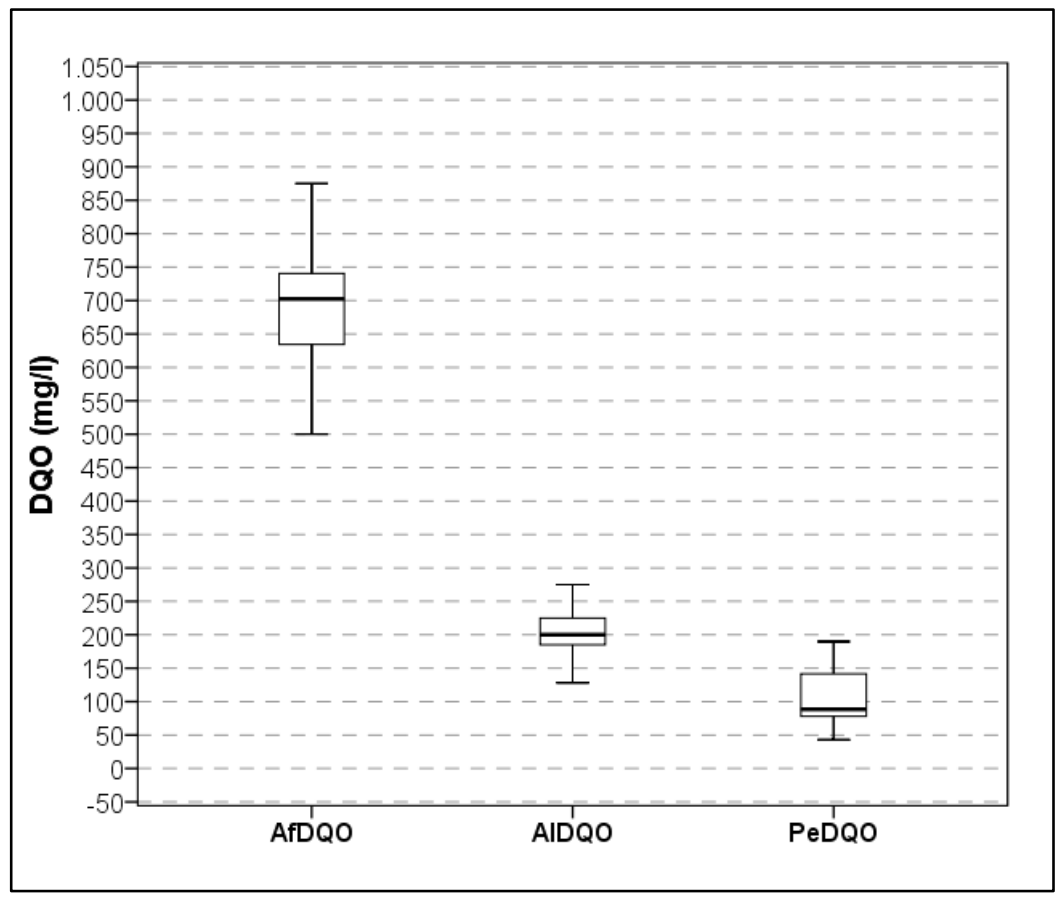

Figura 5.46 - Gráficos box-plot das sequências temporais das concentrações das Demandas Químicas de Oxigênio (DQO em mg/ $\ell$ ) monitorados na pesquisa de microfiltração de efluente do reator $U A S B$ para as amostras: afluente a ETE Gama, alimentação do TQ 01 e do permeado das 61 corridas ensaiadas (28/03 a 20/10/2016).

Legenda: AfDQO...DQO do afluente à ETE Gama, AIDQO...DQO da alimentação ao TQ01 e PeDQO...DQO do permeado.

A remoção parcial do reator $U A S B$ foi responsável pela maior parcela da remoção de DQO, com valor médio levantado de $68 \%$. A unidade de microfiltração acrescentou $48 \%$, em média, a remoção de DQO, dessa forma o tratamento completo registrou uma remoção média de DQO de $84 \%$. 


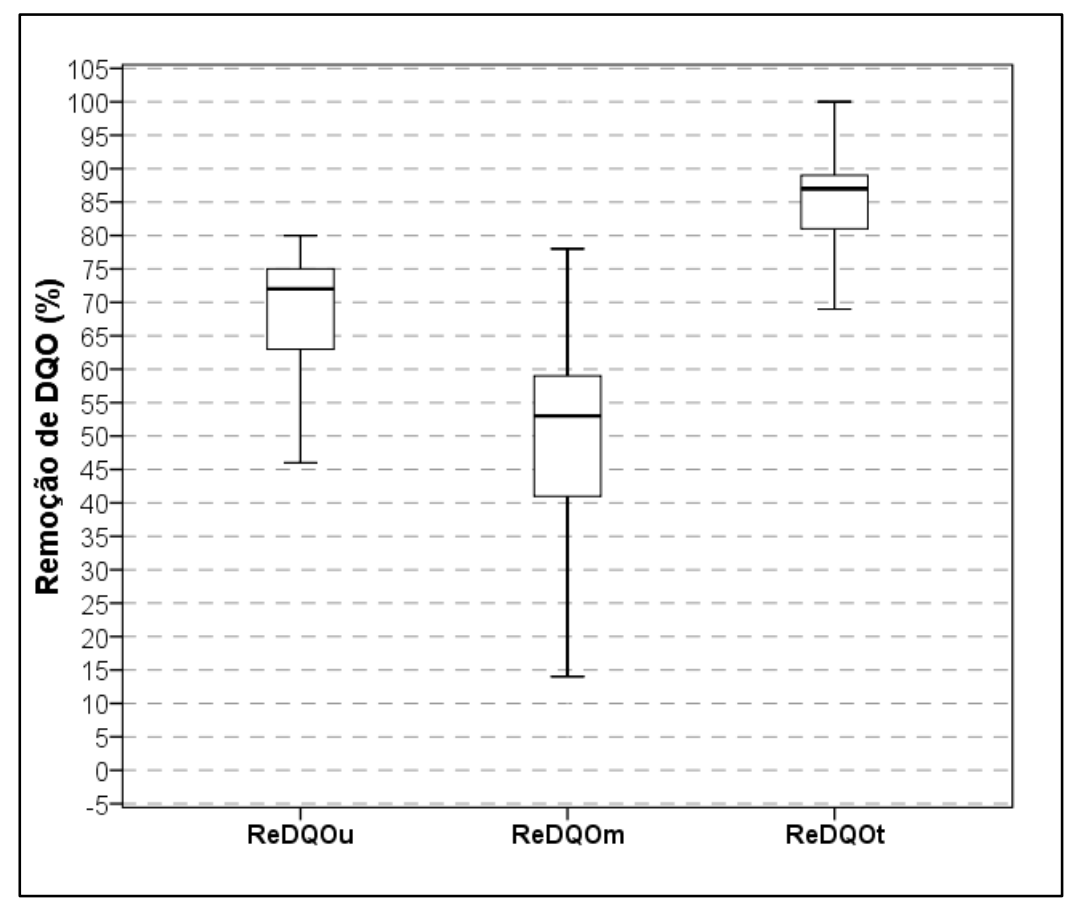

Figura 5.47 - Gráficos box-plot das remoções parciais de DQO no reator UASB (ReDQOu) e nas membranas submersas (ReDQOm) e remoção global do tratamento (ReDQOt) da pesquisa de microfiltração do efluente do reator UASB (28/03 a 20/10/2016).

Na Tabela 5.17 apresentam-se os parâmetros estatísticos (valores mínimo, $1^{\circ}$ quartil $25 \%$, médio, mediana (50\%), $3^{\circ}$ quartil - 75\%, máximo e o desvio-padrão) das séries

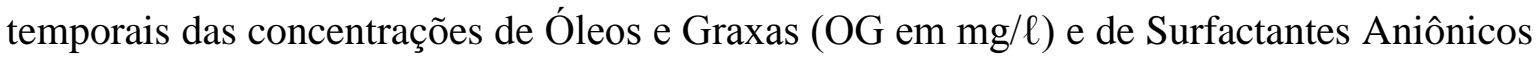
(SA em $\mathrm{mg} / \ell$ ) levantados neste trabalho de microfiltração do efluente do reator $U A S B$ para as amostras da alimentação ao TQ 01 e do permeado durante as 61 corridas ensaiadas.

Tabela 5.17 - Medidas estatísticas das séries temporais das concentrações de Óleos e

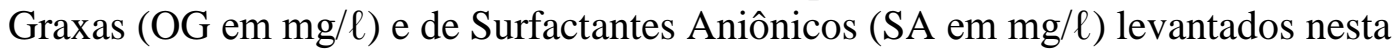
pesquisa de microfiltração de efluente do reator $U A S B$ para as amostras: alimentação do TQ 01 e do permeado das 61 corridas ensaiadas (28/03 a 20/10/2016).

\begin{tabular}{ccccc}
\hline \multirow{2}{*}{ Valores } & \multicolumn{4}{c}{ Ponto de amostragem } \\
\cline { 2 - 5 } & \multicolumn{2}{c}{ Alimentação do TQ01 } & Permeado \\
\cline { 2 - 5 } & AlOG & 0,18 & 26 & 0,11 \\
Mínimo & 32 & 0,53 & 46 & 0,59 \\
$1^{\circ}$ Quartil (25\%) & 40 & 0,96 & 65 & 0,66 \\
Médio & 68 & 0,75 & 58 & 0,63 \\
Mediana (50\%) & 64 & 1,76 & 80 & 0,74 \\
$3^{\circ}$ Quartil (75\%) & 105 & 1,95 & 133 & 1,20 \\
Máximo & 111 & 0,63 & 31 & 0,27 \\
Desvio-padrão & 31 &
\end{tabular}

Legenda: AlOG...OG da alimentação do TQ01, AlSA...SA da alimentação do TQ01, PeOG...OG do permeado e PeSA... SA do permeado. 
Nos gráficos box-plot das Figuras 5.48 e 5.49 ilustram-se as sequências das concentrações de OG $(\mathrm{mg} / \ell)$ e de SA $(\mathrm{mg} / \ell)$ para as amostras da alimentação ao TQ 01 e do permeado.

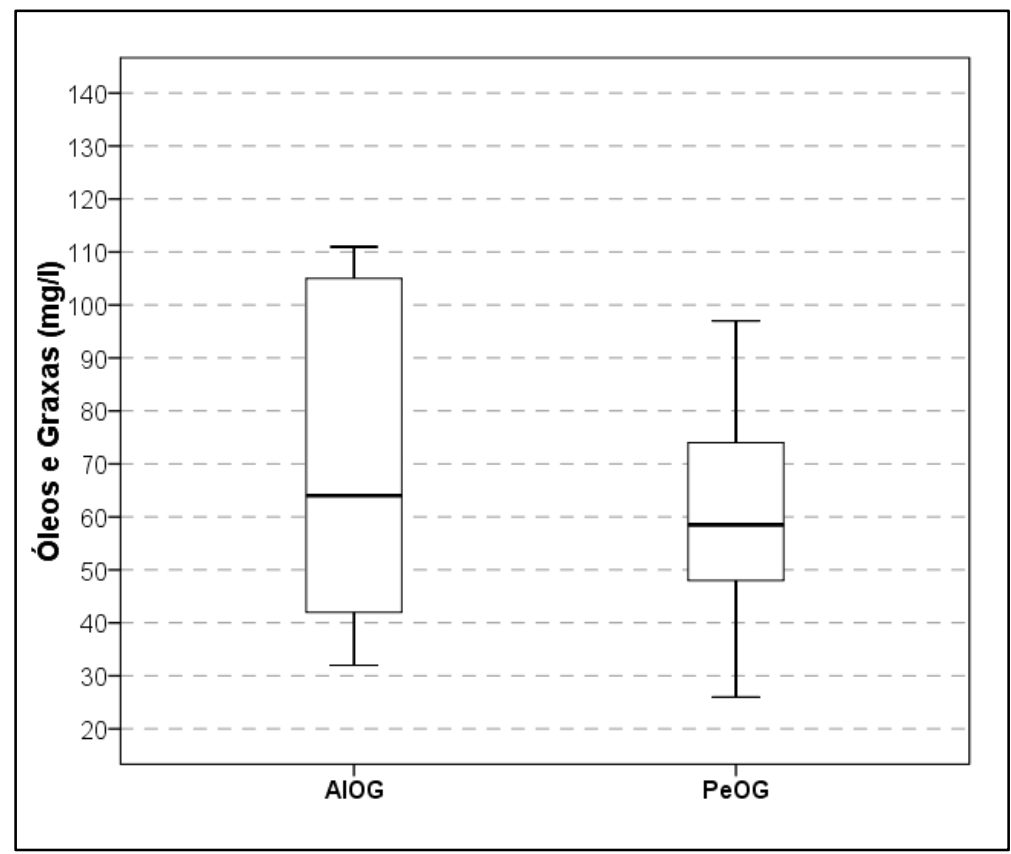

Figura 5.48 - Gráficos box-plot das sequências temporais das concentrações de Óleos e Graxas (OG em mg/ $\ell$ ) monitorados para as amostras da alimentação do TQ01 e do permeado das 61 corridas ensaiadas (28/03 a 20/10/2016).

Legenda: AlOG...OG da alimentação ao TQ01 e PeOG...OG do permeado.

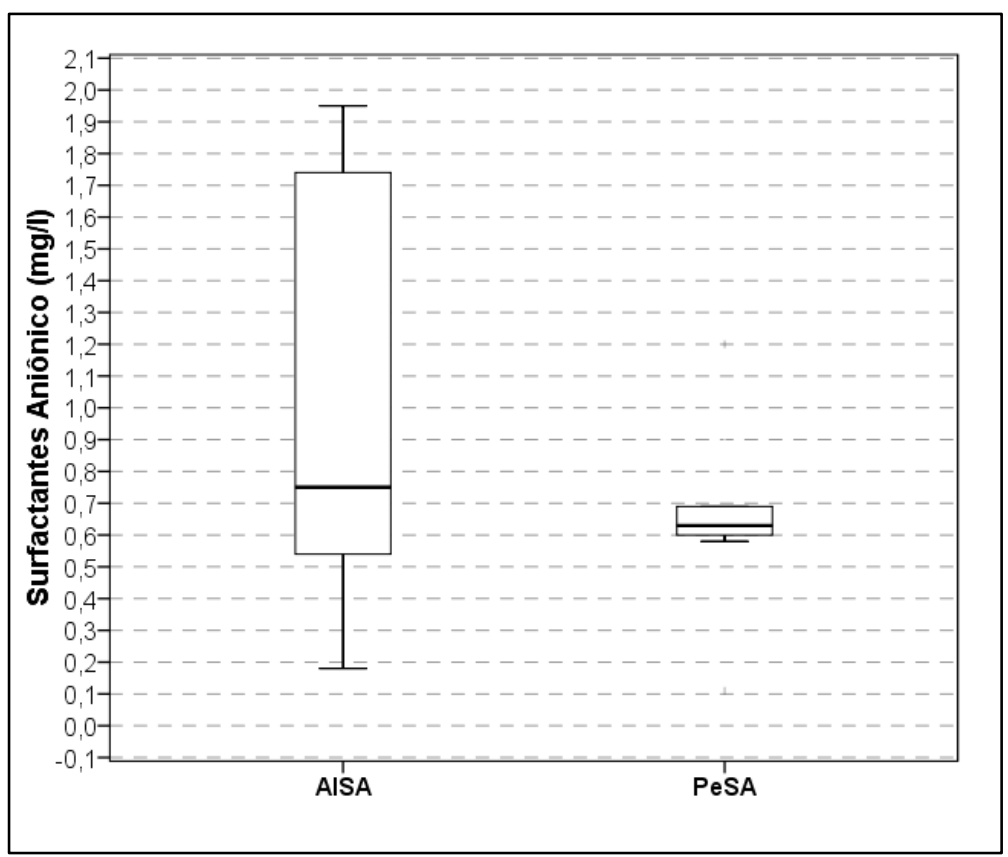

Figura 5.49 - Gráficos box-plot das sequências temporais das concentrações de Surfactante

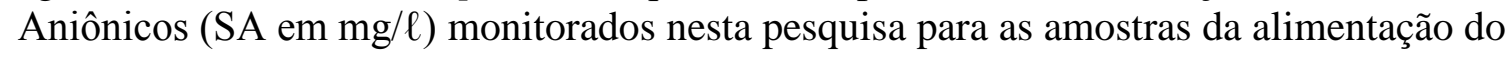
TQ01 e do permeado das 61 corridas ensaiadas (28/03 a 20/10/2016).

Legenda: AlOG...OG da alimentação ao TQ01 e PeOG...OG do permeado 
Constata-se, pelos dados apresentados na Tabela 5.17 e pelas ilustrações dos gráficos boxplot das Figuras 5.48 e 5.49, que os resultados das concentrações de Óleos e Graxas (OG $\mathrm{mg} / \ell$ ) e de Surfactantes Aniônicos (SA - mg/ $\ell$ ) para as amostras de alimentação do tanque de membranas submersas (TQ01) e do permeado são equivalentes, ou seja, não ocorreu qualquer rejeição pela membrana para estas variáveis ao se microfiltrar o efluente do reator $U A S B$. O ocorrido é em consequência do tamanho das moléculas destes compostos, pois muito provavelmente são menores que $0,40 \mu \mathrm{m}$, suposto diâmetro de corte das membranas utilizadas nesta pesquisa e também pelo fato de se encontrarem emulsificados, no caso o OG.

As características microbiológicas da qualidade da água examinadas na presente investigação foram: (i) Coliformes Totais (CT), (ii) Coliformes Fecais (CF) e (iii) Ovos de Helmintos $(\mathrm{OH})$.

A campanha especial de análises das concentrações de Ovos de Helmintos nas amostras de alimentação do TQ01 (efluente do reator $U A S B$ ) e do permeado foram executadas por quatro semanas consecutivas, todas as segundas-feiras, obtendo-se como resultados para todas as 8 amostras as ausência de Ovos de Helmintos Viáveis.

Muito embora as concentrações de Coliformes Totais (CT) tenham sido levantadas para as amostras da alimentação do TQ01 e do permeado durante a operação da microfiltração do efluente do reator $U A S B$, no programa de monitoramento do desempenho global da ETE Gama executado pela CAESB não foram feitas as análises de CT para o afluente à ETE, somente foram executadas as análises dos Coliformes Fecais (CF), portanto na análise dos resultados deste trabalho somente foi abordada a remoção relacionada a CF.

A Tabela 5.18 apresenta os parâmetros estatísticos (valores mínimo, $1^{\circ}$ quartil - 25\%, médio, mediana (50\%), $3^{\circ}$ quartil - 75\%, máximo e o desvio-padrão) das séries temporais dos logaritmos das concentrações de Coliformes Fecais (CF em NMP/100m $\ell$ ) levantados neste trabalho de microfiltração do efluente do reator $U A S B$ para as amostras do afluente a ETE Gama, da alimentação ao TQ 01 e do permeado durante as 61 corridas ensaiadas.

Nos gráficos box-plot da Figura 5.50, exibem-se os valores logarítmicos das concentrações de Coliformes Fecais (NMP/100 m $\ell$ ) registrados nesta pesquisa de microfiltração do efluente do reator $U A S B$ para as amostras: (i) esgoto bruto (afluente a ETE), (ii) 
alimentação ao TQ 01 (efluente do reator $U A S B$ ) e (iii) permeado durante as 61 corridas executadas. Nos gráficos box-plot da Figura 5.51, ilustram-se os resultados encontrados das remoções parciais e da remoção global de CF na presente pesquisa.

Tabela 5.18 - Medidas estatísticas das sequências temporais dos logaritmos dos

Coliformes Fecais (CF em NMP/100 m $\ell$ ) monitorados na pesquisa de microfiltração de efluente do reator $U A S B$ para as amostras: afluente a ETE Gama, da alimentação ao TQ 01 e do permeado das 61 corridas executadas (28/03 a 20/10/2016).

\begin{tabular}{cccc}
\hline \multirow{2}{*}{ Valores } & \multicolumn{3}{c}{ Ponto de amostragem } \\
\cline { 2 - 4 } & $\begin{array}{c}\text { Afluente } \\
\text { à ETE Gama } \\
(\operatorname{logAfCF})\end{array}$ & $\begin{array}{c}\text { Alimentação } \\
\text { TQ 01 } \\
(\operatorname{logAlCF})\end{array}$ & $\begin{array}{c}\text { Permeado } \\
(\operatorname{logPeCF})\end{array}$ \\
\hline Mínimo & 6,60 & 5,54 & 4,49 \\
$1^{\circ}$ Quartil $(25 \%)$ & 6,80 & 6,30 & 4,49 \\
Médio & 6,90 & 6,31 & 4,88 \\
Mediana (50\%) & 6,94 & 6,38 & 4,81 \\
$3^{\circ}$ Quartil (75\%) & 7,00 & 6,38 & 5,16 \\
Máximo & 7,06 & 6,38 & 5,54 \\
Desvio-padrão & 0,16 & 0,20 & 0,41 \\
\hline
\end{tabular}

Legenda: $\log \mathrm{AfCF}$...logaritmo CF do afluente à ETE Gama, logAlCF...logaritmo CF da alimentação ao TQ01 e logPeCF...logaritmo CF do permeado.

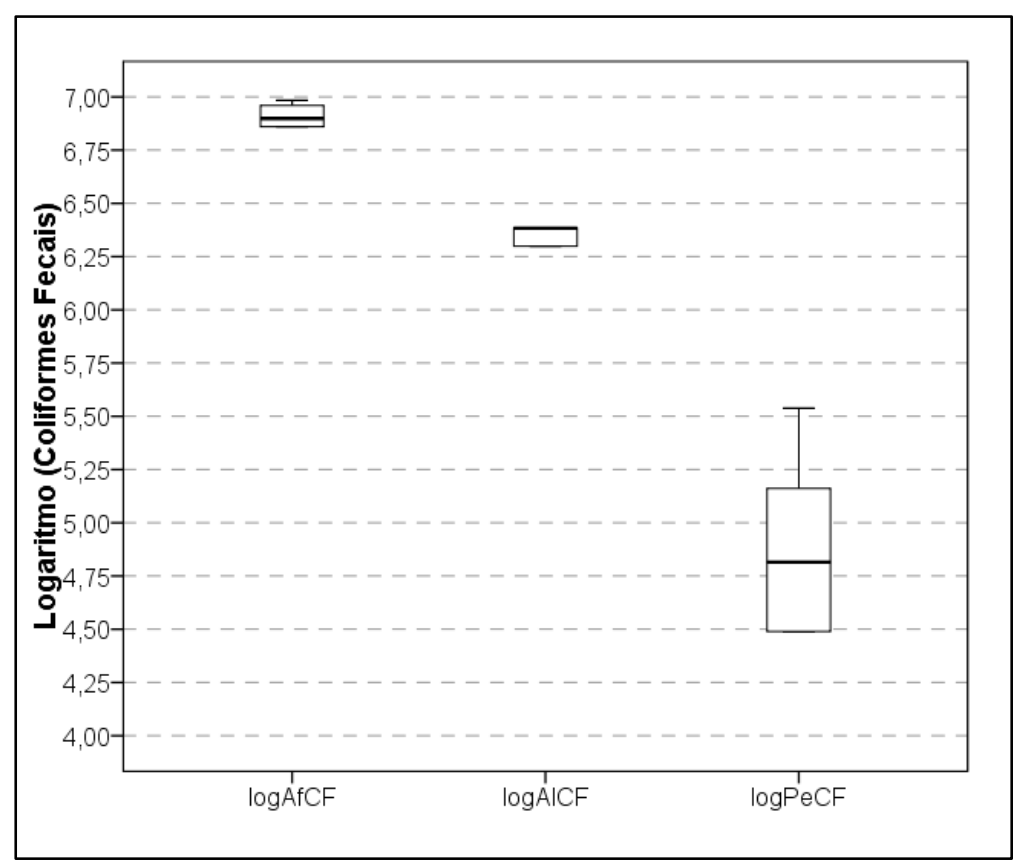

Figura 5.50 - Gráficos box-plot das séries temporais transformadas pela função logaritmo na base 10 das concentrações de Coliformes Fecais (CF em NMP/100 m $\ell$ ) monitorados na pesquisa de microfiltração de efluente do reator $U A S B$ para as amostras: afluente a ETE

Gama, alimentação do TQ 01 e do permeado das 61 corridas ensaiadas (28/03 a 20/10/2016).

Legenda: $\log \mathrm{AfCF} . \log (\mathrm{CF})$ do afluente à ETE Gama, $\log \mathrm{AlCF} . . \log (\mathrm{CF})$ da alimentação do TQ01 e $\log P e C F . . . \log (\mathrm{CF})$ o permeado. 


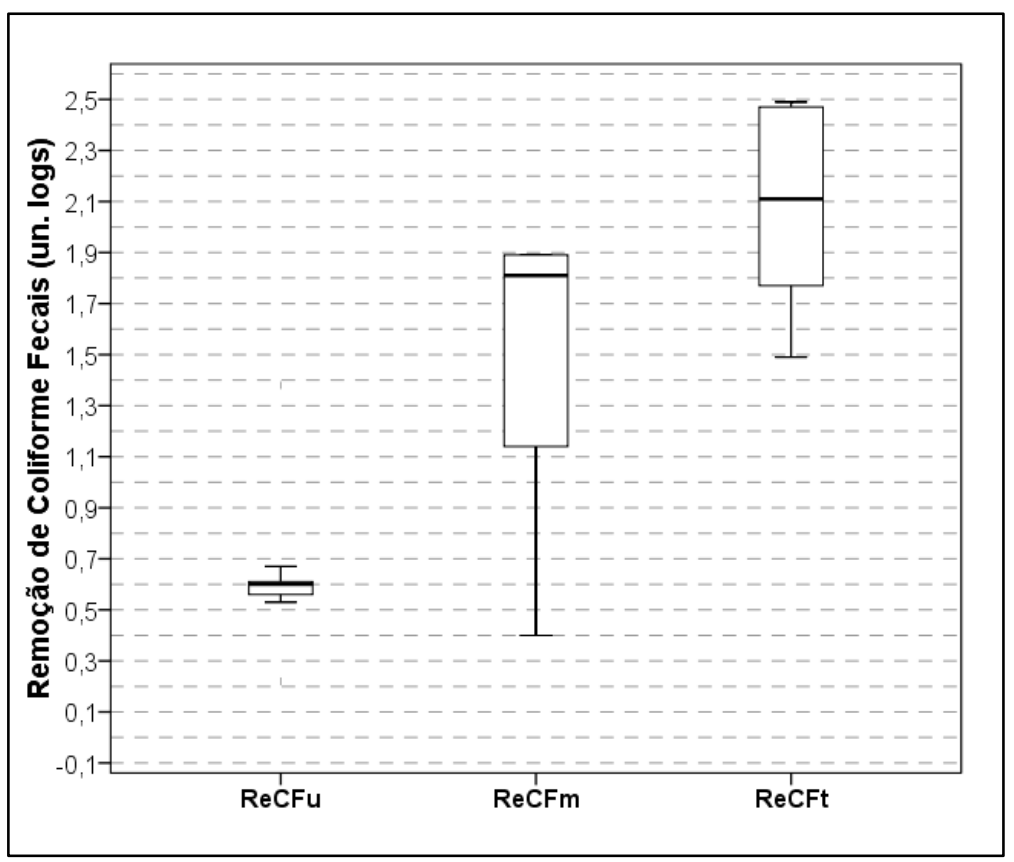

Figura 5.51 - Gráficos box-plot das remoções parciais de Coliforme Fecais (em unidades logarítmicas) no reator $U A S B(\mathrm{ReCFu})$ e nas membranas submersas ( $\mathrm{ReCFm}$ ) e a remoção global do tratamento $(\mathrm{ReCFt})$ da pesquisa de microfiltração do efluente do reator $U A S B$ (28/03 a 20/10/2016).

Quando observados os gráficos box-plot das Figuras 5.50 e 5.51, a remoção média parcial foi de 0,63 unidades logarítmicas para o reator $U A S B$ e 1,46 unidades logarítmicas (unid. logs.) para a unidade de microfiltração por membranas submersas, e perfazendo remoção global de 2,02 unid. logs. O valor médio de remoções de CF obtido neste estudo, de 2,02 unid. logs., é muito inferior ao mínimo necessário para classificar o processo (UASB/FMS) em "E” no PRODES/ANA, que é de 5 unid. logs. como pode ser verificado na Tabela 4.12.

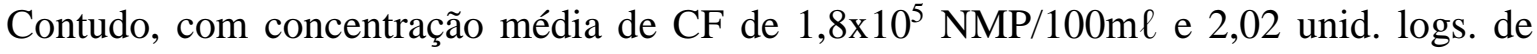
remoção se garantiria que o permeado fosse utilizado como água de reúso para irrigação restrita na agricultura altamente mecanizada e para irrigação irrestrita por gotejamento de culturas elevadas, segundo as diretrizes da OMS (WHO, 2006).

\subsubsection{1 - Considerações Finais}

O resultado de remoção média de DQO (84\%) da presente pesquisa foi inferior ao reportado por Wen et al. (1999), 97\%, mas teve equivalência quando comparado ao reportados por An et al. (2009), na faixa de $81 \%$. Com relação ao SST, a remoção média 
relatada por Wen et al. (1999) foi de 100\%, similar ao resultado alcançado nesta trabalho que foi de $99 \%$. Os valores para o desempenho de microfiltração de efluente primário evidenciados por Metcalf \& Eddy (2007) são inferiores aos deste trabalho, exceção feita à remoção de CF que foi salientada com valor de 5,57 unidades logarítmicas, bem superior ao levantado nesta pesquisa, que foi o de 2,09 unidades logarítmicas.

As concentrações médias alcançadas nesta pesquisa de $110 \mathrm{mg} / \ell$ para DQO, $53 \mathrm{mg} / \ell$ para DBO, 4 mg/ $\ell$ para SST e 100 uT são muito superiores aos valores apontados por Ravazinni et al. (2012) para permeados de microfiltração de efluente de Tanque Séptico, que foram de $8,8 \mathrm{mg} / \ell, 4,2 \mathrm{mg} / \ell, 0,20 \mathrm{mg} / \ell$ e $0,15 \mathrm{uT}$ para DQO, DBO, SST e Turbidez, respectivamente. 


\section{CONCLUSÕES E RECOMENDAÇÕES}

A partir dos resultados obtidos na pesquisa realizada com microfiltração por membranas submersas de efluente de reator UASB, pode-se concluir que:

1. A membrana de poli(éter-imida) mostrou ser susceptível à incrustação (fouling), o que provocou declínio do fluxo médio de permeado durante os dias de operação, no regime de 6 horas/dia durante 4 dias consecutivos, de 7,69 LMH no primeiro dia para 5,48 $\mathrm{LMH}$ no último dia, valores inferiores ao preconizado no projeto da unidade de microfiltração - 10 LMH;

2. A unidade de microfiltração não respondeu de forma adequada ao método utilizado de controle de incrustação de um dia para outro durante a semana de operação, o enxague com água potável, pois demonstrou contínuo declínio do fluxo permeado ao longo dos dias;

3. Do protocolo de limpeza utilizado, somente a limpeza por retrolavagem com água potável, por 30 minutos e pressurizada a $+0,30$ bar, sequenciada pela limpeza hidráulica/química (aeração e dosagem de $\mathrm{NaClO}$ - 15\%) foi eficaz, retornando a resistência da membrana limpa sempre para o valor médio de $1,80 \times 10^{12} \mathrm{~m}^{-1}(1,5 \mathrm{a}$ $\left.2,1 \times 10^{12} \mathrm{~m}^{-1}\right)$

4. A unidade de microfiltração não respondeu de forma adequada ao método utilizado de controle de incrustação ao longo do dia de operação, a retrolavagem, dado que foi observado o contínuo e acentuado declínio do fluxo do permeado ao longo do dia;

5. A perda de permeado relativa ao consumo no uso da retrolavagem diária foi, em média, de quase um quarto da produção (24\%). Esse valor é alto quando comparado com o de um fabricante tradicional de membranas de fibras-ocas (Koch Membrane Systems), de 6\%; 
6. O consumo específico médio de energia elétrica verificado foi de $2,80 \mathrm{kWh} / \mathrm{m}^{3}$, consideravelmente superior ao consumo médio dos resultados levantados para ETEs da CAESB, que é de $0,26 \mathrm{kWh} / \mathrm{m}^{3}$;

7. Os valores das concentrações das séries temporais da Demanda Bioquímica de Oxigênio (DBO em mg/ $\ell$ ) das amostras do efluente do reator UASB (alimentação do TQ01) e do efluente final do tratamento (permeado) atendem ao valor da resolução CONAMA 430/11 (Brasil, 2011) - DBO < $120 \mathrm{mg} / \ell$.

8. O processo (UASB + Filtração por Membranas Submersas - FMS) demonstrou bom desempenho na remoção de matéria orgânica, com remoção média global de $87 \%$ para DBO e $84 \%$ para DQO, enfatizando que a remoção parcial no reator $U A S B$ foi de maior relevância (81\% para DBO e 68\% para DQO), ao mesmo tempo em que, para as membranas, foi de $30 \%$ para DBO e $48 \%$ para DQO;

9. A remoção global de $\mathrm{DBO}$ pela microfiltração do efluente do reator $U A S B$ elevou o padrão do tratamento de "B" (remoção mínima de 60\%) para o nível "E" (remoção mínima de $85 \%$ ) da referência de classificação dos sistemas de tratamento de esgotos sanitários Programa de Despoluição de Bacias Hidrográficas (PRODES) da Agência Nacional de Água (ANA);

10. O processo (UASB/FMS) mostrou-se bom desempenho na remoção de Sólidos Suspensos Totais com remoção média global de 99\%, destacando que a remoção parcial no reator $U A S B$ foi mais significativo, 97\%, enquanto as membranas rejeitaram $69 \%$;

11. A remoção global de SST da microfiltração do efluente do reator $U A S B$ elevou o padrão do tratamento de "B" (remoção mínima de 60\%) para o nível "F" (remoção mínima de 90\%) da referência de classificação dos sistemas de tratamento de esgotos sanitários do PRODES/ANA; 
12. A Turbidez média do permeado de 100 uT é um valor extremamente superior ao relatado na literatura para a microfiltração de efluentes de esgoto sanitário tratados ou não, que é de 0,15 uT;

13. O processo (UASB/FMS) revelou-se pouco eficiente para a remoção de coliformes fecais, com valor médio de remoção de 2,02 unidades logarítmicas, contrariando os valores de remoções relatados na literatura para a microfiltração de efluentes de esgotos sanitários tratados ou não, que é de 5,63 unidades logarítmicas;

14. Não foi possível verificar o desempenho da microfiltração na rejeição de ovos de helmintos, pois os resultados das análises efetuadas para o monitoramento desta variável microbiológica apresentaram valores de "ausência de ovos viáveis" nas amostras da alimentação da planta-piloto de Filtração por Membranas Submersas, ou seja, a remoção total ocorreu no reator $U A S B$, supondo que houvesse ovos de helmintos no esgoto bruto;

15. O valor médio de remoções de CF obtido, de 2,02 unid. logs., é muito inferior ao mínimo necessário para classificar o processo (UASB/FMS) em "E" no PRODES/ANA, que é de 5 unid. logs. Contudo, a concentração média de CF de $1,8 \times 10^{5} \mathrm{NMP} / 100 \mathrm{~m} \ell$ e 2,02 unid. logs. de remoção garantiriam que o permeado pudesse ser usado para o reúso em irrigação restrita na agricultura altamente mecanizada e para irrigação irrestrita por gotejamento de culturas elevadas , segundo as diretrizes da OMS.

Algumas questões levantadas durante esta pesquisa sugerem o desenvolvimento de outros estudos listados a seguir:

1. Avaliação com o mesmo efluente utilizando módulo de membranas submersas de ultrafiltração, visto que o fornecedor das membranas, atualmente, já fabrica e fornece módulos de ultrafiltração compatíveis com unidade de microfiltração desta pesquisa; 
2. Avaliação comparativa de um novo protocolo de limpeza incluindo o relaxamento (injeção de ar soprado) na retrolavagem intercalada durante as etapas de filtração;

3. Avaliação do pós-tratamento do permeado da microfiltração do efluente do reator $U A S B$ utilizando carvão ativado, pois, teoricamente, este processo poderia diminuir os valores de Turbidez, cor e odor do permeado produzido nesta pesquisa; e

4. Avaliação comparativa sem o reator $U A S B$, ou seja, microfiltrando diretamente o esgoto sanitário após o tratamento preliminar (Peneiramento e Desarenação). 


\section{REFERÊNCIAS BIBLIOGRÁFICAS}

Amaral, M. C. S. (2009). Tratamento de efluente de branqueamento de pasta celulósica empregando sistema de microfiltração conjugado com biorreator de membrana. Tese Doutorado em Saneamento, Meio Ambiente e Recursos Hídricos - DESA, UFMG, Belo Horizonte, MG, 377p.

An, Y. Y.; Yang, F.; Bucciali, B.; Wong, F. (2009). "Municipal Wastewater Treatment Using a UASB Coupled with Cross-Flow Membrane Filtration”. Journal of Environmental Engineering (ASCE), 135, 2, 86-91

Andrade, J. P.; Lima, L. G. A.; Gasperi, R. L. P.; Rosseto, R. (2014). "Partida Operacional de Biorreator com Membranas (MBR): EPAR CAPIVAI II". REEC Revista Eletrônica de Engenharia Civil, 8, № 1, 14-20.

APHA-AWWA- WPCF (2005). Standards Methods for the Examination of Water and Wastewater. American Public Health Association $21^{a}$ Edition, Washington DC, USA.

Aptel, P.; Buckley, C. A. (1996). "Categories of membrane operations". In: Water Treatment Membrane Process. American Water Works Association. McGraw-Hill, Chapter 2, 24p.

Arnal, J. M.; García-Fayos, B.; Sancho, M. (2011). "Membrane Cleaning”. In Expanding Issues in Desalination. Ning, R. Y. - Editor, InTech China Publisher, Chapter 3, $23 \mathrm{p}$.

AWWA (2005). Microfiltration and Ultrafiltration Membranes for Drinking Water Manual of Water Supply Practices - M53, First Edition, American Water Works Association, Colorado, USA, 280p.

Barnard, J. L.; Randall, C. W. e Stensel, H. D. (1992). Design and Retrofit of Wastewater Treatment Plants for Biological Nutrient Removal. Water Quality Management Library - Volume 5, Technomic Publishing Company, Inc., Lancaster, Pennsylvania, USA, 417p.

Bixio, D. e Wintgens, T. - Editors (2006). Water Reuse System Management Manual AQUAREC, Official Publications of the European Communities, Luxembourg, Belgium, 678p. 
Bixio, D.; Thoeye, C.; Wintgens, T.; Ravazinni, A.; Miska, V.; Muston, M.; Chikurel, H.; Aharoni, A.; Joksimovic, D.; Melin, T. (2008). "Water reclamation and reuse: implementation and management issues". Desalination, 218, 13-23.

Brasil (2011). Resolução CONAMA 430, de 16 de maio de 2011. Dispõe sobre as condições e padrões de lançamento de efluentes, complementa e altera a Resolução no 357, de 17 de março de 2005. Diário Oficial da União no 92, de 16/05/2011, pág. 89.

Brepols, C. (2011). Operating Large Scale Membrane Bioreactors for Municipal Wastewater Treatment. IWA Publishing, London, UK, 138p.

CAESB (2003). Manual de Instruções, Operação e Controle. Sistema de Esgotamento

CAESB (2015). Relatório Anual sobre Consumo de Energia Elétrica na CAESB - Ano 2015. Documento interno da Companhia de Saneamento Ambiental do Distrito Federal, 55p.

Cerón-Vivas, A.; Morgan-Sagastume, J. M. e Noyola, A. (2012). “ Intermittent filtration and gas bubbling for fouling reduction on in anaerobic membrane bioreactors". Journal of Membrane Science, 423-424, 136-142.

Chang, Y.; Reardon, D. J.; Kwan, P.; Boyd, G.; Brant, J.; Raknes, K. L.; Furukawa, D. (2008). Evaluation of Dynamic Energy Consumption of Advanced Water and Wastewater Treatment Technologies, AWWA Research Foundation, USA, 262p.

Chernicharo, C. A. L (2007). Reatores Anaeróbios - $2^{a}$ Edição, Volume 5, Coleção Princípios do Tratamento Biológico de Águas Residuárias, Editora UFMG, Belo Horizonte, Brasil, 380p.

Chernicharo, C. A. L.; van Lier, J. B.; Noyola, A.; Bressani Ribeiro, T. (2015). “Anaerobic sewage treatment: state of the art, constraints and challenges", Rev. Environ. Sci. Biotechnology, 14, 649-679.

Cheryan, M. (1998). The Microfiltration and Ultrafiltration Handbook - Second Edition, Technomic Publishing, Pennsylvania, USA, 537p.

Costanzi, R. N. (2007). Tratamento de efluentes domésticos por sistemas integrados de lodos ativados e membranas de ultrafiltração visando o reúso de água. Tese de Doutorado em Engenharia Hidráulica, Escola Politécnica, USP, São Paulo. Disponível em: <http://www.teses.usp.br/teses/disponiveis/3/3147/tde-09012008103236/>. Acessado em: 09/07/2013. 
Dezotti, M.; Sant'Anna Jr., G. L. e Bassin, J. P. (2011). Processos Biológicos Avançados para tratamento de efluentes e técnicas de biologia molecular para o estudo da diversidade microbiana, Editora Interciência Ltda, Rio de Janeiro, Brasil, 368p.

Felizatto, M. R.; Pinto Filho, A. C.; Soares, E. S.; Santos, C. A. B.; Catino, R. (2014). "Remoção Biológica de Nutrientes precedido de Reator UASB: O Caso da ETE Gama (DF)". In: Braga, M. B. e Lima, C. E. P. (Eds.) Reúso de Água na Agricultura, EMBRAPA HORTALIÇAS, Brasília, DF, 159-178p.

Field, A. (2009). "Descobrindo a Estatística usando o SPSS - 2 Edição", ARTMED Editora ${ }^{\circledR}$ S.A., Porto Alegre, RS, 688p.

Giménez, J.B.; Marti, N.; Ferrer, J. e Seco, A. (2012). "Methane recovery efficiency in a submerged anaerobic membrane bioreactor (SAnMBR) treating sulphate-rich urban wastewater: Evaluation of methane losses with the effluent", Bioresource Technology, 118, 67-72.

Giménez, J.B.; Robles, A.; Carretero, L.; Duran, F.; Ruano, M.V.; Gatti, M.N.; Ribes, J.; Ferrer, J. e Seco, A. (2011). "Experimental study of anaerobic urban wastewater treatment in a submerged hollow-fiber membrane bioreactor at pilot scale". Bioresource Technology, 102, 8799-8806.

Green, D. W. and Perry, R. H. (2008). "Perry's Chemical Engineer's Handbook, Eight Edition. MEMBRANE SEPARATION PROCESS”, Chapter, McGraw-Hill Professional, AcessEngineering, 105p.

Hai, F. I.; Yamamoto, K. (2011). “Membrane Biological Reactors”. In Wilderer, P, (Eds.), Treatise on Water Science, Elsevier, UK, 571-613.

Hai, F. I.; Yamamoto, K.; Lee, C. H. (2014). Membrane Biological Reactors - Theory, Modeling, Design, Management and Applications to Wastewater Reuse. IWA Publishing, London, UK, 484p.

Hespanhol, I. (2016). Comunicação Pessoal através de entrevista.

Howe, K. J., Hand, D. W., Crittendem, J. C., Trussel, R. R. and Tchobanoglous, G. (2012). MWH's Water Treatment - Principles and Design, Third Edition, John Willey \& Sons, Inc., New Jersey, USA, 1901p.

IPCC (2014). "Climate Change 2014: Impacts, Adaptation, and Vulnerability Part B: Regional Aspects”, In: Barros, V.R., C.B. Field, D.J. Dokken, M.D. Mastrandrea, K.J. Mach, T.E. Bilir, M. Chatterjee, K.L. Ebi, Y.O. Estrada, R.C. Genova, B. Girma, E.S. Kissel, A.N. Levy, S. MacCracken, P.R. Mastrandrea, and L.L.White 
(Eds.) Contribution of Working Group II to the Fifth Assessment Report of the Intergovernmental Panel on Climate Change, Cambridge University Press, New York, NY, USA, 688 p.

Judd, S. (2011). The MBR Book - Principles and Applications of Membrane Bioreactors for Water and Wastewater Treatment. Butterworth-Heinemann/Elsevier, Oxford, UK, 519p.

Koch Membrane Systems (2014). "Princípios Básicos sobre a Tecnologia MBR e tratamento de água e efluentes com Membranas", Curso realizado na CAESB, Brasília, 23/09/2014.

Larrea, A.; Rambor, A.; Fabiyi (2014). “MBR - Experiências em campo: dez anos de sistemas de biorreatores a membrana”, Revista Hydro, IX (98), 14-21.

Lateef, S. K.; Soh, B. Z.; Kimura, K. (2013). "Direct membrane filtration of municipal wastewater with chemically enhanced backwash for recovery of organic matter". Bioresource Technology, 150, 140-155.

Le Clech, P.; Jefferson, B. Chang, I. S.; Judd S. J. (2003). “Critical flux determination by the flux-step method in a submerged membrane bioreactor", Journal of Membrane Science, 227, 81-93.

Lesjean, B.; Huisjes, E. H. (2008). "Survey of the European MBR market: trends and perspectives". Desalination, 231, 71-81.

Levine, A. D.; Tchobanoglous, G.; Asano, T. (1991). "Size distributions of particulate contaminants in wastewater and their impact on treatability". Water Resource, 55, 8, 991-992

Lew, B.; Tarre, S.; Beliavski, M.; Dosoretz, C. e Green, M. (2009). “Anaerobic membrane bioreactor (AnMBR) for domestic wastewater treatment”. Desalination, 243, 251257.

Libânio, P. A. C., Nunes, C. M., de Oliveira, E. F. C. C., Soares, S. R. A., Brito, M. C. S. O. M. (2007). "Implantação e Operação de Estações de Tratamento de Esgotos; Experiências no Âmbito do Programa Despoluição de Bacias Hidrográficas (PRODES)". 24 Congresso Brasileiro de Engenharia Sanitária e Ambiental, Anais (CD ROM). Belo Horizonte, MG.

Lin, H.; Chen, J.; Wang, F.; Ding, L. e Hong, H. (2011). "Feasibility evaluation of submerged anaerobic membrane bioreactor for municipal secondary wastewater treatment". Desalination, 280, 120-126. 
Lin, H.; Peng, W.; Zhang, M.; Chen, J.; Hong, H. e Zhang, Y. (2013). "A review on anaerobic membrane bioreactors: Applications, membrane fouling and future perspectives". Desalination, 314, 169-188.

Mendonça, S. R. e Mendonça, L. C. (2016). Sistemas sustentáveis de esgotos: orientações técnicas para projeto e dimensionamento de redes coletoras, emissários, canais, estações elevatórias, tratamento e reúso na agricultura. Editora Edgar Blücher Ltda., São Paulo, Brasil, 348p.

Metcalf \& Eddy (2003). Wastewater Engineering, Treatment and Reuse - 4th Edition. McGraw-Hill Companies, New York, USA, 1819p.

Metcalf \& Eddy (2007). Water Reuse Issues, Technologies, and Applications. McGrawHill Companies, New York, USA, 1503p.

Metcalf \& Eddy (2016). Tratamento de Efluentes e Recuperação de Recursos. McGrawHill Education, Porto Alegre, RS, Brasil, 1980p.

Mohanty, K.; Purkait, M. K. (2012). "Membrane Technologies and Applications, CRC Press Taylor \& Francis Group, Florida, USA, 503p.

Morgado, M.; Inácio, G. (2014). “Caracterização da composição de resíduos removidos em gradeamento de ETEs”, Revista Hydro, VIII (89), 16-27.

Mulder, M. (1992). Basic Principles of Membrane Technology. Springer Science/Business Media Dordrecht, The Netherlands, 196p.

Noyola, A.; Morgan-Sagastume, J. M.; Güereca, L. P. (2013). Selección de Tecnologías para el tratamiento de aguas residuales municipales. Instituo de Ingenieria UNAM - Universidad Nacional Autónoma de México, México DF, México, 140p.

Pabby, A. K.; Rizvi, S. S. H. e Sastre, A. M. Handbook of Membrane Separations Chemical, Pharmaceutical, Food, and Biotechnological Applications. CRC Press, Boca Raton, FL, USA, 868p.

PAM Membranas Seletivas (2014). Manual de Instalação, Operação e Manutenção, 16p.

Pinnekamp, J. (2003). Membrane Technology for Wastewater Treatment - First Edition. FIW Verlag, Aachen, Germany, 349p.

Porto, R. M. (2006). Hidráulica Básica - Quarta Edição. Editora EESC USP Projeto REENGE, São Paulo, Brasil, 519p.

Pretel, R.; Robles, A.; Ruano, M. V.; Seco, A.; Ferrer, J. (2013). "Environmental impact of submerged anaerobic MBR (SAnMBR) technology used to treat urban wastewater at different temperatures", Bioresource Technology, 149, 532-540. 
Qasim, S. R. (1999). Wastewater Treatment Plants - Planning, Design and Operation. CRC Press, Boca Raton, USA, 1107p.

Radjenović, J.; Matosic, M.; Mijatovic, I.; Petrovic, M.; Barceló, D. (2008). "Membrane Bioreactor (MBR) as an Advanced Wastewater Treatment Technology". Heidelberg Environmental Chemistry, 5 (Part S/2), 37-101.

Ranade, V. V.; Bhandari, V. M. (2014). Industrial Wastewater Treatment, Recycling and Reuse. Butterworth-Heinemann/Elsevier, Oxford, UK, 562p.

Ravazinni, A. M. (2008). Crossflow ultrafiltration of raw municipal wastewater investigations using PVDF tubular membranes. Tese Doutorado em Engenharia para o Ambiente e Território - Politécnico de Milano, Milão, Itália, 313p.

Ravazinni, A. M.; van Nieuwenhuijzen, A. F.; van der Graaf, J. H. M. J. (2005). "Direct ultrafiltration of municipal wastewater: comparison between filtration of raw sewage and primary clarifier effluent". Desalination, 178, 51-62.

Ravazinni, A. M.; van Nieuwenhuijzen, A. F.; van der Graaf, J. H. M. J. (2012). "Direct Membrane Filtration of Wastewater". In: Van Nieuwenhuijzen, A.; Vand der Graaf, J. (Editors). Handbook on Particle Separation Process. IWA Publishing, London, $\mathrm{UK}, 211 \mathrm{p}$

Robles, A.; Durán, F.; Ruano, M.V; Ribes, J.; Ferrer, J. (2012ª). "Influence of total solids concentration on membrane permeability in a submerged hollow-fiber anaerobic membrane bioreactor”, Water Science and Technology, 66 (2), 377-383.

Robles, A.; Ruano, M. V.; García-Usach, F.; Ferrer, J. (2012 ). "Sub-critical filtration conditions of commercial hollow-fiber membranes in a submerged anaerobic MBR (HF-SAnMBR). The effect of gas sparging”, Bioresource Technology, 114, 247254.

Robles, A.; Ruano, M.V; Ribes, J.; Ferrer, J. (2013 $)$. "Performance of industrial scale hollow-fiber membranes in a submerged anaerobic MBR (HF-SAnMBR) system at mesophilic and psychrophilic conditions", Separation and Purification Technology, 104, 290-296.

Robles, A.; Ruano, M.V; Ribes, J.; Ferrer, J. $\left(2013^{\text {b }}\right)$. "Factor that affect the permeability of commercial hollow-fiber membranes in a submerged anaerobic MBR (HFSAnMBR) system", Water Research, 47, 1277-1288. 
Rodrigues, L. D. B. (2012). Reúso de água em Sistemas Aeroportuários utilizando o processo de Ultrafiltração. Dissertação de Mestrado em Engenharia da Escola Politécnica da Universidade de São Paulo, USP, São Paulo, 119p.

SABESP (2010). Manual de Operação - Memorial Descritivo Funcional do Sistema de Comando e Supervisão da EPAI AQUAPOLO, 60p.

Salazar-Peláez, M. L.; Morgan-Sagastume, J. M.; Noyola, A. (2011). "Influence of hydraulic retention time on fouling in a UASB coupled with an external ultrafiltration membrane treating synthetic municipal wastewater", Desalination, 277, 164-170.

Sanitário do Gama - Processo Biológico Anaeróbio em Reator de Fluxo Ascendente e Manto de Lodo seguido de Processo Aeróbio de Lodos Ativados, 96p.

Schmidt, W. G. (1856). Ann. Phys.,49, 337 apud Judd, S. (2011). The MBR BookPrinciples and Applications of Membrane Bioreactors for Water and Wastewater Treatment. Butterworth-Heinemann/Elsevier, Oxford, UK, 519p.

Schneider, R. P. e Tsutiya, M. T. (2001). Membranas Filtrantes para o Tratamento de Água, Esgoto e Água de Reúso. Associação Brasileira de Engenharia Sanitária e Ambiental São Paulo, Brasil, 234 p.

Sethi, S. e Juby, G. (2002). "Microfiltration of Primary Effluent for Clarification and Microbial Removal”. Environmental Engineering Science, 19, 6, 467-475.

Silva, M. K. (2009). Biorreatores com Membranas: uma Alternativa para o Tratamento de Efluentes. Tese Doutorado do Programa de Pós-Graduação em Engenharia Química, Escola de Engenharia, Engenharia Química, UFRGS, Rio Grande do Sul, 180p.

Singh, R. (2006). Hybrid Membrane Systems for Water Purification Technology, Systems Design and Operation. Elsevier Ltd., London, UK, 307p.

Singh, R. (2015). Membrane Technology and Engineering for Water Purification Application, Systems Design and Operation - Second Edition. ButterworthHeinemann/Elsevier, Oxford, UK, 435p.

Skouteris, G.; Hermosilla, D.; López, P.; Negro, C. e Blanco, A. (2012). “Anaerobic membrane bioreactors for wastewater treatment: A review”. Chemical Engineering Journal, 198-199, 138-148. 
Smith, A. L.; Stadler, L. B.; Love, N. G.; Skerlos, S. J. e Raskin, L. (2012). "Perspectives on anaerobic membrane bioreactor treatment of domestic wastewater: A critical review". Bioresource Technology, 122, 149-159.

Souza, M. E. e Vieira, S. M. M. (1986). "Uso do reator UASB para tratamento de esgoto Sanitário”. Revista DAE, 46, 145. 166-168.

Stephenson, T.; Judd, S.; Jefferson, B. and Brindle, K. (2000). Membrane Bioreactors for Wastewater Treatment. IWA Publishing, London, UK, 193p.

Stuckey, D.C. (2012). "Recent developments in anaerobic membrane reactors". Bioresource Technology, 122, 137-148.

Takahashi, S.; Inoue, I. (2010). Guia Mangá de Estatística. Novatec Editora Ltda., São Paulo, SP, Brasil, 215pp.

USEPA (2008). Emerging Technologies for Wastewater Treatment and In-Plant Wet Weather Management. Parsons Corporation, Virginia, USA, 190pp.

van Nieuwenhuijzen, A.; van der Graaf, J. (Editors). Handbook on Particle Separation Process. IWA Publishing, London, UK, 211p.

van Voorthuizen, E.; Zwijnenburg, A.; van der Meer, W.; Temmik, H. (2008). “Biological black water treatment combined with membrane separation”. Water Research, 42 , 4334-4340.

Vidal, C. M. S. (2006). Avaliação da Microfiltração Tangencial como alternativa de tratamento avançado de efluente gerado em sistema de tratamento de esgoto sanitário constituído de reator UASB (Upflow anaerobic sludge blancket) seguido de tanque de aeração. Tese Doutorado do Programa de Pós-Graduação em Hidráulica e Saneamento, Escola de Engenharia de São Carlos, USP, São Carlos, São Paulo, 193p.

Vieira, S. M. M.; Garcia Jr., A. D.; Figueiredo, M. G.; Pomaroli, J. M. A. (1995). Apostila do curso Tratamento de Esgotos e Efluentes Industriais por Digestor Anaeróbio de Fluxo Ascendente. Original Reprográfico CETESB, São Paulo, SP, 72p.

Visvanathan, C. and Abeynayaka, A. (2012). "Developments and future potentials of anaerobic membrane bioreactors (AnMBRs)”. Membrane Water Treatment, 3 (1), $1-23$.

WEF - Water Environment Federation (2006). Membrane Systems for Wastewater Treatment. McGraw-Hill Professional, AcessEngineering, 284p. 
WEF - Water Environment Federation (2012). Membrane Bioreactors: WEF Manual of Practice $N^{o}$ 36. McGraw-Hill Professional, AcessEngineering, 262p.

Wen, C.; Huang, X.; Qian, Y. (1999). “Domestic wastewater treatment using an anaerobic bioreactor coupled with membrane filtration". Process Biochemistry, 35, 335-340.

WHO - World Health Organization (2006). Guidelines for the safe use of wastewater, excreta and greywater - Volume 1 - Policy and regulatory aspects. WHO Library, $114 \mathrm{p}$.

Wintgens, T.; Melin, T.; Shäfer, A.; Khan, S.; Muston, M.; Bixio, D.; Thoeye, C. (2005). "The role of membrane processes in municipal wastewater reclamation and reuse". Desalination, 178, 1-11.

Yoon, S. H. (2016). Membrane Bioreactor Process. CRC Press, 431p.

Zavala, M. A. L.; Pérez, L. B. S.; Reynoso-Cuevas, L. (2014). "Pre-filtration for enhancing direct membrane filtration of graywater from washing machine discharges". Ecological Engineering, 64, 116-119.

\section{REFERÊNCIAS BIBLIOGRÁFICAS CITADAS}

Huisman, L., Ed. (1996). Rapid Filtration - Lecture Notes Watermanagement, Section Sanitary Engineering, Delf University of Technology. 
ANEXOS 
ANEXO 1 - CERTIFICADO DE QUALIDADE DE MÓDULOS Nº 1451

\section{Certificado de Qualidade de Módulos N $^{0} 1451$}

\begin{tabular}{|c|c|}
\hline Identificação do módulo & 716 \\
\hline Processo & Microfiltração \\
\hline Configuração & Submerso \\
\hline Área de Filtração $\left(\mathrm{m}^{2}\right)$ & 6,0 \\
\hline Decaimento de Pressão (0,5@5min) & 0,5 \\
\hline Permeabilidade Hidráulica (L/h.m².bar) & 167,0 \\
\hline Rejeição (\%) & 99,9 \\
\hline
\end{tabular}

Teste de Permeabilidade Hidráulica:

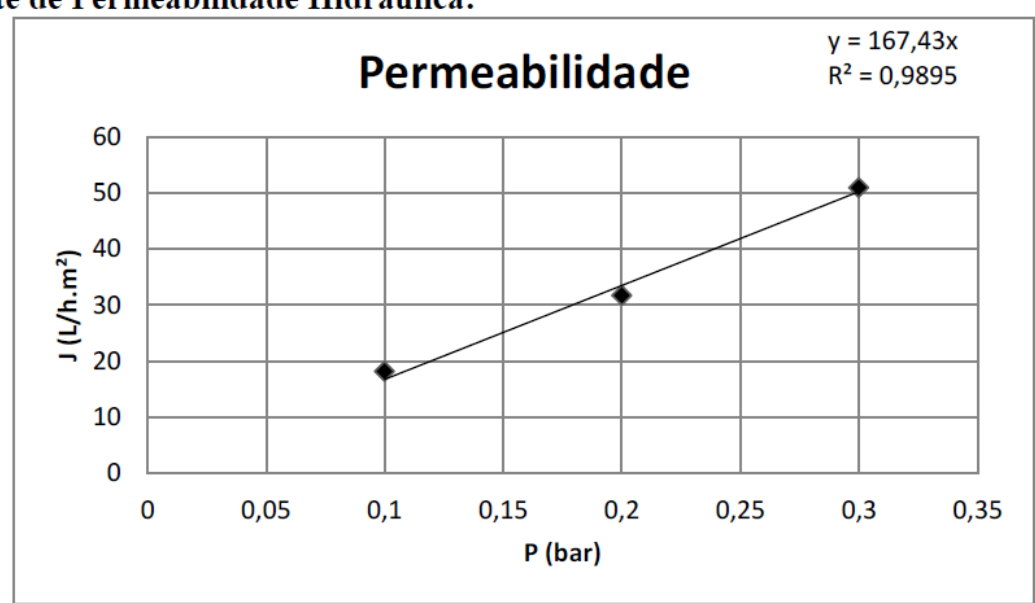

1. Testes executados com água da concessionária de abastecimento local-CEDAE, previamente microfiltrada.

2. Rejeição considerada para filtração de solução de amido de milho a $1,0 \mathrm{~g} / \mathrm{L}$. 
ANEXO 2 - FIGURA REPRESENTANDO AS ESTATISTICAS DESCRITIVAS DO GRÁFICO BOX-PLOT

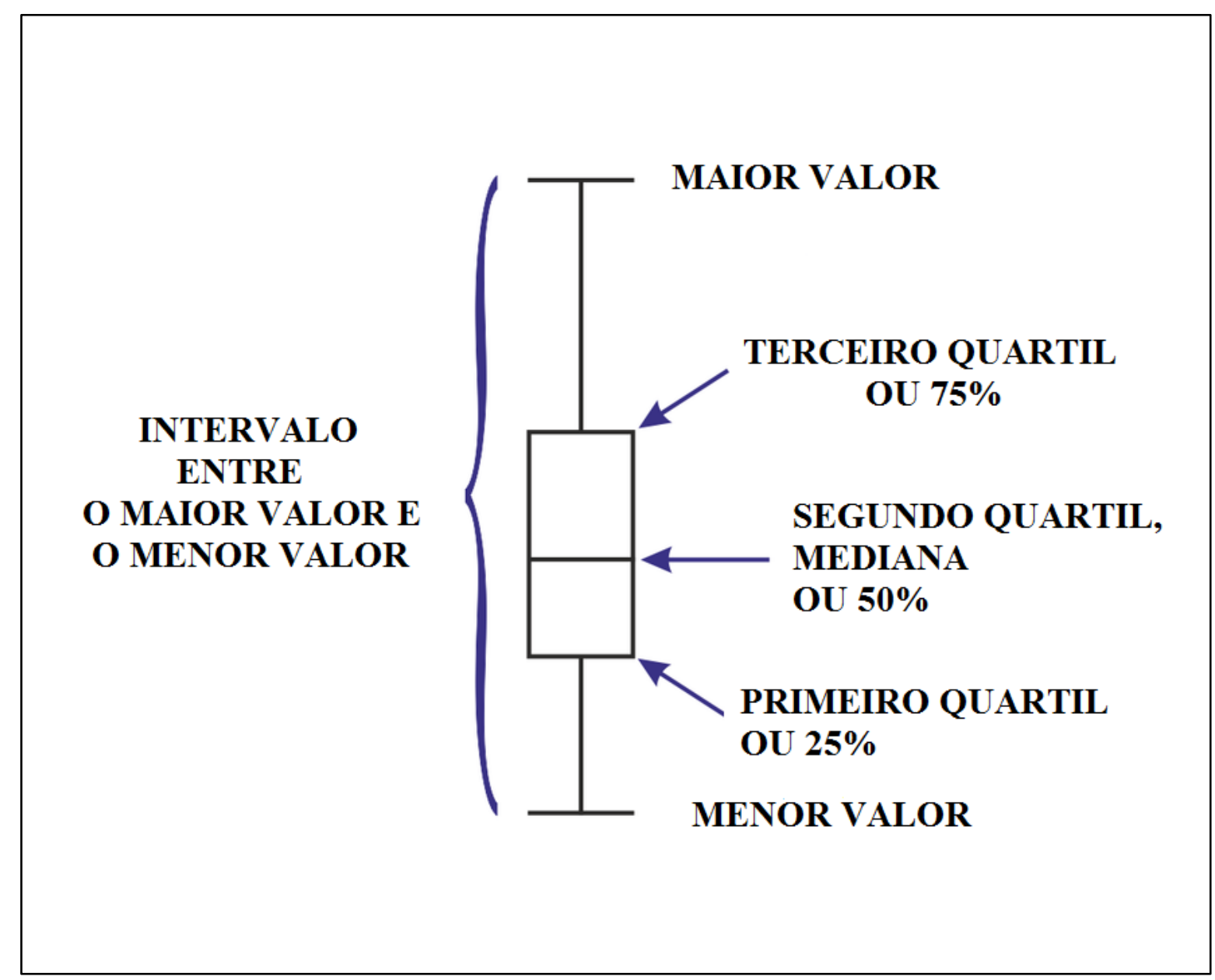

